\title{
The Challenges and Opportunities of Using Mobile Devices to Attain Māori Language Proficiency
}

\section{By Tabitha Gaylyn Kura McKenzie}

A thesis submitted for the degree of Doctor of Philosophy at

Victoria University of Wellington, Wellington, New Zealand.

2014 


\begin{abstract}
What are the effects of using mobile devices as part of teacher professional development focused on teaching and learning the Māori language for Māori immersion educational settings? Answers to this question are explored by researching the extent to which electronic devices could be an effective strategy to address the crisis of the continuing decline of the Māori language. Another issue explored in the research is whether learners make expected gains in language proficiency through the use of mobile devices in comparison to standard face-to-face methods of language instruction.
\end{abstract}

An indigenous framework, Hei Korowai, was used to guide the research and ensure the practices used were culturally appropriate, particularly when entering into and negotiating the research project with participants. Kaupapa Māori and Māori centred approaches were also drawn on to gather data from semi-structured interviews, observations of mobile device use, online questionnaires, and Māori language proficiency tests results. Fifty two participants in total took part in the research, 46 from a PLD programme that used mobile devices and 6 from a separate PLD programme that used mainly face-to-face instruction.

Electronic forms of second language acquisition could be advantageous for learners to access audio and video content on the move and at a time, pace and place convenient for them. The capacity to have literally a library's worth of resources, functions and internet connectivity all in one tool and at the touch of a button could also be of particular significance to users. Conversely, participant attitudes about technology, varied needs for initial and on-going training in how to operate the electronic devices, and interaction preferences were challenges experienced with utilising the device as part of the language learning and teaching process. Videos viewed on the device could also be seen as one-way learning with a lack of spiritual connection and no opportunities for discussion about content, potentially causing road blocks for learners who need extra support.

Face-to-face instruction was a preferred method for participants and the physical presence of the teacher highly valued to allow the space to pose and answer questions and receive an immediate response, which is not possible when learning via videos on a mobile device. However, there was acknowledgement of the complementary nature and value of utilising the mobile device followed by face-toface meetings. 
Evidence suggests that Māori have been quick to adopt and adapt new technologies since the arrival of the early settlers to the shores of Aotearoa. Could technology be the panacea, the cure-all for the revitalisation of the Māori language, a tool that provides access to language, culture and identity to the multitudes? This research tests the hypotheses in the context of two items of modern technology, the iPod Touch $®$ and the iPad $\circledast$.

The limitations of the research include potential bias in interpretation given the researcher's insider position, the relatively small scale of the project, and the absence of a widely accepted theoretical framework for mobile learning. Critical questions that still remain are the implications of promoting 'one Māori language' for a large-scale programme and the risks in doing so for the preservation of tribal dialect and community identity. This study has, however, begun the conversation about the use of mobile devices in Māori medium educational settings, and it may contribute to an understanding of how to design technologies, media, and interactions to support learning within these settings towards innovative practices. 


\section{Preface}

\section{A Personal Introduction}

Adopted at birth by my grandparents I was considered one of the lucky ones. My grandparents, whom I will now address as my mum and dad, grew up in an era where they and their parents were punished for speaking Māori at school. Consequently, Māori was rarely spoken in our home apart from the odd Māori word for household items such as miraka (milk) or pune (spoon). Mum and dad occasionally spoke in Māori to each other when they did not want us to know what they were saying. I remember being fascinated by their ability to communicate in Māori and very curious as to what they were saying. I would ask them what they were talking about, and mum would always reply, "...that's for you to find out". That wero (challenge) put forward by my mum was the beginning of my pursuit to learn my language.

Te reo (the language) and tikanga (protocols) Māori were taught intermittently through waiata (song) and basic words during my primary and intermediate schooling. Formal Māori language classes were offered in secondary school, which I undertook with enthusiasm; however, I finished school with a very basic proficiency in Māori. The lack of opportunities to learn and use Māori in the home and at school may have contributed to my limited Māori language proficiency during my schooling years.

Following on from secondary school I enrolled in a one-year Te Ataarangi programme to further develop my language proficiency. Te Ataarangi is a Māori language programme for adult learners taught in the target language (Māori) (Mataira, 1980). It was developed during the late 1970s by Katerina Te Heikōkō Mataira and Ngoingoi Pewhairangi and modelled on the 'Silent Way' method by Caleb Gattengo (this is discussed further in Chapter One). The classes were facilitated in Māori, which meant I listened and watched a lot more than I spoke in the earlier months of the programme. As my knowledge and understanding of the language increased, so too did my confidence to converse in Māori with my peers and teachers.

Enrolling in to a Bachelor of Education (Teaching) Huarahi Māori degree programme at the Auckland College of Education was my next venture. Apart from the education paper (a college-wide paper), the degree programme was taught through Māori. Te Ataarangi provided me with sufficient knowledge and understanding of my language 
to participate successfully in the Bachelor of Education programme. After graduating I taught in a bilingual classroom within a mainstream school. My Māori language proficiency continued to increase as I was studying and enabled me to be able to teach in a bilingual setting. The students' knowledge and understanding of the Māori language within the bilingual unit ranged from some to none at all. Some of the students did not speak Māori at home, which made it difficult for them to increase their language proficiency. The other two teachers in the bilingual unit were second language learners of Māori. The kaiāwhina (teacher aide) for the bilingual unit classes did not speak Māori but a kuia (elderly woman) appointed as kaitautoko (support person) of the Māori language was called upon to support the language growth within all three classes. Unfortunately our kaitautoko left us after a short time as she was needed elsewhere. There were no other support systems in place that I was aware of to help my colleagues and me increase our Māori language proficiency and the proficiency of our students.

I continued to teach in other schools including a kura kaupapa Māori (Māori immersion school), which also included a wharekura (Māori immersion secondary school). The Māori language proficiency varied among the staff members who were Māori and non-Māori. The turnover of staff members was also high and the reasons for this diverse. Teachers proficient in the Māori language and capable of teaching at secondary school were continually sought. The dearth of proficient Māori speaking teachers meant that some positions were filled with quality teachers who did not speak Māori. In the curent times this dilemma still exists for Māori immersion eduational settings.

My current role is a lecturer at Victoria University of Wellington Faculty of Education and a programme coordinator of a professional learning and development programme. This programme provides service to teachers in Māori medium educational settings to increase their Māori language proficiency as well as knowledge and skill in how to teach language. While this thesis is a contribution to the academic field of language revitalisation, it also aims to inform the pursuit of revitalising the indigenous language of Aotearoa (New Zealand) so that it may flourish once again.

\section{Literary Style}

Many Māori words have been used in this thesis and have been written with frequency. The Māori word is in italics followed by the English word in brackets the 
first time the Māori word is used. Thereafter it is not translated; however, a full glossary of the Māori words used is provided.

A number of participants have also chosen to speak Māori throughout the data collection process. Where participants' quotes that are in Māori have been used in the thesis, the author's interpretation has been provided directly after the original quote. Because the thesis was written in English, it was decided that the quotes also be interpreted in English in order that it be accessible to a wider number of people locally and internationally.

Pseudonym names have also been assigned to participants whose data were used in the thesis. Where participants' quotes have been transcribed the pseudonym name follows in brackets. 


\title{
Acknowledgements
}

\author{
Ehara taku toa i te toa takitahi, \\ Engari he toa takitini. \\ My strength is not that of a single warrior, \\ But that of many.
}

(Tuuta, Bradnam, Hynds, Higgins, \& Broughton, 2004, p. 67)

This whakatauki (proverb) defines the combined efforts of many as more productive than just the individual in a given situation. Fundamental to the combined efforts of many are the aspects of kotahitanga (unity), manaakitanga (expressions of respect or kindness), and whanaungatanga (expressions of support and love within a family). Leadership is also an important aspect that is best described in Māori as rangatira (leader). Rangatira comprises two distinct words - ranga is a derivative of the word raranga, which means 'to weave', and tira simply means 'a group of people'. Hence, literally translated, a rangatira is a person who is able to weave a group of people together in the pursuit of common objectives. Moreover, this whakatauki encapsulates the concepts of whaikoha (respect) and manakohanga (acknowledgement) - respect for those who are both leading or helping as well as acknowledgement of what they have taught you. The importance of these aspects is captured in Haig's (1997, pp. 40-41) comment about growing up with the old people:

\footnotetext{
they'd say to me, 'Titiro, Moko! Whakarongo, Moko!'...I learnt to say yes, never to say no to my old people, and that was what I was taught by my grandfather - accept what they have to say. I am grateful for that because they were trying to get me to maintain my Māoritanga, and that's how they did it.
}

I have had the priviledge of being associated with numerous rangatira, numerous people that have contributed to my identity, to my standing in this world, and to this thesis.

Firstly, I wish to acknowledge my mum and dad for providing me with unconditional love and support. This has enabled me to stand tall in the knowledge that you are always there for me. Your exclusive conversations that we (kids) could not decipher ignited my interest in our language which eventually led me to this thesis. Although you are not here in person, Mum, I know you will be proud of my family and me. I am saddened by the fact that my babies did not get to meet you. I know there would have been so much mutual love between you all. When Russell and Manahi were 
born, I understood what you meant about the amount of love one could have for another being. I love you and miss you very much.

Mum, your eyes gaze out at me from photographs

Your smile, subtle, yet so beautiful and full of love

You are and have always been my poutokomanawa

And I call on you often for guidance, strength and wisdom

You've never failed me and are always there for me

I miss you each and every day and

I'll cherish you till in death we are reunited.

(Adapted from Pehimana, 1995)

To my husband Richard, I wish to acknowledge the support and encouragement you have provided me throughout this journey. You too have played a major part by taking on more responsibilities at home in order for me to complete this research. I am truly blessed to have you in my life and love you more than words can express. To my babies Russell and Manahi, you were both very young during this research journey. You not only presented me with some new challenges but also motivation and drive to complete the task at hand. I missed out on spending a lot of time with you both while I was working on this research at home or at work. I look forward to making it up to you and at the same time hope that I have shown you that you can achieve all that you set your mind to. I love you both to the moon and back.

Rāwiri Toia you are an inspirational person and leader. I am thankful for your encouragement and support to follow this path and I hope you know how much I appreciate and respect you as a colleague and as a friend. This research also acknowledges the hard work that you have done and continue to do for the advancement of our people and our language.

I also wish to thank the teachers, principals and support staff of all the schools who who participated in this research. I am very humbled by the generosity of your hospitality and willingness to participate and share your stories. I hope that my ears, eyes and heart have embraced and captured all that you have shared and that my analysis and presentation conveys the full importance of your stories. I will also endeavour to use the outcomes from this research to contribute to the advancement of our language. 
To Dr Kathie Irwin, thank you very much. You gave so freely of your time to sit and talk with me about my topic during the early stages and towards the end when I was writing the chapters. It was really hard for me being a shy person to ask you for your time. When you agreed I was so overwhelmed and could not wait to meet you. I really appreciated your insightful ideas, feedback and answers to the questions that I posed. Most of all I appreciated that you took the time to meet and talk with a shy young Māori girl just starting out with her PhD. I will never forget what you did for me and I will endeavour to do the same for others. He wahine ātaahua, he wahine toa. Ngā mihi aroha ki a koe.

This section would be incomplete without acknowledging my colleagues at Te Kura Māori and the Faculty of Education who have provided a sounding board for ideas as well as an ear to share my frustrations and struggles. In particular I acknowledge Hiria and Chelsea for the writing days while I was at home with baby and needed some adult conversations. The food was healthy, the company superb, and the writing constructive (most days). Thank you very much ladies for your support throughout this journey. Susan Kaiser, thank you for your kindness and words of wisdom when the deadline was nearing and your expertise in formatting and editing my thesis - you are a true gem! I would also like to thank Professor Jeff Sigafoos for taking the time to read through my chapters and provide invaluable feedback. My running buddy Barrie Gordon, thank you for keeping me honest by making me have to run at your speed. The fresh air, conversations and cardio were all welcomed and needed to revitalise the mind.

To end, I would like to once again thank everyone that I have stated above and others too numerous to mention. I hope that my work does justice for the invaluable time, energy and effort that you have provided me. 


\section{Table of Contents}

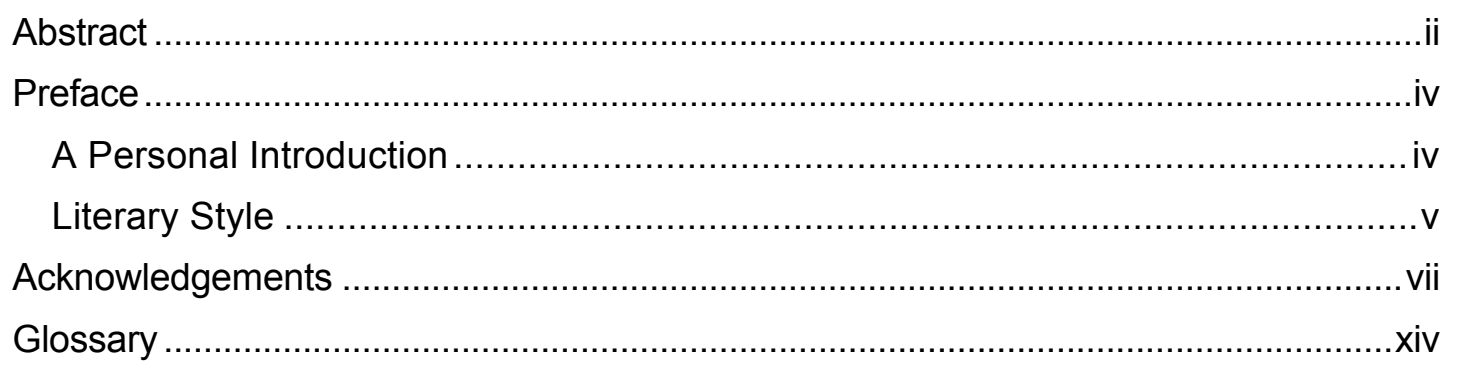

Chapter One Introduction ............................................................................ 1

Whakapiki i te Reo - A Professional Learning and Development Programme (PLD) ..... 4

Chapter Summary and Thesis Overview................................................................. 10

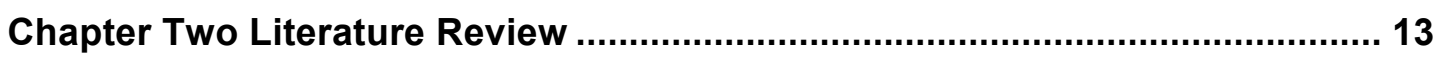

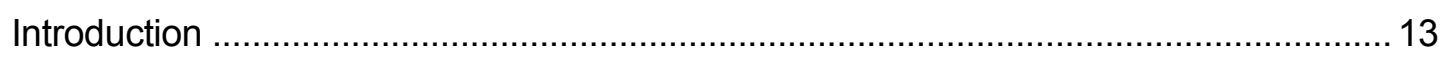

A Brief Account of Māori Language Development in Education .................................... 13

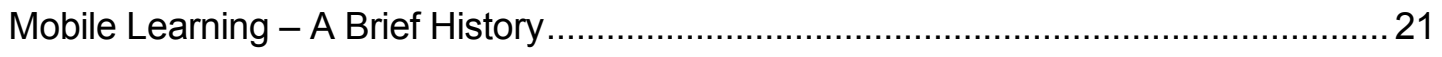

Teacher Professional Learning and Development (PLD) ........................................... 26

The Challenges and Opportunities of Using Technology for Teaching and Learning.... 33

Access - ICT Tools and Resources, Time and Training ................................... 33

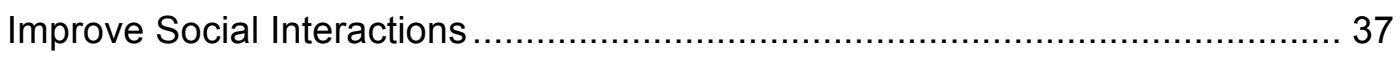

Teachers' Needs, Attitudes and Knowledge ................................................... 39

Student Needs, Attitudes and Knowledge ................................................... 40

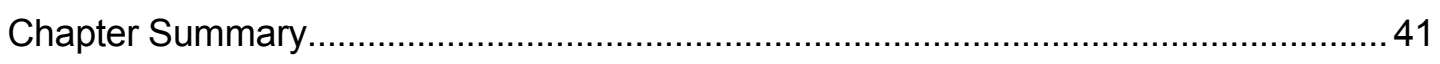

Chapter Three Research Design, Methods and Tools................................... 44

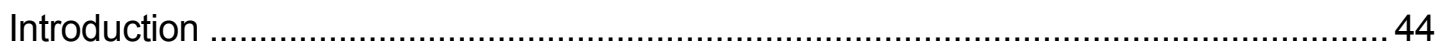

Hei Korowai - An Indigenous Framework .......................................................... 44

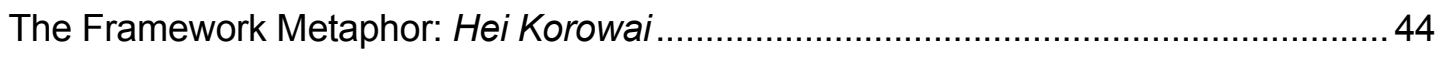

Kaupapa Māori and Māori-centred Research .............................................................. 47

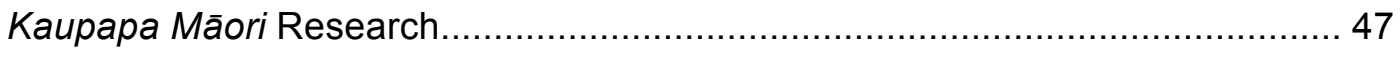

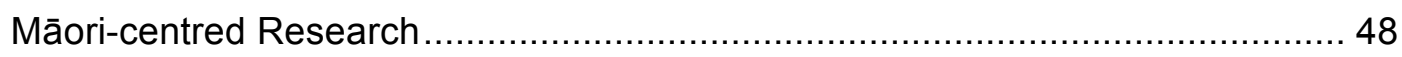

Kaupapa Māori and Māori-centred Research Principles within this Thesis ......... 49

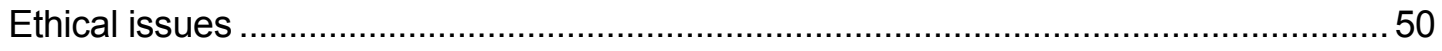

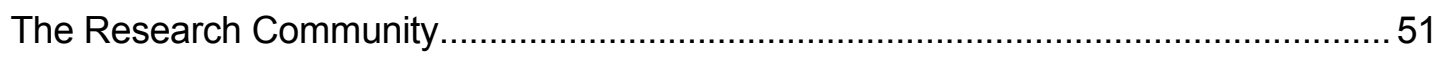

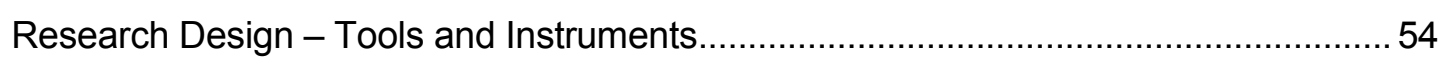

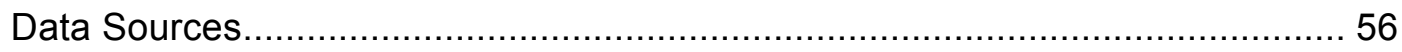

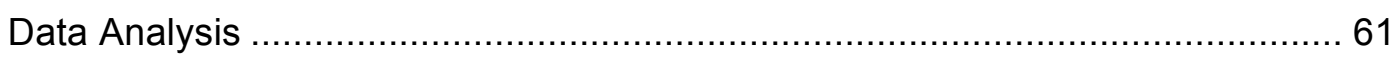

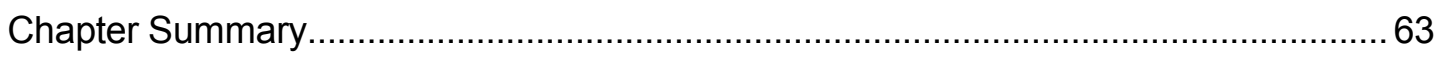




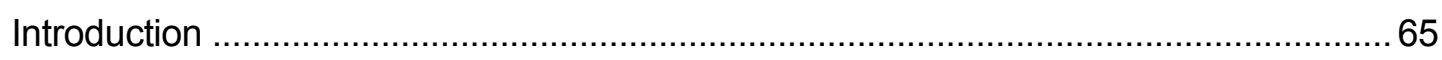

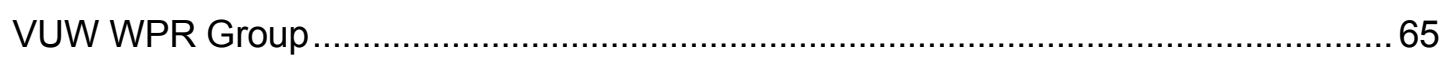

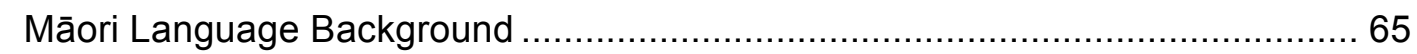

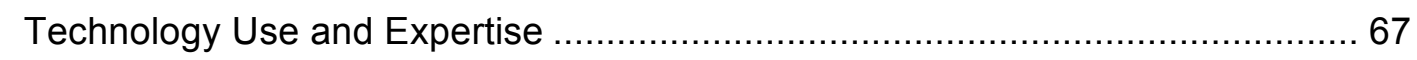

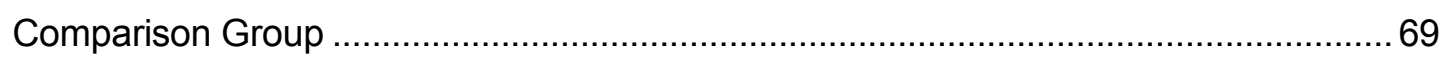

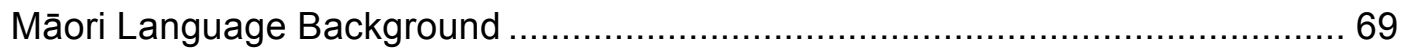

The Opportunities Presented by Mobile Device Use to Attain Māori Language

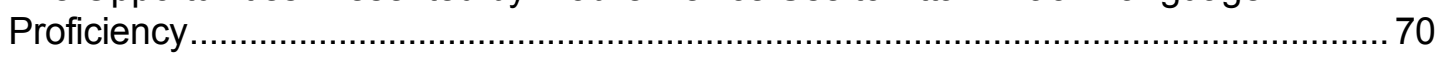

The Challenges Presented by Mobile Device Use to Attain Māori Language

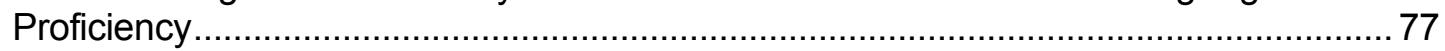

The Opportunities Presented by Face-to-face Instruction to Attain Māori

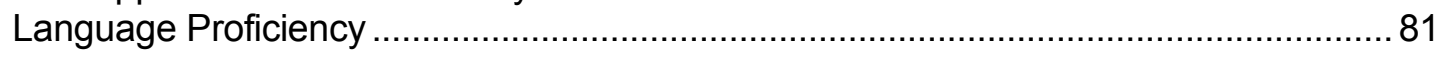

The Challenges Presented by Face-to-face Instruction to Attain Māori Language

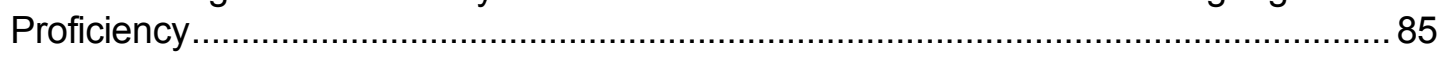

The Opportunities Presented by a Blended Approach to Attain Māori Language

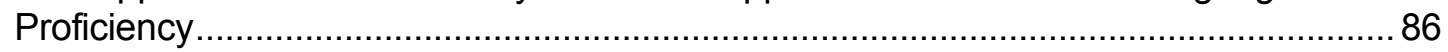

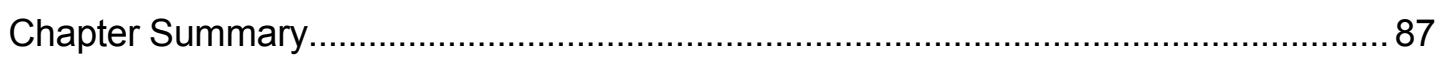

Chapter Five Research Findings - Questionnaire ....................................... 90

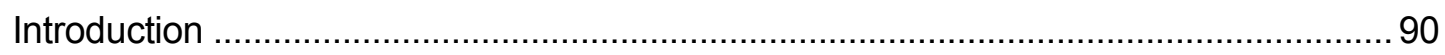

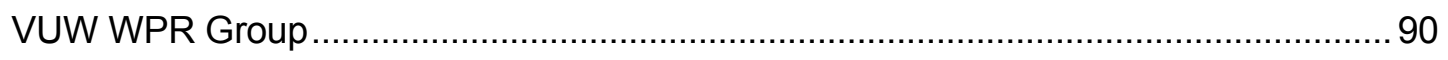

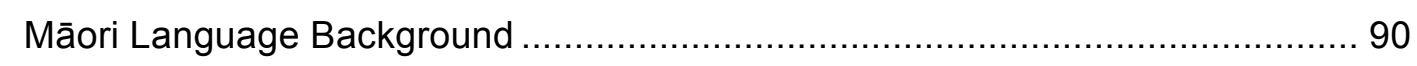

Technology Use and Expertise ............................................................... 91

Challenges and Opportunities Presented by Mobile Devices to Attain Māori

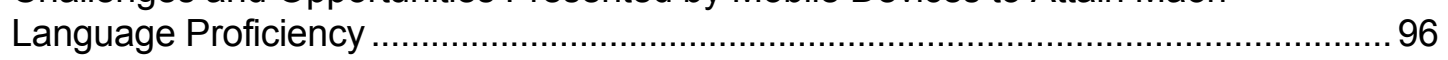

Contribution to Iwi-specific Language, Tikanga and Knowledge ................................. 102

Challenges and Opportunities Presented by Face-to-face Instruction to Attain

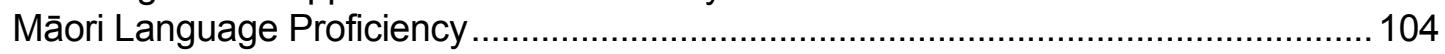

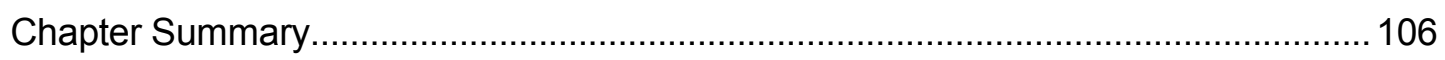

Chapter Six Research Findings - Proficiency Test Results ......................... 109

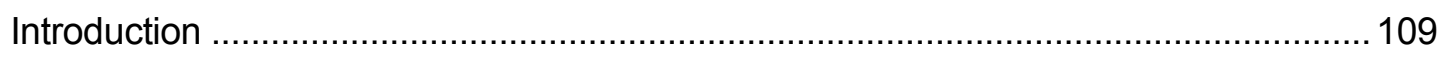

VUW WPR Group Pre and Post-test Results ........................................................ 109

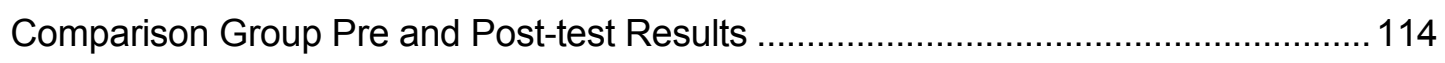

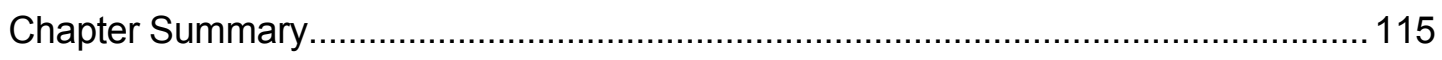

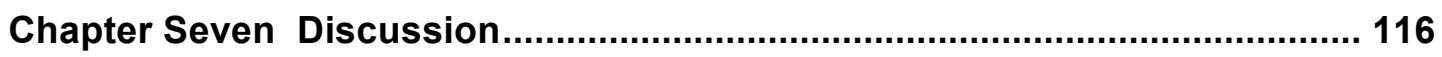

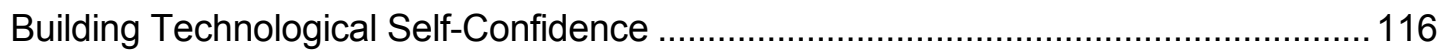

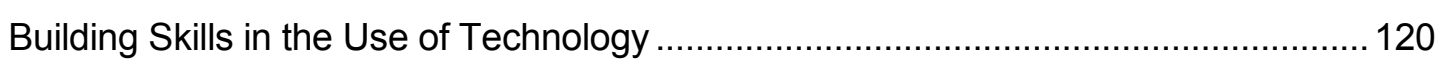

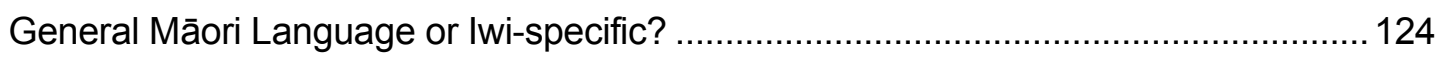

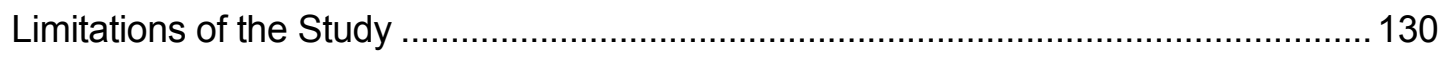

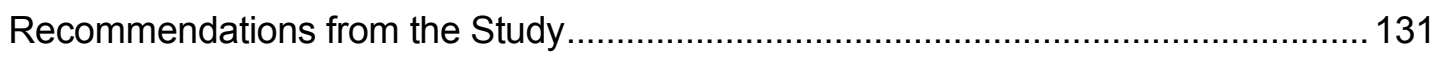


Recommendations for Future Research... 133

Chapter Summary. 134

References. 135

Appendices 146

Appendix 1: Interview Questions - Participant (Main Group) 147

Appendix 2: Interview Questions - In-school Facilitator. 149

Appendix 3: Interview Questions - Regional Co-ordinator 151

Appendix 4: Interview Questions - Participant (Comparison Group) 153

Appendix 5: Observation Criteria 155

Appendix 6: Waikato Proficiency Tests. 157

Appendix 7: Ethics Forms. 182 


\section{List of Tables}

Table 2.1: UNESCO Framework of Language Vitality and Endangerment ............. 20

Table 2.2: Lesson Without Mobile Device Versus Lesson With Mobile Device ....... 25

Table 2.3: Key Issues and Strategies for ICT-related Professional Development ... 32

Table 3.1: Identifying the Use of Hei Korowai within this Thesis 46

Table 3.2: Characteristics of a Kaupapa Māori and Māori-centred Research Approach. 49

Table 4.1: Participants' Expertise to Utilise the Mobile Device 68

Table 5.1: Participants' Expertise to Utilise the iPod Touch $®$. 92

Table 5.2: Participants' Expertise to Utilise the iPod Touch $\AA$ and $\mathrm{iPad} \circledast$................ 94

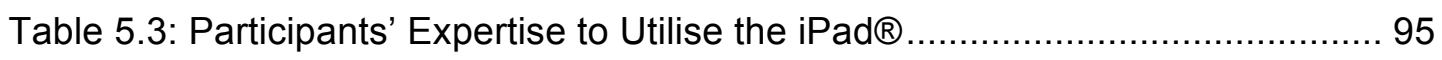

Table 5.4: Utilising the Mobile Device in the Classroom ...................................... 98

Table 5.5: The Use of Video to Improve Knowledge and Understanding of Te Reo Māori 100

Table 5.6: The Effectiveness of the Mobile Device in Particular Aspects of the WPR Programme 100

Table 5.7: Training and Support in the Use of the Mobile Device......................... 101

Table 5.8: Feelings Elicited When Using Mobile Devices ................................ 101

Table 5.9: Preferred Learning Situations (1 - Most Preferred, 6 - Least Preferred)... 105

Table 5.10: The Effectiveness of Different Settings and Relationships ............... 106

Table 6.1: VUW WPR Waikato Pre and Post-test Results .................................. 110

Table 6.2: VUW WPR Participants who Scored 24 or Below in the Pre-test ......... 112

Table 6.3: VUW WPR Participants who Scored 25 or Above in the Pre-test......... 113

Table 6.4: Comparison Group Waikato Pre-test Results ..................................... 114

\section{List of Figures}

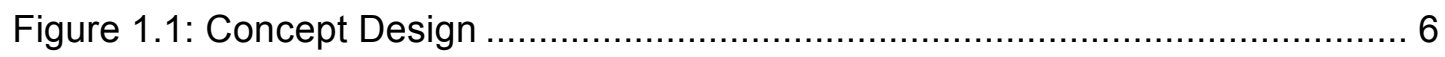

Illustrations $1 \& 2$ : Snapshots of the introduction to a language grammar video....... 8 Illustrations $3 \& 4$ : Snapshots of a language grammar video identifying the language in focus and the base words ('pai' (good) and 'whare' (house)) within the sentence in focus at the bottom of the page.

Illustrations $5 \& 6$ : Snapshot showing the follow-up task encouraging the user to

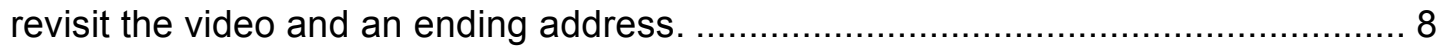

Figure 2.1: How Professional Development Affects Student Achievement ............ 31

Figure 3.1: Puketapu-Hetet, Akopai Wharenui, 2007 ........................................ 45

Figure 3.2: Adaption of Durie's Whare Tapawhā Model ..................................... 55 


\section{Glossary}

Māori Word

Aho

Aotearoa

Aroha

Ātaahua

Hapū

Hōhā

Hopu reo

Hui

Iwi

Iwi-tanga

Kaiako

Kaiāwhina

Kaikōrero

Kaitautoko

Kanohi ki te kanohi

Kapa haka

Karakia

Karanga

Kaumātua

Kaupapa

Kaupapa Māori

Kōhanga Reo

Kōrero

Korowai

Kotahitanga

Kōtui

Kuia

\section{English Word}

Horizontal lines

New Zealand

Love

Beautiful

Sub-tribe

Annoy

Language acquisition

Meeting

Tribe

Tribal culture

Teacher

Teacher aide

Speaker

Support person

Face-to-face

Māori performing arts

Prayer

Spiritual call

Elderly men

Agenda

Concerning Māori matters

Language Nest

Speaking, speech, talk

Māori cloak

Unity

Central thread

Elderly woman 


\begin{tabular}{|c|c|}
\hline Кирu & Word \\
\hline Kura & School \\
\hline Kura Kaupapa Māori & Māori Immersion School \\
\hline Kura Māori & Māori Immersion School \\
\hline Kura-ā-iwi & Tribal school \\
\hline Mahi & Work \\
\hline Mana & Prestige \\
\hline Mana Māori & Māori control \\
\hline Mana Whakaheke & The link to higher learning and knowledge \\
\hline Mana Whakatipu & The growing or learning of new knowledge \\
\hline Manaakitanga & Expressions of respect or kindness \\
\hline Manakohanga & Acknowledgement \\
\hline Marae & Courtyard \\
\hline Mātau & Knowledge \\
\hline Mātauranga & Education \\
\hline Mātauranga Māori & Māori education \\
\hline Mihi & Greetings, thanks \\
\hline Miraka & Milk \\
\hline Mita & Tribal dialect, accent \\
\hline Mokopuna & Grandchildren \\
\hline Mōteatea & Lament \\
\hline Ngā momo tumu & Base words \\
\hline Ngā punga & Particles \\
\hline Ngā rerenga pū & Simple sentences \\
\hline Ngā taonga tuku iho & Treasures from the ancestors \\
\hline Ngā whakahau & limperatives \\
\hline Noa & Neutral phenomenon \\
\hline Pai & Good \\
\hline Pākehā & European \\
\hline
\end{tabular}




\begin{tabular}{|c|c|}
\hline Pakeke & Adult \\
\hline Pakiwaitara & Story \\
\hline Papa kāinga & Home \\
\hline Pono & Truth \\
\hline Pukapuka & Book \\
\hline Pune & Spoon \\
\hline Ranga & To weave \\
\hline Rangatira & Chief \\
\hline Rangatiratanga & Chieftainship \\
\hline Raranga & To weave \\
\hline Reo & Language \\
\hline Reo-ā-tinana & Body language \\
\hline Rohe & Area \\
\hline Rorohiko & Computer \\
\hline Rūmaki & Immersion \\
\hline Rūnanga & Governing council of a sub-tribe or tribe \\
\hline Tamariki & Children \\
\hline Tangihanga & Funeral \\
\hline Tарu & Sacred \\
\hline Te ao Māori & The Māori world \\
\hline Te reo & The language \\
\hline Te reo Māori & The Māori language \\
\hline Te taha hinengaro & Mental \\
\hline Te taha mana whenua & The land, belonging \\
\hline Te taha tinana & Physical \\
\hline Te taha wairua & Spiritual \\
\hline Te taha whānau & Extended family \\
\hline Te Tai Rāwhiti & East Coast \\
\hline Te Tai Tokerau & Northland \\
\hline
\end{tabular}




\begin{tabular}{|c|c|}
\hline Te Tau Ihu & Top of the South Island \\
\hline Te tūāpapa & Background, grounding \\
\hline Te Whanganui-a-Tara & Wellington \\
\hline Tika & Correct \\
\hline Tikanga & Protocols \\
\hline Tira & A group of people \\
\hline Toa & Warrior \\
\hline Tuhituhi & Writing \\
\hline Tukutuku & Ornamental lattice work \\
\hline Tūpuna & Ancestors \\
\hline Wahine & Woman \\
\hline Waiata & Song \\
\hline Wairua & Spiritual \\
\hline Wānanga & Māori immersion tertiary institution, forum \\
\hline Wero & Challenge \\
\hline Wete reo & Language grammar \\
\hline Whaikoha & Respect \\
\hline Whaikōrero & Formal oratory \\
\hline Whakairo & Carvings \\
\hline Whakamā & Shame and embarrassment \\
\hline Whakapakari & Improve \\
\hline Whakapapa & Genealogy \\
\hline Whakapiki Tangata & Enablement, enhancement or empowerment \\
\hline Whakataukī & Proverb \\
\hline Whakatuia & Integration \\
\hline Whānau & Family \\
\hline Whanaungatanga & Expressions of support and love within a family \\
\hline Whare & House \\
\hline Wharekura & Māori immersion secondary setting \\
\hline
\end{tabular}


Wharenui

Whenu
Meeting house

Strands 


\section{Chapter One Introduction}

Ko te reo te mauri o te mana Māori.

The language is the life essence of Māori existence.

(Ministry of Education, 2009b, p. 81)

This opening assertion, made by Sir James Henare in a New Zealand Ministry of Education document, makes the point that Māori language is the foundation on which Māori culture is formed. The Ministry of Education (2009b) acknowledges and supports Sir James' proclamation by stating that language, culture, place, and heritage all play a very important role in shaping one's identity and giving direction and meaning to life (Ministry of Education, 2009b). The importance of Māori language to Māori culture and identity is further emphasised by the Te Reo Māori Claim lodged with the Waitangi Tribunal in 1986:

\footnotetext{
Some New Zealanders may say that the loss of Māori language is unimportant. The claimants in reply have reminded us that the Māori culture is a part of the heritage of New Zealand and that the Māori language is at the heart of the culture. If the language dies the culture will die, and something quite unique will have been lost to the world. $(1989$, p. 5)
}

Ratima and May (2011) argue that the survival and advancement of the Māori language is of local and global significance as it underpins cultural, social, and economic development. The indigenous language of New Zealand is Māori, which is also an official language guaranteed protection under the Treaty of Waitangi. By understanding and using Māori, "New Zealanders become more aware of the role played by the indigenous language and culture in defining and asserting our point of difference in the wider world" (Ministry of Education, 2009b, p. 12). In line with the arguments of two Ministry of Education reports (2006a, 2009a), students who are steeped in Māori language and culture strengthen their identities and their connection to their culture, thereby enabling them to interact successfully in te ao Māori (the Māori world). Students also increase their career and entrepreneurial opportunities due to the ever-increasing range of occupational settings seeking these skills (Ministry of Education, 2006a, 2009b).

In 2010, the Minister of Māori Affairs established a panel called Te Paepae Motuhake (Te Paepae Motuhake, 2011) to inquire into the state of the Māori language spend within New Zealand. The report cited statistics from the Waitangi Tribunal (1989) prepublication of Wai 262 that indicated a decline in the level of 
Māori people who spoke Māori from 25.2\% in 2001 to $23.7 \%$ in 2006. The report also stated that the safety of Māori language survival was at a level that was definitely endangered. Therefore, serious attention needs to be given to the current state of the Māori language as well as a plan to put forward to secure "its future as a living, dynamic, and rich language" (Ministry of Education, 2009b, p. 12).

Recommendations made by Te Paepae Motuhake (2011) included (a) the need to support Māori language teachers to increase the quality of language they use, and (b) the need to embrace technology as a tool to support Māori language revitalisation. Both of these recommendations relate directly to this thesis investigating the use of mobile devices within a professional learning and development programme to increase Māori language proficiency in teachers.

The specific research questions addressed in this thesis were:

1. What are the challenges of, and opportunities for using mobile devices to attain Māori language proficiency?

2. Do learners make expected gains in language proficiency through the use of mobile devices in comparison to standard face-to-face methods of language instruction and, if so, are these differences associated with mobile device use?

This thesis will base its examination on the Victoria University of Wellington (VUW) Whakapiki i te Reo (WPR) professional learning and development (PLD) programme (McKenzie, Toia, \& McRae, 2010). As part of this thesis research, the impact of a separate PLD programme involving face-to-face facilitation to assess the use of mobile devices for language proficiency in comparison to a different (more typical or standard) face-to-face method of language instruction was also examined.

The Education Review Office (2009) noted that the purpose of PLD is to "improve the quality of teaching and to improve student outcomes" (p. 1). In line with this, Guskey (2000) defined professional development as "processes and activities designed to enhance the professional knowledge, skills and attitudes of educators so that they might in turn, improve the learning of students" (p. 16). The Ministry of Education (2007) noted that the use of technology, such as mobile devices, in PLD programmes might be one way to supplement face-to-face instruction and open up new ways of learning. This type of technology might also help to overcome barriers of time and distance, create communities of learning that are supportive, cater for the diverse needs of learners, and enhance learning by providing access to virtual experiences, resources, and tools. A possible role for such technology for the 
purposes of enhancing Māori have also been highlighted within the Ministry of Economic Development's (2008) Digital Strategy 2.0 document, which states that:

The digital world offers opportunities for strengthening Māori identity, expressing a Māori world view and communicating in a global context. Digitising mātauranga Māori (Māori knowledge) can be a powerful way to transmit aspects of culture, heritage and identity to future generations and those who have moved away from their rohe (area). (p. 27)

This digital strategy document also noted that there is value in finding ways to create a digital future for Māori through technologies that will enhance and empower iwi (tribe) and hapū (sub-tribe) and support their realisation of social, cultural, and economic aspirations (Ministry of Economic Development, 2008).

A mobile device can be defined as "any device that is small, autonomous and unobtrusive enough to accompany us in every moment and can be used for educational purposes" (Trifonova, Knapp, Ronchetti, \& Gamper, 2004, p. 3). Examples of mobile devices include cell phones, smartphones, MP3/MP4 players, palmtops or handheld computers (Personal Digital Assistants or PDAs), tablet and laptop computers (Kukulska-Hulme \& Traxler, 2005). Pachler, Bachmair, and Cook (2010) considered laptop computers to sit outside of the context of mobile learning due to their lack of "true portability and ubiquity as well as penetration of a wide range of social contexts" (p. 7). Traxler (2008) also noted the difficulty of considering laptops and tablet PCs (personal computer) as a part of the mobile learning context due to the lack of spontaneity in carrying and time required to start up such devices. Participants within the programme were given an iPod Touch $\AA$ and the regional coordinators an $\mathrm{iPad} \circledast$ for the length of the programme as a tool to support them to increase their Māori language proficiency.

Finally, according to Te Taura Whiri i te Reo Māori (The Māori Language Commission, 2012), the working definition of a highly proficient adult Māori language speaker is someone who is "able to speak, listen, read and write in the Māori language. The speaker is also able to express all of their thoughts, opinions and emotions according to the context and with whom they are interacting" (Ratima \& May, 2011, p. 1). This definition is based on descriptors within the candidates' handbook developed by Te Taura Whiri i te Reo Māori as part of a collection of Māori language proficiency tests. The tests are designed to assess the language proficiency in adult speakers of Māori and give candidates a general indication of their overall language knowledge. A five-level proficiency framework is used to define the candidate's level of proficiency, ranging from Level 1 (basic routine language) to Level 5 (complete proficiency). One of the aims of the VUW WPR 
programme was for participants to increase their proficiency within the four modes of (a) speaking, (b) listening, (c) reading, and (d) writing. The levels of progression for each participant were expected to differ depending on a number of variables, such as the amount of Māori spoken in the home, the quality of Māori language speakers in their support system, and participants' openness to change/learning and participation in the PLD programme.

\section{Whakapiki i te Reo - A Professional Learning and Development Programme (PLD)}

WPR (to raise the proficiency in language) is a PLD programme for teachers in Māori medium educational settings. The programme is aimed at improving teacher capability through increased proficiency, confidence, and application of te reo Māori. WPR also aims to ensure that Māori education is well supported, of high quality, and focuses on increasing student achievement (McKenzie et al., 2010).

Community aspirations to regenerate tikanga (protocols), mātauranga (knowledge), and te reo Māori specific to Māori medium schools and settings are supported in consultation with the whānau, hapū and iwi within the WPR PLD programme (McKenzie et al., 2010).

In 1994, Te Whakapiki Reo (the original name of WPR) was delivered by staff from Waikato University to teachers in Māori medium education settings for one term. The purpose of the programme was to increase the teachers' proficiency in Māori as well as their knowledge of the curriculum documents written in Māori. Two years later, the name of the programme was changed to Te Whakapiki i te Reo and it was expanded to 20 weeks (Te Kanawa \& Whaanga, 2005).

Fast-forward to 2009, the Whakapiki i te Reo contract continues to service Māori medium educational settings, but with more providers, each delivering the programme in their own unique way. From 2009 to 2012, VUW was selected as one of five preferred providers to deliver the WPR PLD to teachers in Levels 1 and 2 (i.e., the $51 \%$ to $100 \%$ Māori language immersion levels) Māori medium educational settings, particularly Kura Kaupapa Māori, Kura Māori (Māori immersion school), Kura-ā-iwi (Tribal school), bilingual and rūmaki (Māori immersion) classes in mainstream schools. Although the educational settings outlined above would require the teachers to be proficient in the Māori language, the level of proficiency of individuals within the different settings varies. Factors that could contribute to 
variances include the teacher's background in Māori language, whether they spoke Māori in the home or around them in general, whether they learned Māori at school or other learning institutions, and whether they currently speak Māori or seek ways to enhance their proficiency.

The VUW WPR programme was initially planned for delivery in a face-to-face mode in Wellington. Teachers from around the country would apply to partake in the programme with the successful applicants attending an intense 20-week programme about Māori language and second language acquisition at VUW (McKenzie et al., 2010). The programme was advertised, expressions of interest were received, and at a later date follow-up calls were made to the prospective participants. During the follow-up calls some of the prospective participants declined the offer of participation. The reasons included the limited number of relief teachers to take the place of the prospective WPR participant, the rural isolation of schools, and logistical problems related to travelling to Wellington. Being away from family and community responsibilities was also of concern as well as the cost of living expenses while undertaking the WPR programme in Wellington. Because of these concerns, there was a need to explore alternative models for delivery of the programme.

Thus VUW WPR team members (including the researcher of this thesis) discussed the PLD needs of schools and teachers as well as the implications of PLD (as outlined above) with principals from around the Wellington region. These conversations contributed to the final design of the VUW WPR programme, a programme that is primarily based within schools and includes the whole school (or most of it) and uses an approach of face-to-face instruction, online support, and digital technology (specifically the iPod Touch ${ }^{\circledR}$ and iPad $\AA$ ) (see Figure 1.1) (McKenzie et al., 2010). 


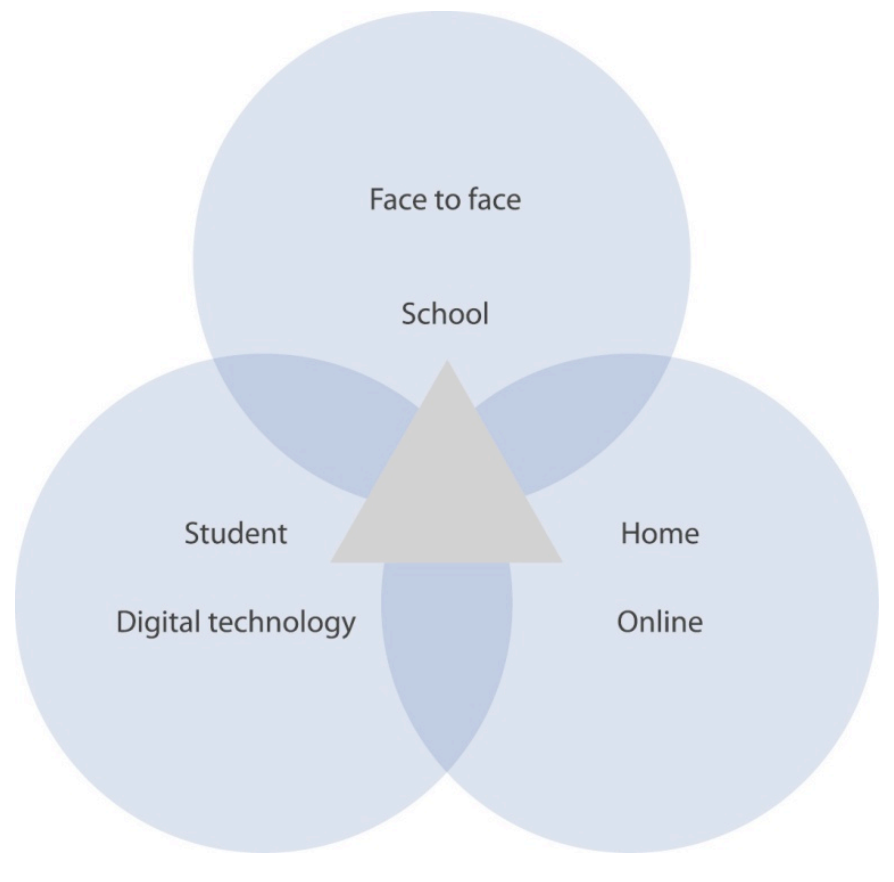

Figure 1.1: Concept Design

Each component of the VUW WPR programme has a number of aspects, activities, or information that are seen as possibly contributing to improved teacher capability through increased proficiency, confidence, and application of the Māori language (McKenzie et al., 2010).

The face-to-face component includes weekly interactions with the regional coordinator and in-school facilitator. The regional coordinator delivers the WPR programme and the in-school facilitator supports the regional coordinator and participants to fulfil programme requirements. Programme requirements entail participants completing all course work, including watching all videos about Māori language and principles of second language acquisition, completing weekly worksheets that relate to the videos, and recording themselves reflecting on their progress throughout the week via the Voice Memos function on the iPod Touch $囚$. Participants are also required to meet regularly with the in-school facilitator or regional coordinator to monitor progress, to gather writing and oral samples of students in their classrooms, and to implement their learning from the PLD programme in the classroom. Participants also have opportunities for discussions with colleagues, allowing collaboration and sharing of knowledge and skills.

The position of the VUW WPR model as a school-based programme is intended to provide participants with opportunities to analyse and trial a range of concepts related to Māori language, second language acquisition, and teaching and learning theories within their classroom on a daily basis. Classroom observations, in-class modelling, weekly 
activities and group discussions are additional opportunities offered to participants. These experiences are intended to provide participants with the skills and knowledge required to identify and plan appropriate intervention to support their own as well as their students' specific linguistic needs. By having the participants at the centre of their own learning and the learning of their students, there were likely to be opportunities to develop facilitative attitudes and skills (Daly, Pachler, \& Pelletier, 2009b; Scrimshaw, 2004). This was also viewed as a means of developing learning approaches tailored to the participants' and the students' needs (McKenzie et al., 2010).

The online component included the same programme material that was initially given to participants at the beginning of the programme in hardcopy or via the iPod Touch $\circledast$ and also made available to participants via the VUW WPR website ${ }^{1}$. Examples of material available via the webpage included electronic copies of workbooks, assessment sheets and information guides, videos of Māori language grammar and second language acquisition principles, audio files of proverbs and colloquialisms as well as links to other resources. A potential advantage of having programme material available via the webpage is that it may give participants opportunities to access the material any time and those who prefer to complete assessments electronically are thus also likely to be better served.

The digital technology component included material that was downloaded to, viewed on, and used with mobile devices (particularly the iPod Touch $\circledast$ or the $\mathrm{iPad} \circledast$ ). Each participant involved in the VUW WPR programme was given an iPod Touch® (MP4 player) to use for the length of the programme. The mobile device was loaded with videos about wete reo (language grammar) and hopu reo (language acquisition) which could be viewed during the whole group meetings or independently at a time, and place suitable for the participant. The material was pre-loaded by a VUW WPR team member to enable participants to access programme content immediately. The participants were also able to use their mobile device in the classroom with their students if they chose to. Some of the language grammar topics examined were $n g \bar{a}$ momo tumu (base words), ngā punga (particles), ngā whakahau (imperatives) and $n g \bar{a}$ rerenga pū (simple sentences). Second language acquisition principles compiled by Rod Ellis (Ministry of Education, 2006b) were examined alongside Paul Nation and John Macalister's (2010) principles of language curriculum design as part of the hopu reo videos. The videos showed an introduction to the topic by presenters, pages with text that corresponded with the commentary, and an outline of follow-up activities. Examples of the language grammar topic were also shown

\footnotetext{
${ }^{1}$ The VUW WPR webpage is www.whakapiki.co.nz
} 
within sentences given on screen, as seen in the illustrations below (Illustrations 16). The videos are in colour and range from approximately 4 minutes to 13 minutes. The reason that the videos are between 4 and 13 mintues was to maintain the user's engagement.
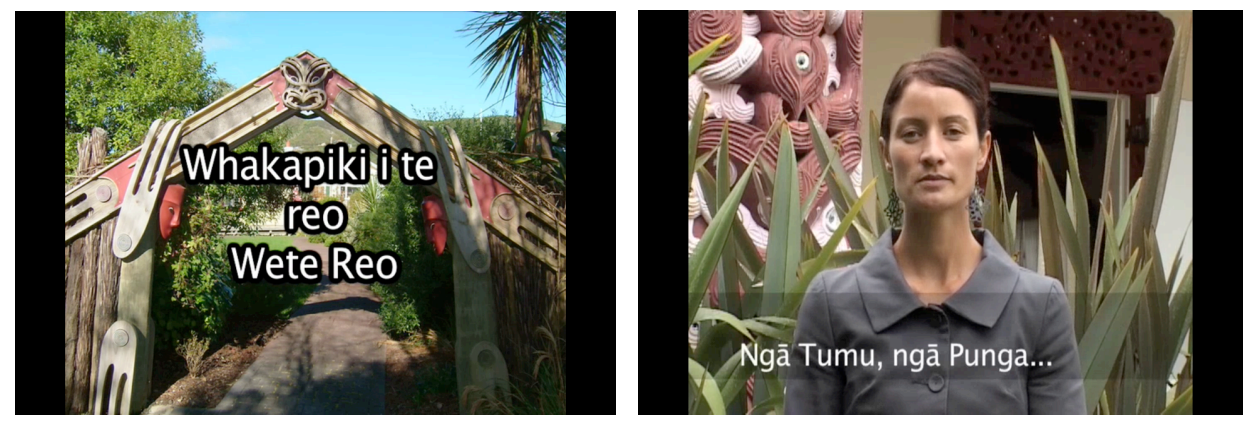

Illustrations $1 \& 2$ : Snapshots of the introduction to a language grammar video.
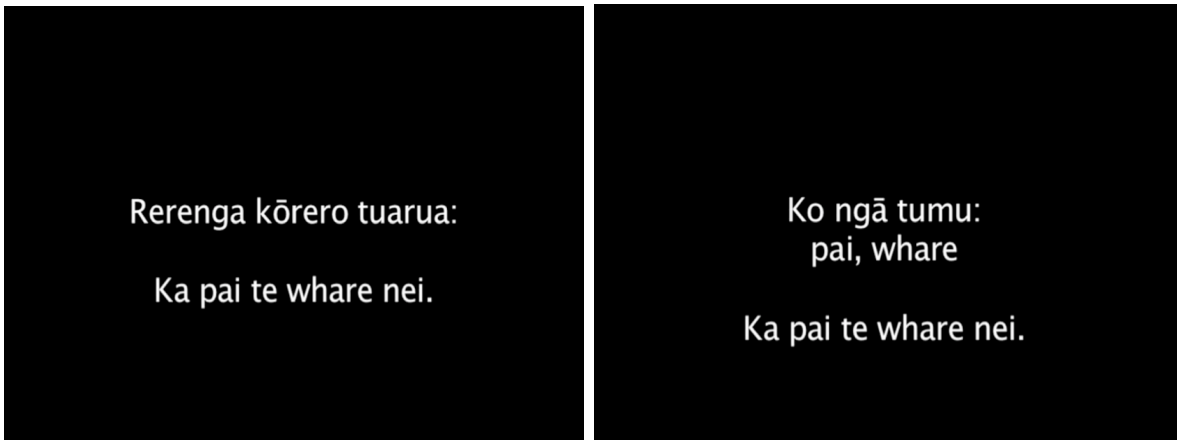

Illustrations 3 \& 4: Snapshots of a language grammar video identifying the language in focus and the base words ('pai' (good) and 'whare' (house)) within the sentence in focus at the bottom of the page.
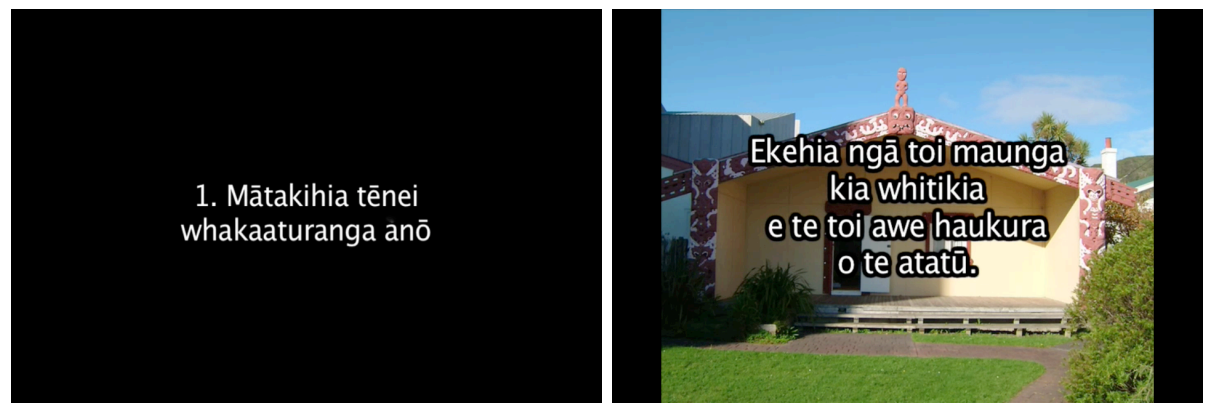

Illustrations 5 \& 6: Snapshot showing the follow-up task encouraging the user to revisit the video and an ending address.

The iPod Touch $®$ and $\mathrm{iPad} \circledast$ (among other mobile devices) also offer a range of functions that have been merged into the device. This meant that users could access a wide range of resources, content, and functionalities potentially at any time and from 
anywhere (Pachler et al., 2010). Examples of functions that are combined into the iPod Touch $®$ included (but were not limited to) calendar, contacts list, video files, still camera, video camera, organiser, music files, web access, email, games, movie player, GPS compass, voice recorder, and a clock. This ubiquitous (existing everywhere) access opens the world up to the user making "the world move at the user's behest" (Pachler et al., 2010, p. 8), thus allowing the user to have an impact on the world.

Participants within the VUW WPR programme receive training on how to use functions on the iPod Touch $\circledast$ to ensure they are able to use the device successfully to meet programme requirements. Examples of these skills include how to turn it on, charge it, turn the volume up and down, and access video and audio files. Participants are also shown how to use the Camera, Video Camera, and Voice Memos functions on the iPod Touch $®$, which allow the user to document situations that they could revisit for critical reflection at their convenience (Pachler et al., 2010). For example, participants were required to record themselves using the Voice Memos function to reflect on their progress. They recorded their reflection in Māori, which could also be used to show any changes in language development.

The VUW WPR programme operates in a school for three years, aiming to have learning embedded within the classroom programmes and for schools to become self-sustainable and self-managing upon completion of the PLD programme. According to Garet, Porter, Desimone, Birman, and Yoon (2001), learning and change are more likely to occur when teachers are actively engaged in learning that is embedded in their daily practice. This in turn might also enhance student learning (Garet et al., 2001).

The VUW WPR programme aimed for a degree of local groundedness by enabling participants to use their own dialect or enabling them to gather and record narratives from native speakers, and hapū and iwi. Nationally connected communities and cultures included the regional coordinators from each region, who attended regular meetings via face-to-face or video conference (Skype), which was intended to provide opportunities for information sharing about programme progress, successes and challenges. 


\section{Chapter Summary and Thesis Overview}

Since the early 1800 s, the state of the Māori language has changed from being the exclusive language spoken by Māori to a language that is 'definitely endangered' (Te Paepae Motuhake, 2011). Significantly for Māori, fluency in te reo Māori is an important characteristic of distinctive cultural identity (Keiha, Moorfield, Ka'ai, \& Spooner, 2008). The survival and advancement of the Māori language is of local, national and global significance, and a new infrastructure for governance is required to ensure that it thrives (Te Paepae Motuhake, 2011).

Recommendations from the Te Paepae Motuhake report into the state of the Māori language identified the need to support teachers of Māori language to increase their proficiency and the potential value of using technology to support revitalisation efforts for the Māori language (Te Paepae Motuhake, 2011).

Towards addressing these challenges, a technology-based PLD programme was developed and evaluated in this thesis research. The programme focused on developing Māori language proficiency of teachers in Māori medium educational settings. Mobile technology devices were selected to help overcome issues such as teacher relief and rural isolation as learning via such devices may enable learners to participate in the learning programme at their convenience. As a PLD tool, the mobile devices might also be helpful in terms of expanding opportunities for teachers to strengthen their understanding of the subjects they teach and widen the repertoire of the instructional strategies they use (Pasnik, 2007). Because little is known about the potential of mobile devices to support teachers of Māori language to attain proficiency in the Māori language, the present research is timely.

This thesis is concerned with Māori language, teacher professional learning and development and mobile learning. Using the structure of a korowai (Māori cloak) metaphorically, the whenu (strands) that make the body of the garment are data gathered from the research participants. The aho (horizontal lines) are the existing literature related to the main themes of the research including Māori language, mobile learning, and teacher PLD. The kotui (central thread) is the research questions which are concerned with Māori language proficiency and Māori language revitalisation. The role of the researcher, as noted in the following assertion quoted in Mead and Grove (2003), is to merely draw together the aho, whenu and kōtui that make up the korowai and create the tāniko (the ornamental border). 
Nāu i whatu te kākahu, he tāniko tāku.

You wove the cloak, I made the border.

(Mead \& Grove, 2003, p. 319)

The thesis endeavours to weave together a korowai and unfold the challenges and opportunities in utilising mobile devices to attain Māori language proficiency. It also aims to unravel the differences associated with mobile device use and face-to-face facilitation when attaining Māori language proficiency.

The next chapter reviews existing literature on Māori language development in education, mobile learning, and teacher PLD. The aim of the review is to acknowledge the existing research and find any gaps in the field.

Chapter three describes the research design, methods, and tools used within the research. An indigenous framework called Hei Korowai developed by academics within Te Kura Māori, VUW is interwoven with Kaupapa Māori and Māori-centred research principles to guide the research process. Moreover, this chapter outlines the process taken to design the questions used to collect data from the semistructured interviews and online questionnaire. Observations of mobile device use and a language proficiency test were also used to elicit information from two groups of research participants and are described in this chapter.

The research findings are split into three and are covered in chapters four, five and six:

- Chapter four outlines the findings from the semi-structured interviews and observations of mobile device use with 17 VUW WPR participants as well as interviews from six participants in a separate WPR programme that use only face-to-face facilitation. Information about participants' Māori language background as well as their technology use and expertise are presented in this chapter. Furthermore, the challenges and opportunities of mobile device use, the challenges and opportunities of face-to-face facilitation, and the opportunities of a blended approach to attain Māori language proficiency are expounded.

- Online questionnaires from 29 VUW WPR participants located in different geographical locations are presented in chapter five. Similar to the outline in chapter four, the participants' Māori language background and their use and expertise with technology are outlined followed by the challenges and 
opportunities of mobile device use and the challenges and opportunities of face-to-face facilitation to attain Māori language proficiency.

- Chapter six presents the Waikato Proficiency pre and post-test results for participants in the VUW WPR and WPR comparison groups. The test results have been utilised to ascertain if learners make expected gains in language proficiency through the use of mobile devices in comparison to standard face-to-face methods of language instruction.

The final chapter discusses issues concerned with building technological selfconfidence, building skills in the use of technology, and whether interventions and initiatives should focus on general Māori language or iwi-specific language. This chapter also outlines the limitations of the study, recommendations from the study, and recommendations for future research. 


\section{Chapter Two \\ Literature Review}

\section{Introduction}

Four decades ago, Sesame Street helped transform television into a tool for learning among young children (Shuler, 2009). Pachler et al. (2010) and Shuler (2009) equate the educational potential of mobile devices for today's generation to that of Sesame Street 40 years ago. Could this be the case for the revitalisation of the Māori language? Olly Ohlsen revolutionised the use of Māori language and sign language as the face of a children's programme called After School during the $1980 \mathrm{~s}^{2}$. Today, there are also Māori language channels and programmes specifically focusing on Māori language with supplementary online interactive exercises and podcasts (a multimedia digital file made available on the Internet for downloading to a portable media player, computer $\left.{ }^{3}\right)$. The current study explored the use of mobile devices for Māori language revitalisation.

Literature about Māori language development in education and mobile learning is reviewed in this chapter. The review also covers PLD perspectives and frameworks as well as the use of technology in education with the focus being on the challenges and opportunities in these areas. The literature reviewed has been widened to the use of technology in education due to the dearth of literature related specifically to technology for Māori language or technology use by Māori learners. The literature review will help to focus the research, and reading around the topic is intended to help to ensure that it contributes to existing theories and perspectives in an informative manner. Gaps that may also be present in the literature will be highlighted alongside a description of how the current study may fill some of the gaps.

\section{A Brief Account of Māori Language Development in Education}

It has been suggested that Māori have always been quick to adopt new technologies and also adapt traditional technologies for new uses, as evidenced through, for example, their welcoming of the trading opportunities offered by the early visitors and settlers (Durie, 1997). Miller (1958) also supported this idea and stated that Māori did in fact acquire new techniques and technologies from

\footnotetext{
${ }^{2}$ Accessed from www.nzonscreen.com

${ }^{3}$ Accessed from http://oxforddictionaries.com
} 
Europeans, and more importantly, managed to do so while still maintaining their cultural identity and ways of being:

With the changes in Western civilization, primitive communities are confronted by alternative ways of behaviour, feeling and values. According to E. G. Wakefield in 1846, the Māori race was doomed, and the only choice was between 'amalgamation and extermination'. That is to say, the Māoris must either submit to the superior logic of the Wakefield System or suffer the consequences. There was, however, a wider range of possibilities; and as things turned out the Māoris, with their inquisitive, instinctive love of life, gradually acquired new techniques, new habits, manners, tastes and accredited dogmas, while retaining a good deal of their own culture. (p. 97)

One of the acquired skills of relevance to this study is the written language. The communications between Māori and Europeans during the early encounters, according to Spolsky (2003), were in Māori, in which the early settlers learned to carry out trading transactions. Up until the early 1800s, no written code had been established for the Māori language and history, however, a rich literature existed based on a highly developed oral technology (Durie, 1997; Karetu, 1975; Karetu \& Waite, 1988). This oral literature consisted of rich language from various aspects such as whakairo (carvings), tukutuku (ornamental lattice work), waiata, whakapapa (genealogy) and whakatauki learned or memorised and then passed on from generation to generation (Karetu, 1975). What is clear, however, is that the Māori did not have a written language code prior to Europeanisation.

With the increase of settlers to New Zealand and the desire from the missionaries to convert Māori to Christianity came the need for written communication in Māori (Durie, 1997). Around the world, opportunities to become literate were often restricted to the elite sections of society. In Māoridom knowledge was also differentiated into that for wider dissemination or for specially selected pupils (Durie, 1997). Thus opportunities for all Māori to learn how to read and write were undertaken with enthusiasm (Durie, 1997; Karetu \& Waite, 1988). According to Miller (1958):

The Māoris were often extraordinarily apt pupils. Their mental activity, their love of discussion and retentive memory made them eager to collect and transmit information. Moreover, so great was the prestige of the pakeha (European) learning that by 1842 there was scarcely a village in the North Island whose members between the ages of ten and thirty could not read and write in their own language, and poorer-class Europeans were taunted for their illiteracy. (pp. 97-98)

In support of Miller's statement, Māori actively acquired the new concepts of literacy and transferred these skills to one another with the help of teaching aids such as 
leaves, charcoal, carved wood and cured animal skins ${ }^{4}$. Unbeknown to Māori, these newly acquired skills would eventually contribute to a devastating period of a loss of their vernacular language (Spolsky, 2003).

In the early 1800s, it is believed that nearly everyone in New Zealand spoke Māori, including the settlers from overseas (Te Puni Kōkiri, 1999). However, that began to change as more settlers came to New Zealand and did not learn to speak Māori. There was also a general trend for these new settlers to demand (and force) Māori to speak more English.

In 1867, the Native Schools Act made English the language of instruction within these schools. Māori children who attended schools were often actively discouraged from speaking Māori and were told to "leave te reo (the language) at the school gate" (Waitangi Tribunal, 1989, p. 15). As a consequence, many of the children became bilingual in Māori and English (Ministry of Education, 2009b; Ministry of Māori Development, 2003). The use of te reo Māori (the Māori language) as a language of communication severely declined over the one hundred years during which this policy was enforced (Simon, Smith, Cram, Hōhepa, McNaughton, \& Stephenson, 2001).

By the 1970s, the Māori language was becoming the language of rural areas (Te Puni Kōkiri, 1999). According to Spolsky (2003), in 1945 one-quarter of the Māori population lived in the urban areas. By the 1970s only one-quarter remained in the rural areas. This was a time of great social change for Māori in their migration from rural to urban areas to provide labour for industrial developments. English was the exclusive language within the urban and industrial areas, which caused Māori adults to speak more English at work and probably also very often at home, resulting in more rapid language loss (Ministry of Māori Development, 2003; Spolsky, 2003; Te Puni Kōkiri, 2010). It was predicted "Māori would be a language without native speakers once the contemporary generation of Māori speaking adults had passed on" (Ministry of Māori Development, 2003, p. 11). This prediction caused grave concern among Māori people, a concern highlighted in a survey conducted by the New Zealand Council of Educational Research between 1973 and 1978. The survey showed that only $18 \%$ to $20 \%$ of Māori were fluent in the Māori language and that most of these fluent speakers were elderly (Benton, 1981; Ministry of Education, 2009b).

\footnotetext{
${ }^{4}$ Accessed from www.nzhistory.net.nz
} 
In response to the realisation of the serious plight for the language, a range of Māori-led initiatives began aimed at regenerating the Māori language and reasserting Māori identity (Ministry of Education, 2009b; Reedy, 2000). In 1978, Rūātoki School became the first official bilingual school in New Zealand. Then in 1979, the Te Ataarangi movement, developed by Katerina Te Heikōkō Mataira and Ngoingoi Pewhairangi, was established to restore Māori language knowledge to Māori adults. It is based on Caleb Gattegno's 'The Silent Way' “... which is neither a structural nor a direct...method of teaching but a way in which everything and everyone serves one aim: to make everyone into the most competent learner" (Mataira, 1980, p. 48). Cuisenaire rods, wall charts, and hand signals are the types of tools used in the first stage of learning to trigger utterances and help students create their own statements. According to Gattegno (cited in Mataira, 1980), a reasonable expectation from such a programme includes an accent similar to that of a native speaker, an ease of conversation related to vocabularies, compositions and events, and an ability to understand appropriate texts in both languages.

Teacher training and support for Māori language in schools was another important initiative aimed at regenerating the Māori language. Benton (1981) reported on a group of 46 students who commenced a special one-year course for nativespeakers of Māori. The aim was for these students to become Māori language teachers for the secondary school sector. The programme received criticism from a number of organisations including the New Zealand Educational Institute, the primary teachers' professional association, and from Ngā Tamatoa (a group of Māori who played an important role in revitalising the Māori language). The groups commented on the lack of qualified lecturers for the programme and were concerned that current Māori staff would be overloaded if they were expected to carry additional teaching in the new programme. A recommendation was put forward to extend the programme to primary and intermediate schools. There was also a concern that the programme was tokenistic, however, despite such criticisms, the programme continued and has filled a gap by enabling secondary schools to offer Māori language classes. In 1980 the graduates were permitted to teach in primary schools, intermediate schools, and secondary schools, also filling a gap in those settings.

Benton (1981) argued that teachers and students in Māori educational settings have suffered from a lack of adequate resources in that

"Māori-language teachers were required to be much more resourceful, and make do with far fewer published materials, than most of their colleagues 
teaching other modern languages. Despite all the improvements, the range of materials available and opportunities for professional and in-service training have been far from adequate" (pp. 38-39).

Another significant event in the revitalisation of the Māori language was the birth of kōhanga reo (language nests), a movement aimed at producing fluency in the Māori language among preschool children. The first Kōhanga Reo opened in Pukeatua, Wellington in April 1982 (Te Puni Kōkiri, 1999).

Kura Kaupapa Māori was the next step in the schooling sector for the language. According to Reedy (2000), with the success of kōhanga reo, parents who had committed themselves and their children to the cause of revitalising the language were determined to continue the Māori language-schooling pathway. The first Kura Kaupapa Māori, Te Kura Kaupapa Māori o Hoani Waititi, was established in Henderson, Auckland in 1985 (Reedy, 2000; Te Puni Kōkiri, 1999).

In 1986, a successful claim to the Waitangi Tribunal led to the Government passing the Māori Language Act 1987, which declared Māori as an official language of Aotearoa and also created Te Taura Whiri i te Reo Māori, the Māori Language Commission (Ministry of Education, 2009b). Te Taura Whiri i te Reo Māori supports the growth of the Māori language through the development of new terminology, focuses on raising standards of language use, and develops language planning for whānau (family) and iwi (Ministry of Māori Development, 2003; Te Taura Whiri i te Reo Māori, 2012). According to Reedy (2000), Government support for the revitalisation of the Māori language was extremely important for Māori as well as the wider New Zealand culture. He states further that

\begin{abstract}
"It anchors Māori hopes to a solid commitment base by Government on behalf of all New Zealanders. It is signalling that their representative body of Government considers the survival of Māori language a worthy objective for the future health of the language and the Nation. Second, it awakens the nation to a collective responsibility. Thirdly, it restores dignity to the Māori language and allows Māori people to recognise once again value in the language that too many had put aside because of the physical and psychological denigration witnessed throughout its history of contact" (Reedy, 2000, p. 163).
\end{abstract}

In the early 1990s, Kura Kaupapa Māori extended their services to offer secondary school subjects, resulting in wharekura. Māori language at the tertiary level was developed next as a result of the initiatives that occurred in the 1980s. According to Te Wānanga o Raukawa (www.wananga.com), the Crown recognised Te Wānanga o Raukawa as a wānanga (tertiary institution) under the Education Amendment Act in 1993; however, it had been operating since 1981. In the years to follow, two more wānanga were established: Te Wānanga o Aotearoa (1993) and Te Whare Wānanga 
o Awanuiārangi (1997). Each wānanga focuses on mātauranga Māori, te reo Māori and their maintenance, development, and dissemination (Te Puni Kōkiri, 1999).

In 1994, three draft curriculum documents written in Māori were released (Te Kanawa \& Whaanga, 2005). According to Te Kanawa and Whaanga (2005), teachers in Māori medium educational settings for whom the curriculum documents were written, had limited opportunities to improve their language proficiency and knowledge of the new curriculum documents. Consequently, Waikato University approached the Ministry of Education with a proposal to support the teachers in Māori medium education settings with their language proficiency and their knowledge of the curriculum documents. The Waikato University proposal was approved and thus Te Whakapiki Reo was established (see 'Whakapiki i te Reo' below, for further information).

Initiatives, such as Te Whakapiki i te Reo, helped to support the growth of Māori language speakers and skills, which were aims of the Māori Language Strategy developed by the Government in 1997 (Ministry of Education, 2009b). The Māori Language Strategy was reviewed and revised in 2003 and is the most commonly held version to date (Te Puni Kōkiri, 2010). The revised Māori Language Strategy outlines the Government's need to strengthen language skills, language use, education opportunities, community leadership and recognition of the Māori language (Te Puni Kōkiri, 2010). Moreover, the Māori Language Strategy aimed for Māori language to be widely spoken by Māori and all New Zealanders, to be valued by all New Zealanders and a common awareness of the need to protect the language by 2028 (Ministry of Education, 2009b; Ministry of Māori Development, 2003; Te Puni Kōkiri, 1999; 2010). According to Reedy (2000), the University of Waikato developed a Māori language proficiency assessment tool for the Ministry of Education in 1999, which was an outcome of the Ministry's initiative (see Appendix 6).

In 1999, the first Māori Education Strategy was also launched with three main goals in mind. These were to raise the quality of mainstream education for Māori, to support the growth of high-quality kaupapa Māori (concerned with Māori matters) education, and to support greater Māori involvement and authority in education (Ministry of Education, 2009a). By 2006, the Ministry of Education had started to redevelop the strategy and released the final document, Ka Hikitia - Managing for Success: The Māori Education Strategy 2008 - 2012, in 2008. The intent of the strategy is for Māori to enjoy education success as Māori (Ministry of Education, 2009a). One of the four main focus areas within the strategy is Māori language in 
education. The foci within this area include the establishment of processes for Māori-medium schools, effective teaching and learning of and through te reo Māori, building the evidence base for mātauranga Māori, and strengthening the supply of quality teachers by providing a range of high quality PLD programmes to improve teachers' te reo Māori proficiency (Ministry of Education, 2009a).

In 2009, Te Puni Kōkiri commissioned Research New Zealand to undertake research into the attitudes, values, and beliefs of New Zealanders towards the Māori language. This research aligns with the Mãori Language Strategy and its aim to strengthen recognition of the Māori language (Te Puni Kōkiri, 2010). The outcomes of the research that pertain to the current thesis found that $68 \%$ of the Māori population believed that not enough Māori language is currently being spoken, a percentage that has not changed considerably since 2003 (Te Puni Kōkiri, 2010).

In July 2010, Te Paepae Motuhake, an independent panel appointed by the Minister of Māori Affairs, reviewed the Māori language sector and the Māori language strategy to ascertain the current health of the Māori language (Te Paepae Motuhake, 2011). Discussions with Māori language leaders and the public from 14 regions throughout New Zealand, as well as the panel's own expertise about language revitalisation, contributed to the final report for this review. The panel utilised a framework (see Table 2.1) based on research by the United Nations Educational, Scientific and Cultural Organization (UNESCO) that measures the degree of language vitality and endangerment. According to UNESCO (2003), one of the major evaluative factors of language vitality is intergenerational language transmission - whether or not language is being transmitted from one generation to the next. The UNESCO framework, alongside statistics concerning the use of Māori language in households with children, indicated that the state of the Māori language was between 'definitely endangered' and 'severely endangered' (Te Paepae Motuhake, 2011). 
Table 2.1: UNESCO Framework of Language Vitality and Endangerment

\begin{tabular}{|l|l|}
\hline \multicolumn{1}{|c|}{ Degree of Endangerment } & \multicolumn{1}{c|}{ International Language Transmission } \\
\hline Safe & $\begin{array}{l}\text { The language is spoken by all generations; } \\
\text { intergenerational transmission is uninterrupted }\end{array}$ \\
\hline Vulnerable & $\begin{array}{l}\text { Most children speak the language, but it may be restricted } \\
\text { to certain domains (e.g., home) }\end{array}$ \\
\hline Definitely endangered & $\begin{array}{l}\text { Children no longer learn the language as mother tongue } \\
\text { in the home }\end{array}$ \\
\hline Severely endangered & $\begin{array}{l}\text { The language is spoken by grandparents and older } \\
\text { generations; while the parent generation may understand } \\
\text { it, they do not speak it to children or among themselves }\end{array}$ \\
\hline Critically endangered & $\begin{array}{l}\text { The youngest speakers are grandparents and older, and } \\
\text { they speak the language partially and infrequently }\end{array}$ \\
\hline Extinct & There are no speakers left \\
\hline
\end{tabular}

The two main recommendations of the report were a focus on the re-establishment of Māori language in the home and development of a new infrastructure for governance to ensure accountability and "value for money" (Te Paepae Motuhake, 2011 , p. 5). There were 11 recommendations in the report, two of which relate directly to this research. Specifically, Te Paepae Motuhake recommended that technology be embraced as a tool to support the revitalisation of the Māori language and that teachers of Māori language be given the support required to achieve high levels of proficiency. PLD might be viewed as one potentially useful approach for providing teachers with this support.

Fast-forward to the $21^{\text {st }}$ century, Māori are still adopting new technologies to advance and excel in this ever-changing world. Monte Ohia argued, "if we turn our back on e-learning, we turn our back on the future" (Institutes of Technology of Polytechnics of New Zealand (ITPNZ), n.d., p. 3). Ohia was a member of a Māori reference group discussing the critical success factors of the effective use of elearning (the use of information and communication technologies to support or facilitate teaching and learning) with Māori. Due to the rapid transformation of technology, Māori need to be in a position of exploring and using technology with confidence (ITPNZ, n.d). Te Paepae Motuhake (2011) supports this statement and recommends that technology be embraced to revitalise the Māori language. The introduction of mobile devices within the current research was a way of keeping up with the modern world and the way of the future for some participants. If we take into account the history of our ancestors and the outcome of acquiring Western ideas, values and literacy skills, one must ask if there is a price to pay with the modern technologies to support the revitalisation of Māori language? Or should the question be, what is the price we pay if we do not engage with these tools? 


\section{Mobile Learning - A Brief History}

The use of mobile devices in teaching and learning is part of a relatively new field called mobile learning. Mobile learning has familiar connotations such as the concept of learning in general, learning by and through technologies, and learner mobility (Kukulska-Hulme \& Traxler, 2005; Pachler et al., 2010; Traxler, 2008). There is on-going debate about the distinction between mobile learning and other forms of distance learning, such as e-learning and online learning (Kukulska-Hulme \& Traxler, 2005; Laurillard, 2007; Pachler et al., 2010). Traxler (2008) wrote that mobile learning 'focuses in on the learners' experiences and emphasises ownership, informality, spontaneity, portability and context" (p. 14). These could be viewed as important characteristics that distinguish mobile learning from e-learning and online learning. Kukulska-Hulme and Traxler (2005) offered a range of attributes which they said characterised mobile learning such as it being "spontaneous, personal, informal, contextual, portable, ubiquitous (available everywhere) and pervasive (so integrated with daily activities that it is hardly noticed)" (p. 2). Laurillard (2007) argued that mobile learning emphasises the nature of the physical environment in which the learner is placed and thus it promotes a "digitally-facilitated site specific learning experience" (p. 156), something that was not possible with a desktop computer or landline.

There is limited research both nationally and internationally about the challenges and opportunities for using mobile devices within PLD programmes that aim to attain proficiency in language. To date, there appear to have been no studies that have explicitly examined the use of mobile devices within PLD programmes for teachers within Māori educational settings. In light of this gap, the present research was designed to investigate the use of mobile devices to attain proficiency in the Mãori language. Te Paepae Motuhake (2011) recommended supporting teachers to increase their proficiency in the Māori language and the need to embrace technology to help revitalise the Māori language. The present research is thus timely and relevant to these recommendations. In addition, the present investigation is consistent with recommendations in the New Zealand Curriculum (Ministry of Education, 2007) and the Digital Strategy 2.0 (Ministry of Economic Development, 2008).

As with the definition, there does not appear to be any widely accepted learning theory associated with mobile learning. This could be impeding the effective assessment, pedagogy and design of new applications (apps) for learning (Shuler, 2009). There is, however, a range of perspectives and approaches used by various 
researchers to try to understand, analyse and theorise examples of mobile learning practices (Pachler et al., 2010). To name a few, Lave and Wenger's (1991) 'Situated Learning' framework views learning as a method for meaning-making in context, for instance an apprenticeship in work-based learning contexts. Sharples, Taylor, and Vavoula (2005) offer a framework for analysing mobile learning to complement theories of classroom, workplace and informal learning. They also aim to inform the design of new environments and technologies to support mobile learning. Laurillard's 'Conversational Framework' was designed to describe the minimal requirements for supporting learning in formal education. It can be used to critique both traditional and digital learning designs and illustrate why digital forms offer an integrated and motivating learning environment more than a traditional form (an example of the framework in use is provided in this chapter). More recently, Kukulska-Hulme (2012) has offered a framework for next generation designs that support language learning defined by time and place.

Mobile technology and the availability of mobile services and apps are developing rapidly. Researchers (Kukulska-Hulme, 2012; Pachler et al., 2010; Shuler, 2009) argue the need for relevant conceptual frameworks to be developed in order to understand and interpret learner practices with these tools. In addition, Sharples and colleagues (Sharples, Taylor, \& Vavoula, 2007) suggest the need to promote enriching conversations between learners and teachers across different contexts. This may support teachers' understanding of how to design technologies, media and interactions to support learning across contexts, and how to integrate mobile technologies within education to enable innovative practices.

According to Sharples, Arnedillo-S'anchez, Milrad, and Vavoula (2008) the foundations of mobile learning were laid over 30 years ago with the Xerox Dynabook project. This project proposed a self-contained, portable knowledge manipulator the size of a notebook, which would allow children to explore, create and share dynamic games and simulations. The creation of the Dynabook led to the development of personal computing (Sharples et al., 2008). More widespread experimentation with mobile devices for learning happened from the mid 1990s (Pachler et al., 2010). At that time the focus was on exploring which devices could be used for teaching and learning in an educational context. One such project was implemented in the United Kingdom between 2002 and 2003. It evaluated the use of mobile devices (mainly PDAs) to support school leaders and teachers with management and administration as well as teachers and students with teaching and learning (Pachler et al., 2010; Perry, 2003). Altogether, 150 teachers from 31 schools in England took part in the 
project and 100 devices were made available for students' use. In general, responses from head teachers and senior management teams about the use of PDAs were positive. The responses from teachers were mixed, reporting some advantages as well as potential weaknesses of the device for teaching and learning. Perry (2003) concluded that further research is needed regarding the extent to which managers, teachers, and pupils change their work habits and mind-sets as a result of the technology.

Over time there has been a shift in focus from the devices themselves to the use of such devices for learning outside the classroom, which is demonstrated in 'The Learning Lab Initiative' (Centre for Knowledge Societies, 2005; Pachler et al., 2010). This initiative was a response to the educational challenges in Bangalore, India, and sought to create educational content that was engaging and made use of mobile Information and Communication Technologies (ICT) to enhance learning outcomes (Centre for Knowledge Societies, 2005; Pachler et al., 2010). Students attending local government schools who were aged between 13 and 15 years old took part in the initiative and were trained in how to use various devices (such as GPS devices and rich media capable mobile phones). They then undertook a range of activities that enabled them to move beyond the confines of the classroom and explore their new environment.

In 2005, Kukulska-Hulme and Traxler argued that the then current mobile devices were not designed specifically for learning despite being used for learning. Questions were posed about how far features of existing mobile devices could be altered to fit educational goals. Another question was whether learning activities needed to be revised to fit with the mobile technologies.

More recent thinking has focused on the mobility of the learner and the design of learning spaces as well as informal and lifelong learning (Laurillard, 2007; Pachler et al., 2010). Learner mobility is concerned with being able to engage in educational activities without the limitations of physical locations (Kukulska-Hulme \& Traxler, 2005; Sharples, 2006). Kukulska-Hulme and Traxler noted that mobile learning could be seen as learning from books, digital resources, people or places while in various locations outside of the classroom. However, what is new in mobile learning is the possibilities presented by the most recent technologies - the portable, lightweight devices that fit in the palm of your hand or pocket and differ to other forms of media (Kukulska-Hulme \& Traxler, 2005). 
The capability and functionality of the technology associated with mobile devices is also new to the realm of mobile learning such as its accessibility and the merging of services and functions into a single device (Pachler et al., 2010). Functions that can be combined into a mobile device could include (but are not limited to) calendar, contacts list, video files, still camera and video camera, organiser, music files, web access, email, games, movie player, GPS compass, phone, voice recorder, and a clock. The merging of multiple functions into one device means users of mobile devices can access a wide range of resources, content, and functionalities at any time and from anywhere.

The nature of public and private spaces is being redefined by the use of mobile devices (Kukulska-Hulme \& Traxler, 2005). Basic situational awareness and alertness is needed in order to navigate, survive, and appreciate the new, often uncontrolled, environments the devices are used in (Sharples, 2006). Changing focus from the real world to a specific device could be challenging (Sharples, 2006). Learning is also becoming more personal and independent but at the same time connected and collaborative (Kukulska-Hulme \& Traxler, 2005). Feelings of inclusion or exclusion could prove problematic when groups of users are using a mobile device as some people may not be able to see content on the device.

This focus on mobility has also moved on from delivering content to mobile devices, to "the processes of coming to know and being able to operate successfully in, and across, new and ever changing contexts and learning spaces" (Pachler et al., 2010, p. 6). Examples of these are context-aware technologies used for field trips and tourist visits (Walker, 2006, cited in Sharples, 2006).

Laurillard (2007) provides an example of an art lesson without the use of mobile devices and then compares this to the same lesson with the use of mobile devices (see Table 2.2). The aim of the lesson was to develop students' understanding of an art exhibition. 
Table 2.2: Lesson Without Mobile Device Versus Lesson With Mobile Device

\begin{tabular}{|l|l|}
\hline Lesson without mobile devices & Lesson with mobile devices \\
\hline $\begin{array}{l}\text { Teacher introduces work of the } \\
\text { catists and provides extracts of the } \\
\text { students to read in advance. }\end{array}$ & $\begin{array}{l}\text { Teacher introduces work of the artists and provides } \\
\text { extracts of the catalogue linked to key paintings for } \\
\text { students to read in advance and download to mobile } \\
\text { device. }\end{array}$ \\
\hline $\begin{array}{l}\text { Teacher provides guide to key } \\
\text { paintings for students to work in } \\
\text { pairs in the gallery. Students write } \\
\text { notes to take back to class. }\end{array}$ & $\begin{array}{l}\text { Teacher provides guide to key paintings for students } \\
\text { to work in pairs in the gallery with digital codes for } \\
\text { each painting. Instructions to identify features in } \\
\text { particular paintings, upload answers and check } \\
\text { against teacher's model answer. Set quiz questions } \\
\text { to challenge other pairs, answer questions from other } \\
\text { pairs, record these and observations on paintings } \\
\text { and upload to shared website. }\end{array}$ \\
\hline $\begin{array}{l}\text { In class students report on what they } \\
\text { noticed and the notes they took. }\end{array}$ & $\begin{array}{l}\text { Students work in pairs in the gallery, using the guide, } \\
\text { making notes, checking observations against } \\
\text { teacher's, setting and answering challenges, } \\
\text { recording and uploading ideas and observations (with } \\
\text { teacher's help). }\end{array}$ \\
\hline $\begin{array}{l}\text { Teacher summarises their } \\
\text { comments in terms of the intended } \\
\text { thesis. }\end{array}$ & $\begin{array}{l}\text { Students report back on what they noticed and the } \\
\text { notes they took using the whiteboard to display } \\
\text { records and notes. }\end{array}$ \\
\hline & $\begin{array}{l}\text { Teacher summarises their comments in terms of the } \\
\text { intended thesis, an edited version of the students' } \\
\text { data and made available on the school website. }\end{array}$ \\
\hline
\end{tabular}

The comparison in Table 2.2 gives an example of how a lesson using mobile devices could be 'richer', primarily because "the mobile devices digitally facilitate the link between students and data while they are in the site-specific practice environment" (Laurillard, 2007, p. 166). The digital facilitation provided by the teacher is to set up motivating, collaborative, and competitive connections between the students. Contributing to a product at the end of the process might also motivate the students. Although the activity could be achieved without the use of mobile devices, Laurillard contends that it would be harder to manage because paper technology does not facilitate the process. Dede (2008) compared the support of ICT with engaging learners, presenting content and modelling skills to how a carpenter would use their tools - the hammer, saw and screwdriver. The significance of the analogy is "1). Tools make the job easier and 2). The result is of higher quality than possible without the tools" (p. 43).

Researchers (Kukulska-Hulme \& Traxler, 2005; Pachler et al., 2010) agree there is still a lot more work to be done if mobile devices are to be widely adopted for use in educational settings. Included in this is the need for more projects to be focussed on learning gains in order to gather evidence of the outcomes of using mobile devices for teaching and learning. The current research is about the challenges and 
opportunities related to the use of mobile devices for enabling students to gain proficiency in te reo Māori.

\section{Teacher Professional Learning and Development (PLD)}

In New Zealand recently, the terms 'professional development' and 'professional learning' have been merged to describe what teachers gain from a formal professional development programme as well as informal learning along the way. Thus, 'professional learning and development' refers to the often diverse ways in which teachers might further develop their teaching skills, abilities and approaches for the benefit of students (Education Review Office, 2009). The purpose of professional development is for educators to develop, implement, and share practices, knowledge, and values in order to improve the learning of students (Guskey, 2000; Schlager \& Fusco, 2003). Moreover, professional development is described by Schlager and Fusco as a "career-long, context-specific, continuous endeavour that is guided by standards, grounded in teacher's own work, focused on student learning, and tailored to the teacher's stage of career development" (p. 205). Professional development also employs the collaborative efforts of teachers, school leaders, school management, the wider school community, and external experts.

Timperley, Wilson, Barrar, and Fung (2007) developed a framework to analyse the effectiveness of the professional learning experiences across 97 studies, including 24 from New Zealand. Four features were identified as contributing to effective professional development in terms of having a positive impact on student outcomes. These are:

1. The context of professional learning and development

Within the professional learning context, seven elements were identified as important for effective professional learning that impact positively on a range of student outcomes. These included:

(i). Extended timeframes (between six months and two years was common in the studies examined) for opportunities to learn and frequent contact by providers was necessary to allow change in teacher practice.

(ii). The engagement of external expertise to deliver content that is meaningful and manageable for classroom teachers.

(iii). Teachers' engagement in learning at some point was more important than initial volunteering.

(iv). Content was consistent with current research findings and policies. 
(v). Dominant discourses were challenged, for instance the impact of teacher practice on student relationships and how to teach particular curricula effectively.

(vi). Opportunities to interact in a professional community of practice were more important than if the professional development was in school or off site.

(vii). Effective school leadership that actively supports the professional learning of staff by providing opportunities for teachers to learn, access to expertise, and opportunities to discuss the learning as a group.

2. The content of professional learning and development

According to Timperley et al. (2007), there were four key features that pertained to the content delivered in the professional development. These included:

(i). The integration of theory and its translation into practice.

(ii). Clear links between teaching and learning as well as student and teacher relationships.

(iii). The use of assessment to focus teaching and review effectiveness.

(iv). Sustainability of continued or improved student outcomes once the professional development is withdrawn. Sustainability depended on teachers' depth of understanding of theory in order to decide on the most appropriate practice. It was also dependent on teachers being able to evaluate the impact of their teaching and identify the next steps (Timperley et al., 2007).

3. The type of activities constructed to promote professional learning No one particular activity was more effective than others (Timperley et al., 2007). An important factor was the opportunities given to teachers to learn and apply new understandings and skills. For example, listening to experts was not sufficient enough to change practice by itself.

4. The learning processes and teacher's responses

Timperley et al. (2007) noted that changing teacher practice was difficult and that understanding the processes involved in changing teacher practice was a neglected area in the studies they examined. Still, it would seem important for teachers to understand new information in order to make changes to their current practice and acquire the skills of on-going inquiry into practice. 
Many professional development programmes tend to be a series of unrelated, shortterm workshops and presentations with little follow-up or guidance for implementation (Guskey, 2000). Dede (2006) and Borko (2004) concur that many of the one-day workshops or seminars offered to teachers lack quality and are "intellectually superficial, disconnected from deep issues of curriculum and learning, fragmented, and non cumulative" (Ball \& Cohen, 1999, pp. 3-4). Thus, the one-day workshops or seminars are often perceived as a time to update teachers' knowledge rather than an opportunity for in-depth and sustained learning (Ball \& Cohen, 1999). Moreover, this type of professional development continues to attract a "steady stream of subscribers...the professional equivalent of yo-yo dieting for many teachers" (Ball \& Cohen, 1999, p. 4). Teachers leave with new ideas, new teaching strategies, and yet another binder filled with blackline-masters to add to the dusty shelf of other "wilted cast-offs of staff development workshops" (Ball \& Cohen, 1999, p. 4). However, the experience rarely changes teacher practice sufficiently to impact on student outcomes (Timperley et al., 2007).

Guskey (2000) argues that workshops and presentations offered outside school hours or designated days can be effective, especially when educators need to obtain specific information about new programmes, new instructional approaches or resources. The key component is the accompaniment of appropriate follow-up activities to the workshops and presentations. Teacher professional development is more than a series of training workshops, meetings and in-service days, and is rather "a process of learning how to put knowledge into practice through engagement in practice within a community of practitioners" (Schlager \& Fusco, 2003, p. 205).

Over time, new models of professional development programmes have emerged and evolved. Guskey (2000) has identified seven major models of professional development including training, observation/assessment, involvement in a development/improvement process, study groups, inquiry/action research, individually guided activities, and mentoring. Each model is briefly outlined below alongside the advantages and limitations.

Training is the most common form of professional development and typically involves a presenter or a team of presenters sharing their ideas and expertise with a large group of educators through a variety of group-based activities. Effective training includes "an exploration of theory, role-modelling, simulated practice, 
feedback about performance, and coaching in the workplace" (Guskey, 2000, p. 23). The major limitation with training is that it offers few opportunities for choice or individualisation.

The observation/assessment model uses collegial observation to provide educators with feedback on a specific aspect of teaching, for example lesson design, instructional practices, or classroom management. Both parties can gain important insights from the process of the observation; however, it does require a lot of time from the observer and the one being observed.

Involvement in a development process such as reviewing a curriculum or designing a new programme enables participants to increase their specific knowledge and skills as well as their ability to work collaboratively and share in decision making. A weakness of this model is the restriction to a relatively small number of staff members.

Study groups involve the entire staff of a school that is divided into groups to find solutions to common problems. Each group focuses on one aspect of the same bigger problem or issue and is given opportunities to share their findings and recommendations with the whole staff. Issues with study groups include the timeconsuming nature of reviewing research evidence and ensuring that all members have opportunities to contribute equally to the group.

The inquiry model is intended in part to help educators become more reflective practitioners by formulating valid questions about one's own practice and pursuing objective answers to those questions (Guskey, 2000). This process requires significant time and initiative by the individual.

The individually guided activities require educators to select their own professional development goals and then the activities they believe will help achieve their goals. Individuals are assumed to be motivated and capable of self-directed and selfinitiated learning. This model enables flexibility, freedom of choice and individualisation, yet is vulnerable to individuals "reinventing the wheel" (Guskey, 2000 , p. 28) or limiting their collaboration and professional sharing.

The mentoring model entails the pairing of an experienced and highly successful educator with a less experienced colleague to discuss professional goals, share ideas and strategies about effective practice, undertake observations, provide 
feedback on current practice and make plans for improvement. Mentoring can offer a highly individualised approach; however, it can also limit opportunities for broader collaboration and collegial sharing.

The explanations of the models reveal the differences in assumptions, expectations, and beliefs about professional growth between each, signifying the limitations of any single model to prove effective for all individuals under all conditions. Instead, Guskey (2000) recommends a professional development plan based on a combination of models to ensure that professional development efforts are highly effective and "remain intentional, ongoing, and systemic" (p. 29). Whatever the combination of models, it is pertinent for educators to keep up to date with the constant growth of the knowledge base in education and to continually refine their practice (Guskey, 2000). Timperley and colleagues (2007) argue that PLD can play a key role in helping educators to increase their knowledge base and improve their effectiveness, which may in turn increase student achievement.

Although new professional development approaches and models have emerged, there remains a shortage of high quality programmes (Yoon, Duncan, Lee, Scarloss, \& Shapley, 2007). In the United States, the 'No Child Left Behind' (NCLB) Act (2001) focused on child achievement outcomes including a mandate for teachers to receive high quality learning opportunities to support children's learning. Borko (2004) argues that the NCLB Act did not outline what high-quality professional development comprised or how it should be made available to teachers. Yoon and colleagues (2007) have identified five criteria for professional development to be considered high quality in accordance with the NCLB Act. The criteria include the need for PLD to be sustained, intensive, and content-focused, and to be aligned with and related to curriculum and student achievement standards as well as assessments. PLD should also improve and increase teachers' knowledge of the subjects they teach while advancing their understanding of effective instructional strategies (based on research). In addition, PLD should be evaluated regularly to show the effects on teacher effectiveness and student achievement.

Alongside claims of a shortage of high quality PLD programmes is the need for better information on how these programmes affect student achievement. Yoon et al. (2007) examined more than 1300 studies identified as potentially addressing the effect of PLD on student achievement in three subjects (mathematics, science, and reading and English/language arts). The report stated that PLD affects students in 
Professional three steps, namely that it enhances teacher knowledge and skills, which in turn development improves classroom teaching and raises student achievement (see Figure 2.1).

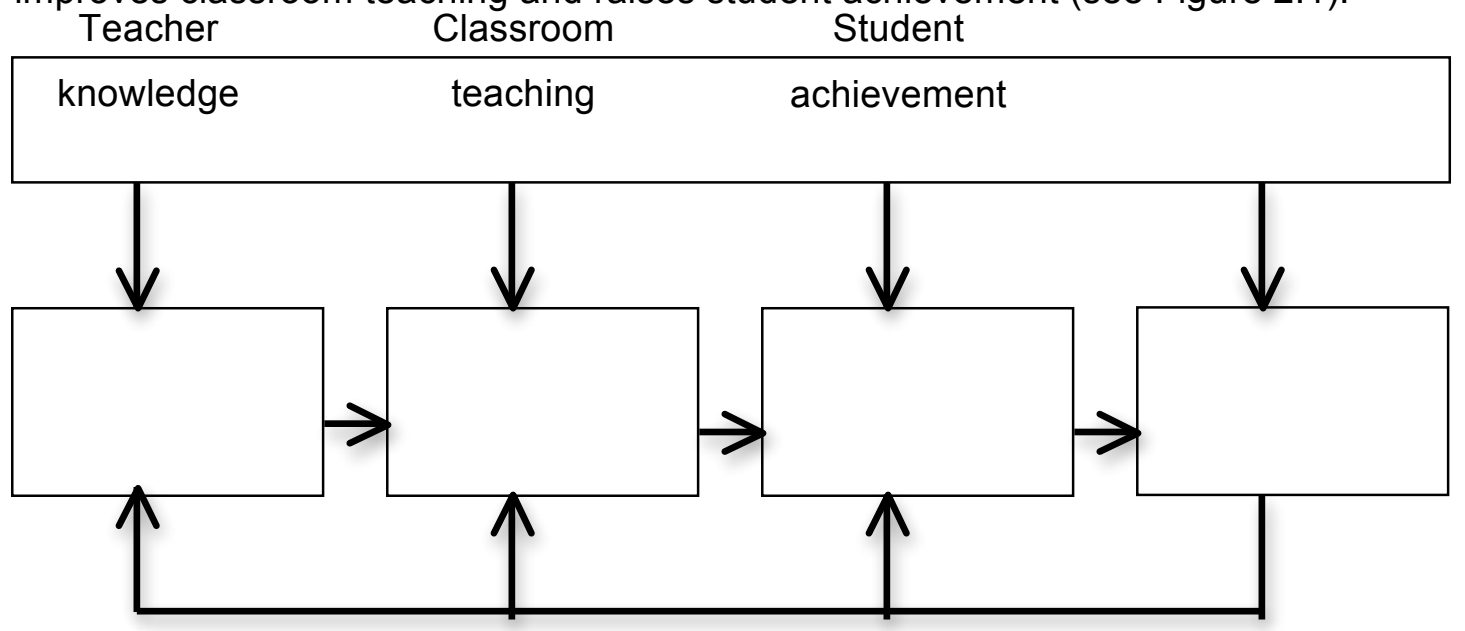

Figure 2.1: How Professional Development Affects Student Achievement

Step 1: The programme must be of high quality by being intensive, sustained, content focused and strongly implemented. It must also be based on sound theories of teacher learning and change.

Step 2: Teachers must have the motivation and skills to apply the learning to classroom teaching while receiving on-going support from colleagues and professional development providers.

Step 3: Appropriate assessments that evaluate student progress and achievement need to be developed and administered (See Yoon et al., 2007, p. 4 for more information).

Of the 1300 studies that were examined in the research, only nine met the researchers' standards, emphasising the need for more high quality PLD programmes for teachers that address the direct effect on teachers and the indirect effect on students (Yoon et al., 2007).

There are some commonalities for effective PLD across various subject matters as well as issues pertinent to ICT-related PLD that need to be highlighted. Vrasidas and Glass (2007, p. 93) have identified eight key issues and strategies for effective ICT-related PLD based on their own experiences as well as a review of the literature (see Table 2.3). 
Table 2.3: Key Issues and Strategies for ICT-related Professional Development

\begin{tabular}{|l|l|}
\hline Key Issue & Strategy \\
\hline Learning designs & $\begin{array}{l}\text { Design programmes based on what we know about how ICT can } \\
\text { support learning }\end{array}$ \\
\hline $\begin{array}{l}\text { Authentic } \\
\text { engagement within } \\
\text { teachers' contexts }\end{array}$ & $\begin{array}{l}\text { Situate programmes in teachers' context so that activities are } \\
\text { authentic }\end{array}$ \\
\hline $\begin{array}{l}\text { Opportunities for } \\
\text { reflection }\end{array}$ & $\begin{array}{l}\text { Design activities that encourage participants to use ICT and } \\
\text { reflect on their practice }\end{array}$ \\
\hline Collaborative efforts & $\begin{array}{l}\text { Encourage the use of ICT for collaboration among all } \\
\text { stakeholders in the design, implementation, and evaluation of } \\
\text { programmes }\end{array}$ \\
\hline On-going support & Use ICT and online technologies to provide on-going support \\
\hline Informal learning & Provide opportunities for informal learning and support \\
\hline Systemic effort & $\begin{array}{l}\text { Coordinate professional development with broader ICT and } \\
\text { school improvement efforts }\end{array}$ \\
\hline Leadership & $\begin{array}{l}\text { Foster leadership that nurtures innovation, change, and the } \\
\text { creation of schools as learning organisations }\end{array}$ \\
\hline
\end{tabular}

Students and adults learn best when actively engaged in meaningful activities, when intrinsically motivated, and when given opportunities to collaborate with others. In addition, students and adults learn best when given time and space to critically reflect on their work, when activities are based on the real world, and when their work is regularly evaluated (Vrasidas \& Glass, 2007). Ball and Cohen (1999) also suggest that teachers require opportunities to examine other practitioners and to learn more about the subjects and the students they teach.

School leadership and management play an important role in the successful integration of ICT PLD. This includes having the appropriate ICT infrastructure and technologies available and by creating a culture that is open to change and innovation, which is what Vrasidas and Glass (2007) describe as a learning organisation. Leadership must also emphasise lifelong learning where all members are engaged in learning and leading. Additionally, PLD providers must support teachers with on-going training and supply resources they need to integrate ICT into their classroom. 


\section{The Challenges and Opportunities of Using Technology for Teaching and Learning}

\section{Access - ICT Tools and Resources, Time and Training}

One of the potential advantages of mobile devices is that they might provide access to learning content and material to users. In 2004, Osaka Jogakuin College (Japan) provided first year undergraduates with iPods ${ }^{\circledR}$ to support language learning (McCarty, 2005). Students downloaded podcasts of English language news broadcasts from the web in order to carry out homework assignments. In this case, the mobile devices were deliverers of content rather than used to communicate with other learners.

In the same year, Duke University (Durham, North Carolina) also provided their first year undergraduates with iPods $\AA$ to support language learning (Belanger, 2005). The students used the device for listening and speaking activities and had access to Spanish songs and narratives recorded by native speakers. Audio information and glossaries supplied to accompany course textbooks and tutor feedback on students' work were also made available to students. Students reported that access to portable digital audio course content was particularly valuable.

Moreover, mobile devices might improve access for students from economically disadvantaged communities and those from developing countries. Handheld devices can provide learning resources to support and "advance digital equity, reaching and inspiring populations at the edges" (Shuler, 2009, p. 5). Mobile learning encourages learning in a real-world context by allowing students to access and process information from outside of the classroom (Shuler, 2009). Users have the ability to access and interact across different contexts continuously and spontaneously (Kukulska-Hulme \& Shield, 2008).

The portability of mobile devices presents a number of ubiquitous opportunities for teaching and learning beyond the confines of the classroom (Abdous, Camarena, \& Facer, 2009; McQuillan, 2006; Pasnik, 2007; Perry, 2003). In 2009, a report was undertaken by the Joan Ganz Cooney Centre at Sesame Workshop to illustrate how mobile technologies (for instance cell phones, iPod $®$ devices and portable gaming platforms) could be used for learning (Shuler, 2009). One of the key opportunities for mobile technologies for learning highlighted in the report was the anywhere, any time aspect that they could bring to learning. 
Students learning languages at the Brearly School in New York City used the iPod $®$ to listen to a variety of materials downloaded from the school's internal server (McQuillan, 2006). McQuillan states, "The portability of the $\mathrm{iPod} \circledast$ allows them to listen at home or on the bus to school-wherever and whenever they can" (p. 5). Learners can participate in the learning programme at their convenience. Laurillard (2007) concurs and states that the mobile device gives the user ownership and control of what, when, and where to learn.

In 2007, a trial group of 10 students at one university in New Zealand used iPods $®$ to assist them to complete their Māori language assignments. These students were long distance learners and therefore were not restricted to having to attend regular class programmes with the facilitators. One of the aims of the module was to help develop students' oral communication skills, allowing them to practise situational and functional Māori language skills. Before the use of the iPods $®$, students were expected to listen to, and record, responses on audiotapes in the university's language laboratories, then hand completed assessments to tutors. Students involved in the trial who had computer and Internet access used mobile $\operatorname{iPod} \circledast$ technology instead. The course content and language tools were uploaded to videocapable $\mathrm{iPods} \AA$ meaning that students were no longer confined to a language laboratory within the university campus (Keiha et al., 2008). This also meant that "...the tyrannies of cassette tapes and their increasingly unsympathetic and unreliable recorders and players" were gone (Keiha et al., 2008, p. 3).

Mobile technologies enable users to access resources stored on the device or retrieved via the device integrating in-class and out-of-class learning (Rosell-Aguilar, 2007). Thus, users are able to utilise their spare time or waiting time productively, for instance while waiting for public transport and while travelling (Kukulska-Hulme \& Pettit, 2009).

Learning at one's own pace is also a potential advantage of ICT-based learning (Webb, 2006). According to Yunus (2007) and Webb (2006), ICT tools can provide access to authentic language such as emails to language experts as well as online discussions with e-pals. Students have space to be able to practise their speaking skills in private, in ways in which they could not do in a traditional classroom. ICT tools can also provide access for teachers by way of networking and sharing ideas with other colleagues during PLD training sessions.

Conversely, lack of access to ICT tools, professional development, and on-going training is a recurring theme in the literature used for this review (Abdous et al., 2009; 
Webb, 2006; Yunus, 2007). Yunus investigated the factors that affected the use of ICT and the perceptions of the teachers' skills in ICT use among those who taught English as a Second Language (ESL) in Malaysia. The general agreement of teachers' responses to challenges involving access included low quality or out-of-date hardware (such as printers and computers), a lack of access to the computer laboratory, and a lack of time and opportunities to gain computer skills and ICT oriented pedagogy.

Despite a significant investment of staff time and resources there were other barriers to using the $\mathrm{iPods} \circledast$. Storing, accessing, sharing and distributing content were major challenges as there were multiple systems that needed to be managed. There were no systems in place for purchasing audio content in bulk for academic use. There were also limitations of the device, for example the only way to load content was by synchronisation, and the recordings made on the iPod $₫$ were not of a high quality for some academic contexts. The lack of knowledge and understanding of some faculty staff and students of how to utilise the iPod® functionality and applications for academic use was another barrier (Belanger, 2005). Perry (2003) also agrees that a lack of technical support provided to users and problems with linking to networks are challenges related to technology use.

Daly, Pachler, and Pelletier's (2009a) research echoes these challenges in that the lack of easy access to flexible ICT in classrooms in England was reported to have serious detrimental effects on teachers involved in their study of continuing professional development for ICT in Key Stages 1-4 (National Curriculum). The lack of time to learn new technical skills for use in the classroom and consolidate knowledge to use technology effectively were also challenges as reported by the teachers. The researchers in this study noted that teachers needed more time to explore the technology following the training sessions. Time to discuss practice with colleagues was another need as well as the time to develop experimental approaches to teaching and learning. There were, however, some schools that built time for reflection into staff meetings where an ICT slot was a regular feature that impacted positively on teachers.

Webb (2006) and Yunus (2007) also reported the need for training in the use of ICT, for well-maintained hardware and software, and for low-cost access to ICT. These may result in preventing the entrenching or extension of existing disadvantages for some adults learning English for speakers of other languages (ESOL). Webb's study compared the effects of different settings situated in Australia and the types of tutoring on the learners' experiences and perceptions of the value of the CD-ROM (ICT-based learning) for learning English. Another challenge reported by Webb was that features in 
the software (CD-ROM) were required to encourage self-monitoring and enable learners to focus on learning objectives to meet their own interests and needs.

Students are also impacted by the lack of access to ICT tools. Yunus (2007) and Abdous et al. (2009) reported that students' lack of computer skills was a barrier to their use of ICT tools. Integrating personal multimedia players, cell phones and handheld devices (mobile assisted language learning) into the foreign language classroom is becoming common in many secondary and higher education institutions (Abdous et al., 2009; Yunus, 2007). Abdous et al. (2009) undertook a small-scale study with eight foreign language classes at Old Dominion University in Virginia to compare the academic benefits of integrating podcasts into the curriculum against using them as a supplementary or review tool. Some students involved in the study felt that lack of in-class training in how to subscribe, download and save podcasts was a barrier to using the podcasts. Students also thought that the podcasts would not be helpful to their learning or did not have the time to download them. There is a possibility that these barriers could have been overcome if students had been given in-class training in how to subscribe, download, and save the podcasts at the beginning and throughout their course. Abdous et al. (2009) found that mobile assisted language learning is changing the way foreign languages are being taught and the way students study. In addition, the researchers felt that instructors (teachers) were beginning to rethink how they conducted their classes and how they used their classroom time with the addition of these mobile devices. The study provides initial evidence that podcast technology has the potential to provide greater benefits if it is used more than simply as a tool for reviewing. However, the researchers stated that more rigorously designed studies, which control how instructors use the technology, are needed in order to determine whether the differential effects are significant, and to identify which instructional use produces the largest learning gains.

Jones (2004) suggests further research into ICT barriers including looking at sectorspecific and subject-specific barriers. Such work could be targeted at key areas of education where levels of ICT use need to be improved. Jones also suggests researching the barriers and enablers specific to individual technologies, such as the $\operatorname{iPod} \otimes$, which could help increase the use of these technologies in the classroom, thus making the current study of the challenges and opportunities of mobile devices to attain proficiency in the Māori language timely and important.

Distinct features of the mobile device such as its size, instant start-up, and battery life are also potential advantages of these technologies that were reported by teachers in 
the United Kingdom. As already noted, between 2002 and 2003 a project comprising approximately 150 teachers from 30 schools in England was undertaken evaluating the use of devices (mainly PDAs) to support teaching and learning (Perry, 2003). The cost (in comparison to laptop computers) and outdoor use were other advantages of the device outlined by the users. Shuler (2009) also adds that mobile devices can help overcome many of the challenges associated with larger technologies, as they fit more naturally within various learning environments.

On the other hand, Perry (2003) noted that the screen size was a disadvantage of the mobile device for some users as was its lack of robustness for schools. Poorly designed mobile technologies negatively affect usability and can distract children from learning goals (Shuler, 2009). The small screen size was also a physical aspect that might prevent an optimal learning experience, as outlined by Shuler, as was the restricted text entry and the limited battery life.

\section{Improve Social Interactions}

The successful implementation of any initiative is likely to be dependent to some extent on school leadership related to guidance, organisation and motivation (Waiti, 2005). The Kaupapa Ara Whakawhiti Mātauranga project encompassed a number of school improvement initiatives including upgrading school ICT infrastructure and improving teachers' professional capability through ICT (Waiti, 2005). Most principals involved in the project were positive about the project although were initially unclear of the longterm practicalities. School leaders need to determine their school's priorities and be able to link these with the ICT initiative (Waiti, 2005). Another important factor is to gain teachers' buy-in to the initiative to increase the rate of success.

Mobile technologies would seem to have the power to promote and foster collaboration and communication, and are deemed essential for twenty-first century success (Shuler, 2009). Snyder, Jones, and Lo Bianco (2005) reported that adults involved in their study broadly acknowledged the social and cultural importance of the use of ICT. The quality of teaching and learning improved considerably when these were built around a concrete social purpose and a specific technology. Webb (2006) also agrees that when learners' social aspects are taken into account with the introduction of new technology, this has the potential to increase their motivation and enable them to take greater control of their learning. Māori tertiary students enrolled in an e-learning (technology rich learning environment) setting, who preferred face-to-face instruction, felt stressed and anxious at times due to the isolated nature of the e-learning environment (Tamati, 2008). In order to make the e- 
learning environment a viable option for the Māori learner, the learning needs to be created with purpose and context (Snyder et al., 2005) but, more importantly, learners need to maintain face-to-face contact with their peers (Tamati, 2008).

Snyder and colleagues (2005) noted that effective implementation of technology consisted of good teacher-learner and learner-learner relations. These relationships helped with the construction of new meanings and understandings about technology along with the development of an appropriately critical response towards its use. According to Daly et al. (2009a), a strong sense of community ethos is vital to effective ICT professional development. Opportunities to talk in small groups, network with other colleagues (Gray, Pilkington, Hagger-Vaughan, \& Tomkins, 2007; Yunus, 2007) and share resources enables teachers to build trusting relationships that impact positively on their teaching and learning (Daly et al., 2009a).

Webb (2006) found that tutor support was critical in fostering IT skills and encouraging independent learning and progression within an ICT-based environment. Within these ICT-based environments students appeared to be spending most of their time in a one-to-one relationship with the computer acting as a tutor; however, learning was still a social activity (Webb, 2006). The role of the tutor was "significant in constructing a physical and social space for learning and for interacting with fellow learners and tutors as well as the computer" (Webb, 2006, p. 503). Tutors used their personal and social skills to provide the learners with a comfortable and relaxed environment and to increase the learners' confidence to work independently (Webb, 2006). The learners, as noted in the following comment by one female learner, valued this: "They're very important factors, the people. If you think that there is somebody responsible and you can ask that is very good, but all the time, I don't think you need it" (Webb, 2006, p. 496). Webb concluded that at first sight the ICT-based learning environments involved in her research did not seem to encompass any broad cultural experiences though they might have been more saturated with cultural learning than some traditional classrooms.

A related theme to social interactions is working with the wider school workforce. In schools there are a number of non-teaching staff members or teacher aides who can contribute to the students' or teachers' learning by being included in the professional development activities (Daly et al., 2009a). Daly et al. give examples of an e-learning manager supporting staff in the hands-on implementation of technology in the classroom as well as teacher aides undertaking action research 
about how to teach with an interactive whiteboard and supporting the use of technologies for pupils' learning.

\section{Teachers' Needs, Attitudes and Knowledge}

Teachers need to make radical changes to the way they teach in order to make full use of ICT (Scrimshaw, 2004). This idea is supported by Pasnik (2007) who states that teachers must acquire the skills and (ICT) tools to support their on-going learning if they are to keep pace with the complex and constantly changing world. As a professional development tool, the iPod® expands opportunities teachers have to strengthen their understanding of the subjects they teach and widen the repertoire of the instructional strategies they use (Pasnik, 2007).

According to Yunus (2007), teachers had positive attitudes towards using ICT in teaching ESL and viewed ICT as having the potential to support new learning experiences within their contexts. Conversely, the majority of teachers indicated the need to know how to integrate ICT in teaching, which may have been a reflection of their lack of skills and confidence in using ICT in teaching or simply a lack of awareness of the possibilities.

Teachers involved in integrating the interactive whiteboard into their modern foreign language classes (Gray et al., 2007) were aware of the board's possibilities and exploited its potential through personal experience, chance discoveries, purposeful trial and error, small-scale dissemination, and the gradual building up of useful materials. Gray et al. (2007) present the voices of four modern foreign language teachers situated in one United Kingdom secondary school as they strove to comply with the government policy to embed ICT into their pedagogic practice to improve teaching and learning. The researchers also found that the teachers were alert to, and welcoming of, change providing it was in manageable steps and was not too disruptive of current balances. Furthermore, the teachers wanted to keep up to date with technology but in their own time and at their own pace.

A strong feature of effective professional development in ICT reported by Daly et al. (2009a) was the opportunity for teachers to observe effective teachers working with ICT in context. School leadership granted limited opportunities for teachers interviewed in this study to observe each other in class. Teachers also reported tensions between the need for their individual development and school priorities. 
Where teachers were able to see explicit relevance of technology to enhancing their practice, motivation increased along with the willingness to make the effort and find time to change. In support of this, Pasnik (2007) states the key to effective integration of ICT into the classroom is coordinating it with the classroom programme. Time to prepare teaching and learning materials is also a challenge for teachers involved in integrating the interactive whiteboard into their classrooms (Gray et al., 2007). Teachers said that preparation of teaching and learning materials for subject-specific needs was very time intensive and materials for teaching and learning were selected to engage students, thus reducing the teacher's role in motivating and managing them. Management and control were reported as the prime benefits of integrating the interactive whiteboard into modern foreign language classes by enabling teachers to exercise crowd control more easily and subtly with less open conflict with their students.

\section{Student Needs, Attitudes and Knowledge}

Learners are all different, requiring instruction to be adaptable to individual and diverse learner needs (Shuler, 2009). Researchers (Scrimshaw, 2004; Shuler, 2009) contend that there are significant opportunities for genuinely supporting the diverse needs of learners as well as independent and individualised learning. Pasnik (2007) states that the $\mathrm{iPod} \circledast$ can be utilised to "...promote collaborative, independent, and differentiated learning, adapting to the needs of each learner" (p. 1). In addition, the $i \mathrm{Pod} \circledast$ offers new opportunities to increase the effectiveness of language teaching and learning (McQuillan, 2006). An example of this includes the ability to deliver large quantities of comprehensible language on the $\mathrm{iPod} \otimes$ to students in an efficient and convenient manner. Students "who are exposed to a greater quantity of comprehensible language in and out of the classroom have higher levels of language proficiency than students using different methodologies" (McQuillan, 2006, p. 4). The $i P o d \circledast$ has a number of features and applications that can be used for instruction or assessment including the ability to listen to, and view, audio and video content, to record audio that can be used for instruction or assessment, and to develop podcasts. At the Brearly School in New York each student in the language learning classes was required to keep an 'audio diary' recorded by a microphone on their $\mathrm{iPod} \circledast$ to upload to the school server for the teacher to listen to and assess (Pasnik, 2007).

Teachers of foreign language classes at one university in the United States (Abdous et al., 2009) felt that podcasts were an effective study tool to facilitate the completion and evaluation of assignments in foreign language classes. Teachers 
also believed that ICT helped their students understand English better through reading comprehension programmes, online discussions, and language learning and teaching materials teachers sourced from the Internet. Conversely, students reported that they did not download the podcasts for their language course because they did not have time to download them and they thought the podcasts would not be useful.

The motivation levels of learners is also another aspect to this theme and is a quality required to become a successful ICT-based ESOL learner (Webb, 2006). The motivation levels of adult learners involved in the English language learning programme varied and related to learners' ambitions to feel included in the host community as reported by Webb. The ICT-based learning programme reduced some aspects of social exclusion enabling the learners to speak more within the host community. Previous experience with ICT also contributed to successful learning.

Abdous et al. (2009) stated that second language learning can be enhanced by podcasting technology as found in prior studies; however, these studies have not examined the effectiveness of different instructional uses of podcasts in language acquisition. Stanley (2006) explores how podcasts could be used to support classroom-based learning, for example by encouraging learners to develop their own podcasts, upload them, and share them with peers. Stanley argues "there is much to be said about involving learners in the act of publishing a podcast, especially if there is a real audience out there, which the learners can detect" (2006, p. 6). In this situation the communication is one way between the podcast and learner but also, possibly, from learner to a wider audience (Kukulska-Hulme \& Shield, 2008).

\section{Chapter Summary}

As this thesis proposes to identify the challenges and opportunities of using mobile devices to attain Māori language proficiency, it was important to weave together the existing literature in the fields of Māori language and Māori education, mobile learning, and teacher professional development.

Māori have been adopting and adapting new technologies since the arrival of early settlers to Aotearoa in the early 1800s. Moreover Māori acquired new concepts of written language to add to the existing highly developed oral language. However, these newly acquired skills would eventually contribute to a devastating period of a loss of language (Spolsky, 2003). In response to the serious predicament of the 
language, a range of Māori-led initiatives began in the 1970s aimed at regenerating the Māori language (Ministry of Education, 2009b; Reedy, 2000). Examples of these initiatives include the establishment of kōhanga reo and kura kaupapa Māori, the development of Te Ataarangi to help adults learn Māori and various strategies developed by the New Zealand Government to support Māori language, and education growth. Despite the various policies and initiatives put in place by the Government to support Māori language growth there is a serious need to continue to regenerate the Māori language that is described as 'definitely endangered' and 'severely endangered' according to UNESCO framework of Language Vitality and Endangerment (2003).

This thesis supports recommendations from Te Paepae Motuhake (2011) to assist teachers to increase their Māori language proficiency and to embrace technology as a tool to revitalise the Māori language. PLD could be one potentially useful pathway for providing teachers with this support as well as the use of mobile devices. Literature reviewed in this chapter revealed that professional development programmes could assist educators to increase their knowledge base and improve their effectiveness (Timperley et al., 2007). Moreover, Vrasidas and Glass (2007) identified eight key issues and strategies for effective ICT-related PLD, including the need to design programmes based on how ICT can support learning, to provide authentic engagement within teachers' contexts, and to provide opportunities for teachers to use ICT and reflect on their practice. Other key issues included the need to use ICT and online technologies to provide on-going support for informal and formal learning and the need for school leadership to foster and nurture innovation and change (Vrasidas \& Glass, 2007).

This review has also revealed a wide range of reasons for implementing mobile technology in teaching and learning and its potential value for supporting the revitalisation efforts for the Māori language. The issues discussed focused on access to ICT tools, time and training, social interactions as well as teacher's and student's needs, attitudes and knowledge. This chapter argues that the potential challenges of using technology, in particular mobile devices, are a lack of training in how to operate the device, a lack of access to devices, and time to learn how to use them. Other challenges included the small screen size, the limited battery life, and a lack of robustness for use in schools.

Conversely, the potential advantages of using mobile devices is that they might provide users access to learning content and material stored on the device or 
retrieved via the device, they are portable presenting opportunities for teaching and learning beyond the classroom, and they may enable the user to learn at their own convenience and pace.

The review also highlighted gaps in the research including the need for more rigorously designed studies that control how instructors use technology to identify which instructional use produces the largest learning gains and research into ICT barriers that is sector and subject-specific (Abdous et al., 2009; Jones, 2004). In light of these gaps, little is known about the potential of mobile devices to support teachers to attain Māori language proficiency, which makes the present research timely. 


\section{Chapter Three \\ Research Design, Methods and Tools}

\section{Introduction}

This chapter begins by outlining an indigenous framework called Hei Korowai used by the researcher to guide the research process. Kaupapa Māori theory and Māoricentred approaches were a central part of the framework. The ethical issues that arose for the researcher are also outlined as well as the processes used to enter into and negotiate the topic with the research participants. Finally, the research community is described and the tools and instruments used to gather and analyse the data are explained.

\section{Hei Korowai - An Indigenous Framework}

For the processes of entering into and negotiating research projects with participants, the researcher used an indigenous framework design, Hei Korowai (Taiwhati, Toia, Te Maro, McRae, \& McKenzie, 2010), which was developed by researchers within Te Kura Māori, VUW, as an ethical guide for researchers working in Māori fields. The researchers were situated within an academic department focused on Māori and Pacific peoples but located within a mainstream university. Thus, they were cognisant of challenges confronting Māori researchers within a predominantly western tertiary system and the importance of bringing tikanga Māori to the fore within this context. The framework uses the structure of the korowai metaphorically to be the practice and reflective tool exercised when a Te Kura Māori researcher engages in research involving people. The researcher's membership within Te Kura Māori has allowed her to utilise the set of protocols within $\mathrm{Hei}$ Korowai to move effectively within the schools undertaking the WPR PLD programme, access participants and collect data upon which this research is based.

\section{The Framework Metaphor: Hei Korowai}

Ka noho te korowai ki te ao tangata, hei kākahu mō te tangata, hei tāwharau i te whakaaro me te mahi a te tangata. 


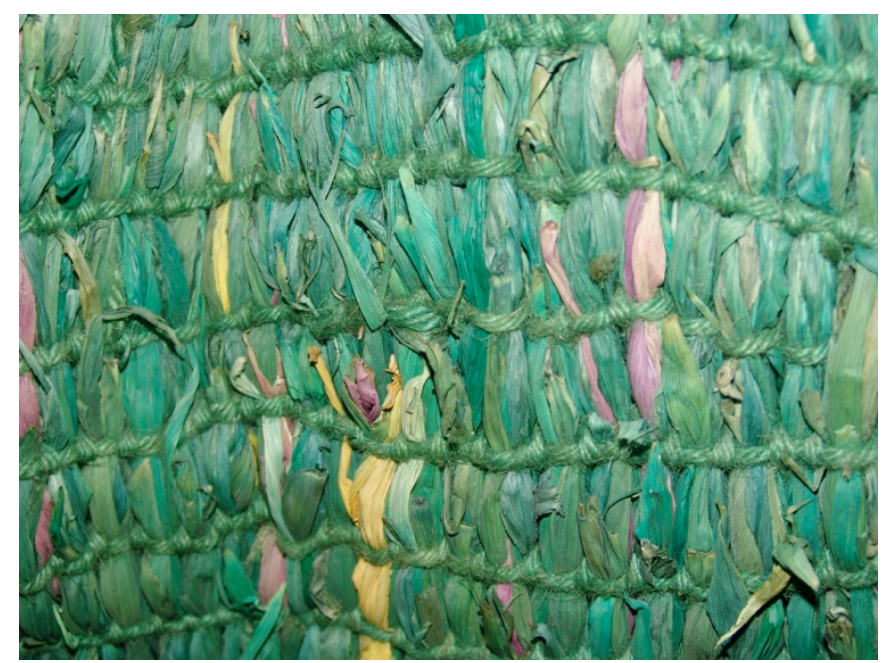

Figure 3.1: Puketapu-Hetet, Akopai Wharenui, 2007

Hei Korowai (Taiwhati et al., 2010) states that the researcher figuratively wears the korowai to inform the research direction and purpose. The strands of the korowai weave together the researcher and the participants to provide an interconnectedness of practice, transparency, and reflexivity. There is also an acknowledgement of spiritual links, humanity in people, and our flaws. The concept of interconnectedness links to the Māori concept of whanaungatanga and emphasises the importance of relationships and connectedness.

Hei Korowai acknowledges two key elements from a Māori epistemological base:

(a) Mana Whakaheke (the link to higher learning and knowledge) is founded upon rangatiratanga (chieftainship), mana (prestige), tapu/noa (sacred/neutral phenomenon), mātau (knowledge) and tika/pono (correct/truth). These concepts and constructs are constant in the preparation, practice, and reporting of information or analysed data.

(b) Mana Whakatipu (the growing or learning of new knowledge) includes, but is not exclusive to, participant safety, respect, positioning, and reflexivity. Mana Whakatipu is the learned nature of mankind as proposed by the researcher.

There is also a central thread called Kötui that weaves together the areas of Mana Whakaheke and Mana Whakatipu. The elements identified in the central thread are compassion, spiritual knowing, language, and identity, which reinforce the ethos of the framework as a safety mechanism and a cultural guide. 
Table 3.1 outlines some of the characteristics within Hei Korowai alongside statements affirming whether and how the characteristic was reflected during the negotiations phase of this thesis.

Table 3.1: Identifying the Use of Hei Korowai within this Thesis

\begin{tabular}{|c|c|}
\hline $\begin{array}{l}\text { Hei Korowai } \\
\text { Characteristic }\end{array}$ & Whether and How the Characteristic was Reflected in this Thesis \\
\hline $\begin{array}{l}\text { Mana Whakatipu } \\
\text { - Respect }\end{array}$ & $\begin{array}{l}\text { For the VUW WPR group, the researcher emailed all principals to } \\
\text { inform them of the research. The researcher then informed the } \\
\text { regional coordinator of each region and worked alongside them to } \\
\text { organise a face-to-face meeting with the participants. } \\
\text { For the comparison group the researcher initially discussed the } \\
\text { research with the Project Director via a face-to-face meeting. A follow- } \\
\text { up email was then sent with the information form, consent form and a } \\
\text { brief overview of the types of questions the interviewees would be } \\
\text { asked to ensure transparency. The Project Director then informed the } \\
\text { principals involved in their programme and gave their details to the } \\
\text { researcher to contact them. }\end{array}$ \\
\hline $\begin{array}{l}\text { Participant } \\
\text { Safety }\end{array}$ & $\begin{array}{l}\text { For the VUW WPR group, the participants were informed of the } \\
\text { research at a face-to-face meeting. The participants were then given } \\
\text { an information sheet for their records and a consent form to return } \\
\text { immediately or via post if they agreed to partake. } \\
\text { For the comparison group, the principals informed the participants } \\
\text { involved in the WPR programme of the research and then let them } \\
\text { choose to participate. Those who agreed to partake informed the } \\
\text { principal who then passed on their contact details to the researcher. } \\
\text { All participants from both groups were invited to partake in the } \\
\text { research and were told their present or future relationship with VUW } \\
\text { or the WPR contract would not be affected in any way if they chose } \\
\text { not to. }\end{array}$ \\
\hline - Positioning & $\begin{array}{l}\text { The VUW WPR group knew the researcher and her involvement in } \\
\text { the PLD programme; however, the comparison group was made } \\
\text { aware of this situation. }\end{array}$ \\
\hline - Reflexivity & $\begin{array}{l}\text { The researcher is aware that she represents not only herself but also } \\
\text { her family, her role as a VUW staff member and her role as a WPR } \\
\text { staff member as she engages with the research community and } \\
\text { therefore performs in a professional manner. }\end{array}$ \\
\hline $\begin{array}{l}\text { Mana Whakaheke } \\
\text { - Mana } \\
\text { - Rangatiratanga }\end{array}$ & $\begin{array}{l}\text { The researcher acknowledges that the participants are repositories of } \\
\text { those that have gone before and also recognises the knowledge and } \\
\text { experience the participants bring with them. }\end{array}$ \\
\hline $\begin{array}{ll}\text { Kōtui } \\
\text { - } & \text { Compassion } \\
& \text { Knowitual } \\
\text { - } & \text { Language } \\
& \text { Identity }\end{array}$ & $\begin{array}{l}\text { The researcher draws upon her own knowledge of tikanga as well as } \\
\text { those advocated by L. T. Smith (2005) when engaging with the } \\
\text { research community. These include but are not exclusive to } \\
\text { respecting people, their views and their decisions, presenting herself } \\
\text { to people face-to-face as much as possible, looking and listening first } \\
\text { and then speaking and not flaunting her knowledge. }\end{array}$ \\
\hline
\end{tabular}

The researcher acknowledges that she has a vested interest in the successful fulfilment of protocols embedded in Hei Korowai and has observed the protocols where appropriate during the course of entering into and negotiating the research, data collection, and writing process. 
Hei Korowai was not designed to be a comprehensive framework for research with Māori and therefore also draws upon kaupapa Māori research methodology principles.

\section{Kaupapa Māori and Māori-centred Research}

Kaupapa Māori theory is a framework for enabling us to theorise and practise Māori research that validates Māori knowledge, Māori language and protocols, and the multiple ways of doing things (L. T. Smith, 1996). It is also used to design interventions that can make a positive improvement for Māori people (Reinfeld \& Pihama, 2007). Hei Korowai draws upon kaupapa Māori principles espoused by L. T. Smith (2005) including aroha ki te tangata (a respect for people), kanohi kitea (the seen face, that is, present yourself to people face-to-face), titiro, whakarongo ... kōrero (look, listen ... speak), manaaki ki te tangata (share and host people, be generous), kia tūpato (be cautious), kaua e takahi te mana o te tangata (do not trample over the mana of people), and kaua e mahaki (do not flaunt your knowledge).

This thesis uses both Kaupapa Māori and Māori-centred research principles. The principles of each method will now be outlined followed by an examination of how these methods are located within this thesis.

\section{Kaupapa Māori Research}

Kaupapa Māori research is based on a Māori worldview that rejects outside control over what constitutes authority and truth and promotes an epistemological version of validity. This approach to validity locates the power within Māori cultural practices where what is and is not acceptable research is determined by the research community (Bishop, 2005). Therefore, the verification of research, the authority of research, and the quality of its representation of the experiences and their perspective of the participants are judged by criteria constructed and constituted within Māori culture (Bishop, 2005). A major reason why Kaupapa Māori research came into practice was the continual dissatisfaction of Māori communities with orthodox research projects that did not seem to make any difference to their social, educational or cultural conditions. Another important reason was the emergence of a growing number of Māori scholars who had experienced the research culture of higher education and understood Māori community frustrations with what appeared to be the absence of commitment and accountability to those communities, and set 
out to find new ways of seeking engagement and verification of their conditions. The following questions are examples of the verification: "What is their culture? What is their status? What is their age? What is their kaupapa (agenda)? What parts of the story will be important to them? What parts will be safe to tell them?" (Bishop, 1997, p. 42). This is further supported by Irwin who characterised Kaupapa Māori as "research, which involves the mentorship of elders, which is culturally relevant and appropriate while satisfying the rigour of research" (cited in L. T. Smith, 1999, p. 184; see also Cunningham, 1999; Tuuta et al., 2004).

Graham Smith (1990), a founding member of Kura Kaupapa Māori in Auckland (Pihama, Smith, Taki, \& Lee, 2004), has written extensively about Kaupapa Māori initiatives and states that Kaupapa Māori research is:

related to being Māori; ...presupposes that the survival and revival of Māori language and Māori culture is imperative; presupposes that the struggle for autonomy over our own cultural well being, and over our own lives is vital to Māori survival. (pp. 2-3)

Kaupapa Māori research, according to Cunningham (2000), is research where Māori are significant participants and where the research team is typically all Māori.

\section{Māori-centred Research}

Māori-centred research, according to Durie (1997), is based on three key principles including, Whakapiki Tangata (enablement, enhancement or empowerment), Whakatuia (integration), and Mana Māori (Māori control).

Whakapiki Tangata has the research community at the core of the research with their inclusion continuing beyond the conclusion of the research. The outcomes of the research should also enable, enhance, and empower the research community's status (Graham, 2009).

Whakatuia represents a Māori worldview and is about integrating a range of factors such as the individual and the collective, the mind, body and soul, and people and the environment (Graham, 2009).

Mana Māori relates directly to concerns of control over Māori research relating to Māori. Durie (1997) notes that this principle has Māori as the 'drivers' of Māori research rather than passive participants (Graham, 2009). According to Cunningham (2000), one of the limiting characteristics of this type of research is the dual accountability to mainstream, and to some extent Māori, control. Researchers 
will need to meet the expectations of (mainstream) funders and reviewers and the expectations of Māori.

\section{Kaupapa Māori and Māori-centred Research Principles within this Thesis}

As outlined above, this thesis contains both Kaupapa Māori and Māori-centred research principles. The characteristics of Kaupapa Māori and Māori-centred research are outlined in Table 3.2, alongside statements affirming whether and how each characteristic was reflected in this thesis.

Table 3.2: Characteristics of a Kaupapa Māori and Māori-centred Research Approach

\begin{tabular}{|c|c|c|}
\hline $\begin{array}{l}\text { Research } \\
\text { Characteristic }\end{array}$ & Kaupapa Māori Research & Māori-centred Research \\
\hline $\begin{array}{l}\text { Research is based on a } \\
\text { Māori worldview and } \\
\text { incorporates Māori } \\
\text { concepts of knowledge, } \\
\text { skills, experiences, } \\
\text { attitudes, processes, } \\
\text { practices, customs, } \\
\text { language, values and } \\
\text { beliefs. }\end{array}$ & \multicolumn{2}{|c|}{$\begin{array}{l}\text { Mihi (greetings) were exchanged before the interviews, allowing } \\
\text { interviewees and the researcher to talk about each other's } \\
\text { backgrounds. The questions pertaining to the research were then } \\
\text { asked. Participants who elected to complete the questionnaire } \\
\text { had space at the beginning of the questionnaire to provide this } \\
\text { information. } \\
\text { The researcher also provided food as a way of showing } \\
\text { appreciation for the interviewees' contribution to the research, } \\
\text { sharing in this with them where time permitted both parties, thus } \\
\text { allowing more time to talk. } \\
\text { The research is concerned with increasing the Māori language } \\
\text { proficiency of teachers in Māori medium educational settings as } \\
\text { well as their students. }\end{array}$} \\
\hline $\begin{array}{l}\text { Research should take } \\
\text { into consideration Māori } \\
\text { culture and preferences. }\end{array}$ & \multicolumn{2}{|c|}{$\begin{array}{l}\text { The researcher was guided by her own knowledge and beliefs of } \\
\text { tikanga as well as an indigenous framework called Hei Korowai } \\
\text { when negotiating research. The researcher informed the principal } \\
\text { of each school about the research and then met face-to-face with } \\
\text { the participants involved in the WPR PLD programme inviting } \\
\text { them to participate in the research. }\end{array}$} \\
\hline $\begin{array}{l}\text { Research should be } \\
\text { focused on areas of } \\
\text { concern to Māori and } \\
\text { should arise from their } \\
\text { self-identified needs and } \\
\text { aspirations. }\end{array}$ & \multicolumn{2}{|c|}{$\begin{array}{l}\text { The survival and revival of Māori language and Māori culture is } \\
\text { imperative to Kaupapa Māori research and relates to this } \\
\text { research as teachers share their experiences of using an } \\
\text { intervention tool (mobile devices) or face-to-face methods to } \\
\text { attain Māori language proficiency. } \\
\text { The PLD initiative relating to this research derives from the efforts } \\
\text { of the Māori community to regenerate the Māori language. }\end{array}$} \\
\hline $\begin{array}{l}\text { Māori should control the } \\
\text { research. }\end{array}$ & & $\begin{array}{l}\text { This research is based on a } \\
\text { PLD initiative funded by the } \\
\text { Ministry of Education; } \\
\text { therefore, accountability is to } \\
\text { the Ministry of Education as } \\
\text { well as the Māori community. } \\
\text { The researcher will also need } \\
\text { to meet the expectations of } \\
\text { the reviewers of this thesis. }\end{array}$ \\
\hline
\end{tabular}




\begin{tabular}{|c|c|c|}
\hline $\begin{array}{l}\text { Research } \\
\text { Characteristic }\end{array}$ & Kaupapa Māori Research & Māori-centred Research \\
\hline $\begin{array}{l}\text { The research team } \\
\text { should be typically } \\
\text { Māori, Māori should be } \\
\text { significant participants } \\
\text { in the research and be } \\
\text { active participants at all } \\
\text { stages of the research } \\
\text { process. }\end{array}$ & $\begin{array}{l}\text { A researcher who is Māori, who } \\
\text { can speak Māori, and who has } \\
\text { experience in Māori educational } \\
\text { settings facilitated this research, } \\
\text { guided by two supervisors who } \\
\text { are professors, one Māori and } \\
\text { one non-Māori. }\end{array}$ & \\
\hline $\begin{array}{l}\text { Research should } \\
\text { empower and have } \\
\text { positive outcomes for } \\
\text { Māori. }\end{array}$ & \multicolumn{2}{|c|}{$\begin{array}{l}\text { The aim of this research was to gain knowledge and } \\
\text { understanding about the challenges and opportunities of using } \\
\text { mobile devices to attain Māori language proficiency. As a result, } \\
\text { the researcher may be able to draw upon that knowledge as a } \\
\text { basis for seeking and refining creative solutions for Māori } \\
\text { advancement and excellence in the Māori language. }\end{array}$} \\
\hline $\begin{array}{l}\text { Māori people being } \\
\text { researched should be } \\
\text { active participants at all } \\
\text { stages of the research } \\
\text { process. }\end{array}$ & $\begin{array}{l}\text { Participants in the WPR PLD } \\
\text { programme were informed of, } \\
\text { and invited to partake in, the } \\
\text { research via a face-to-face } \\
\text { meeting. Participation was } \\
\text { voluntary and participants were } \\
\text { able to withdraw from the } \\
\text { research if they wished. } \\
\text { Interviewees were also emailed } \\
\text { a transcript of their interview to } \\
\text { check for accuracy before } \\
\text { analysis was undertaken. A } \\
\text { fundamental feature of the } \\
\text { process will be the changes } \\
\text { made to the WPR PLD } \\
\text { programme as a result of this } \\
\text { research. }\end{array}$ & $\begin{array}{l}\text { The researcher set the } \\
\text { questions for the interviews } \\
\text { and questionnaires and gave } \\
\text { the participants an } \\
\text { opportunity to add any other } \\
\text { comments at the end. }\end{array}$ \\
\hline $\begin{array}{l}\text { Researchers should be } \\
\text { accountable to research } \\
\text { participants. }\end{array}$ & $\begin{array}{l}\text { All interviewees were emailed } \\
\text { their transcripts to review and } \\
\text { give feedback. }\end{array}$ & \\
\hline $\begin{array}{l}\text { Research should be } \\
\text { assessed by culturally } \\
\text { appropriate methods. }\end{array}$ & $\begin{array}{l}\text { An online questionnaire was } \\
\text { used in this research to cover a } \\
\text { range of geographical locations } \\
\text { and participants as well as face- } \\
\text { to-face interviews and } \\
\text { observations, which is a } \\
\text { culturally appropriate method } \\
\text { when working with Māori. }\end{array}$ & \\
\hline
\end{tabular}

Source: Adapted from Graham, Meyer, McKenzie, McClure, and Weir (2010).

\section{Ethical issues}

One potential impediment identified within this research essentially centred on the researcher's involvement within the PLD programme and the problematic nature of 'insider' research. As a programme coordinator of WPR the researcher is physically located within this research. There are tikanga involved in the insider position, to be upheld throughout the duration of the research as well as beyond when presenting data at conferences and in publications. There is potential for problems to arise over 
perceived conflicts of interest between the research and the research community. The researcher also has an established professional relationship with some of the participants, which could either facilitate or hinder interview responses, and thus their actions or decisions about options. Building rapport with all interviewees and making them feel comfortable during the interview is necessary to ensure an in-depth interview as a conversation takes place (Bishop, 1997).

At the outset of the research, the potential issue of the researcher as programme coordinator was addressed explicitly in the ethics application. Participant confidentiality, anonymity, respect and trust have been assured throughout the research process. Participants' details have been securely stored in a pass-worded area online and in a locked filing cabinet on site at the university where the researcher works. Furthermore, supervisor guidance and adherence to the research objectives clearly defining the research was an alternative way of ensuring limited bias.

There were other considerations to be mindful of that could be accomplished with careful review and planning throughout the fieldwork component of the research. Examples of these considerations included:

- geographical location and travel impacting on access to the research community;

- financial considerations and their impact upon time, travel and access to participants;

- the capacity to maintain shared communication and dialogue with the research community throughout the entire research process.

These considerations are common features of engaging in research and could be easily overcome with effective planning.

\section{The Research Community}

In undertaking this research, the researcher used her insider knowledge as a programme coordinator of the WPR PLD programme to access participants.

The research communities for this research were sourced through two separate WPR programmes: (1) VUW WPR, eight schools within four clusters, from 2009 2012, one Resource Teacher of Māori and two regional coordinators; and (2) WPR 
Comparison group, three schools within one cluster from 2010 - 2011 and one facilitator.

\section{VUW WPR}

Participants at eight schools from Te Tai Tokerau (Northland), Te Tai Rāwhiti (East Coast), Te Whanganui-a-Tara (Wellington) and Te Tau Ihu (Top of the South Island) participating in the VUW WPR programme from 2009 - 2012, one Resource Teacher of Māori and two regional coordinators took part in the research.

The stakeholders involved in the VUW WPR programme who participated included:

\section{Regional Coordinators}

The role of the regional coordinator was to facilitate the programme with the support of the in-school facilitator. The regional coordinator meets regularly with the inschool facilitator and participants to discuss the specific learning outcomes for the week, complete activities related to the learning outcome, and provide technical and pedagogical resources and support. The regional coordinator also coordinates, monitors, and assesses the participants' progress and collates this information for the principal and the WPR team reporting requirements.

\section{In-school Facilitators}

The role of the in-school facilitator is to support the regional coordinator with the facilitation of the programme. The in-school facilitator liaises with the regional coordinator and gathers assessments for the purposes of the participant progress and the WPR reporting requirements.

\section{Participants (teachers and other staff members)}

The participants are responsible for carrying out all course work such as watching the podcasts and completing activities and assessments. Participants are also required to meet regularly with the in-school facilitator and/or regional coordinator, demonstrate how they implement their learning from the programme in the classroom, and gather samples of students' work to show this implementation. Administration staff, library staff, and kaiāwhina from some schools also choose to take part. These staff members carry out course work but are not required to provide student samples of work given their possible lack of impact on students' learning.

The researcher contacted the principal of each school via phone and email to discuss the purpose of the research and ask permission to invite teachers to participate. 
When approval from principals was obtained, the regional coordinator of each of the four clusters was informed of the research and liaised with to organise face-to-face meetings with participants. The researcher then met with participants face-to-face and described what the research involved, how it would be reported, and the public availability of findings. The participants were also informed of the right to withdraw from the project at any time until the end of data collection along with information on how to do so. Information sheets and consent forms were given to participants for two options: (a) Option 1 included the interview, the observation, and the use of Waikato Proficiency test results; and (b) Option 2 included the online questionnaire and the use of the Waikato Proficiency test results.

Participants were encouraged to partake regardless of whether they were using the devices every day or only once monthly, as feedback reflecting different levels of use could reveal challenges, opportunities and potential associated with the mobile devices. Participants were provided opportunity to ask questions and the option to return the consent form immediately after the presentation or later, via post, if they chose to participate.

Potential research participants were selected based on key demographic factors including gender, age, geographical location, current use of technology and staff currently participating in the programme to ensure a range of perspectives. However, there were very few males involved in the VUW WPR programme, resulting in an unequal gender balance.

\section{WPR Comparison Group}

Participants at four schools and one facilitator within one region involved in another WPR programme undertaken between 2010 and 2011 were approached to participate in the research.

The researcher contacted the project directors of two other WPR programmes who were using a face-to-face method of programme delivery for the comparison group interviews. One project director agreed that the researcher approach the schools involved in their programme and gave the details of the four schools that participated between 2010 and 2011. The principal of each school was contacted via phone and email to discuss the purpose of the research and ask permission to invite teachers to participate. The four principals agreed to this research and passed on information sheets and consent forms to the teachers. Teachers from three schools agreed to participate in the research. 


\section{Research Design - Tools and Instruments}

Frameworks developed by Warschauer (2004), Webb (2006) and Durie (1999) influenced the overall design of the questions used to collect data from the interviews and the online questionnaire.

Warschauer designed a framework comprising four types of resources that affect how people use ICT, including the:

- Physical, such as access and devices;

- Digital, such as the materials and the content available;

- Human, such as the types of literacy practices and education; and

- Social, such as communities and institutional structures in which the ICT is used.

Webb (2006) used the four dimensions described by Warschauer (2004) as a framework for examining the experiences of adult speakers of other languages learning English through ICT. These comprise:

- The physical including the organisation of the hardware and the settings in which the CD-ROM software was used;

- The digital including the CD-ROM content and the pedagogical assumptions of the materials, tasks and assessments;

- The human including the practices and experiences of the learners and the tutors and centre managers;

- The social including the institutional arrangements and organisation within which tutors and learners used the software.

Webb's (2006) framework reminded the researcher of the Whare Tapawhā, a model developed by Durie (1999), which compares health to the four walls of the whare. All four dimensions are necessary to ensure strength and symmetry.

The researcher used Durie's (1999) and Webb's (2006) models as a basis for developing her own dimensions within a framework for exploring the challenges and opportunities of using mobile devices to attain Māori language proficiency. Te taha tinana (physical), te taha hinengaro (mental), te taha whānau (extended family) and te taha wairua (spiritual) are from Durie's (1999) model. The researcher felt it was necessary to acknowledge the research participants' backgrounds, experiences and prior learning and the contribution these will make to the new journey they are about to 
nengaro

meeting house)

lairua

arenui)

nana whenua

here wharenui sits)

\section{Te taha tinana}

undertake and therefore added te tūāpapa (background, grounding) to the model. Te taha mana whenua (the land, belonging) was atotakdedhtonly the researcher to

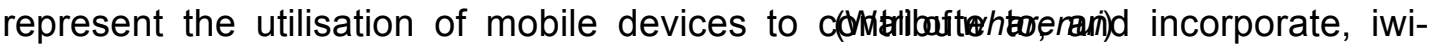
specific language and knowledge (see Figure 3.2 below).

\section{Te tūāpapa}

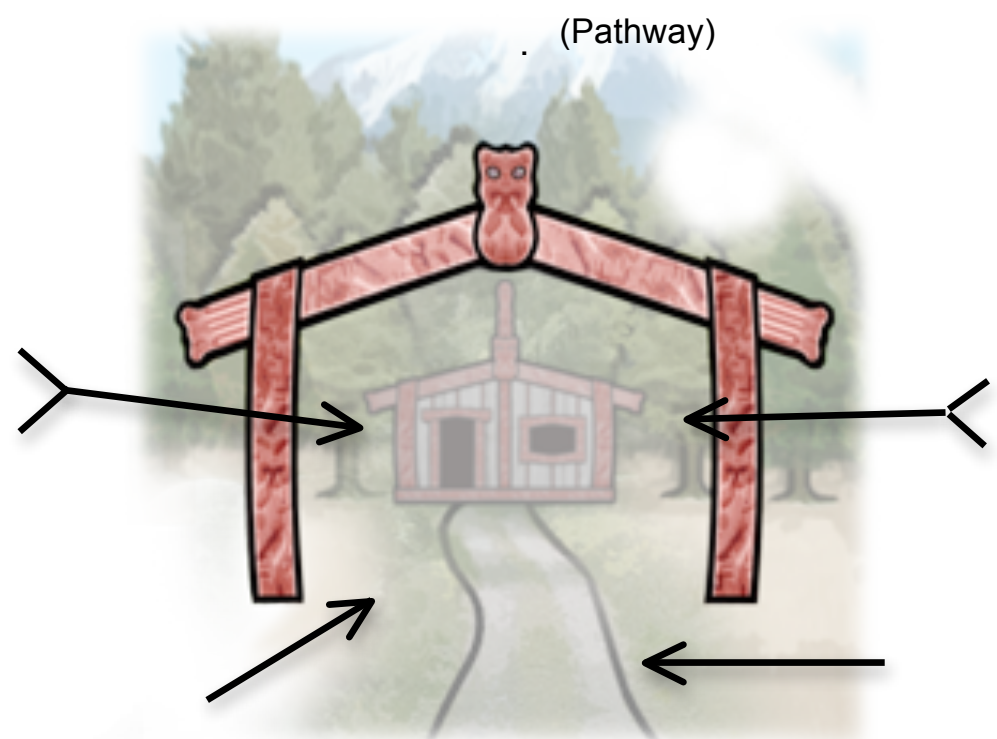

Figure 3.2: Adaption of Durie's Whare Tapawhā Model

The backgrounds of the participants are important and are represented by the following dimension:

\section{Te tūāpapa}

As the participants enter onto the marae (courtyard) and walk up the pathway to the wharenui, the importance of their backgrounds, experiences and prior learning is acknowledged as well as the contribution these will make to the new journey they are about to undertake.

The new learning takes place within the four walls of the wharenui and on the land where the wharenui rests and is represented by the following dimensions:

Te taha tinana

This dimension is one of the four walls of the wharenui and represents the organisation of the hardware and the settings in which the mobile devices are used in the WPR PLD programme.

Te taha hinengaro

Another one of the four walls of the wharenui, this dimension represents the mobile device content and the pedagogical assumptions of the materials, tasks, and assessments. 
Te taha whānau

Interactions and relationships with others are important in the learning and teaching process. This dimension is another wall within the wharenui and represents the educational and organisational settings within which the regional coordinators, in-school facilitators and participants use the mobile devices to attain Māori language proficiency.

Te taha wairua

The fourth wall of the wharenui is te taha wairua and represents the practices and experiences of the regional coordinators, in-school facilitators and participants involved in the PLD programme.

Te taha mana whenua

The land on which the wharenui rests is also very important and represents the utilisation of mobile devices to contribute to, and incorporate, iwi-specific language and knowledge.

These six dimensions were used to develop the questions for the data sources used in this research. The questions were designed to build a rapport with the interviewee, to gather some background information about the person completing the questionnaire, to answer the questions central to the thesis, and to draw out any further information the participants may want to share.

Two separate groups took part in this research, including participants involved in the VUW WPR programme and participants involved in another WPR programme.

\section{Data Sources}

The data sources for the VUW WPR participants encompassed:

- Semi-structured interviews;

- Observations of mobile device use;

- Online questionnaire; and

- Waikato Proficiency Test pre and post-results.

The data sources for the WPR comparison group encompassed:

- Semi-structured interviews; and

- Waikato Proficiency Test pre and post-results. 


\section{Semi-structured interviews}

Bishop (1997) states:

Research involving Māori knowledge and people needs to be conducted in culturally appropriate ways that fit Māori cultural preferences, practices and aspirations in order to develop and acknowledge existing culturally appropriate approaches in the method, practice and organisation of research. (p. 39)

The preferred approach to these interviews was to allow the participants to tell a story, enabling the "participants' stories to gain the authority and the validity that the researcher's story has had for so long" (Bishop, 1997, p. 42). The intention of this approach is for the research participant to use the researcher to bring their situation or their worldview to the attention of the audience (Bishop, 1997, 2005; L. T. Smith, 2005). Bishop (1997) suggests developing collaborative stories "by means of sequential, semi-structured, in-depth, interviews as conversations" (p. 41) in order to address indigenous people's desire for self-determination in educational research. Bishop also suggests facilitating on-going collaborative analysis and construction of meaning or explanations about the experiences of the research participants.

The primary research tool for this research has been the semi-structured interviews with 17 participants involved in the VUW WPR programme. The 17 interviewees were made up of 14 Māori, and three non-Māori. Fourteen of the 17 interviewees were female and three were male who were teaching staff (some of whom were in-school facilitators), non-teaching staff or regional coordinators of the VUW WPR programme. Twenty participants gave consent to be interviewed; however, three participants decided not to participate in the research.

Interviews were also undertaken with six participants involved in another WPR programme. All six participants were Māori, female, and were either teaching staff or a facilitator of the programme. This particular programme uses a face-to-face approach and the responses from these interviews were used to compare Māori language proficiency attainment via a blended approach of face-to-face and mobile devices or face-to-face only.

Prior to starting these interviews, a practice interview was undertaken with a current participant involved in the VUW WPR programme to enable the researcher to practise this role. The interview questions were asked in a practice interview with a participant who agreed to the interview being observed by one of the thesis supervisors, allowing subsequent review and feedback on both the interview questions and process. The 
practice interview also provided opportunity to gather constructive feedback from the interviewee about the questions and the interviewing process.

The participants who opted to take part in the interview were given an explanation of the interview process including the recording of the interview with participant consent to allow later transcription. Research participants were given the option of declining a recorded interview if they so desired; all participants agreed to the recording.

At the beginning of each interview the participant was greeted, the research objectives were clarified, and an explanation was given of the research process and the disclosure of what would be happening to the information obtained from the interview. This included information about use of the data and where printed copies would be stored to protect confidentiality. Participants were also given the option of answering questions in Māori or English. At the conclusion of each interview, each participant was thanked for taking part in the interview and contributing input for the research.

Each interview was limited to one-hour maximum and conducted at a location agreed between the researcher and the interviewee. Interviews were conducted face-to-face. The importance of face-to-face for Māori coincides with the New Zealand Council for Educational Research's (2004) Critical Success Factors and Effective Pedagogy for e-learning in Tertiary Education which states that Māori students need to interact with staff and other students in ways other than the web, which is consistent with cultural preferences. Teachers involved in the Te Poutama Tau professional development project preferred "kanohi ki te kanohi hui (face-toface meetings), with facilitator visits in individual kura (school) as follow-up" (Te Maro, Averill, \& Higgins, 2008, p. 45).

\section{Observation of Mobile Device Use}

The 17 participants from the VUW WPR programme who were interviewed were also observed demonstrating their ability to use the different functions of the mobile device for the purposes of the programme. As noted in Chapter One, some of the programme requirements entailed participants watching videos about Māori language and principles of second language acquisition as well as recording themselves reflecting on their progress throughout the week via the Voice Memos function on the iPod Touch®. Each observation took approximately 20 minutes and was undertaken at the conclusion of the interview. A list of twenty functions was included in the observation criteria based on the functions the researcher thought the participant needed to utilise the mobile device successfully for the purposes of the VUW WPR programme. Prior to starting the observation, the list was checked by 
a current VUW WPR staff member to ensure coverage of functions used in the programme.

This list of twenty functions included how to:

1. Turn on the iPod Touch $® / \mathrm{iPad} \circledast$

2. Charge the iPod Touch $® / \mathrm{iPad} \circledast$

3. Attach the iPod Touch $\circledast / \mathrm{iPad} \circledast$ to the computer

4. Locate the Music folder

5. Listen to music files

6. Turn the volume up and down

7. Scroll up and down the files to select a song

8. Locate the Movies folder

9. View the Wete reo or Hopu reo videos

10. Fast forward or rewind the videos

11. Locate the Voice Memos function

12. Record using the Voice Memos function

13. Custom label audio recordings

14. Retrieve past audio recordings in Voice Memos

15. Copy audio recordings to a computer

16. Turn on Wi-Fi to connect to the Internet

17. Synchronise content from the computer to the iPod Touch $₫ / \mathrm{iPad} \circledast$

18. Use the Settings function (to change time and date, sounds etc)

19. Access the Internet via Safari

20. Access email using iPod Touch $® / \mathrm{iPad} \AA$ (includes the initial set-up)

The process of the observation was explained to participants including presenting the observation criteria and explaining the recording of participants as a High, Medium or Low user. Participants were asked to demonstrate the functions on the observation criteria from 1 to 20 and were then given an opportunity to demonstrate their ability to utilise other functions that were not part of the list of 20 . The most common function participants listed was the use of the camera to take still photos and movies. This function was not selected by the researcher because the first iPod Touch $®$ that was used in the WPR programme did not have a camera. The newer version of iPod Touch $®$ has the camera function and the participants who joined the WPR programme in 2011 acquired these and were therefore able to comment on their use of the camera. On reflection, the camera is a function that could and should be used by the participants to increase, monitor, and assess their own and their students' te reo Māori development and it would have replaced one of the 
criteria currently on the list (possibly Access the Internet via Safari) if all participants had access to it.

The functions demonstrated correctly were totalled, and the participant was recorded as a High user, a Medium user, or a Low user. Participants were designated Low users if they demonstrated $0-5$ functions, Medium users if they demonstrated 6 - 15 functions, and High users if they demonstrated $16-20$ functions. The observation criteria were then given to the participant for verification of what was demonstrated and confirmed as the final mark.

\section{Online Questionnaire}

An online questionnaire was used in addition to the interviews to gather responses from a wider range of participants located in a range of geographical locations. Twenty-nine participants completed the online questionnaire. Twenty-six of the 29 participants were Māori and three were non-Māori who were either teaching staff (some who were in-school facilitators), non-teaching staff, a resource teacher of Māori or a regional coordinator of the VUW WPR programme.

Thirty-six participants gave consent to undertake the online questionnaire. Three email addresses were incorrect and attempts to contact the participants via the regional coordinator did not eventuate in the participants passing on another email address. Four additional participants did not complete the online questionnaire within the designated schedule despite follow-up and reminder emails. Thus 29 participants in total completed the online questionnaire.

Prior to distributing the online questionnaire, a then current WPR staff member who was not part of the participant sample completed the questionnaire to provide feedback on the clarity of the questions and an estimate of the time needed to finish it. This was also a valuable exercise to test whether the questions would elicit appropriate information to address the research questions.

The participants who opted to complete the online questionnaire were provided instructions and a timeframe along with a link to the online questionnaire using the email address provided on their consent form. The online questionnaire took approximately 20 minutes to complete, and participants were given the option of responding in Māori or English as with the interviews.

The research participants who completed the online questionnaire had some control of the research in the questions they chose to answer. They were also given the 
opportunity and space to include any other comments they felt were relevant and/or were not covered by the questionnaire.

The Qualtrics Survey Software used to design and facilitate the questionnaire had a number of useful functions enabling the researcher to track the progress of the questionnaires, to send reminder and thank you emails, and to view the responses in a range of ways. When the timeframe for completion of the online questionnaires expired, the responses were exported from the Qualtrics Survey Software as a Microsoft Word document for coding in order to address the research objectives.

\section{Language Proficiency Test}

As part of the VUW WPR PLD programme, participants undertake the Waikato Proficiency Test at the beginning and end of the programme each year. This attestation test was developed by Waikato University to assess proficiency in te reo Māori through the modes of reading, writing, listening, and speaking. Each test takes approximately one hour and is administered and marked by the in-school facilitator and/or regional coordinator of each school/cluster. There are two Waikato Proficiency tests based on different topics; however, the same test is used at the beginning and end of the same year.

All participants in this research were asked for their permission to use their pre and post-test results from the Waikato Proficiency Test to substantiate the interview, observation, and online questionnaire results.

\section{Data Analysis}

Data from the questionnaires, interviews, observations and the Waikato Proficiency Test results were analysed to answer the research question 'What are the challenges and opportunities of using mobile devices to attain Māori language proficiency?'

Data from the interviews were used to answer the research question 'Do learners make expected gains in language proficiency through the use of mobile devices in comparison to standard face-to-face methods of language instruction and, if there are differences, which of these can be associated with mobile device use?'

Transcribers were employed to transcribe all of the interviews. Both transcribers had been utilised by colleagues within the Education Faculty and other Masters and Doctoral students on a number of occasions. One transcriber could not speak or 
understand Māori and was employed to transcribe the interviews that were in English, while the other transcriber who could speak Māori transcribed the interviews that were all or mainly in Māori. The transcribers signed confidentiality agreements and were sent all audio files of the interviews via email. The interview transcripts were returned via email to the interviewees to ensure accuracy and validity. Validity is not a new process for Māori people as stated by Bishop (2005); however, a term known as ngā taonga tuku iho (treasures from the ancestors) is used to evaluate whether a process or a product is valid for them. Bishop (1997) states that researchers need to ensure "what people say should be presented unaltered and not analysed in any way beyond that which the respondent undertook" (p. 41).

During the data collection phase, the information and notes collected were documented and verified by the research participants by way of an email. Print copies were filed and stored under lock and key, and electronic versions were backed up onto Dropbox (a cloud-based computing application) and an external hard drive.

The aim of the semi-structured interviews was for the narratives to provide the thick description necessary for research (Creswell, 2009; Merriam, 1998). The interview data from the VUW group and the comparison group were exported into Word documents and analysed separately. Answers to each interview question from interviewees were collated into two documents, one for the VUW group and another document for the comparison group, under the headings associated with the researcher's adapted Whare Tapawhā model (Durie, 1999). These headings were te tūāpapa, te taha hinengaro, te taha tinana, te taha wairua, te taha whānau, and te taha mana whenua. The narratives were analysed by eliciting key terms or words. These key terms or words were then categorised into themes with the supporting narratives. At this stage the narratives were recorded with the participants' real names; however, pseudonyms were eventually given to each participant. The observations of the mobile device use were tabled to show how well the interviewees could use the 20 functions on the mobile device and included in the semi-structured interviews section of the thesis. This information provided background information about the participants' capability to use the mobile device according to the observation criteria (see Appendix 5 - Observation Criteria).

The data analysis process for the questionnaires was also similar to that of the interviews. The data from the questionnaire were exported from the Qualtrics 
website into a Word document for the VUW group. This function exported each respondent's answer under each question which were also associated with headings from the researcher's adapted Whare Tapawhā model (Durie, 1999). The narratives were analysed by eliciting key terms or words that were then categorised into themes with the supporting narratives or by using tables containing information within the thesis. Once again, the narratives were initially recorded with the participants' real names; however, pseudonyms were eventually given to participants whose narratives were used in the thesis.

The Waikato Proficiency Test results were collated into two tables, one table documented the pre and post-test results from participants in the VUW group and the other table documented pre and post-test results from the comparison group. Within the tables the results for each of the two sections (Tuhituhi (Writing) and Kōrero (Speaking)) were identified as well as the changes that had occurred in their knowledge of the Māori language from the pre to the post-test.

\section{Chapter Summary}

The principles of a framework called Hei Korowai were drawn upon as the researcher entered into and negotiated with the research community. The framework was developed by researchers within Te Kura Māori, VUW as an ethical guide for researchers working within Māori settings (Taiwhati et al., 2010). The researcher's membership within Te Kura Māori allowed her to utilise Hei Korowai and the ways she used the framework are outlined in this chapter. Hei Korowai was not initially designed to be a comprehensive research framework but rather a way of bringing the importance of acknowledging tikanga Māori when working with Māori participants or in Māori settings. Thus Hei Korowai also draws on kaupapa Māori research principles.

Kaupapa Māori research is based on a Māori worldview that rejects outside control over what constitutes authority and truth, locating the power within Māori cultural practices (Bishop, 2005). A continual dissatisfaction of Māori communities with research projects that did not seem to make any difference to their social, educational or cultural conditions was a major reason why Kaupapa Māori research was developed and practised. Māori-centred research, like Kaupapa Māori, represents a Māori worldview, has the research community at the core and has Māori as the drivers of research rather than passive participants (Cunningham, 2000; Durie, 1997; Graham, 2009). Māori-centred research, unlike Kaupapa Māori 
research, has dual accountability to mainstream (Cunningham, 2000; Durie, 1997; Graham, 2009). Research methodology that encompasses a Kaupapa Māori and Māori-centred approach was outlined in this chapter to show the way in which the principles were located throughout the research process.

The ethical issues that arose in the research centred on the researcher's involvement within the PLD programme and the problematic nature of this position and its impact on various people was outlined. The two research communities invited to partake in the research were then described and the processes undertaken to enter into, negotiate, and carry-out the research.

The tools and instruments used to gather data comprised semi-structured interviews, observations of mobile device use, online questionnaires and pre and post Māori language proficiency tests. Descriptions of the tools and the numbers of participants involved in each were outlined as well as the framework adapted from Durie's (1999) Whare Tapawhā model by the researcher to develop questions for the data sources. The processes used to analyse and elicit information from the data sources have been explained at the end of the chapter. The next chapter presents the narratives gathered from the semi-structured interviews and the observations of mobile device use to identify the challenges and opportunities of using mobile devices to attain Māori language proficiency. 


\section{Chapter Four \\ Research Findings - Semi-structured Interviews}

\section{Introduction}

The findings elicited from the semi-structured interviews and observations of mobile device use with participants involved in the VUW WPR programme and the semistructured interviews with the comparison group are outlined in this chapter. The purpose of the comparison group was to provide perspectives from participants involved in a programme that used only face-to-face instruction. In order to maintain the anonymity and confidentiality of the research participants' stories collated from the fieldwork phase of the research, each of the participants has been given a pseudonym. The narratives provided by the participants documented throughout this chapter will be indicated by italics and referenced according to that participant's pseudonym. Within some quotes the researcher has also used square brackets [ ] to indicate the addition of a word or words to add clarity.

This research set out to examine the challenges and opportunities of using mobile devices to attain Māori language proficiency. It also sought to ascertain if learners make expected gains in language proficiency through the use of mobile devices in comparison to standard face-to-face methods of language instruction and, if there are differences, which of these can be associated with mobile device use by exploring the participants' experiences within the WPR programme.

In order to understand the context of the research, the respondent's background of Māori language is outlined within their groups (VUW WPR Group and Comparison Groups) including their reason for undertaking the programme and indicated places and methods used to learn te reo Māori in the past. The VUW WPR group was also questioned about their history with technology and their expertise to operate mobile devices. The interview results gathered from both groups are then explored.

\section{VUW WPR Group}

\section{Māori Language Background}

The research revealed wide-ranging personal reasons for undertaking the WPR programme. The primary reason for taking part in the programme was to improve proficiency in te reo Māori, enabling participants to teach students more effectively. 
Participants were also interested in identifying language errors, finding out "why those errors are occurring and how we might address them" (Puāwai).

Professional and personal growth was another popular reason with one participant stating that in order to survive in the profession they "would need to do some kind of intense PD. That's where Whakapiki came into it" (Waiari).

In some cases, the choice to undertake the programme was a school-wide decision or one made by management. This arrangement was happily accepted by the majority of participants, but not all, which may have impacted on their engagement with the programme. One participant highlighted the nature of the school environment and the need to be a part of the programme that benefits students, alongside colleagues. Other reasons participants undertook the programme included not having to move to another place, thus being able to spend more time with family, the "opportunity to impact on more than one classroom" (Te Ahu) and receiving an iPod Touch $®$ for the length of the programme.

Participants were asked to describe their history of learning Māori. The majority of participants were fortunate to have learned at home, with the next common pathway being university or polytechnic. Te Ataarangi helped a number of participants develop Māori language proficiency while a few others learned through their schooling years or while they were staff members at their children's kōhanga reo.

In regards to the methods used to learn te reo Māori, the majority of participants learned by listening, for example listening to others around them, listening to elders, listening to the teachers who spoke only Māori while attending Te Ataarangi classes or listening to Māori waiata. For those who learned at school or university, the Māori language series Te Rangatahi by Hoani Waiti and Te Whanake by John Moorfield were common resources used to teach and learn te reo Māori as well as kapa haka (Māori performing arts). One participant said quality reo (language) was spoken around them on a regular basis, for example at home and also while attending different meetings with grandparents.

When asked to identify the most effective method for learning te reo Māori, participants expressed a preference for an immersion environment. This includes the Te Ataarangi method, listening to others speaking Māori and learning in a faceto-face environment. The use of books and language series that teach te reo Māori, 
such as Te Whanake, was the next preferred choice and includes learning in a structured way with a focus on grammar.

\section{Technology Use and Expertise}

Everyone had access to and used the computer. The majority used a variety of technologies such as the cell phone, Internet, smartboard, television, stereo, camera and digital portfolios. A few participants also used the iPad $\AA$, iPhone $\AA$ or iPod Touch $₫$ prior to receiving the iPod Touch $®$ for the WPR programme.

Five participants said they were scared of technology or found it threatening as indicated in the following narrative "being of the semi older generation they're a bit threatening at first because it's something new" (Tumanako). However, this feeling of apprehension was usually overcome with support from others with how to use the device, for instance, after a demonstration of how to work the device from teenagers in the house. Using new technology was "a place of the known and not knowing" (Kaitiaki) and some were scared of breaking it or "pushing the button and then stuffing something up" (Te Ahu).

The remaining participants enjoyed using the mobile devices with some considering themselves as learners and others feeling like they could not operate without them:

I feel like my right arm's cut off if I can't find either of them [mobile devices]. (Huhana)

Fewer than half of the participants were "a little bit apprehensive" (Te Ahu) about the use of mobile devices to attain proficiency in te reo Māori; they were not sure how it would work or how it would be effective. Other participants were interested in, and excited by, the premise of using mobile devices as indicated in the following comments:

\footnotetext{
I was quite interested to see how that would work because I had never come across it before. It was definitely a drawcard the fact that it's the latest technology and they are so easy to use. I thought it was a good idea. (Tuia)

I was so excited. I think that's the way to learn. Learning Māori on the iPod®, it's here and it's now and this is where the future lies. (Mead)
}

Interviewees were observed operating specific functions on the mobile device (iPod Touch $®$ or $\mathrm{iPad}()$ ) to demonstrate their expertise. The results have been collated in Table 4.1. 
Table 4.1: Participants' Expertise to Utilise the Mobile Device

\begin{tabular}{|c|c|c|c|c|}
\hline$\#$ & Question & $\stackrel{\infty}{\rightleftharpoons}$ & 2 & 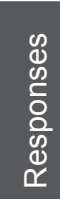 \\
\hline 1 & Turn on the iPod Touch $® /$ iPad® & 17 & 0 & 17 \\
\hline 2 & Charge the iPod Touch $® / \mathrm{iPad} \circledast$ & 17 & 0 & 17 \\
\hline 3 & Attach the iPod Touch $\circledast / \mathrm{iPad} \circledast$ to the computer & 16 & 1 & 17 \\
\hline 4 & Locate the Music folder & 16 & 1 & 17 \\
\hline 5 & Listen to music files & 16 & 1 & 17 \\
\hline 6 & Turn the volume up and down & 16 & 1 & 17 \\
\hline 7 & Scroll up and down the files to select a song & 16 & 1 & 17 \\
\hline 8 & Locate the Movies folder & 16 & 1 & 17 \\
\hline 9 & View the Wete reo or Hopu reo videos & 17 & 0 & 17 \\
\hline 10 & Fast forward or rewind the videos & 16 & 1 & 17 \\
\hline 11 & Locate the Voice Memos function & 14 & 2 & 17 \\
\hline 12 & Record audio using the Voice Memos function & 12 & 5 & 17 \\
\hline 13 & Custom label audio recordings & 6 & 11 & 17 \\
\hline 14 & Retrieve past audio recordings in Voice Memos & 12 & 5 & 17 \\
\hline 15 & Copy audio recordings to a computer & 7 & 10 & 17 \\
\hline 16 & Turn on Wi-Fi to connect to the Internet & 9 & 8 & 17 \\
\hline 17 & Synchronise content from the computer to the iPod Touch $₫ / \mathrm{iPad} \circledast$ & 6 & 11 & 17 \\
\hline 18 & Use 'Settings' function i.e. sounds, time and date... & 11 & 6 & 17 \\
\hline 19 & Access the Internet via Safari & 11 & 6 & 17 \\
\hline 20 & $\begin{array}{l}\text { Access email using iPod Touch } ® \text { (includes able to set up email } \\
\text { details) }\end{array}$ & 11 & 6 & 17 \\
\hline
\end{tabular}

The 17 participants who were observed locating different functions or performing specific actions on their mobile device for the purpose of the VUW WPR programme generally were able to do so successfully. All participants could turn on the iPod Touch $\AA$, charge it, and view the wete reo and hopu reo videos. All but one participant (all different participants) could attach the device to the computer, change the volume and fast-forward or rewind the videos. Another participant who could not locate the Movies folder where the wete reo and hopu reo videos are, used the search function instead to access these, a function not assessed in the observation but helpful to know. Overall this participant was only able to demonstrate six of the 20 functions and although they would be able to view the videos for the VUW WPR programme, they would require a lot of training in order to utilise the mobile device more effectively. Four other participants would require assistance to use the Voice Memos function for the purposes of the programme and then the majority of the participants would require training for other functions such as turning on WiFi to connect to the Internet (Internet access is required first), accessing email, and synchronising content from the computer. Operating these 
functions is not needed to meet programme requirements (for example, viewing wete reo and hopu reo videos or recording reflections via the Voice Memos function) but does enable participants to take advantage of what is available. Overall, the request for more or on-going training in the utilisation of the mobile device is valid and necessary to exploit this technology fully for the purposes of teaching and learning the Māori language.

The last function identified above, synchronising content from the computer, would require a participant's computer to be registered with the device; however, all devices are given to the participants loaded with content and registered to a VUW WPR computer. This was also a challenge indicated by participants who wanted to download apps and other content to their device, but could not do so because they did not have the knowledge.

\section{Comparison Group}

\section{Māori Language Background}

Participants reported that they undertook the WPR programme to learn how to teach the Māori language to students, to ensure what was being delivered was in Māori and at an appropriate level for the students and making "sure [the teacher is] delivering correct reo" (Rangi).

All of the participants were fortunate to have learned Māori at home or had Māori spoken in their everyday surroundings. Listening, watching, and speaking were the main methods used to learn te reo Mãori reported by the participants. The following statements illustrate how two participants said that they had learned by listening and watching others, particularly elders:

He nui tonu taku ako i te reo-ā-tinana, ā te whakarongo tonu.

I learn mainly by hands-on and listening. (Amokura)

Nā te mea i tipu mai au i roto i te reo i konei, i te kāinga, i waenganui i ngā koroua, kuia. Whaiwhai haere i taku koroua ki ngā tangihanga, me taku kuia. Kāore au i ako mā te pepa, mā te whakarongo, titiro êrā mea katoa.

Because I grew up immersed in the language, here at home amongst the elders. I would follow my grandfather and nan to funerals. I did not learn from paper, but rather by listening and watching. (Ngarongo)

The most effective places to learn te reo Māori, according to the participants, include learning environments such as the home, school and the marae. Listening to te reo Māori being spoken through oratory, songs, history and stories of the meeting houses 
told while at the marae were favoured modes of learning. In addition, learning the linguistics and structures of the language were also considered significant.

I runga i te marae. Ngā whaikōrero, ngā waiata, ngā hītori, ngā kōrero o roto i te whare, whare tipuna, ngā hïtori kei roto i te whare tipuna.

On the marae. The formal oratory, songs, the history, the stories of the sacred meeting house, the history within the sacred house. (Erueti)

Ko te āhuatanga wetewete, te wāhanga $i$ āhua whakaatuhia mai. Ko te mōhio pea ki te whakatakoto tika.

The grammar aspects, the aspects that show the workings. The knowledge to structure the language correctly. (Manawanui)

The opportunity to have an external person present in the classroom to role model different ways to teach through Māori was appreciated by the majority of participants in this group. In contrast, one person was initially taken aback by the idea of improving her proficiency in te reo Māori as she identified herself as a fluent speaker. However, she soon came to the conclusion that the spoken and written language used in the classroom was different to that used in formal situations or in everyday settings, which changed her attitude towards the idea of the PLD.

He āhua whakahīhī. Kei au te mita o te reo. Engari ka kuhu mai ana koe ki te kura, he reo atu anō. He reo rerekē anō me mātua mōhio ki ngā momo tikanga o te tuhi i te reo.

I was a bit arrogant and proud [at first] because I am fluent. But when one goes into a school, it's a different type of language and one must know the different aspects, rules and protocols for example written language. (Amokura)

\section{The Opportunities Presented by Mobile Device Use to Attain Māori Language Proficiency}

Participants were questioned about the opportunities presented by the use of mobile devices to attain proficiency in te reo Māori, including features and functions of the mobile devices which, for them, might make learning te reo Māori more effective and efficient. Participants in the VUW WPR programme regarded this new initiative very positively, viewing the use of mobile devices as modern:

Using the devices is an advantage so we're up front in terms of using these technologies. When you see schools with iPads $\AA$ on their stationery lists then they're years behind in Māori medium, but now we can be up in front, leading the way. (Mana)

The use of mobile devices in the domain of Māori language learning in particular was seen as the way of the future: 
If it means that this is the way that maintains the survival of our reo, I say yes, it is the way. This is the future way of learning Māori. (Mead)

Interviewees commented on the need to move forward in today's world by bringing technology into the classroom, thus catering for the students who were described by one participant as "IT kids" (Tumanako) seen to be familiar with or receptive to technology. A participant commented:

The kids are teaching me how to go onto the web. I think that's how it should be because I think any one person shouldn't have all the answers, there should always be a shared approach. (Aroha)

The narratives in this chapter explore the advantages and opportunities presented by the use of mobile devices to attain proficiency in te reo Māori, categorised into four themes - distinct features and functions of mobile devices, accessibility, support tool for teaching and learning, and the contribution of mobile devices to iwispecific language and knowledge.

The development of mobile and wireless technologies has opened up a range of possibilities within the domain of language learning. The multiple features of the iPod Touch $\circledast$ and $\mathrm{PPad} \circledast$ make them an excellent resource for teaching and learning a language because "everything is in one package" (Huhana). The features on the multi-touch portable devices that participants found useful included being able to use the calendar, write notes, set reminders, record video or voice, take photos and play music or videos. The devices can also connect wirelessly (or via mobile network) to the Internet allowing online functions such as emailing or web browsing. Users can also connect to the iTunes Store to buy and download music, videos or apps such as games, books and reference material.

Overall, participants considered the mobile devices easy to operate. The camera was a feature used by numerous interviewees with one stating that it "shows a lot of reo-ā-tinana (body language) that we would normally miss" (Wiremu). This research participant may be implying that during a regular lesson in the classroom a lot of signals given out by students in the form of body language may be missed by the teacher due to the amount of interaction occuring. One participant described the use of the video camera to capture 'snapshots' of learning in the classroom:

Gives life. It gives the actual capturing at the moment, at the time of the reo. Pictures just show something but this actually captures the life at that time and the körero (talk) of the child. It captures the liveliness; the parents can actually put themselves in that. That's my baby talking, living and breathing. (Mead) 
The videos developed for the VUW WPR programme and downloaded to the mobile devices were considered effective because of the visual aspects, specifically being able to see the presenter:

[The videos are] engaging because I can see you. (Waiari)

On the videos, two presenters introduce the topic at the beginning of the video and explain the follow-up activities at the end. By being able to view examples of the topic in the form of sentences on the screen while listening to presenters, participants reported that they could revisit content:

It's repetitive, you can keep listening and confirming things. If you don't know something you can always go back and watch it again. (Mead)

If I'm in the classroom and I know there's something on the iPod® that relates to that l'll go back and look for it. (Wikitoria)

In contrast, another participant noted that in a face-to-face situation all the information must be absorbed "in at once" (Waiari) as there may be no opportunity to follow up on any issues or queries.

In today's environment, the iPod® technology also allows participants to literally carry anywhere a library full of resources such as videos, reference materials and games for learning and teaching the Māori language. As noted earlier and supported by Pasnik (2007), McQuillan (2006) and Abdous et al. (2009), the portability of mobile devices means that learning opportunities can be taken beyond the confines of the traditional classroom or learning environment. The $\mathrm{iPod} \circledast$ is small enough to fit in one's pocket, has an in-built speaker for use without ear phones, and also has ear phones to allow the user to listen privately. The iPad's $\AA$ small size and light weight also make it easier to carry than a laptop. Having the programme material in the form of videos, audio files or as apps on the device meant that participants did not need to carry extra books with them to view the programme content:

Its practicality is that you can put it in your pocket. On my way home from picking up my husband that's as simple as it can be and that's a real advantage for a mum or even a teacher is it's not an extra Reihana book or Bruce Biggs book that you have to carry round. (Waiari)

The portability of the devices enabled participants to take the device home with them to complete work for the programme. Some also took the opportunity to listen or view material during their morning walks or while travelling to and from work:

Having it available at home. We have some kaiako (teachers) on the programme that take it on their morning walks and they listen to the videos, where others will be listening to music on their morning walks. (Mana) 
Having the programme content readily available was seen as giving participants more independence. One research participant would attach the $\mathrm{iPad} \otimes$ to a Smartboard to present PowerPoint slides or videos pertaining to planned WPR lessons. The research participant stated that the use of technology had "enhanced my delivery of Whakapiki" (Te Ahu). Other participants enjoyed the flexibility the mobile device provided as they were able to complete lessons at their own pace or use other features or functions on the device without having to ask others for help. This was particulary appreciated by those who preferred to work independently or those who considered themselves beginners and accessed the content at a time and place where they felt safe:

They're happy to learn off the video in their own time. They feel safe and engage with it as a one-to-one facilitator. (Mana)

It enables me to go home and do the work, even though we shouldn't. You're able to. You're able to do it in your own time, it makes [it] less stressful, [and you] get your work done on time. (Manaaki)

[With the iPod®] you get to go through lessons fast or slow at your own pace. I like the idea of having the information readily available if I wanted to reflect on them or if I hadn't heard something. (Waiari)

I do feel more confident I suppose by having this tool because if I do need support and I don't want to hōhā (annoy) anybody, everyone's busy. I can just come in here [office] or jump in my car and just put it on and just listen. Listen and watch. (Aroha)

It's made me more independent whereas l'd have to, if I didn't have that knowledge myself l'd have to interrupt the kaiako and say excuse me do you know the kupu (word) for....and now I can do that for myself. So that's a little bit of self-motivation for me there. And time wise it's instant and again not having to go to the teacher and wait for her and you know it saves time. (Tumanako)

One participant summed up the advantages of having programme content on the mobile device:

Being able to have a bank of stuff readily available if you wanted it anywhere. I think that's the biggest advantage. It's a bit of a cliché you can do them anywhere. I don't know when l'm going to get that spare half an hour, when I do it's good to be able to whip it out quickly and do it and that's what I like. I don't have to plug in a laptop, charge it, get into my file, wait for the Internet to come on. I can just turn it on and go to it straightaway. (Waiari)

In reminiscing on the beginning of their language journey, one participant recalled carrying notebooks to record phrasing:

Twenty years ago when I started on this language journey we were encouraged to pull out little notebooks and write down phrasing we would hear on marae or at lectures. I was always a little bit uncomfortable about it because I thought that people would be looking at you. It's a bit invasive if you're sitting there writing people's words. I think that the discretion of an iPod® is a great asset. (Te Ahu) 
Mobile devices can incorporate use of various apps such as the Voice Memos function, the Notepad, the Video Camera or the Camera that can be used to record speakers or events in place of a notebook. These can be seen as less invasive as implied by the research participant.

Learning Māori at home through one's own dialect is the most preferred method, but this is not the reality of the majority of participants involved in the WPR programme. A number of participants live outside their tribal areas; they want to improve their proficiency in Māori but cannot or choose not to travel back to their tribal area to learn:

Some of us living in the city can't travel back to our marae...But because l'm here l've got to find other means to sustain my reo and whakapakari taku reo (improve my proficiency). So I find that having these, the iPods $®$ are a great help. In one respect I still have to go back to our papa kāinga (home) and learn our reo. For now and at this time I feel that this is very supportive. (Mead)

It gives you access to kaiako for speakers of the language without necessarily having to be face-to-face. Access to lessons and to be able to listen to the reo without actually having to have those people present. Especially in a kura like this or in this area as well, in this region, it might not be accessible to get the kaiako here and get the speakers here. (Tuia)

The mobile devices used in the VUW WPR programme can provide participants with access to the Māori language experts they seek without having to "travel away from work" (Aroha).

For participants, mobile devices were seen as ubiquitous in enabling them to access their material any time, anywhere, making them a great learning tool. Each participant in the VUW WPR programme receives a mobile device to utilise for the length of the programme along with a workbook and teaching resources. The mobile device is loaded with videos outlining Māori language grammar and approaches to language acquisition which participants can view during the weekly whole group session or independently in their own time. One participant reported that their Māori language development had:

\footnotetext{
...been a positive on-going learning process with whānau and staff. Because we have the same mahi (work) on our iPods $₫$ we are able to communicate about what have you been learning and what didn't you get and our own understanding of what we thought it was but it's not. (Aroha)
}

The regional coordinators used the mobile devices (attached to a smartboard or projector) to display the video rather than presenting the language topic verbally during whole group meetings. One participant reported: 
It's easier...you have the lesson there and you just facilitate discussion and further explanation. It's different media as well, it's engaging watching. (Mana)

Apart from discussing the video content during the whole staff meetings, this session also provided opportunity for the regional coordinator to share ways participants could use different features on the mobile devices. This included how to download and install apps for the participants' own language development or for use in the classroom. These sessions were considered very helpful and served as a refresher of "how to do things, how to find things that they've already done and can't find" (Mana).

Overall, the participants expressed a favourable attitude towards the use of videos to increase Māori language proficiency, particularly as an example and model of quality language:

With a video you're getting a quality of reo that might not be always there face-to-face. So it acts as a supplement, where you're able to correct as you go. The videos are fairly clear about the structure, about the grammar. Teachers I know say I don't say that and we'll say okay, what do you say and how can we deconstruct it that way? (Puāwai)

Three participants reported that the video and audio content accessible via the mobile device promoted a wairua (spiritual) feeling, particularly if they knew the person on the video or if they could relate to the concept being spoken of:

It does bring wairua into the class...the wairua that comes out from a song or of people you know. (Tapiata)

I wouldn't say wairua as such, as being physically there. But you do get a wairua feeling especially when it's someone you know or if you can relate to the concept. This [iPod®] is the next best thing to having ā-wairua though. (Mead)

Knowing who is the kaikōrero (speaker) too helps and what they bring about the kāinga. I can engage in the person and the person I know and the values that the kaumātua (elderly men) and kuia (elderly women) give us from the kāinga. (Kaitiaki)

The grammatical rules and sentences explained in the videos provided the participants with structure they could use and reflect on not only with their own language use but also teaching the language to the students:

I watch whatever our kaupapa is for the day. I would have a look and see okay what part of this can I use to help myself and to implement back in the classroom. (Aroha)

Participants disclosed various ways they used the mobile device and its features as a tool for teaching and learning language. One example included recording 
language spoken by participants and students for oral assessments and running records. Participants were encouraged to record themselves speaking in Māori with the Voice Memos function on the mobile device as a way of evaluating their language. One participant said despite not wanting to listen to her own voice, she agreed that having a record of her oral language was good. "It was good to see how we're talking and how you could better yourself" (Manaaki). The Voice Memos function was also used by another participant to record their new entrant pupils speaking Māori. The participant would then "go back and listen to them especially to put into the portfolios of a verbal conversation with a child and on their selfreporting" (Mead). The audio recordings would also be shared with parents: "Mothers sometimes come in the classroom and I can play this back. So it's good for sharing things with parents" (Mead).

Other examples comprised taking photos with the device in the classroom as evidence and documentation of learning and downloading apps from the iTunes store for teacher and student use in the classroom:

I use it [the iPod Touch $囚$ ] to bring it into the classroom more as a tool for the kids like finding Māori language resources and the applications and trying them out in the class. An iPod®, great for one-to-one, but you can't really use it for more than one. I see it as a tool for individualised learning or a follow-up activity for when they've finished their work because they're really into it. (Tuia)

I get online and use the dictionary. If we're looking for a word bracelet l'll put that in there and get the right word for the children to use in their sentence structures. It seems to be working and they know that I'm going to do it. (Tumanako)

The videos were developed for the VUW WPR programme with its focus on general grammatical rules for the Mãori language rather than for a specific dialect or dialects. Is this the role of the VUW WPR programme? Should the VUW WPR programme have content that covers specific dialects and iwi? The majority of the participants interviewed in this research agreed to the idea of having videos that showcase different dialects. One participant explained that this makes learning:

More personalised. It brings about a lot more awareness of those differences because it's not just one language, not just one way of using it. (Tumanako)

Iwi-specific language videos were thought to be able to "play a substantial part in whānau and hapū development in terms of the language" (Te Ahu). The Video Camera or Voice Memos function on the mobile devices could be used to record local elders speaking in and about the language, for instance "mōteatea (lament), 
idioms and formulaic expressions" (Te Ahu). Recording local elders or native speakers was considered important because:

They've got their own mita (accent), they've got their own kupu. If you could have them at your fingertips just to listen to it would be invaluable. (Wikitoria)

The recordings could then be collated for "schools to build up their own resource banks and use it to convey an idea to someone from another iwi or rohe for their own development" (Mana). The idea of having recordings to inform tribal or dialectal differences was also supported:

You could probably do the lessons in different dialects [and] if you have different tikanga. That would be a good step especially in wharekura...[if] your kids don't know about it you'd be able to access lessons and say this is how they do it in Tainui, that would be helpful. (Waiari)

Mobile devices can be used to capture iwi-specific language and knowledge and make a valuable contribution to those involved in the VUW WPR programme. Whether the resources are videos or audio recordings developed by the VUW team or alongside the participants, the majority of the research participants agreed that:

Everyone's got their own ways of saying things in different dialects, in different iwi, it is important. (Mead)

\title{
The Challenges Presented by Mobile Device Use to Attain Māori Language Proficiency
}

Teachers are busy professionals with high demands and heavy workloads placed on them. The following participants reflected on this sentiment of workload and the lack of time available to fulfil the WPR programme requirements:

\author{
It's just another thing that I need to do. (Huhana) \\ It's just finding time really. (Wikitoria) \\ Some of them look at it as just being extra work and we try not to make it like \\ that. (Te Ahu)
}

The final comment above relates to the position of the VUW WPR model as a school-based programme. The model was designed to provide a high quality programme which participants were supported to implement in their classroom on a regular basis. The goal here was to ensure as limited amount of extra work as possible added to the participants' busy schedules. 
Other participants commented about the lack of time they had available to fulfil programme requirements. Nevertheless, they felt a personal responsibility to manage their time better:

I don't use it everyday just because I run out of time. l'd like to be able to use it more often. I would probably need to plan myself a bit better. It is a personal goal for me to improve my reo because of my mokopuna (grandchildren) especially for them and for myself. So in order for me to do that I need to put things in place to make sure if I have this tool [the iPod®] to pay more attention to it. (Aroha)

I think just being so busy, I suppose that will call for management of time to be able to schedule in the iPod®. (Tapiata)

Alongside the theme of attitudes towards workload is the attitude towards technology, including getting the user's buy-in, learning how to use technology, and keeping up to date:

You can take a horse to water but you can't force him to drink. (Tumanako)

In other cases age was reported as a factor, for example reluctance of some of the older participants who were:

...a bit anxious about using the technology. I could give a couple of examples of the older ones that haven't used it [or] don't really use it at all in comparison to say the majority, especially the younger ones who catch on to those things a lot quicker [and] tend to thrive. (Te Ahu)

Being a whole-school model "you are always going to have some reluctance" (Korimako) and one way of dealing with this is "reassuring them it's okay, it's all good, you don't have to be an expert straightaway. It's just there to help you" (Mana). Once successful utilisation and integration of technological tools has been achieved, the next challenge is "keeping up to date...with all the new technology" (Te Ahu). Participants reported the need to keep up to date with technology for the benefit of the students and the world in which we live:

It's keeping up with the technology. I think that the onus is on me to do that because l've got all these young people growing up with it, they're only five years old but jeepers they know everything. Just give them the phone and away they'll go. They'll do everything except ring. And l'm happy for that to happen. So we have to move towards that and I think technology is the world we live in. You know it's the way we're going to communicate, mass communication, social networking. [If I] don't know how that works then my senior students are at a disadvantage. (Puāwai)

The notion of accessibility is tied not only to the advantages of mobile devices used to attain Māori language proficiency but also the challenges presented by the use of 
mobile devices. Access to training in how to utilise the mobile devices was a challenge shared by participants:

...navigating our way around it, just getting to know it. When it gets flat, where do you turn it on? That type of stuff. Orientating yourself around it and going through the different programmes that are already installed on your iPod® and checking through. (Mead)

Not knowing. Just being given the iPod® and no instructions. I'm a person that likes to have a look at instructions before I touch it. If I don't have it [instructions] then I very rarely play with it. (Kaitiaki)

Possibly being given more support in terms of how to use it [the iPod®]. (Tuia)

I'm not scared of the new technology it's just that if I don't know how [to use it] I get frustrated and then l'll just give up. (Karaka)

Participants also commented on needs for ongoing training in "how to use the $\operatorname{iPod} \circledast$ more effectively" (Wiremu) in order to "...make the most of it both for myself and in the classroom" (Waiari). They were also aware that the devices had features and functions that were not used and requested opportunities to explore those capabilities.

The small size of the device was a hindrance for one of the participants who "has got arthritic hands, so holding it can be a bit of a problem" (Te Ahu). For other participants, the small screen size limited their use of the device:

The iPod's $®$ far too small for me as far as screen size and reading [is concerned] because I wear glasses. Using the iPod® I've tried it a few times but I don't know whether it's my nails or what but I can't seem to manage it. This I can, the iPad® I can. (Korimako)

I find now though that I tend to like watching stuff I prefer it on a big screen. The Whakapiki stuff is fine because it's short but watching long Waka Huia programmes l'd probably just go into my rorohiko (computer) and watch it. (Tuia)

I'll be honest about it I had bought another MP3, because I know an MP3 for recording. I've used it on the marae when I go in to record some of the speakers and to me that was much easier for me to use for recording purposes out there. But the iPod® [is] too big at the moment for my pocket to carry onto the marae. (Wiremu)

The mobile devices used in the VUW WPR programme include Apple's iPod Touch $\AA$ and $\mathrm{iPad} \circledast$. These devices work best with Apple products although they still function with other technological devices commonly found in schools. The compatibility of the mobile device with other technological tools found in school was a challenge:

[It will] be good once they [iPads $®$ ] can marry with the boards [smartboards]. (Mana) 
Access to appropriate resources was also a challenge for participants:

We want to hook it up to the computers. We can hook it up to a projector but we have to bring our own personal laptops to school and hook it up to be able to project it so that our kids can watch all at once instead of your turn, your turn. It would be better if we all watched it at once and if they have any questions we could answer them all at once instead of answering that same question twenty times. (Manaaki)

The limited number of devices was a common challenge for participants, who were proactive in finding ways to use their device in the classroom with the students. Access to "a whole class [set] of iPods $®$ " (Mead) was a common request:

I haven't got enough, l've got twenty new entrants and one iPad®, it's not going to work. We need more. (Korimako)

A lack of interaction with the videos was also a challenge for participants. The videos used in the VUW WPR programme are presented by two programme facilitators seen by viewers. However, for the most part, participants see text written on a black page narrated by the facilitators. One participant described the videos as a "very flash textbook, all your material is there but you still need to have those interactions" (Korimako).

What you hear is what you get so if there's any ambiguity in there, there's no place to fix it up. I suppose it's all one way. (Wikitoria)

This one way learning may also "lead to questions that create roadblocks for kids [that] can't move on until you've answered that question" (Waiari). The VUW WPR programme has a number of face-to-face meetings facilitated by the regional coordinator or in-school facilitator in order to overcome this challenge:

If they're on the video [you] are unable to have the opportunity for feedback, to answer questions, so I take that sort of job. (Te Ahu)

For some participants there was "just no connection" (Kaitiaki) with the videos; however, this same participant admitted that you could get a wairua feeling from a song or a person you knew on the video. There were "not enough samples for wete reo", and "more iwi-related" (Wiremu) samples of language were requested:

The Waka Huia I never really listened. I wasn't really interested in listening to somebody else's iwi. If it had been my own, or locally an iwi that l'm familiar with, then I would have watched the whole thing [video]. So I wasn't keen on it. (Wiremu)

I suppose because it's been not of the kāinga, of the iwi. And I really want to listen to the reo of the kāinga. If you put somebody we know from home [I] would be more interested. (Kaitiaki) 
The focus for the videos is general grammatical rules of the Māori language rather than a specific dialect, as noted earlier. According to one participant:

In many ways it's been a stumbling block in Whakapiki, the generic spell that's presented when some of the more staunch members are that's not [how we say it]. But you know that's always going to happen isn't it? If the generic could be partnered alongside the local maybe. (Korimako)

\section{The Opportunities Presented by Face-to-face Instruction to Attain Māori Language Proficiency}

Although content for the VUW WPR programme was loaded on to the mobile devices, participants still had opportunities for interaction and discussion during whole group and one-to-one sessions. Therefore, the comments within this section are a culmination from the VUW WPR participants and the WPR comparison group participants.

Face-to-face instruction presented a number of advantages for participants to increase their Mãori language proficiency, for instance the physical presence of the regional coordinators and in-school facilitators who created a supportive environment and included opportunities for discussion, to give feedback, and to share ideas.

Within the VUW WPR programme, the in-school facilitators are usually staff members within the school selected to be advocates for participants as well as the regional coordinator who facilitates the programme. The role of the in-school facilitator is appreciated by participants who say that "[the in-school facilitator] has lessened our workload and in terms of that we can just focus on what we've come in to do as opposed to how we're going to make it happen. She's taking care of that" (Huhana).

The regional coordinator is also usually from the location of the schools they are working with. Some participants commented that having someone:

[they are] already familiar with [makes them] feel a bit safer and you probably give a little more. (Tumanako)

For those who are unfamiliar with the regional coordinator, face-to-face interactions can help both parties: 
Good relationships between participants and programme facilitators are pertinent to the success of all parties involved:

You need to build a good relationship as regional coordinator with your participants. If they believe in you and trust you then they'll listen to what you've got to say. That takes time to build so it's really important to build that initially. (Mana)

Participants valued the knowledge, understanding, and proficiency in the Māori language that regional coordinators had. In one case, the regional coordinators were of the older generation and were treasured not only for their knowledge of the language but also for words of old they would use:

Koirā te painga o te mahi Whakapiki i te Reo, i roto i ngā kura. Ka kuhu mai ngā kuia rā. Ko te rongo i ngā kupu tawhito kei a rātou.

That indeed is one of the advantages of Whakapiki $i$ te Reo, that it is inschool. The regional coordinators come to us. We are able to hear the words of old that they use. (Amokura)

Their physical presence in the schools also (unintentionally) changed the behaviours of students due to the high regard assigned to them:

When they come in the children are different because they have that elder respect as opposed to a younger teacher. Ko a tātou tamariki o te kāinga (our children from home here), they know, they have another personality when it comes to their elders. And it was beautiful to see the respect that we thought was learnt was dying. (Amokura)

The importance of the high level of proficiency held by the regional coordinator was also reinforced:

The proficiency of the regional facilitator has been a great example of where you can be because he himself is a second language learner. So you know one day you could hopefully be up there. And just in the sense that he knows situations that we all are in and even though we're all different he's been there at some stage. So he's able to empathise with us as participants, help us to engage with him and he's pretty knowledgeable. At the same time he's also able to say oh I don't know. Nothing worse than somebody telling you some lies or making it up on the spot. So the humbleness that he has helps us to feel confident and safe in our environment that we're in. (Waiari)

Both the in-school facilitator and the regional coordinator are on site weekly or daily (in some schools the regional coordinator has an office on site) to assist participants or facilitate either in-class, one-to-one or group sessions. Participants valued having the regional coordinator on site:

Face-to-face is really, really important. You've got someone to come to and ask questions and have a chance to kōrero with. Having that weekly contact and face-to-face contact if we didn't have that with [the regional coordinator] I couldn't see the programme staying on. (Tuia) 
Regional coordinators not only facilitate regular face-to-face sessions but also make themselves available to attend other meetings held in the school. They provide support and encouragement to participants, including meeting specific learning needs identified by participants:

Our staff certainly value that sort of presence. (Korimako)

They would come with their resources and would have a chance to speak with the $R C$ and say what we don't want and what we want, can we look at this. Then if $x x x$ hasn't got it, $x x x$ will call $x x x$ and see if they have any and if they are free to come then we'll organise a PD day with other kura to make it worthwhile them coming down. (Ngarongo)

Face-to-face was still seen by participants as most important:

[It is] the number one way to teach, ā-tinana (in person). It allows that person to be there instantly for you. It's instant feedback, it's quick. It's just that presence. (Mead)

Physical presence creates a whole different dynamic in the room. (Karaka)

As noted above, the role of the regional coordinator is to facilitate face-to-face sessions with participants comprising in-class, one-to-one or whole group. The inclass sessions allowed regional coordinators opportunities to role model new ideas, strategies, techniques, and lesson planning for teaching and learning Māori. These were well received by participants:

It has been the classroom support that has actually helped me. (Wiremu)

Ko te mea miharo ki au, ko te kuhu mai a xxx ki te role model.

The thing I like best is when xxx comes in to role model. (Te Ataakura)

Conversely, another participant spoke of the in-class role modelling and despite the fact that it demonstrated "new ways of teaching...You always revert back to your own style" (Ngarongo).

Having the regional coordinator in the classroom meant having "that person there to support and correct instantly" (Tumanako) and opportunities "to pose questions...about classroom delivery" (Wiremu). Participants could put new learning:

...into practice straightaway and then you know whether it's working or not for you after you've done it for a whole week. But you change it to suit you as the kaiako. (Ngarongo)

Whole group sessions were also regularly facilitated by regional coordinators and provided a pathway to success for many participants. Participant comments 
highlighted positive, supportive environments created by the whole group sessions, where participants were able to draw upon one another's strengths to help each other:

It's great because we have one another to glean off, having been part of the whole Whakapiki i te Reo group. So it has been a good impact for me. (Aroha)

You've got other people to go to and they're in the same boat. The pool of teachers that are in the group aren't all at the same level; we're all sort of sprout off here and there for different things, so you're able to draw on your strengths for each other at different times if you need to. Yeah I think it's more so you're not in isolation, that's the biggest thing unless you want to be. (Waiari)

We're all at different levels but we're all in the same boat, we're all in it for the same reason. And that's uplifting. We can bounce things off each other and we often do. We will go to our one-to-one sessions and we'll come out and then we'll talk to each other about you know what it involved for them and what it involved for me and where they went next and sort of gives you ideas yourself about where to from here. (Tumanako)

They're able to support each other across all levels. (Te Ahu)

The whole group situation was also likened to "the second teacher in the room when the teacher's not there because you're all teachers and you're all able to ask each other the answers to different things" (Waiari).

Opportunities to practise language in the whole group sessions with other learners were also an advantage. In some cases this included engaging with teachers involved in WPR from various schools at sessions held during the holidays. Learners are able to work in pairs, small group, or whole group situations. The weekly whole group sessions were viewed as having impacted positively on participants, by making them aware of the language being used by them and their students. This in turn enables them to identify any language errors and gaps in spoken and written language. The identified errors can then be addressed individually and deliberately in order to be corrected:

I really look forward to our Thursdays and l've just gained so much from it, especially my own errors and errors that I hear from the children and ways of how I can fix it and how I can develop te reo. It's been valuable with [the regional coordinator] on Thursdays. (Wikitoria)

Through a lot of Whakapiki classes on a Thursday, we get together and discuss some language errors that we hear in our children but it's also that we hear in ourselves. So it's been really good and when I hear errors in my own children then I'll make a concerted effort to fix it up in the classroom too. (Wikitoria)

You become more aware of what you're saying and l've certainly seen that in myself. It's like someone telling you you've got something on your top lip. And across our whānau it's very much that case. Our learning is a lot more explicit now, we talk about what we are learning, we talk about the way we learn...So it has made an impact. I've noticed also in perhaps our more reluctant users of te reo that there's an increase. (Korimako) 
The WPR programme aims to support the regeneration of tikanga, mātauranga and te reo Māori by consulting and working with kura, whānau, hapū and iwi. How this aim is met varies across the regions involved in WPR. One participant spoke of the benefits of having regional coordinators, who were elders from the area, working alongside whānau, staff, and students:

Ko te āta kite i ngā whānau i te kura katoa, me ngā tamariki, me ngā tokorua, o rātou kuia e mahi tahi ana. Koirā te mea, ko te mahi tahi a ō tātou kuia o te kāinga. Te kuhu mai ki roto i te kura.

To see the families at school, the children and the two elder ladies working together is fantastic. That is an advantage, working alongside two of our elders. (Amokura)

Face-to-face instruction also provided space and opportunties to discuss and debate language, to share ideas with others and, more importantly, to get immediate feedback. Face-to-face instruction can also be "spontaneous and it can change as you go so it can follow the direction in terms of what comes up for either the kaiako or the student. So it's responsive to what is said in the course of the lesson and all the conversation" (Tuia).

Having a group of people involved in the same programme means participants are able to have conversations about learning with each other, for example when monitoring students' Māori language progress: "If the whole school's doing it you can actually get a bigger picture as they move up the different levels" (Te Ahu).

Conversations can also be had about the teaching and learning taking place in the classroom:

So if they're doing that in their class and you're in a senior class well you're doing the wrong thing. (Manaaki)

\section{The Challenges Presented by Face-to-face Instruction to Attain Māori Language Proficiency}

A variety of disadvantages and challenges of face-to-face instruction were reported by participants. These included the need for school leader and participant buy-in for programme success. The relationship between the regional coordinator, the school, and the participants was also seen to be an important aspect to programme success. One participant recalled the challenge of having to maintain a balance between the school routine and the WPR programme and making it clear to the "RCs too or they'll take over the whole day with Whakapiki i te Reo" (Amokura). 
Availability of the regional coordinator was also a challenge for another participant who would make contact via email rather than any other means due to timing issues and the busy schedule of the regional coordinator.

In regards to learning face-to-face, some participants prefer to learn "in their own time when they're in their own safe environment" (Mana). Mobile devices loaded with programme content are tools that can allow participants to access their learning at a time that is convenient for them and at a place they prefer.

Sessions that are facilitated face-to-face can also be limiting in regards to the opportunities the learners have to gain an understanding or to ask for clarification: "In lectures you could listen to a kaumātua and you could really engage with them, but you won't get all the kōrero" (Kaitiaki).

In a group situation, one might have "to wait for the group if you want to wait or they may move too fast for you" (Waiari).

\section{The Opportunities Presented by a Blended Approach to Attain Māori Language Proficiency}

The VUW WPR programme utilises both face-to-face facilitation and mobile devices to deliver content, a model regarded by most participants as having "merits for both" (Puāwai):

We're lucky because we have both. We have the video, we have the learning on there and then we have the teacher who teaches to that video and so we're in a win-win there. (Huhana)

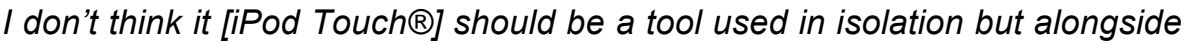
face-to-face instruction. It is really good to have that structured lesson laid down that you can revisit. But then it's also good to have face-to-face because then it can be more tailored to your needs and you're getting the students to speak as well. (Tuia)

I think it's an effective way of teaching because you get the information delivered to the participants and they still have the opportunity for kōrero and questioning afterwards. (Te Ahu) 
Regional coordinators encourage participants to view the videos before attending the whole group session and the one-to-one session "so that they can come to the lecture and have some questions already sorted" (Te Ahu). This strategy was appreciated by one participant who felt that it made learning more effective:

The pro is that the $R C$ reinforces what you were supposed to have done prior to coming to the meeting on the Monday. (Huhana)

In general there was support for a blended approach to attain proficiency in the Māori language. The use of face-to-face facilitation and mobile devices:

...complement each other because the video is actually the spark for the discussion and the interaction. (Korimako)

\section{Chapter Summary}

The mobile devices used in the VUW WPR programme presented numerous advantages for participants to improve their Māori language proficiency even though slightly fewer than half of the participants were initially anxious and questioned how this model would work or how it would be effective. Using the devices in Māori medium educational settings provided a pathway to be leaders in education within New Zealand rather than continuing to follow in the footsteps of mainstream educational settings. Exploiting technology in the classroom also enabled participants to cater for students' needs and engage their interest in learning because of their familiarity with technology. The tool's light weight, portability and multi-functionality empowered users with the flexibility to learn at a time, place, and pace that was convenient for them. The capacity to have resources, functions to capture and document moments and Internet connectivity all in one tool and at the touch of a button was of particular significance. The videos that focused on aspects of Māori language developed for the VUW WPR programme gave participants access to Māori speakers that they may not otherwise have had, alongside a quality of language proficiency they also sought. The videos were also engaging and informed participants of grammatical structure and rules about the language. There was no need to carry any books about language learning or any other tool to capture or document snapshots of teaching or learning. The mobile device could also contribute to capturing and presenting iwi-specific language and knowledge valuable for all learners to understand the richness and the differences between iwi throughout New Zealand.

The challenges that related to mobile device use were finding time to maximise the tool; however, some participants also felt a personal responsibility to manage their own time better. This challenge was also taken on-board by the VUW WPR team 
who endeavoured to limit extra workload by supporting participants to implement learning in classroom practice on a regular basis. A lack of training to operate the device was also experienced by some participants as well as on-going support to maximise its full potential. Although the size of the device made it portable, the small screen was a hindrance for some. Additional challenges included compatibility with other technologies participants used as well as limited devices for students. The videos was also seen as one-way learning with a lack of spiritual connection and no opportunities for discussion about content potentially causing road blocks for learners who needed extra support. Finally, the generic nature of the language videos were also a disadvantage outlined by participants who suggested more iwispecific resources as well as an increase of sentence samples within each video. Although the generic nature of the VUW WPR programme was described as a weakness, the support for iwi-specific resources was actually an advantage with potential to enhance learning experiences for all users.

Face-to-face instruction was still considered most important for participants, and was also how the majority first learned Māori. The physical presence of the regional coordinator was valued alongside their knowledge and proficiency in the language. Having the regional coordinator on site also provided space to create an environment that was safe for learning, gave immediate feedback, and provided opportunities for interaction, discussion, and role modelling. The in-school facilitator role supported the regional coordinator and participants, decreasing the workload for both parties. The whole group sessions created a community that was able to have learning conversations about language as well as teaching and learning practice because they were all involved in the same programme.

The challenges of face-to-face instruction, according to the participants, were school leader and participant buy-in to the programme as well as the availability of the regional coordinator and how they maintained the time allocated to the PLD programme. The group situation proved ineffective for participants who preferred to learn in their own time or when they were in a safe environment. Moreover, face-toface instruction could also be limiting in the opportunities for the learners to gain understanding or to ask for clarification, and the group may have progressed too quickly or slowly for the learners.

Finally, there were participants who supported both face-to-face instruction and the use of mobile devices. One participant described how the language videos could be viewed before the whole group face-to-face sessions. Participants were encouraged to 
undertake this by regional coordinators, as they would also be the spark for the discussion and the experiences had during the whole group sessions. Furthermore, the language videos could be revisited anywhere and at any time and the face-to-face session could be tailored to meet participant needs and allow opportunities for language output. 


\section{Chapter Five \\ Research Findings - Questionnaire}

\section{Introduction}

An online questionnaire was administered to participants involved in the VUW WPR programme to gather responses from a wider audience in different geographical locations. This section outlines the responses from 29 of the 36 participants (a response rate of $80 \%$ ) who consented to complete the online questionnaire.

To reiterate, this research set out to examine the challenges and opportunities for using mobile devices to attain proficiency in te reo Māori. It also sought to ascertain if learners make expected gains in language proficiency through the use of mobile devices as opposed to standard face-to-face methods of language instruction and, if there are differences, which of these can be associated with mobile device use by exploring the participants' experiences within the WPR programme.

In order to gain an understanding of the research participants' backgrounds, their history of Māori language learning is outlined including their reason for undertaking the programme, methods used, and places where they previously learned Māori. Their history with technology and expertise in operating mobile devices is also described followed by an exploration of the results gathered from the questionnaire.

\section{VUW WPR Group}

\section{Māori Language Background}

The reasons why participants took part in the programme were to improve their proficiency in te reo Māori, including their fluency, their knowledge of correct grammar and ability to converse in Māori as well as their classroom delivery of te reo Māori. However, four participants noted their reason as a whole-school initiative rather than as an individual choice, which may have impacted on their engagement in the programme. Three other participants were part of the WPR or school support team and were involved to provide assistance to the students and teachers at the schools in which they worked.

Participants were asked to explain their history of learning Māori in order to understand their background. Learning through educational settings that included 
school, polytechnic, university or Te Ataarangi was the main pathway taken to learn Māori by the majority of the participants. The remaining participants grew up learning Māori and heard Māori being spoken at home, at grandparents' homes or within their daily environment. Hearing Māori being spoken all around by native or fluent speakers and speaking Māori with parents and grandparents were the main methods used to learn te reo Māori by these participants. One participant said Māori "was the only language spoken in my home since the day I was born" (Hirini).

For those who learned at school or university, teacher directed learning and learning through books such as the Te Whanake series by John Moorfield was common. One participant recalled their experience being taught Māori as "boring high school delivery" (Te Rangimārie). Perhaps this participant was referring to the type of delivery where the teacher stands at the front of the class and talks for the entire time or where participants complete activities from a book and have limited interaction or opportunities for discussion with the teacher or fellow peers.

When asked to identify the most effective method for learning te reo Māori, listening to and speaking with others such as native speakers and grandparents was preferred. Included in this was also being brought up with Māori language, which is believed to be the best and most effective method for learning one's mother tongue (Te Paepae Motuhake, 2011). Learning face-to-face or in a classroom setting was the next favoured choice and includes the Te Ataarangi method, the use of books that teach te reo Māori and learning grammatical rules. Participants also thought that using a "hands-on approach with authentic experiences to make meaning of the concepts" (Whetū) and "being corrected in a safe environment" (Te Oranga) were beneficial when learning Māori.

\section{Technology Use and Expertise}

Participants were asked to rate their expertise in utilising specific technologies to explain their history of, and attitude to technology. The Internet was the most highly rated technology with participants measuring themselves as having 'very good' capability, followed closely by the video player, the DVD player, and the computer. Participants then measured themselves as 'good' at using the iPod Touch $₫ / M P 3$ player and a handheld computer or a PDA. The iPad® (separate from the VUW devices), iPhone ${ }^{\circledR}$, digital camera, GPS and LCD were other technologies participants acknowledged that they used. 
The remaining questions pertain specifically to iPods $₫$ and $i P a d s ®$. For the purposes of WPR, 23 participants had an iPod Touch $®$, one person only an $\mathrm{iPad} \circledast$ (their personal device) and five both an iPod Touch $®$ and iPad®. The majority of participants said they used their device either once a week, 2-3 times a week, or on a daily basis. Three people used their device 2-3 times a month, another two once a month, and one person said they have never used their device. Interestingly, this participant was involved in the programme because it was a whole-school initiative rather than an individual choice, which may explain the lack of engagement with the device and the PLD. When asked to explain reasons for their lack of use, limited time was the main reason and another had their own iPhone ${ }^{\circledR}$ (which they could use with the programme) and did not want to be responsible for an iPod Touch $®$ as well.

Participants were asked to rate their ability to utilise various components of the mobile device they used. Tables 5.1, 5.2 and 5.3 record participants' answers beginning with those who only used the iPod Touch $®$ followed by those who used the $\mathrm{iPod} \operatorname{Touch} \AA$ and the $\mathrm{iPad} \otimes$ and then the one participant who only used the $\mathrm{iPad} \circledast$.

Table 5.1: Participants' Expertise to Utilise the iPod Touch ${ }^{\circledR}$

\begin{tabular}{|c|c|c|c|c|c|c|c|c|}
\hline \# & Question & 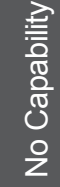 & 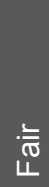 & $\begin{array}{l}\text { ㅇ } \\
80 \\
0\end{array}$ & $\begin{array}{l}\overline{8} \\
8 \\
0 \\
\mathbb{0} \\
\mathbb{1} \\
>\end{array}$ & 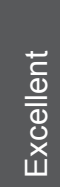 & 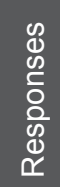 & $\stackrel{\frac{\Gamma}{\mathbb{D}}}{\stackrel{\mathbb{D}}{\Sigma}}$ \\
\hline 1 & Turn on the iPod Touch $®$ & 0 & 0 & 3 & 3 & 17 & 23 & 4.61 \\
\hline 2 & Charge the iPod Touch $®$ & 0 & 0 & 3 & 2 & 18 & 23 & 4.65 \\
\hline 3 & Attach the iPod Touch $®$ to the computer & 0 & 1 & 4 & 2 & 16 & 23 & 4.43 \\
\hline 4 & Locate the Music folder & 1 & 0 & 4 & 1 & 17 & 23 & 4.43 \\
\hline 5 & Listen to music files & 1 & 0 & 4 & 2 & 16 & 23 & 4.39 \\
\hline 6 & Turn the volume up and down & 0 & 0 & 3 & 3 & 17 & 23 & 4.61 \\
\hline 7 & Scroll up and down the files to select a song & 1 & 0 & 3 & 2 & 17 & 23 & 4.48 \\
\hline 8 & Locate the Movies folder & 1 & 1 & 4 & 2 & 15 & 23 & 4.26 \\
\hline 9 & View the Wete reo or Hopu reo videos & 0 & 0 & 3 & 1 & 19 & 23 & 4.70 \\
\hline 10 & Fast-forward or rewind the videos & 0 & 0 & 4 & 2 & 17 & 23 & 4.57 \\
\hline 11 & Locate the Voice Memos function & 0 & 1 & 3 & 2 & 17 & 23 & 4.52 \\
\hline 12 & Record audio using the Voice Memos function & 0 & 2 & 2 & 3 & 16 & 23 & 4.43 \\
\hline 13 & Label audio recordings & 2 & 3 & 6 & 2 & 10 & 23 & 3.65 \\
\hline 14 & Retrieve past audio recordings in Voice Memos & 0 & 3 & 4 & 3 & 13 & 23 & 4.13 \\
\hline 15 & Copy audio recordings to a computer & 3 & 5 & 6 & 2 & 7 & 23 & 3.22 \\
\hline 16 & $\begin{array}{l}\text { Synchronise or copy files from a computer to } \\
\text { your iPod Touch } \circledast\end{array}$ & 4 & 6 & 5 & 1 & 7 & 23 & 3.04 \\
\hline 17 & Turn on Wi-Fi to connect to the Internet & 7 & 3 & 3 & 1 & 9 & 23 & 3.09 \\
\hline 18 & Access the Internet via Safari & 8 & 3 & 2 & 0 & 10 & 23 & 3.04 \\
\hline 19 & Browse the Internet using Safari & 8 & 2 & 3 & 0 & 10 & 23 & 3.09 \\
\hline 20 & Upload applications from iTunes & 4 & 4 & 5 & 2 & 8 & 23 & 3.26 \\
\hline 21 & Other (please elaborate) & 16 & 2 & 2 & 0 & 3 & 23 & 1.78 \\
\hline
\end{tabular}


Overall, the 23 participants rated themselves as having good expertise in all of the iPod Touch $\circledast$ components. Viewing the wete reo and hopu reo videos was the component marked as easiest for the participants. The videos should be viewed on a regular basis as part of the WPR programme, and everyone knew how to use this function as is indicated in the results (number 9 in Table 5.1 above).

The other functions where the participants scored a mean of 4 or higher (numbers 1-12, and 14) allow the successful use of the iPod Touch $\circledast$ for the purposes of the programme. These include being able to turn on the iPod Touch $®$, charge it, locate and view music files and videos, fast-forward and rewind these, and turn the volume up and down. Being able to locate and use the Voice Memos function is another basic component participants know how to use as is retrieving past recordings.

The components numbered 15-20 enable the participants to take advantage of the other applications the iPod Touch $®$ offers. In general, the participants rated themselves as having good ability in operating these aspects as well as number 13 Label Audio Recordings. These components enable freedom of access to browse the Internet by connecting via $\mathrm{Wi}-\mathrm{Fi}$ and uploading apps from the iTunes store. A challenge noted by participants related to Internet connection and hardware compatibility. In one school there was no wireless access to the Internet, and in another access to the Internet via the mobile device was not encouraged by management but by the desktop and laptop computers instead. There was also a conflict of compatibility with the Apple hardware used in the VUW WPR programme and the hardware used in the school. Some participants thought that this affected their ability to add content from their computers to the iPod Touch ${ }^{\circledR}$ that was preloaded with content from an Apple computer.

Participants reported that they were also able to label their own audio recordings from the Voice Memos function, copy these recordings to the computer, and synchronise files from the computer to the iPod Touch $\circledast$.

An opportunity to provide detail of other ways the mobile device is utilised was given to participants who noted that they type lyrics on to the iPod Touch ${ }^{\circ}$, download music, upload photos, send and receive emails, and text on their mobile device. 
Table 5.2: Participants' Expertise to Utilise the iPod Touch $®$ and $\mathrm{iPad} \circledast$

\begin{tabular}{|c|c|c|c|c|c|c|c|c|}
\hline \# & Question & 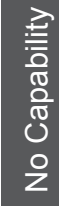 & $\begin{array}{l}\text { 产 } \\
\stackrel{5}{\leftarrow}\end{array}$ & $\begin{array}{l}8 \\
8 \\
0\end{array}$ & $\begin{array}{l}\text { ㅇ } \\
8 \\
0 \\
\mathbb{0} \\
\end{array}$ & 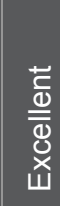 & 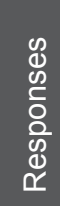 & 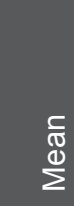 \\
\hline 1 & Turn on the mobile device & 0 & 0 & 1 & 1 & 3 & 5 & 4.40 \\
\hline 2 & Charge the mobile device & 0 & 0 & 1 & 1 & 3 & 5 & 4.40 \\
\hline 3 & Attach the mobile device to the computer & 0 & 0 & 1 & 1 & 3 & 5 & 4.40 \\
\hline 4 & Locate the Music folder & 0 & 0 & 1 & 1 & 3 & 5 & 4.40 \\
\hline 5 & Listen to music files & 0 & 0 & 1 & 1 & 3 & 5 & 4.40 \\
\hline 6 & Turn the volume up and down & 0 & 0 & 1 & 1 & 3 & 5 & 4.40 \\
\hline 7 & Scroll up and down the files to select a song & 0 & 0 & 1 & 1 & 3 & 5 & 4.40 \\
\hline 8 & Locate the Movies folder & 0 & 0 & 1 & 1 & 3 & 5 & 4.40 \\
\hline 9 & View the Wete reo or Hopu reo videos & 0 & 0 & 1 & 1 & 3 & 5 & 4.40 \\
\hline 10 & Fast forward or rewind the videos & 0 & 0 & 1 & 2 & 2 & 5 & 4.20 \\
\hline 11 & Locate the Voice Memos function (iPod Touch $®$ ) & 0 & 0 & 1 & 1 & 3 & 5 & 4.40 \\
\hline 12 & $\begin{array}{l}\text { Record audio using the Voice Memos function (iPod } \\
\text { Touch } \circledast \text { ) }\end{array}$ & 0 & 0 & 1 & 1 & 3 & 5 & 4.40 \\
\hline 13 & Label audio recordings (iPod Touch $®)$ & 0 & 2 & 1 & 0 & 2 & 5 & 3.40 \\
\hline 14 & $\begin{array}{l}\text { Retrieve past audio recordings in Voice Memos (iPod } \\
\text { Touch } ® \text { ) }\end{array}$ & 0 & 1 & 0 & 1 & 3 & 5 & 4.20 \\
\hline 15 & Copy audio recordings to a computer (iPod Touch $\circledast$ ) & 0 & 1 & 1 & 1 & 2 & 5 & 3.80 \\
\hline 16 & $\begin{array}{l}\text { Synchronize or copy files from a computer to your } \\
\text { mobile device }\end{array}$ & 0 & 2 & 1 & 0 & 2 & 5 & 3.40 \\
\hline 17 & Turn on Wi-Fi to connect to the Internet & 0 & 1 & 0 & 2 & 2 & 5 & 4.00 \\
\hline 18 & Access the Internet via Safari & 0 & 1 & 0 & 1 & 3 & 5 & 4.20 \\
\hline 19 & Browse the Internet using Safari & 0 & 0 & 1 & 1 & 3 & 5 & 4.40 \\
\hline 20 & Upload applications from iTunes & 0 & 1 & 0 & 1 & 3 & 5 & 4.20 \\
\hline 21 & Other (please elaborate) & 2 & 0 & 1 & 1 & 1 & 5 & 2.80 \\
\hline
\end{tabular}

The five participants who used the iPod Touch $₫$ and $\mathrm{iPad} \circledast$ indicated that they were very capable of utilising the majority of the components outlined in Table 5.2. The only aspects the participants rated themselves as having good expertise in was labelling audio recordings, copying audio recordings to a computer and synchronising or copying files from a computer to a mobile device.

One of these five participants said they used their mobile devices to browse Facebook. 
Table 5.3: Participants' Expertise to Utilise the iPad®

\begin{tabular}{|c|c|c|c|c|c|c|c|c|}
\hline$\#$ & Question & 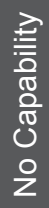 & 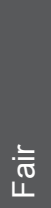 & $\begin{array}{l}8 \\
8 \\
\end{array}$ & $\begin{array}{l}\text { ठ } \\
0 \\
0 \\
\mathbb{0} \\
\mathbb{0} \\
>\end{array}$ & 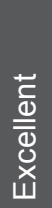 & 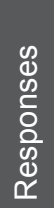 & $\stackrel{\frac{c}{\mathbb{D}}}{\stackrel{\infty}{\Sigma}}$ \\
\hline 1 & Turn on the $\mathrm{iPad} 囚$ & 0 & 0 & 0 & 1 & 0 & 1 & 4.00 \\
\hline 2 & Charge the $\mathrm{iPad} \circledast$ & 0 & 0 & 0 & 1 & 0 & 1 & 4.00 \\
\hline 3 & Attach the $\mathrm{iPad} \circledast$ to the computer & 0 & 0 & 0 & 1 & 0 & 1 & 4.00 \\
\hline 4 & Locate the Music folder & 0 & 0 & 1 & 0 & 0 & 1 & 3.00 \\
\hline 5 & Listen to music files & 0 & 0 & 1 & 0 & 0 & 1 & 3.00 \\
\hline 6 & Turn the volume up and down & 0 & 0 & 1 & 0 & 0 & 1 & 3.00 \\
\hline 7 & Scroll up and down the files to select a song & 0 & 0 & 1 & 0 & 0 & 1 & 3.00 \\
\hline 8 & Locate the Movies folder & 0 & 0 & 1 & 0 & 0 & 1 & 3.00 \\
\hline 9 & View the Wete reo or Hopu reo videos & 0 & 0 & 1 & 0 & 0 & 1 & 3.00 \\
\hline 10 & Fast-forward or rewind the videos & 0 & 0 & 1 & 0 & 0 & 1 & 3.00 \\
\hline 16 & $\begin{array}{l}\text { Synchronise or copy files from a computer to } \\
\text { your iPad® }\end{array}$ & 0 & 1 & 0 & 0 & 0 & 1 & 2.00 \\
\hline 17 & Turn on Wi-Fi to connect to the Internet & 0 & 0 & 1 & 0 & 0 & 1 & 3.00 \\
\hline 18 & Access the Internet via Safari & 0 & 0 & 0 & 1 & 0 & 1 & 4.00 \\
\hline 19 & Browse the Internet using Safari & 0 & 0 & 0 & 1 & 0 & 1 & 4.00 \\
\hline 20 & Upload applications from iTunes & 0 & 0 & 1 & 0 & 0 & 1 & 3.00 \\
\hline 21 & Other (please elaborate) & 0 & 0 & 1 & 0 & 0 & 1 & 3.00 \\
\hline
\end{tabular}

The participant whose responses are displayed in Table 5.3 was very capable of turning on the $\mathrm{Pad} \circledast$, charging it, attaching it to the computer, and accessing and browsing the Internet. The participant also indicated they are good at other components applicable to the WPR programme (numbers 4-10). However, copying audio recordings to a computer and synchronising or copying files from a computer to a mobile device were two areas requiring more help. Numbers 11-15 did not apply to the $\mathrm{iPad} \circledast$ because the device did not have the Voice Memos function as a standard app. However, the Voice Memos function is a standard app on the iPod Touch®.

There are a number of other features available on the iPod Touch $®$ and iPad $\AA$ that allowed the participant to take full advantage of the components on offer. Participants were asked to indicate how often they operated the functions listed in Table 5.3 which included those used when accessing content or completing activities for the VUW WPR programme. The Settings, Voice Memos, Calendar, Calculator, Clock, iTunes, Videos, Photos and Music features were used sometimes. Two participants indicated that they had never used the Voice Memos feature, four the Videos feature, six the Photos feature and five the Music feature. Interestingly, the Voice Memos function is required in the VUW WPR programme to 
record oral reflections of the participants' progress and the Videos feature is utilised to view the wete reo and hopu reo videos.

The majority of the participants rarely used Contacts, Mail, Notes, Maps, Safari, YouTube and the App Store. These findings align with the results about training in how to operate these functions on the device and could also be attributed to the lack of WiFi access in some schools, which is needed to activate Safari, You Tube, Maps, Mail and the App Store. Those who did operate these functions used the Notes to store lyrics for songs, the Internet to browse Facebook, and the Clock to set reminders.

\section{Challenges and Opportunities Presented by Mobile Devices to Attain Māori Language Proficiency}

The small size and light weight of the mobile device meant that participants were able to transport them easily and operate them at a time and place that was convenient, for example when travelling on public or private transport:

You can use the $i P o d \circledR$ at a time that suits you, i.e. on the bus. (Matiu)

The device also has the capability to connect to technologies such as a television or projector to display on a larger screen, which participants experienced during their whole staff meetings with the regional coordinator. This was particularly beneficial for those participants who were of the older generation or who were visually impaired:

The screen is too small for me. My eyes get tired. (Kahukiwa)

The small screen size was a challenge for some participants as indicated in the comment above and is discussed further in this section.

The ability to store and access programme content or functions that are readily available on the mobile device was also beneficial for learners:

It is always available to watch and revise/clarify learning. (Whenua)

The user was able to access the content on the device and control when and how they viewed it, which was very empowering, and one of the main benefits of learning a language offered by this technology. In particular, being able to revise content as many times as needed in order for the information to be understood, being able to 
pause and rewind the videos while viewing them, and essentially learning at a pace appropriate for the user were advantages of using the mobile device:

Because you already have the programme on the iPod® you could always go back and reflect when doing your assignments and activities and when planning te reo programmes to help teachers develop their own reo in Māori medium, kura kaupapa and mainstream classes. (Hirini)

The proficiency levels of participants in the VUW WPR programme varied greatly between those who were native speakers and those who were beginners. According to Nation and Macalister (2010), if learners feel personally threatened when learning a language, progress in acquiring the language could be difficult or slow. Thus, seeing the teacher on the mobile device screen (via the language videos) was less intimidating than being face-to-face for some participants, specifically those who were less confident with the language. The user could view the videos at a pace that suited them and also take risks when repeating sentence structures or identifying language items discussed in the language videos without feeling pressured or embarrassed if they made a mistake:

It is less nerve wracking when the teacher is on the screen, I am not whakamā (embarrassed) if I make mistakes. (Paikea)

I prefer it as face-to-face can make you feel inadequate, whereas there isn't that pressure with the videos. (Ahorangi)

It's not as scary [as face-to-face] because I can take my time and rewind and listen again without feeling embarrassed. (Mihirangi)

Being able to operate the device at a time that was convenient for the user was very appealing and effective for some, which also resulted in an increase in confidence to operate the device:

The idea of having a device that I am able to operate in my own time has been effective. This is an avenue that has given me confidence in using technology at another level. (Ariana)

The participants were asked about the value of the mobile device as a tool for teaching and learning and all but two regarded the device as valuable. Of the two participants who disagreed with the statement, one said, "face to face learning is the most valuable tool" (Awa) while the other stated "If I were able to use it [the programme material] on my personal iPhone ${ }^{\circledR}$ then it would have been more valuable to me. However, I do see value in mobile devices as learning tools" (Huria). Although the latter statement disagrees with the question, it seems that this was due to the inconvenience of having two devices rather than a lack of value placed on the device as a learning tool. One participant who valued the mobile device revealed 
that the technology was often the hook for many to engage in the learning, especially students.

Consequently, participants were asked to indicate whether or not they incorporated mobile device related tasks in the classroom with their students (see Table 5.4).

Table 5.4: Utilising the Mobile Device in the Classroom

\begin{tabular}{|c|c|c|c|c|c|}
\hline \# & Question & 을 & $\stackrel{\mathscr{E}}{\succ}$ & $\begin{array}{l}\mathscr{Q} \\
\mathbb{D} \\
\mathscr{C} \\
\varnothing \\
\stackrel{\circ}{0} \\
\mathbb{d} \\
\propto\end{array}$ & $\stackrel{\substack{\mathbb{D} \\
巳}}{\sum}$ \\
\hline 1 & $\begin{array}{l}\text { I am motivated to find ways to utilise the mobile device in the } \\
\text { classroom }\end{array}$ & 11 & 18 & 29 & 1.62 \\
\hline 2 & $\begin{array}{l}\text { I assign daily or weekly mobile device related tasks that support the } \\
\text { learning of te reo Māori }\end{array}$ & 21 & 8 & 29 & 1.28 \\
\hline 3 & $\begin{array}{l}\text { My students have access to the mobile device at any time during the } \\
\text { day }\end{array}$ & 22 & 7 & 29 & 1.24 \\
\hline 4 & My students have access to the mobile device during the week & 19 & 10 & 29 & 1.34 \\
\hline 5 & $\begin{array}{l}\text { I provide short-term tasks using the mobile device that utilise different } \\
\text { applications (such as Voice Memos) }\end{array}$ & 20 & 9 & 29 & 1.31 \\
\hline
\end{tabular}

Although only a third of the participants assigned mobile related tasks or provided students with access to their device (iPad $\AA$ or $\mathrm{iPod}$ Touch $\AA$ ) in the classroom, it was encouraging to see an increase in those who were motivated to find ways to maximise its potential. The participants who assigned mobile-related tasks commented on its ease of operation and use for teaching and learning, especially with students:

It provides me with extra training to support my teaching in class with my children. (Māui)

Both devices [iPad® and iPod Touch $®$ ] are handy and effective teaching tools that also seem to excite tamariki (children). (Awa)

The discrepancy between the number of participants who were motivated to utilise the mobile device in the classroom and those who provided tasks and access to the device to their students could be due to some of the participants not being classroom teachers but rather support staff, as well as a lack of training in how to use the device in the classroom. Another challenge noted by participants was the lack of devices for student use. Participants are allocated one iPod Touch $®$ for their personal use in the programme and only have this device to use in the classroom with students which is problematic because students have to wait for long periods of time to use the one device: 
I feel they are awesome tools for children as well as adults. I would love to have a small set (6) available for use in the classroom. (Te Oranga)

The tamariki would love to have the iPad® to work with, as the screen is bigger and it can give us links to the Māori reo interactive programmes for the tamariki to learn and engage with. [It also] makes it easier for the kaiako as we Māori medium teachers have enough to create and develop. (Whetū)

I think there are a number of messages within the participant's comment above. The iPad $\circledast$ would be more beneficial than the iPod Touch $®$ in the classroom because the bigger screen size would enable small groups of students to operate and/or view the device at the same time as opposed to the iPod Touch ${ }^{\circledR}$ where only one or two students at the most would be able to operate it or view it comfortably. The device would enable access to Māori digital content and interactive programmes that may be available on the device and on the Internet (Internet connectivity is needed). This in turn allows teachers to incorporate ready made resources into their classroom programme resulting in a more engaging learning environment for students and, more importantly, less time creating or developing resources in Māori themselves which has been the case for teachers in Māori medium educational settings for a long time. There is, and continues to be, a lack of quality Māori language digital resources available for teachers and students in Māori medium educational settings in comparison to the English medium educational settings.

Videos about wete reo and hopu reo were developed by the VUW WPR team specfically for the VUW programme. These videos are loaded on to the iPod Touch ${ }^{\circledR}$ given to each participant which are viewed during the whole group meetings or independently at a time and place suitable for the user (as described in Chapter One: Introduction). The videos comprise an introduction to the topic by presenters (members of the VUW WPR team) followed by pages of text that correspond with commentary about the topic and a summary of follow-up activities at the end. Participants were asked to comment on the different aspects that made up the video and its effect on their language learning (see Table 5.5). 
Table 5.5: The Use of Video to Improve Knowledge and Understanding of Te Reo Māori

\begin{tabular}{|c|c|c|c|c|c|c|c|c|}
\hline$\#$ & Question & 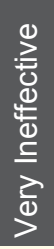 & 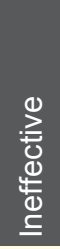 & 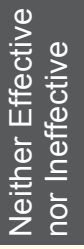 & 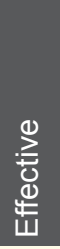 & 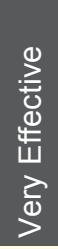 & 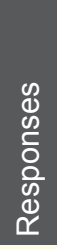 & $\underset{\substack{\frac{C}{\mathbb{N}} \\
\stackrel{\mathbb{N}}{\Sigma}}}{ }$ \\
\hline 1 & Being able to see people on the screen & 0 & 1 & 6 & 14 & 8 & 29 & 4.00 \\
\hline 2 & Hearing the presenters speaking te reo Māori & 0 & 0 & 3 & 10 & 16 & 29 & 4.45 \\
\hline 3 & Seeing the words on the screen & 0 & 0 & 3 & 11 & 15 & 29 & 4.41 \\
\hline 4 & $\begin{array}{l}\text { Seeing examples of the language topics in } \\
\text { sentences on the screen }\end{array}$ & 0 & 0 & 2 & 10 & 17 & 29 & 4.52 \\
\hline 5 & Seeing examples of the language topic in Māori & 0 & 0 & 3 & 9 & 17 & 29 & 4.48 \\
\hline
\end{tabular}

On the whole, participants indicated that the design of the language videos to support knowledge and understanding of te reo Māori was effective. Seeing examples of the language topics in sentences on the screen that were also in Māori were deemed very effective for the majority of the participants as well as hearing the presenters speaking Māori. Seeing people on the screen was the lowest rated aspect; however, it was still considered effective by the majority of participants. This may be concerned with the idea of face-to-face interaction that is considered important for Māori people.

With regard to increasing knowledge and understanding of the Māori language, the wete reo videos were considered most effective for improving knowledge of grammatical rules in te reo Māori followed by improving knowledge of vocabulary and improving listening and understanding. Improving speaking in te reo Māori was considered the fourth aspect affected by the use of the mobile device, then improving writing and improving reading respectively (see Table 5.6).

Table 5.6: The Effectiveness of the Mobile Device in Particular Aspects of the WPR Programme

\begin{tabular}{|c|c|c|c|c|c|c|c|c|}
\hline \# & Question & 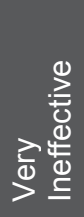 & 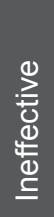 & 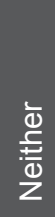 & 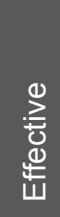 & 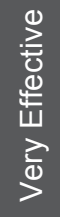 & 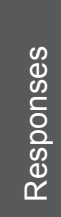 & $\begin{array}{l}\frac{C}{\mathbb{D}} \\
\stackrel{\mathbb{d}}{\Sigma}\end{array}$ \\
\hline 1 & Improving reading in te reo Māori & 1 & 1 & 11 & 12 & 4 & 29 & 3.59 \\
\hline 2 & Improving writing in te reo Māori & 1 & 1 & 7 & 15 & 5 & 29 & 3.76 \\
\hline 3 & Improving listening and understanding te reo Māori & 1 & 1 & 4 & 15 & 8 & 29 & 3.97 \\
\hline 4 & Improving speaking in te reo Māori & 0 & 1 & 6 & 19 & 3 & 29 & 3.83 \\
\hline 5 & Improving my knowledge te reo Māori vocabulary & 2 & 0 & 3 & 16 & 8 & 29 & 3.97 \\
\hline 6 & $\begin{array}{l}\text { Improving my knowledge of grammatical rules in te } \\
\text { reo Māori }\end{array}$ & 1 & 0 & 3 & 12 & 13 & 29 & 4.24 \\
\hline
\end{tabular}


Participants were also asked to describe the training and support they had received to operate the mobile device.

Table 5.7: Training and Support in the Use of the Mobile Device

\begin{tabular}{|l|l|l|l|l|l|}
\hline \# & Question & & & & \\
\end{tabular}

As noted in Table 5.7, three-quarters of the participants received training in how to operate the device. Seven people indicated that they did not receive any training, which may have contributed to their lack of use to support learning or ill feelings about the device itself. Consequently, just over half of the participants indicated that the mobile device was too complex to operate at times and too scary:

Frustration when I can't work out how to do a certain application. (Whenua)

Overwhelmed. (Te Rangimārie)

On the other hand, all participants indicated that when they operated the device they experienced feelings of excitement at times, as well as an engagement in their thinking (see Table 5.8).

Table 5.8: Feelings Elicited When Using Mobile Devices

\begin{tabular}{|c|c|c|c|c|c|c|}
\hline \# & $\begin{array}{l}\text { What feelings are elicited when you use the mobile } \\
\text { device? }\end{array}$ & $\begin{array}{l}\stackrel{\bar{\Phi}}{d} \\
\frac{0}{Z}\end{array}$ & 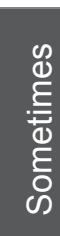 & $\overbrace{\frac{3}{4}}^{\infty}$ & 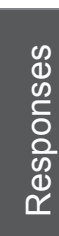 & 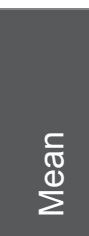 \\
\hline 1 & Excitement & 1 & 20 & 8 & 29 & 2.24 \\
\hline 2 & Engagement in my thinking & 0 & 13 & 16 & 29 & 2.55 \\
\hline 3 & I think it is too complicated & 13 & 16 & 0 & 29 & 1.55 \\
\hline 4 & I think it is scary & 22 & 7 & 0 & 29 & 1.24 \\
\hline 5 & Other (please elaborate) & 19 & 8 & 2 & 29 & .41 \\
\hline
\end{tabular}

Furthermore, 16 participants indicated that they had not received any training in how to utilise their device in the class, which could also be attributed to the lack of mobile 
device related tasks assigned by the teachers for their students. Additionally, one participant suggested opportunities to observe others operating the device in the classroom with their students as exemplars for their own teaching practice:

I would have liked a bit more in-depth training in the use of our iPods $₫$ in our kanohi-ki-te-kanohi sessions at the very beginning of our course so that I could operate it more confidently. Especially concerning the Wi-Fi, emailing and voice memos. (Whenua)

In regards to on-going support with the mobile device, 16 participants received this and all but one participant said they were able to approach others to help them use their device if and when needed. In summary, everyone participating in the WPR programme required initial and on-going training in how to utilise their mobile device for the purposes of the programme as well as in the classroom.

\section{Contribution to Iwi-specific Language, Tikanga and Knowledge}

The capability of the mobile device to provide access to a variety of teachers, speakers, dialects and perspectives about the Māori language was valued by participants. They were very positive about the ways mobile devices could incorporate iwi-specific language, tikanga and knowledge suggesting that this approach was an effective method for promoting the language and another avenue for communicating. The device was also described as being useful for "storing a much wider range of material pertaining to these aspects of te ao Māori" (Aniwā).

Furthermore, mobile devices present an opportunity for:

those of us who do not live in our iwi rohe but want to keep our dialects, tikanga etc alive. (Whenua)

The most common recommendation made by participants was the development of more resources in Māori concerning Māori language, tikanga and history from different iwi throughout the country that would be easily accessible for all who wanted them:

Having more iwi specific kaupapa. (Wairere)

Kia kaha tonu ki te hopu i ngā reo o ngā iwi katoa.

Continue to record the language of all tribes. (Airini)

Examples of the types of resources recommended included "links to pages of whakataukī, pakiwaitara (stories) and other pages" (Paikea), and "more pukapuka (books), podcasts of children [and] videos or plays" (Te Oranga). The development of apps "that are iwi-specific or areas of the podcasts that allow you to select the iwi, 
tikanga or knowledge" (Te Oranga) was another suggestion. Other suggestions included "an acknowledgement of alternatives specific to iwi alongside" (Hira) the language grammar videos that are already utilised in the WPR programme or the development of new videos about tikanga and history.

The following comment affirmed the mobile device as a great tool to capture Māori tikanga and history and suggested developing videos similar to those used in the WPR programme to analyse tikanga and history from different iwi:

\begin{abstract}
Akuni pea koinei te taputapu pai rawa hei hopu i ngā tikanga me ngā hïtori. Pēnā anō ngā hōtaka o Whakapiki engari kāre e wetehia te reo ka wetehia ngā tikanga, ngā hïtori ake o tēna iwi, o tēnā iwi.

This indeed is a great tool for capturing our protocols and our histories. We could use the videos used in the Whakapiki programme but rather than analysing the language, we could analyse the histories of different tribes. (Māhaki)
\end{abstract}

The use of the Voice Memos or the Video Camera function to record elders speaking Māori was another suggestion made by participants to incorporate iwispecific language, tikanga and knowledge as shown in the following comments:

Collecting pakiwaitara from kaumātua on video. (Matariki)

Pai te īputa hei hopu i ngā maramara kōrero o te tokorua, takirōpū rānei.

The iPod Touch $®$ is great for capturing the little bits of discussion between couples or groups. (Airini)

Record our pakeke (adults) and kaumātua when we are at the marae for tangihanga (funerals) or wānanga (forum). Record them when they are at kura for karakia (prayer) and wānanga. (Miriama)

Many of our great speakers need to be recorded on the iPod® to give us the power to listen to greatness. Whaikōrero (formal oratory) would be a great focus for men and karanga (spiritual call) for women. (Māui)

Building relationships with different stakeholders is also very important and it was suggested that the WPR team liaise with rūnanga (governing council of a sub-tribe or tribe) and encourage stakeholders such as Te Taura Whiri i te Reo Māori to have input into the programme. These relationships may also contribute to conversations about the sustainability of the programme after the withdrawal of the VUW WPR team at the end of the three-year period. 


\section{Challenges and Opportunities Presented by Face-to-face Instruction to Attain Māori Language Proficiency}

The physical presence of a teacher in the room was a superior medium for learning for some participants rather than only seeing "the picture and hear[ing] the voice of the teacher" (Hirini) on the mobile device. Teacher presence in the room also provided space and opportunities for participants to ask questions and discuss any arising matters in a broad manner that helped learners to understand the concepts:

When the teacher is physically in the room you are able to talk through your concerns if you are confused, and the teacher is able to feed you with more examples to help you not only understand but grasp the concept. (Whetū)

You are able to ask questions on the spot to gain clarity [and] ask for more examples if need be. (Ariana)

He pai ake te kanohi ki te kanohi, kia whakawhiti kōrero me te whakaaro whānui mā tēnā mā tēna o ngā kaupapa o te wā.

Face-to-face is better for discussions and in-depth debates about various topics. (Te Ataakura)

What is significant about the physical presence of the teacher is the opportunity to get an immediate response to any questions or queries unlike the videos on the iPod Touch $\circledast$ where the knowledge transfer is only one way, from the device to the user:

You can ask a teacher a question immediately when kanohi-ki-te-kanohi. (Whenua)

In kanohi ki te kanohi you can ask or discuss specific parts that you need help with or didn't understand. Whereas the iPod® can only give you what is on there. (Te Oranga)

There was, however, acknowledgement from one participant about the benefit of the iPod Touch ${ }^{\circledR}$ for learning Māori and the whole-group meetings. The participant considered being able to learn Māori from the content on the device and also taking part in discussions about the dialogue on the video facilitated by the regional coordinator during whole group meetings very beneficial for all participants in the VUW WPR programme:

He mea ako $i$ roto $i$ te koanga ngakau $i$ te mea $i$ reira hoki a $x x x x$ [the regional coordinator] hei tautoko i nga korero mai runga i te iPuta, aa, $i$ whai waa matou te wananga me te matapaki i nga kaupapa matua o Whakapiki.

It is wonderful because $x x x$ [the regional coordinator] is there to support us and work through the content on the iPod®. We also have time to debate and discuss the main topics of the programme - Whakapiki. (Māhaki) 
Face-to-face facilitation can also be tailored to suit individual learning styles, knowledge, or abilities and provide support and motivation for those who need it:

I would rather the teacher in the room, as it makes me concentrate harder and focus. With the individual learning you need to be motivated and selfdriven. (Hinewai)

Participants were questioned about their preferred learning situations based on the various settings provided in the VUW WPR programme (see Table 5.9). The most preferred learning situation was one-to-one meetings with the in-school facilitator or regional coordinator. Staff meetings with colleagues and the in-school facilitator or regional coordinator was preferred next, followed by viewing the language videos on the television with colleagues, viewing the videos on the mobile device with a colleague, and viewing the videos on the mobile device independently. Talking with colleagues in informal situations was the least preferred learning situation selected by participants.

Table 5.9: Preferred Learning Situations (1 - Most Preferred, 6 - Least Preferred)

\begin{tabular}{|c|c|c|c|c|c|c|c|c|c|}
\hline \# & Answer & 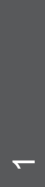 & $N$ & $m$ & $\nabla$ & 10 & $\omega$ & 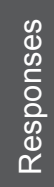 & $\begin{array}{l}\frac{C}{\mathbb{D}} \\
\stackrel{\mathbb{D}}{\Sigma}\end{array}$ \\
\hline 1 & $\begin{array}{l}\text { One-to-one meetings with the in-school facilitator } \\
\text { or regional co-ordinator }\end{array}$ & 9 & 2 & 1 & 2 & 2 & 3 & 19 & 2.74 \\
\hline 2 & $\begin{array}{l}\text { Viewing the videos on my mobile device } \\
\text { independently }\end{array}$ & 4 & 2 & 5 & 3 & 3 & 5 & 22 & 3.64 \\
\hline 3 & Talking with my colleagues in informal situations & 0 & 4 & 4 & 6 & 3 & 3 & 20 & 3.85 \\
\hline 4 & $\begin{array}{l}\text { Viewing the videos on my mobile device with a } \\
\text { colleague }\end{array}$ & 1 & 5 & 7 & 2 & 4 & 3 & 22 & 3.55 \\
\hline 5 & $\begin{array}{l}\text { Staff meetings with my colleagues and the in- } \\
\text { school facilitator or regional co-ordinator }\end{array}$ & 5 & 2 & 4 & 6 & 5 & 1 & 23 & 3.30 \\
\hline 6 & $\begin{array}{l}\text { Viewing the videos on the television with my } \\
\text { colleagues }\end{array}$ & 5 & 8 & 1 & 2 & 3 & 7 & 26 & 3.42 \\
\hline
\end{tabular}

In addition to the preferred learning situations, participants were asked to rate the effectiveness of the various settings offered in the VUW WPR programme (see Table 5.10). These settings related to the whole-school, in-school approach that uses a regional coordinator and in-school facilitator to deliver the WPR programme in the participating school. Moreover, it included the whole staff meetings, one-toone meetings, the mobile device as a tool for programme delivery and in-class observations. Overall, participants rated all seven learning situations as effective with little difference between them. According to the 'mean' scores, a whole school approach including staff meetings to introduce and discuss learning were 
considered the most effective learning situations. An in-school approach where external providers go to the schools to deliver the programme and observing someone teaching in te reo Māori in the classroom were selected next, followed by the support of an in-school facilitator who is a staff member and having one-to-one meetings with the in-school facilitator or regional coordinator. Having a mobile device to view videos and listen to songs, proverbs and audio files in te reo Māori independently scored the lowest 'mean'; however, it was still deemed an effective method to increase Māori language proficiency.

\section{Table 5.10: The Effectiveness of Different Settings and Relationships}

\begin{tabular}{|c|c|c|c|c|c|c|c|c|}
\hline \# & Question & 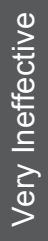 & 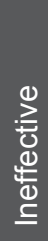 & $\begin{array}{l}\frac{0}{0} \\
\frac{0}{0} \\
\frac{0}{0} \\
\frac{0}{0} \\
\frac{0}{5}\end{array}$ & 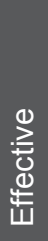 & 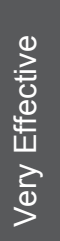 & 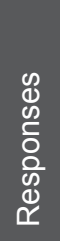 & $\underset{\substack{\mathbb{N} \\
\mathbb{N}}}{\stackrel{c}{\Sigma}}$ \\
\hline 1 & $\begin{array}{l}\text { Whole school approach - Having all or the majority of } \\
\text { the staff involved in Whakapiki i te Reo }\end{array}$ & 2 & 0 & 1 & 8 & 17 & 28 & 4.36 \\
\hline 2 & $\begin{array}{l}\text { In-school approach - Having the Whakapiki i te Reo } \\
\text { providers come into the school to deliver the programme }\end{array}$ & 1 & 1 & 3 & 8 & 15 & 28 & 4.25 \\
\hline 3 & $\begin{array}{l}\text { Having a staff member who is an in-school facilitator } \\
\text { (lead teacher) }\end{array}$ & 1 & 1 & 6 & 5 & 15 & 28 & 4.14 \\
\hline 4 & $\begin{array}{l}\text { Having staff meetings to introduce and discuss the } \\
\text { learning }\end{array}$ & 1 & 1 & 2 & 7 & 17 & 28 & 4.36 \\
\hline 5 & $\begin{array}{l}\text { Having one-to-one meetings with the in-school facilitator } \\
\text { or regional co-ordinator }\end{array}$ & 2 & 2 & 2 & 6 & 16 & 28 & 4.14 \\
\hline 6 & $\begin{array}{l}\text { Having a mobile device to view videos and listen to } \\
\text { songs, proverbs and audio files in te reo Māori } \\
\text { independently }\end{array}$ & 2 & 2 & 2 & 8 & 14 & 28 & 4.07 \\
\hline 7 & $\begin{array}{l}\text { Observing someone teaching in te reo Māori in the } \\
\text { classroom }\end{array}$ & 2 & 0 & 2 & 9 & 15 & 28 & 4.25 \\
\hline
\end{tabular}

\section{Chapter Summary}

Findings from the online questionnaire indicate that the mobile device as a tool for learning Māori language offers various opportunities for the user. Having the control to operate the device and access content anywhere and any time was very empowering for the user and one of the main benefits of learning a language offered by this technology. Being able to revisit the content, being able to pause and rewind the videos while viewing them, and essentially learning at a pace appropriate for the user were affordances of the mobile device for users.

Seeing the teacher on the mobile device screen (via the language videos) was also less intimidating than being face-to-face for those less confident with the Māori language. Using the mobile device meant the user could take risks repeating 
content in the videos without feeling pressured or embarrassed if they made a mistake.

The functionality and capability of the devices were also valuable for the participants in the PLD programme. The device could be connected to other technologies to display material on a projector or interactive whiteboard catering for participants who preferred a bigger screen (for example, the visually impaired) or for a bigger audience. The devices were also easy for students to operate and complete mobile-related activities assigned by some of the participants, although only having one device was a hindrance and more devices for student use were requested. Providing students with mobilerelated activities was not common practice by the participants; however, the majority were motivated to do this. Another challenge outlined by participants was a lack of training in how to operate the device and a lack of knowledge of using the tool in the classroom; thus, everyone participating in the WPR programme required initial and ongoing training and support in these areas in order to exploit the device's potential.

Participants considered the language videos used in the VUW WPR programme an effective resource to support knowledge and understanding of the Māori language. In particular, the language videos supported users to improve their knowledge of grammatical rules and knowledge of vocabulary, and also improved their listening skills and understanding of the language being spoken.

The language videos also provided the user access to speakers of the Māori language to which a few participants would not usually have had access because of their geographical location and lack of Māori speakers in their area. There were also suggestions to access a broader range of speakers by creating iwi-specific language videos, thus contributing to iwi, hapū, whānau, kura and the VUW WPR programme. The recommendations provided by participants included capturing and documenting local elders speaking in Māori about the language and its protocols and creating videos or podcasts similar to the existing VUW WPR language videos tailored to different iwi. Participants also suggested building relationships with rūnanga and Te Taura Whiri i te Reo Māori who may contribute to the current programme as well as conversations about the sustainability of the programme after the withdrawal of the VUW WPR team at the end of the three-year period.

Conversely, the majority of participants preferred face-to-face instruction for learning, which was also the method described as most effective in the participants' history of learning Māori. In a face-to-face situation the physical presence of the 
teacher was highly valued as was the space provided for posing questions, getting an immediate response and discussing issues, which is not possible when learning via videos on a mobile device. However, there was acknowledgement of the complementary nature and value of viewing the videos on the mobile device before the whole staff meeting with the regional coordinator who used the video as the impetus for the discussion. Face-to-face instruction was also preferred because it could be tailored to suit individual learning styles, knowledge, or abilities and provide support and motivation for those who needed it. This chapter endeavoured to weave together narratives from the participants who completed the online questionnaire about the challenges and opportunities of using mobile devices to attain Māori language proficiency. The next chapter presents the results from the Waikato Proficiency pre and post-tests for the VUW WPR participants and the WPR comparison group. 


\section{Chapter Six \\ Research Findings - Proficiency Test Results}

\section{Introduction}

Participants involved in the VUW WPR programme and WPR comparison group were required to undertake the Waikato Proficiency pre and post-tests as part of the programme (see Appendix 6). The reason for including the test results in this research was to ascertain if learners make expected gains in language proficiency through the use of mobile devices in comparison to standard face-to-face methods of language instruction; moreover, if there were differences, identify which of these could be associated with mobile device use by exploring the participants' experiences within the programme.

In order to maintain the anonymity and confidentiality of the research participants' results, each of the participants was given a pseudonym. The data in this chapter have been gathered from the participants who were interviewed in this research as well as those who completed the questionnaire. The VUW WPR and the comparison group results are tabled separately to show any differences. Moreover, in 2011 the Tuhituhi and Kōrero sections of the test were highlighted as the focus for all WPR providers, hence the reason why they are the only two modes documented in the tables below. Narratives of the results from each group are provided followed by a summary.

\section{VUW WPR Group Pre and Post-test Results}

Forty-six participants from the VUW WPR programme took part in this research. Of those 46 participants, five were regional coordinators or in-school facilitators and were not required to complete the test; therefore, they are not included in the table below, leaving just the 41 participants who completed it. In some cases, the Tuhituhi and Körero sections of the proficiency test were administered on different days. Thus some participants were absent the day the test was administered or did not complete the test for reasons unknown; hence these results are missing. There was also one participant who left the school and has no post-test result. 
Table 6.1: VUW WPR Waikato Pre and Post-test Results

\begin{tabular}{|c|c|c|c|c|c|c|c|}
\hline \multirow[t]{2}{*}{ Participant } & \multicolumn{3}{|c|}{ Pre-test Results } & \multicolumn{3}{|c|}{ Post-test Results } & \multirow[b]{2}{*}{ Change } \\
\hline & $\begin{array}{c}\text { Tuhituhi } \\
\text { /25 }\end{array}$ & $\begin{array}{c}\text { Kōrero } \\
\text { /25 }\end{array}$ & $\begin{array}{l}\text { Total } \\
/ 50\end{array}$ & $\begin{array}{c}\text { Tuhituhi } \\
\text { /25 }\end{array}$ & $\begin{array}{l}\text { Kōrero } \\
\text { /25 }\end{array}$ & $\begin{array}{c}\text { Total } \\
/ 50\end{array}$ & \\
\hline Participant 1 & 25 & 21 & 46 & 22 & 20 & 42 & -4 \\
\hline Participant 2 & 15 & 18 & 33 & 21 & 20 & 41 & +8 \\
\hline Participant 3 & 6 & 7 & 13 & 15 & 10 & 25 & +12 \\
\hline Participant 4 & 12 & 13 & 25 & 20 & 17 & 37 & +12 \\
\hline Participant 5 & 8 & 10 & 18 & 23 & 10 & 33 & +15 \\
\hline Participant 6 & 20 & 18 & 38 & 21 & 20 & 41 & +3 \\
\hline Participant 7 & 21 & 20 & 41 & 21 & 20 & 41 & 0 \\
\hline Participant 8 & 14 & 15 & 29 & 22 & 15 & 37 & +8 \\
\hline Participant 9 & 18 & 15 & 33 & 18 & 16 & 34 & +1 \\
\hline Participant 10 & 22 & 18 & 40 & 22 & 20 & 42 & +2 \\
\hline Participant 11 & 21 & 20 & 41 & 21 & 23 & 44 & +3 \\
\hline Participant 12 & 21 & 15 & 36 & 22.5 & 18 & 40.5 & +4.5 \\
\hline Participant 13 & 16 & 18 & 34 & 19 & 19 & 38 & +4 \\
\hline Participant 14 & 21 & 23 & 44 & - & - & - & - \\
\hline Participant 15 & 23 & 21 & 44 & 21 & 21 & 42 & -2 \\
\hline Participant 16 & 25 & 23 & 48 & Exit & - & - & - \\
\hline Participant 17 & 13 & 15 & 28 & 18 & 19 & 37 & +9 \\
\hline Participant 18 & 9 & 11 & 20 & 19 & 19 & 38 & +18 \\
\hline Participant 19 & 12 & 10 & 22 & 23 & - & 23 & +1 \\
\hline Participant 20 & 14 & 14 & 28 & 20 & 19 & 39 & +11 \\
\hline Participant 21 & 9 & 9 & 18 & 10 & - & 10 & -8 \\
\hline Participant 22 & 19 & 18 & 37 & 19 & 18 & 37 & 0 \\
\hline Participant 23 & 18 & 15 & 33 & 20 & 17 & 37 & +4 \\
\hline Participant 24 & 13 & 14 & 27 & 14 & 15 & 29 & +2 \\
\hline Participant 25 & 20 & 20 & 40 & - & - & - & - \\
\hline Participant 26 & 20 & 20 & 40 & - & - & - & - \\
\hline Participant 27 & 11 & 16 & 27 & 14 & 16 & 30 & +3 \\
\hline Participant 28 & 17 & 17 & 34 & 19 & 19 & 38 & +4 \\
\hline Participant 29 & 11 & 11 & 22 & 13 & 13 & 26 & +4 \\
\hline Participant 30 & 19 & 18 & 37 & - & - & - & - \\
\hline Participant 31 & - & 5 & 5 & - & - & - & - \\
\hline Participant 32 & - & 5 & 5 & - & - & - & - \\
\hline Participant 33 & 20 & 19 & 39 & 25 & 25 & 50 & +11 \\
\hline Participant 34 & 25 & 23 & 48 & - & - & - & \\
\hline Participant 35 & 17 & 25 & 42 & 25 & 25 & 50 & +8 \\
\hline Participant 36 & - & - & - & 18 & 21 & 39 & \\
\hline Participant 37 & 7 & 12 & 19 & 21 & 22 & 43 & +24 \\
\hline Participant 38 & 15 & 25 & 40 & 23 & 25 & 48 & +8 \\
\hline Participant 39 & 15 & 15 & 30 & 21 & 23 & 44 & +14 \\
\hline Participant 40 & - & - & - & - & - & - & - \\
\hline Participant 41 & - & - & - & - & - & - & - \\
\hline Average & 15 & 16 & 31 & 19 & 18 & 37 & \\
\hline
\end{tabular}


The results in Table 6.1 show that nine of the 41 participants scored less than 25 out of a possible 50 points in the pre-test; however, two of these participants did not complete the Tuhituhi section. The group average in the pre-test for Tuhituhi was 15 and 16 for Kōrero, culminating in an overall average of 31 out of 50 .

Two participants scored less than 25 in the post-test; however, one participant only completed the Tuhituhi section scoring 23, an increase of 11 points from the pre-test. Therefore one might assume that this participant would have increased the mark in the Kōrero section, had it been completed, to attain more than 25 out of 50 . The other participant only completed the Tuhituhi section scoring 10, an increase of 1 point from the pre-test. However, in this case it is not as easy to assume the participant would have scored 25 or more in total, as the pre-test Kōrero mark was 9. The group average in the post-test for Tuhituhi was 19, an increase of 4 , and Kōrero was 18, an increase of 2 , with an overall average increase by 6 to 37 .

Changes from the pre to the post-test include an increase of an overall average from 31 to 37 out of 50 . Three participants scored less in their post-test than they did in their pre-test; however, one participant only completed the Tuhituhi section in the post-test hence the decrease in mark. Two participants had no change, scoring the same marks in the pre and post-test. In contrast, a number of participants had significant growth from their pre and post-test, one in particular increasing their posttest mark by an outstanding 24 points.

It appears that from the data the most significant gains were made by those who scored poorly (24 or less out of 50 marks) in the pre-test. These six participants were numbers $3,5,18,19,29$ and 37 and as a group increased their mark from the pre to the post-test by an average of 12.3 (see Table 6.1). On the other hand, the 19 particpants who scored well in the pre-test ( 25 or more out of 50 marks) increased their mark by an average of 10.6 marks from the pre to the post-test. These participants were numbers $2,4,6,8-13,17,20,23,24,27,28,33,35,38$ and 39 . There were also two participants who scored well in the pre-test and scored the same in their post-test (participants 7 and 22) while two others (participants 1 and 15) scored more than 40 marks in the pre-test but decreased their mark in the post-test.

There are a number of questions that come to mind from the results above. Could the results mean that the material on the mobile device was pitched at a low proficiency level and therefore only engaged those who were struggling with the Māori language? 
Are those who are scored well in the pre-test uninterested in the material and therefore don't engage with the material or the mobile device to develop their proficiency further? Is the lack of growth of those who scored well an artefact of the 'ceiling effect' (the inadequacy of a test to measure the true ability and intelligence of a child. Each intelligence or achievement test usually has an upper limit (ceiling) designed to be the highest attainable score ${ }^{5}$ )? Or could it be simply that learning via mobile device does not suit those who are more proficient? A more thorough investigation into different types of learners, their preferences and their Māori language proficiency growth could be topics for future research.

The six participants who scored 24 or less in the pre-test and increased their post-test results all undertook the WPR programme to develop their own Māori language proficiency (see Table 6.2). Five participants felt they were good or excellent at operating the mobile device and one did not answer this question (participant 29). Five valued it as a learning tool and one felt it was just another thing to do (participant 5). Two participants used the mobile device 2-3 times per week (participants 3 and 37) and four participants used it once a week (participants 5, 18, 19 and 29). Having the teacher in the room or learning in a group situation was preferred by three participants (participants 5, 18 and 19) and one participant preferred the teacher in the class as well as the mobile device loaded with material (participant 3). Another preferred viewing the podcast on the television with colleagues (participant 29) and the final participant (participant 37) said they preferred the teacher in the classroom in one answer, they preferred viewing the podcast on their device independently in another answer and then they felt that the mobile device was ineffective for viewing podcasts, and listening to songs and audio files of proverbs.

Table 6.2: VUW WPR Participants who Scored 24 or Below in the Pre-test

\begin{tabular}{|c|c|c|c|c|c|c|}
\hline $\begin{array}{l}\frac{n}{\pi} \\
\frac{0}{0} \\
\frac{0}{0} \\
\frac{\pi}{\pi} \\
0\end{array}$ & 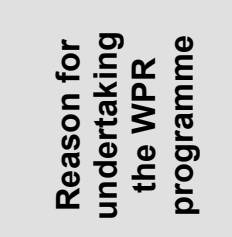 & 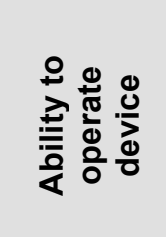 & 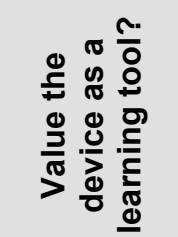 & 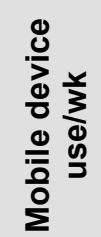 & 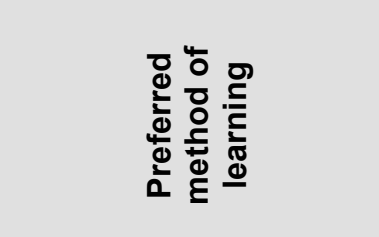 & 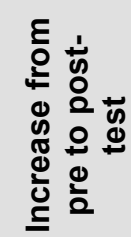 \\
\hline 3 & \multirow{6}{*}{$\begin{array}{l}\text { Increase Māori } \\
\text { language }\end{array}$} & Good & Yes & $2-3$ & $\begin{array}{l}\text { Teacher in room, mobile } \\
\text { device }\end{array}$ & +12 \\
\hline 5 & & Very good & $\begin{array}{l}\text { Another } \\
\text { thing to do }\end{array}$ & once & Teacher in room, group & +15 \\
\hline 18 & & Excellent & Yes & once & Teacher in room, group & +18 \\
\hline 19 & & Good & Yes & once & Teacher in room, group & +1 \\
\hline 29 & & - & Yes & once & Podcast on tv & +4 \\
\hline 37 & & Good & Yes & $2-3$ & $\begin{array}{l}\text { Teacher in room, } \\
\text { podcast independently, } \\
\text { mobile ineffective for } \\
\text { viewing podcasts }\end{array}$ & +24 \\
\hline
\end{tabular}

${ }^{5}$ http://psychologydictionary.org/ceiling-effect/ 
The results from Table 6.2 show that on average participants who used their mobile device more often, increased their post-test results by more than those who used the device less. The participants who used their device between two and three times each week increased their post-test result by 18 whereas the participants who used their device once a week averaged a 9.5 mark increase.

Table 6.3: VUW WPR Participants who Scored 25 or Above in the Pre-test

\begin{tabular}{|c|c|c|c|c|c|c|}
\hline 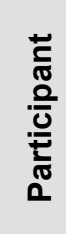 & 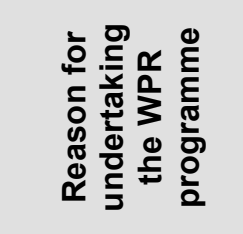 & 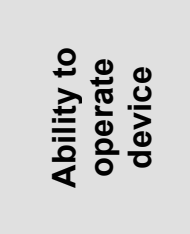 & 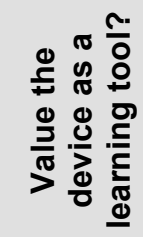 & 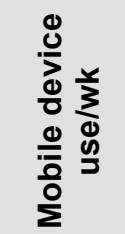 & 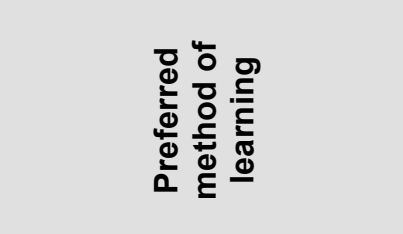 & 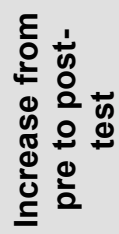 \\
\hline 2 & $\begin{array}{l}\text { Increase Māori } \\
\text { language }\end{array}$ & Good & Yes & 2 & Repetition, using books & +8 \\
\hline 4 & $\begin{array}{l}\text { Learning } \\
\text { programme } \\
\text { about reo }\end{array}$ & Good & Yes & $1-2$ & Te Ataarangi & +12 \\
\hline 6 & $\begin{array}{l}\text { School-wide } \\
\text { decision }\end{array}$ & $\begin{array}{l}\text { Reasonably } \\
\text { comfortable }\end{array}$ & Yes & 3 & $\begin{array}{l}\text { Grammar based focus, } \\
\text { immersion }\end{array}$ & +3 \\
\hline 8 & $\begin{array}{l}\text { Increase Māori } \\
\text { language }\end{array}$ & Good & No & $\begin{array}{l}\text { Once } \\
\text { month }\end{array}$ & Learning at home & +8 \\
\hline 9 & $\begin{array}{l}\text { Increase Māori } \\
\text { language }\end{array}$ & $\begin{array}{l}\text { Okay but } \\
\text { scared of it }\end{array}$ & $\begin{array}{l}\text { Yes, } \\
\text { good } \\
\text { things }\end{array}$ & 0 & Te Ataarangi & +1 \\
\hline 10 & $\begin{array}{l}\text { Had to, school- } \\
\text { wide decision }\end{array}$ & Good & Yes & $\begin{array}{l}\text { Once a } \\
\text { month }\end{array}$ & $\begin{array}{l}\text { Being amongst fluent } \\
\text { speakers }\end{array}$ & +2 \\
\hline 11 & $\begin{array}{l}\text { Increase Māori } \\
\text { language }\end{array}$ & Okay & Yes & $\begin{array}{l}\text { Once a } \\
\text { month }\end{array}$ & Using it with others & +3 \\
\hline 12 & $\begin{array}{l}\text { Increase Māori } \\
\text { language }\end{array}$ & Good & Yes & $1-2$ & Te Ataarangi & +4.5 \\
\hline 13 & $\begin{array}{l}\text { Increase Māori } \\
\text { language }\end{array}$ & Okay & Yes & $1-2$ & $\begin{array}{l}\text { Being immersed in the } \\
\text { language }\end{array}$ & +4 \\
\hline 17 & $\begin{array}{l}\text { Increase Māori } \\
\text { language }\end{array}$ & Excellent & Yes & $2-3$ & $\begin{array}{l}\text { Viewing podcast on TV } \\
\text { with colleagues }\end{array}$ & +9 \\
\hline 20 & $\begin{array}{l}\text { Increase Māori } \\
\text { language }\end{array}$ & Excellent & Yes & $2-3$ & $\begin{array}{l}\text { One-to-one meetings with } \\
\mathrm{RC}\end{array}$ & +11 \\
\hline 23 & $\begin{array}{l}\text { Increase Māori } \\
\text { language }\end{array}$ & Excellent & Yes & $\begin{array}{l}2-3 \\
\text { month }\end{array}$ & $\begin{array}{l}\text { Staff meeting with } \\
\text { colleagues, and mobile } \\
\text { device use }\end{array}$ & +4 \\
\hline 24 & $\begin{array}{l}\text { Increase Māori } \\
\text { language }\end{array}$ & Excellent & Yes & Once & $\begin{array}{l}\text { One to one meetings with } \\
\mathrm{RC} \text {, hearing others speak }\end{array}$ & +2 \\
\hline 27 & $\begin{array}{l}\text { Increase Māori } \\
\text { language }\end{array}$ & Good & Yes & $2-3$ & $\begin{array}{l}\text { Viewing podcasts } \\
\text { independently }\end{array}$ & +3 \\
\hline 28 & $\begin{array}{l}\text { Increase Māori } \\
\text { language }\end{array}$ & Very good & Yes & $2-3$ & $\begin{array}{l}\text { Speaking with native } \\
\text { speakers, staff meeting }\end{array}$ & +4 \\
\hline 33 & $\begin{array}{l}\text { School-wide } \\
\text { PD }\end{array}$ & Good & Yes & $\begin{array}{l}\text { Once } \\
\text { month }\end{array}$ & $\begin{array}{l}\text { Speaking with others, } \\
\text { viewing podcast with } \\
\text { colleagues }\end{array}$ & +11 \\
\hline 35 & $\begin{array}{l}\text { Increase Māori } \\
\text { language }\end{array}$ & - & - & Never & $\begin{array}{l}\text { Listening, one-to-one } \\
\text { meetings with RC }\end{array}$ & +8 \\
\hline 38 & $\begin{array}{l}\text { Increase Māori } \\
\text { language }\end{array}$ & Excellent & Yes & $\begin{array}{l}2-3 \\
\text { month }\end{array}$ & Listening & +8 \\
\hline 39 & $\begin{array}{l}\text { Increase Māori } \\
\text { language }\end{array}$ & Very good & Yes & $\begin{array}{l}2-3 \\
\text { week }\end{array}$ & $\begin{array}{l}\text { Te Ataarangi, viewing } \\
\text { podcasts with colleagues }\end{array}$ & +14 \\
\hline
\end{tabular}


Once again, there seems to be on average more growth from the pre to post-test by those participants who used the mobile device more often than those who used it on a monthly basis or not at all. From Table 6.3, the participant who used the mobile device once a week had a average of 2 marks, participants who used the device 1-2 times per week averaged a 6.8 increase, and the participant who used it twice a week averaged an 8 mark increase. The six participants who used the device between two and three times per week averaged a 7.3 increase compared to a 6 mark average increase for those who used the device once a month. The two participants who used the device 2-3 times per month averaged a 6 mark increase as well as the two participants who did not use the mobile device at all.

\section{Comparison Group Pre and Post-test Results}

One of the research participants in the comparison group was a regional coordinator; therefore, only five pre and post-test results are included in Table 6.4. Additionally, the participants in the comparison group only undertook the test at the beginning of the year due to insufficient time to repeat it at the end of the year.

Table 6.4: Comparison Group Waikato Pre-test Results

\begin{tabular}{|c|c|c|c|c|c|c|}
\hline \multirow{2}{*}{ Participant } & \multicolumn{3}{c|}{ Pre-test Results } & \multicolumn{3}{c|}{ Post-test Results } \\
\cline { 2 - 7 } & $\begin{array}{c}\text { Tuhituhi } \\
/ 25\end{array}$ & $\begin{array}{c}\text { Kōrero } \\
/ 25\end{array}$ & $\begin{array}{c}\text { Total } \\
/ 50\end{array}$ & $\begin{array}{c}\text { Tuhituhi } \\
/ 25\end{array}$ & $\begin{array}{c}\text { Kōrero } \\
/ 25\end{array}$ & $\begin{array}{c}\text { Total } \\
/ 50\end{array}$ \\
\hline Participant A & 10 & 18.5 & 28.5 & - & - & - \\
\hline Participant E & 22 & 23 & 45 & - & - & - \\
\hline Participant I & 22 & 22.5 & 44.5 & - & - & - \\
\hline Participant O & 22 & 23 & 45 & - & - & - \\
\hline Participant U & 22 & 21 & 43 & - & - & - \\
\hline Average & 19.5 & 21.5 & 41 & & & \\
\hline
\end{tabular}

The results from the comparison group were largely very high. The average for the Tuhituhi section was 19 and for Kōrero 21 out of a possible 25. The overall average for this group was 41 out of 50 with four scoring very high marks and leaving little room for improvement in terms of this test, although it would have been interesting to see any change specifically with Participant A who scored 28.5 initially. 


\section{Chapter Summary}

As part of the WPR programme participants were required to undertake the Waikato Proficiency test. Pre and post-test results from 46 VUW WPR participants were gathered and analysed alongside five WPR comparison group participants pre-test results.

The pre and post-test results from the VUW WPR participants were both less than the comparison group's pre-test results. There were, however, positive changes from the VUW WPR participants' pre-test and post-test results including an overall average increase from 31 to 37 and a decrease from nine to three participants scoring less than 25 out of 50 . Moreover, there was significant growth from individuals in the post-test with one participant increasing their score by an incredible 24 points. In contrast, those in the comparison group scored an overall average of 41 out of 50 in their pre-test, which was the only test completed due to a lack of time to undertake the post-test at the end of the year.

Unfortunately, the incomplete data from the comparison group could not be used to ascertain if learners make expected gains in language proficiency through the use of mobile devices in comparison to standard face-to-face methods of language instruction. However, the pre and post-test results from the VUW WPR group have presented two very interesting points. The first point is that the most significant gains were made by those who scored poorly in the pre-test. This group increased their mark from the pre to the post-test by an average of 12.3 (see Table 6.2) whereas the 19 particpants who scored well in the pre-test only increased their mark by an average of 10.6 marks (see Table 6.3). The second point was that there appeared to be more growth on average from the pre to the post-test by those who used the mobile device more often than those who used it less (see Tables 6.2 and 6.3). 


\section{Chapter Seven \\ Discussion}

This thesis endeavoured to find out the challenges and opportunities of using mobile devices to attain Māori language proficiency. The issues that will be discussed in this chapter highlight the need to build technological self-confidence and skills in the use of technology. The potential opportunities and challenges of technology to support Māori language and culture are also explored as well as the implications of promoting a general Māori language to the multitudes rather than iwi-specific language and knowledge. Recommendations to educators and school leaders in Māori medium educational settings in association with PLD providers will be outlined, followed by suggestions for future research.

\section{Building Technological Self-Confidence}

It is argued that to be beneficial for classroom instruction, digital technologies need to at first be accepted by teachers and students (Ifenthaler \& Schweinbenz, 2013; Yuen \& Ma, 2008). Shohel and Banks (2012) support this by noting that teachers ultimately determine the extent to which an innovation occurs or is adopted successfully. Perceived usefulness and perceived ease of use are two constructs in Davis' (1989) Technology Acceptance Model (TAM) that might determine one's intention to operate technology. Yuen and Ma (2008) found that perceived usefulness was not a significant factor for teacher acceptance of an online learning platform. However, the perceived ease of use had a strong direct positive effect on a user's intention to apply the e-learning system. Conversely, perceived usefulness was a strong determinant for accelerating special education teachers' acceptance of handheld computers, alongside ease of use and intention (Adiguzel, Capraro, \& Wilson, 2011). In the current research, participants were asked how they initially felt about using the mobile devices for developing their language proficiency and the value they placed on the device as a tool for language learning. Ease of use and perceived usefulness were the advantages of mobile devices that were often noted by participants. However, there were a few participants who felt apprehensive about using the tool for language development and preferred face-to-face instruction instead. The inconsistencies of the two constructs from the TAM within the three studies suggest that technology adoption might be seen as a complicated area of learning that can be influenced by existing beliefs, anxieties and perceptions, all of which should be taken into account 
when deciding on implementing technology in education (Adiguzel et al., 2011). In addition, Davis' model has been criticised for having only two constructs and for being independent of the organisational context (Adiguzel et al., 2011; Ifenthaler \& Schweinbenz, 2013). This shortcoming has led to adaptations of Davis' original model (for example by Adiguzel et al., 2011) or the development of new models for example the Unified Theory of Acceptance and Use of Technology (e.g., Venkatesh, Morris, Davis, \& Davis, 2003).

Despite the importance of evidence regarding the impact of innovations, there is a dearth of research about teachers' perspectives and acceptance of technological innovations (Ifenthaler \& Schweinbenz, 2013). A better understanding of the key factors that influence the acceptance of technology in a school context may provide useful insights into integration sustainability (Ifenthaler \& Schweinbenz, 2013). The current study did not address the issue of integration sustainability, but it did highlight its importance and suggests that it could be a topic for future research.

To understand the aspects that may influence technology acceptance or rejection more clearly, it would be beneficial for individuals or entities exploring the possible integration of new technology to undertake research that focuses directly on their users and their perceptions of technology. Furthermore, it is important to consider users' preferences and uses of technology to determine prior knowledge and also current abilities with technology (Karabulut, LeVelle, Li, \& Suvorov, 2012). Participants in the current research were asked to indicate the value they placed on the mobile device as a tool for teaching and learning. A few participants considered face-to-face instruction more valuable than mobile device use for teaching and learning. According to Blake (2009), face-to-face negotiations about and in the target language carried out between native and second language speakers can increase the quantity of oral producation, increase cultural awareness, and enable engaging connections with the target language. On the other hand, language practice mediated by technology, for example interactions with fluent or native speakers via the Internet, could be a valuable alternative for those who do not have access to real-life face-to-face interaction with fluent or native speakers (Karabulut et al., 2012). One respondent in the current study valued technology but indicated a preference for being able to use their personal iPhone ${ }^{\circledR}$ for the programme rather than being required to have an additional device. Kukulska-Hulme (2005) highlighted this potential pitfall of mobile technologies in that learners may reject their use. They may dislike having to carry multiple devices (their own and one for the project), especially if required to input data and then return the device at the end 
of the project or if they considered their own device to be better than the one being loaned to them. Instructors need to have a clear understanding of the types of technology students are using or not using as well as the rationales for adopting or rejecting certain tools. This might help instructors gear the teaching and learning towards students' needs and preferences and re-purpose technological tools for use in language learning (Karabulut et al., 2012).

In terms of prior knowledge and use of technology in general, all participants in the current study had access to and used computers. The majority used a variety of technologies such as cell phone, camera, iPad®, and smartboards on a regular basis. Although the participants had experience with a range of technologies, Karabulut and colleagues (2012) argued that the "mere exposure to technology in everyday life does not automatically make them successful language learners who know how to effectively use technology for educational purposes" (p. 357). In order to make technology enhanced language learning more efficient, students might benefit from having sufficient scaffolding in how to operate the new technological tools (Karabulut et al., 2012). Initial training in how to operate technologies for language learning might also be crucial for the successful utilisation and adoption of technology in education. For technology to be successfully integrated in the classroom, it may need to be centred on students' learning and based on sound pedagogy and appropriate theoretical perspectives (Ifenthaler \& Schweinbenz, 2013; Karabulut et al., 2012).

Shohel and Banks (2012) argued that professional development is most effective when there is an on-going process that includes proper well-designed training and an individual follow-up. An orientation workshop was part of the support system for teachers involved in a school-based technology-enhanced PLD programme in Bangladesh (Shohel \& Banks, 2011). The workshop involved briefing the teachers about the PLD intervention as well as training in how to operate and use the mobile device (i.e., an Apple iPod $囚$ ) and supporting materials. The orientation workshop appeared to be important for providing the teachers with a good understanding of the programme as well as the skills and knowledge of how to operate the device, which according to Shohel and Banks (2013), has "considerable potential to enhance teaching and learning across all sectors of education" (p. 39). The potential of digital media to enhance learning was also echoed by Gee and Hayes (2011) who stated:

It is popular today for people to write books to say that some aspect of digital media (social media, the Internet, video games, and so forth) is bad or 
ruining our culture or endangering our civilization. There are others who think that digital media are a panacea: for example, they think that just by giving poor children computers and the Internet we could close the gap in school performance between the rich and poor. No technology - books, television, computers, video games, or the Internet - by itself makes people good or bad, smart or stupid. Such technologies have effects only in terms of how, when, and why they are put to use. They have different effects in different contexts of use. They can be forces for good or ill. A computer connected to the Internet in the hands of a child with good mentoring is often a force for learning. It may not be in other circumstances. The real issue, then, is social, that is, who has and who does not have mentoring, not technology alone. (pp. 4-5)

The amount of operational training of the device that participants in the current study were provided with varied from individual to individual. Although the results suggested that the majority of participants were able to utilise the device to access material for the programme, there were some who did not receive any initial training or who did not appear to maintain this knowledge. This lack of training in how to operate the tool could have impacted on the participants' attitude, acceptance and adoption of the device for their own learning and as an instructional tool.

Initial and on-going training in how to operate the technology could be crucial for teachers to maximise the tool's potential for their own learning and use in the classroom with students. Teachers who are using technology also need to be provided with ongoing training and support to ensure they are not experiencing difficulties and to continue to enhance their learning and teaching. Ongoing training and support in the utilisation of the mobile device was a common request from participants in the current study. In particular, participants asked for training in how to operate all features and functions on the device as well as examples of how to implement their new skills and use the device in the classroom with students. Shohel and Banks (2011) claimed there is a need for teachers to have authentic support within the context of their classrooms. This type of support may enable teachers to put learning into practice and determines its effectiveness. Teachers require concrete and practical suggestions to understand how to implement their learning as well as technology in the classroom. More importantly, teachers also need to know how to make changes to their current practice because "instructional change must be incremental and specific" (Shohel \& Banks, 2012, p. 39).

New technologies are altering the ways in which people work, increasing the need for new knowledge and new types of skills (Shohel \& Banks, 2012). These technologies are also providing alternatives for teaching and learning and offering potential solutions to challenges such as flexibility of time, location, content, and form (Shohel \& Banks, 2012). On the other hand, a potential disadvantage with the 
increase in flexibility of time, location and content provided by new technologies is the assumption that users are then available at any time and any place, which might cause problems, such as increasing a learner's workload and always being "online". In the current study participants noted the significant advantage of the device's capacity to hold and access a range of material. The tool also had functions to capture and document moments and Internet connectivity all in one tool and at the touch of a button. Participants and regional coordinators could develop, store and access their material on the mobile device and connect it to other technologies (e.g., a television or a Smartboard) to present to or share with students, staff or parents. This example supports Shohel and Banks' (2012) argument that technology is playing an increasing role in education and that mobile technologies in particular can play a significant role in the development of teacher practice. Displaying material on a projector or a bigger screen also catered for those participants in the current research who were of the older generation or who were visually impaired and found the small screen size of the device a challenge. Included were participants with physical impairments who found the icons too small to operate the device. Rainger (2005) suggested features on the device that could be improved to enhance accessibility for potential users. These include 'live' text-to-speech (screen reading and document reading), speech recognition (both text transcription and for initiating commands), an external screen magnifier, and keyboard commands with navigational prompts. The text-to-speech function could be an issue when reading text that is in Māori and is a function that could be explored further. Another option could be to provide the users who have accessibility issues with a larger device.

The tool's light weight, portability and multi-functionality also appeared to empower users with the flexibility to learn at a time, place and pace that were convenient for them (McQuillan, 2006). Participants in the current research were able to operate the device whenever they had a spare moment, described by Kukulska-Hulme and Pettit (2009) as interweaving learning with other activities in everyday life, for example when travelling to and from work or during morning walks. This affordance caters to the ondemand flexibility "congruent with learners' increasingly mobile, always-connected lifestyles" (Kukulska-Hulme \& Shield, 2008, p. 273) and also enables the user to utilise 'hostage' or waiting time productively (Kukulska-Hulme \& Pettit, 2009).

\section{Building Skills in the Use of Technology}

There appeared to be a recognition by participants in the current study of the need to use technology in the classroom to engage students, described as 'Digital Natives' 
who have been surrounded by and have used toys and tools of the digital age and who are all "native speakers of the digital language of computers, video games and the Internet" (Prensky, 2001, p. 1). According to Prensky, the 'Digital Natives' not only think and process information differently from their predecessors (including some of their current teachers), but they also speak an entirely new language as a consequence of the copious amounts of interaction they have had in this ubiquitous environment. Thus educators may need to reconsider the instructional methods they use to facilitate learning as well as motivate and engage the 'Digital Natives' in their classrooms. Karabulut and colleagues (2012) found that there was a mismatch between the students' and teachers' rationales for using technology for learning French. Students viewed the device only as a tool, whereas the teacher viewed the device as a tool as well as a source for language development. The teacher also believed that the students would have no trouble using the technology because they were 'Digital Natives'. However, some of the 'Digital Natives' did find certain tools problematic and experienced difficulties integrating them into their learning of the French language. Moreover, there were students who preferred face-to-face instruction to a technology-based learning activity in some cases; for example, some students requested opportunities for in-class interactions in the target language (French) rather than French-speaking films or videos for viewing on the mobile device.

In the current study, face-to-face instruction was considered a superior medium for learning compared with seeing the teacher on the mobile device screen. Teacher presence in the room provided opportunities for participants to collaborate with peers, to ask questions, and discuss topics in depth. The ability to get an immediate response to questions was also one of the advantages of face-to-face instruction. Conversely, sessions that were facilitated face-to-face were also considered to be limiting in regards to the opportunities the learners have to gain an understanding or to ask for clarification. In a group situation one might also have to wait for the rest of the group or, on the other hand, the group may move too fast for some individual learners.

In addition to having the skills to apply the learning in the classroom, Shohel and Banks (2011) argued that teachers must also have an inner desire for new strategies and practices to do so as it is this inner desire that supports the spark of successful innovation. This inner desire or motivation to adopt technologies that Shohel and Banks (2012) speak of also appeared to be present for participants in the current research. That is, there appeared to be a difference between those who expressed a desire to integrate the mobile device in the classroom programme and 
the few who assigned mobile device related tasks to support the learning of Māori. Reasons for this could be many and varied, for example a lack of training in how to utilise the device, a lack of skills in how to apply the learning and utilise the device in the classroom as well as a lack of motivation. This highlights a question that the researcher could have asked participants, which was to explore the opportunities (or lack of) they had to share the mobile related tasks they or others used in the classroom with students. However, there was an increase in the number of participants who were interested in finding ways to maximise the device's potential from those who assigned mobile-related tasks. The participants who assigned tasks using the device commented on its ease of operation and use for teaching and learning, especially with students. Some participants in the current study installed apps (a Māori language dictionary and e-books in Māori) onto their device. The Māori dictionary app was used by a participant to search for Māori words they or their students needed while in the classroom, an approach also known as just in time knowledge' (Kukulska-Hulme \& Traxler, 2005; Wishart, 2009). Before the introduction of the mobile device, this particular participant would ask the teacher in the classroom for the Māori word. With the advent of the mobile device and the installation of the Māori dictionary app, the participant could be more independent by being able to search for words without having to interrupt the teacher for assistance. Although a hardcopy dictionary could have been used instead, the mobile device is quick and easy. Other potential advantages of having the dictionary on the mobile device rather than in a book is that the device can be carried anywhere and used to search for words at any time; it is also lightweight and discrete. The device can be concealed from bystanders or peers while searching for words in the dictionary if the user wishes.

Other participants used the mobile device in various ways to document learning in the classroom. Examples included using the camera to take photos of students in the classroom or of their work and using the Voice Memos function to record students reading and speaking. Participants would then use the evidence for assessments such as running records and oral assessments that would be added to e-portfolios (a digitised collection of artefacts) and shown to parents during parent interview evenings. According to researchers (Aubusson, Schuck, \& Burden, 2009; Garrett, 2009), video recording classroom interactions can serve pedagogical purposes. Authentic interactions, artefacts and anecdotes can be captured through mobile technologies without causing interruptions to the speakers and analysed by the teacher at a convenient time (Aubusson et al., 2009; Garrett, 2009). The analysis and synthesis of the footage can then be shared with learners encouraging 
collaborative reflective practice which may improve teacher and student learning (Aubusson et al., 2009; Garrett, 2009).

Mobile technology and podcasting might play a significant role in providing teachers and students with material that supports them to develop language proficiency. Chen (2011) contended that videos can introduce language learners to various aspects of real life and help contextualise the learning process. In addition, videos that combine sounds, images and text as well as socio-cultural information might be a valuable tool for teaching language and culture (Chen, 2011).

The mobile devices used in the current study were loaded with programme content that included a range of videos and audio files in Māori and English. Some participants indicated that the design of the language videos to support knowledge and understanding of the Māori language was effective. Seeing examples of the language topics in sentences on the screen that were also in Māori was reported to be very effective for the majority of the participants as well as hearing the presenters speaking Māori and seeing people on the screen. The videos were also considered most effective for improving knowledge of grammatical rules followed by improving vocabulary, listening, and understanding.

According to Shohel and Banks (2012), audio and video material loaded onto mobile devices has the potential to impact positively on teachers' learning by providing them with opportunities to enrich their language. Another important aspect is trying to ensure learners' comfort level when learning the language. In the current study, participants commented positively about their ability to view videos on the device in their own time. The portability and convenience of the device allowed them to take risks when repeating sentence structures or identifying language items discussed in the language videos without feeling pressured or embarrassed if they made a mistake since "whakamā - 'shame and embarrassment' - is a strong disincentive to learning" (Te Paepae Motuhake, 2011, p. 25). Similarly, progress in language acquisition may be slower if the learner feels personally threatened by difficulties in learning (Nation \& Macalister, 2010). Therefore, seeing the teacher on the mobile device screen (via the language videos) was less intimidating than being face-toface for some participants, especially those who were less confident with the language. The ability to pause and rewind the videos to consolidate the learning and revisit the content on the device gave the user ownership and control of what, when, and where to learn (Laurillard, 2007). Participants also used the mobile devices when they were in a comfortable or safe place to complete tasks, which was 
particularly beneficial for those who preferred to work independently or who had low proficiency and preferred privacy for study. For example, the user could view the language videos at a pace that suited them by pausing and rewinding the content.

Video content could also provide teachers with concrete examples of good practice to enhance their pedagogical techniques and instructional practice (Shohel \& Banks, 2012). Conversely, Karabulut and colleagues (2012) found that students involved in their study had varied views of the benefits of using technology such as watching videos or movies for the development of second language oral proficiency. The language videos used in the current study were intended to give participants access to Māori speakers that they might not otherwise have had access to. On the other hand, the language videos were also seen as one-way learning with no opportunities for discussion about content, potentially causing roadblocks for learners who needed extra support. Hülsmann (2009) claimed that podcasting is not a technology for sustaining discussion or interactions, but rather a stimulus. Shohel and Banks (2012) agreed that mobile technologies in general are not to replace existing technologies, such as computers, pens or paper or face-to-face instruction, but rather a means for complementing current practices or providing something additional.

\section{General Māori Language or Iwi-specific?}

Many of the earlier interventions aimed at revitalising the Māori language, such as Te Ataarangi and Kōhanga Reo, were focused on creating a large quantity of language speakers by engaging as many people as possible (O'Regan, 2006). The interventions aimed to regenerate and revitalise Māori language in general rather than tribal dialects. The language videos used in the current study also focused on the general rules of the Māori language rather than iwi-specific dialects. Are there implications for promoting 'a standard Māori language' for large-scale initiatives and what are the risks in doing this for the preservation of tribal dialect and community identity?

According to O'Regan (2006), some academics and teachers promoted a 'standard' version of the Māori language in the earlier stages of revitalisation efforts. This type of Māori language was incorporated into educational resources and programmes rather than dialectal differences with the argument that the standardisation made the language more accessible to the multitudes and catered to new learners in particular. The standardisation led to the simplification of the language with a range 
of Māori words being replaced by a smaller number of more commonly known words. The problem with this, was that the level of simplification would not equip learners with the language needed to be able to converse proficiently beyond the classroom in which they learned or in everyday situations (O'Regan, 2006).

With the plight of the Māori language caused by colonisation and urbanisation there was a perceived need for large-scale initiatives to regenerate the Māori language even if the initiatives promoted a standard language. O'Regan (2006) also supported this idea and stated that, "one theory may suggest that such a step was a necessary evil to help us get to the point that we see ourselves in today, where the necessary critical mass of speakers is established" (p. 165).

More recently, initiatives for revitalising the Māori language have focused on language quality and the type of language learned, for example a focus on tribal dialects (O'Regan, 2006). One example of this is Ngāi Tahu's Māori language strategy "Kotahi Mano Kaikā, Kotahi Mano Wawata - a thousand homes achieving a thousand aspirations" (O'Regan, 2006, p. 161). The strategy was established in 1995 but launched in 2002 and sought to create one thousand homes within the iwi of Ngāi Tahu speaking Māori by 2020 (O'Regan, 2006). Although the language videos in the current study are not focused on a particular tribal dialect, an aim of the programme was to work alongside the kura, whānau, hapū and iwi to incorporate their own dialect or own language into the programme as per the communities' aspirations. A participant in the comparison group commented on the value of having regional coordinators who are from the iwi who not only speak the language fluently but also use iwi-specific words that are also the words of old or "ngā kupu tawhito..." (Amokura). Comments from participants in the VUW programme about regional coordinators being from the local iwi and the benefits of this for learning the local dialect were less evident. Participants commented positively about the capability of the mobile device to provide access to a variety of teachers, speakers, dialects, and perspectives about the Māori language.

So does technology support, promote and enhance Māori language and culture? If so, how? The participants in the current research were generally very positive about the ways mobile devices could be used to incorporate iwi-specific language, tikanga and knowledge suggesting that this approach was an effective method for promoting the language. The majority of participants stated that iwi-specific resources utilised on the mobile devices would make learning more personalised and would be a great resource to show tribal differences to their students. 
A common example provided by the participants included recording native speakers and local elders talking about the language (including for example idioms, formulaic expressions and songs of old) and in the language. The footage could then be used to create videos or audio and video podcasts. The Voice Memos function or the Video Camera could be used to record the speakers and then software on the computer, for example iMovie or Garage Band, or apps on the $\operatorname{iPod} \circledast$ or $\operatorname{iPad} 囚$. iMovie could be used to create movies or video and audio podcasts, thus providing valuable knowledge and resources to the kura, whānau, hapū and iwi. The recordings could be used to develop knowledge of the local language within the school and also to identify tribal differences.

Participants also suggested re-recording the language videos used in the current research in different dialects. One participant said this would be particularly helpful for students attending wharekura or for the students who do not know the differences between the tribes. Castagno and Brayboy (2008) state that including cultural pedagogies, histories, and language features in the curriculum enables schools to be more culturally relevant and responsive to students.

Whānau, hapū and iwi are key support mechanisms for the preservation and maintenance of te reo Māori throughout the kura. By localising the focus of language, whānau, hapū and iwi can be empowered to take ownership for the direction and sustainability of the programme once the PLD is withdrawn (McKenzie \& Toia, 2013). According to Shohel and Banks (2012), the focus of professional development must also move from primarily being delivered by external experts to being in school where learning is embedded in the classroom and from "ad hoc development of skills to the production of content-specific skills and knowledge" (p. 28). In order for PLD to be successful it must be sustainable and related to everyday teaching (Shohel \& Banks, 2012). PLD that concerns Māori language should also enable whānau, hapū and iwi to be involved in the process of supporting, maintaining, and advancing the local dialect and the language in general. The current study did not investigate the extent to which opportunities were provided to whānau, hapū and iwi for this involvement but this could be a valuable topic for future research. 
The ideal of whānau, hapū and iwi connected to one's language is supported by Te

Paepae Motuhake (2011) which states:

Whatever means are employed in the transmission of te reo Māori, it is still the most widely held belief that the learning of one's primary language is best and most effectively delivered at the mother's breast. But of course 'Mother' needs to know te reo Māori too. (p. 25)

In the changing world, 'Mother' ought to be interpreted as 'whānau' as the supporting networks that sustain the learning of Māori. Wharehuia Milroy, a Tūhoe elder, encourages the learning of one's language in the home environment and argues:

If a child is not brought up within the Māori world, the vital roots of the language will not be anchored correctly. Yes, they will speak the language, but that language won't carry the spirit, the way of the Mãori world. It will be a trivialised language, where the words are Māori, but the base thinking will not be Māori. Besides that, you also have to contend with the structurally incorrect language of the teachers. If the teacher's language is horridly out of skew, then so will the child's (be) - and those imperfections will be entrenched (Winitana, 2011, p. 310).

For many Māori people learning at home did not appear to be an option and the various initiatives developed out of the 1980s have provided other pathways to attain proficiency. However, Wharehuia Milroy questioned the impact of the educational pathways such as language nests, immersion schools and tertiary institutions when surveys continue to indicate that numbers are dropping (Winitana, 2011). Milroy (cited in Winitana, 2011) recalled an elderly indigenous gentleman's summation from overseas of all the types of endeavours he was told to undertake to secure his language so that it would not die as he describes and evaluates the initiatives that have taken place for the Māori language:

We must write down our language. Well, we've written the Māori language down and it still continues to die. We must produce a dictionary. Same again, we have, and what, it's still on the decline. We must produce people who are expert in the language. And we have, yet it hasn't halted the regression. We must produce expert linguists who are also expert teachers. No joy there, the language is still on the slide. We must establish bilingual schools, English and Māori in our case. All done, but still no difference. We must let the schools teach the language - we do. But no luck there. We must produce our cultural arts as catalysts for awakening the language. There's our carvings and our artworks, but still the language hasn't returned. We must bring in the international language experts - the likes of Fishman and Spolsky - who have all been here, and not one shred of difference. We must take our recording machines and capture the words of our old people as they fall from their mouths. We must visit the sound and film archives and gather their speeches. All done, I'm afraid, and the language hasn't budged. We must produce CDs - again, all completed, but still no difference with the language. We throw the blame here, we throw the blame there, we place it at the feet of the government, but, as sure as eggs, it comes back to us, ourselves. If there is no desire, no deep-seated yearning, to give life back to the language, then, it will never come back to life. (pp. 311-312) 
Milroy contended that in the end it comes down to individuals to nurture and champion the language within the family (Winitana, 2011). The heart of the matter is how we get to that deep-seated desire in each individual who "Hunger for identity, meaning and self-worth. He kōingo mō te tuakiri tangata" so aptly termed by Penetito (2010, p. 249). How do we embrace and nurture the yearning in order to mobilise their learning, "their own mita (tribal dialect), iwi-tanga (tribal culture) and ranga (tribal leadership, as in rangatira)"? (Penetito, 2010, p. 259). There are many Māori people who want their language, culture, and identities to not only survive but to advance and excel. Māori want:

\begin{abstract}
to know their language; they want their traditional institutions (the marae, for example) to flourish; they are hungry to learn about their ancient history as well as their interpretations of colonial history; they are aware their ancestors keenly sought much that belonged to European civilisation, and they want to honour that desire with at least the same amount of vigour as their tūpuna (ancestors) demonstrated; they want to maintain those aesthetics that derive from the Māori world, which make them unique in the world; and, more than anything else, they do not want to be limited in any way in terms of where and how they regain these (Penetito, 2010, p. 252).
\end{abstract}

This study and other research (Ministry of Economic Development, 2008; Te Paepae Motuhake, 2011) proposed that there is value in finding ways to create a digital future for Māori, particularly ways that sustain and advance Māori language, through technologies. To echo the words of Sir Apirana Ngata about pursuing the benefits of western and Māori society:

E tipu, e rea mo nga ra o tou ao; ko to ringa ki nga rakau a te Pakeha hei ora mo te tinana, ko to ngakau ki ngā taonga a o tipuna Maori hei tikitiki mo to mahuna, a ko to wairua ki to Atua, nana nei nga mea katoa.

Grow up oh tender plant to fulfill the needs of your generation; Your hand clasping the weapons of the pakeha as a means for your physical progress, Your heart centred on the treasures of your Māori ancestors as a plume upon your head, Your soul given to God the author of all things. (Hutt Valley Tribal Committee, 1960, pp. 32-33)

The tools of the Pākehā (European), which Māori have always been quick to adopt and adapt, provide alternatives for teaching and learning by offering potential solutions to meet challenges such as access, flexibility, time, location, and content, particularly given the urgency of finding ways to ensure the survival of the Māori language.

The thesis has attempted to weave together a korowai with the kōtui unfolding the challenges and opportunities in utilising mobile devices to attain Māori language proficiency. It also aimed to unravel the differences associated with mobile device use and face-to-face facilitation when attaining Māori language proficiency and in 
doing so has filled a gap in the field by outlining barriers that are both subject and sector specific.

The aho were the existing literature related to Māori language, mobile learning and teacher professional learning and development. The literature revealed the serious need to regenerate the Māori language from a state of endangerment, according to UNESCO framework of Language Vitality and Endangerment (2003). This thesis supported the need to increase teachers' Māori language proficiency and to embrace technology as a tool to revitalise the Māori language. Thus, PLD that uses mobile devices was explored as a potentially useful pathway for teachers to increase their Māori language proficiency.

The existing literature exposed a wide range of reasons for implementing mobile technology in teaching and learning and its potential value for supporting the revitalisation efforts for the Māori language. The challenges were a lack of training in how to operate the device, a lack of access to devices and time to learn how to use them, the small screen size, the limited battery life, and a lack of robustness for use in schools. On the other hand, the advantages were access to learning content and material stored on the device or retrieved via the device and the portability of the device that also enabled users to learn at their convenience and pace.

The whenu that made the body of the garment were data from semi-structured interviews, observations of mobile device use, online questionnaires and pre and post Māori language proficiency tests for a group of 46 VUW WPR participants and six WPR participants from a comparison group. The data sources revealed a range of challenges and opportunities for using moble devices and face-to-face facilitation separately to increase Māori language proficiency as well as the opportunities for a blended approach. The proficiency test results also showed that those who used the mobile device for the purposes of the WPR programme on average increased their post-test results more than those who used it less often.

Drawing together the aho, whenu and kōtui that make up the korowai and creating the tāniko, the researcher has revealed aspects that may contribute to an understanding of how to design technologies, media, and interactions to support learning within Māori medium language settings. 
The limitations of the study, recommendations for educators, school leaders and PLD providers are described next as well as future research initiatives and a chapter summary.

\section{Limitations of the Study}

The current study has offered a perspective on the potential challenges of, and opportunities for, using mobile devices to attain Māori language proficiency. Throughout the process a number of limitations were encountered that need to be considered. One of the limitations is the potential for bias in interpretation given my involvement as programme coordinator in the VUW WPR programme. I have outlined this insider position in Chapter Three: Research Design, Methods and Tools and have been mindful to maintain correct protocols throughout the duration of the research and beyond (e.g., when presenting at conferences). These protocols include being respectful of participants' confidentiality and perspectives and maintaining a professional relationship with them throughout the data collection process and beyond.

This research was also a relatively small-scale project with 46 participants from one programme taking part. In 2011, there were approximately 99 participants in total in the VUW WPR programme, thus approximately half were involved in this sample. The comparison group from the second tertiary institution programme was only a small part of the research that aimed to explore if there were any differences between face-to-face instruction only and the use of mobile devices. In addition, the offer was made to another WPR programme that declined to take part in the research. There was also another school within the WPR comparison group that was given the opportunity to be a part of the research, but they too declined. The results from the Waikato Proficiency pre and post-test were also incomplete and were unable to show any evidence to contribute to the research.

The results from this research may not apply to all of the participants in the VUW WPR programme, nor would it be appropriate to generalise the findings of this qualitative research to make strong claims about the use of mobile devices in teaching and learning te reo Māori. Nevertheless, these results provide a glimpse of the challenges of, and opportunities for using mobile devices to attain proficiency in Māori language. There is urgency for research such as the current study to investigate the types of technologies that support Māori language revitalisation in 
view of the vulnerabilities and challenges highlighted by Te Paepae Motuhake (2011).

The lack of a widely accepted theoretical framework for mobile learning may also have contributed to the lack of effective assessment, pedagogy, and design of new applications for learning (Shuler, 2009). However, this study has started the conversation about the use of mobile devices in Māori medium educational settings, and may contribute to an understanding of how to design technologies, media and interactions to support learning within these settings to enable innovative practices.

\section{Recommendations from the Study}

Recommendations directly from this study are offered for educators and school leaders in Māori medium educational settings as well as professional development providers who are considering or who are currently utilising mobile devices for developing Māori language proficiency.

To understand more clearly the aspects that may influence technology acceptance or rejection, it may be beneficial for educators to assess the students' use of technology and their preferences to determine prior knowledge and current capabilities with technology. This information can help tailor the teaching and learning towards students' needs and preferences and re-purpose technological tools for language learning. Educators may also reconsider the instructional methods they use to facilitate learning as well as motivate and engage the 'Digital Natives' (students raised in a world where their toys and tools are of the digital age) in their classroom. These students speak, think, and process information differently to their predecessors (Prensky, 2001), and thus require new or different methods of instruction and tools to cater for their needs. Technologies, mobile devices in particular, should not, however, be perceived as a replacement for face-to-face facilitation or pen and paper but rather a means of complementing current practice or providing something additional.

It is imperative that educators and schools involve whānau, hapū and iwi in language planning as they can be key support mechanisms for the preservation, maintenance and sustainability of te reo Mãori throughout the schools and the region. 
School leaders and managers who are considering PLD for developing language proficiency involving technology for their staff should be aware that the potential of new technologies to transform teaching and learning is heavily dependent on educators' abilities to see the affordances. It is also further dependent on schools having the infrastructure, inspiration, capability, and opportunities for innovation to achieve these kinds of teaching and learning. Moreover, school leaders and managers could consider users' perceptions, preferences, and uses of technology before selecting technologies to be used in schools and classrooms. Before purchasing equipment it may be beneficial for school leaders to assess the teachers' use of technology and their preferences to determine prior knowledge and current capabilities with technology. This information can determine the aspects that may influence technology acceptance or rejection and help to identify the most appropriate technology or technologies for staff.

Professional learning and development providers who utilise technologies within their programmes could also assess the participants' use of technology, their preferences and current ownership to determine prior knowledge and current capabilities. Teacher attitude and acceptance towards technology are strong determinants for the successful use of technology for teaching and learning. The perceived ease of use is hypothesised to be a fundamental determinant for the successful pedagogical use of technology. In regards to ownership, participants may dislike having to carry multiple devices (their own and one for the project), especially if required to input data and then return the device at the end of the project or if they consider their own device to be better than the one being loaned to them. Therefore, providers could allow participants to utilise their own devices for the programme or think about alternative ways for the schools to own the devices by purchasing them.

Initial and on-going training in how to operate technology is crucial for participants to gain confidence to operate the tool and maximise its potential as they work towards building language proficiency. Training in how to utilise the tool in the classroom with students may also be beneficial for participants as well as examples of technology-related tasks or opportunities to observe the tool being used by students. A challenge noted by participants in the current study was the lack of devices for student use; therefore PLD providers could ensure they have sufficient resources to service the participants and their students if they are part of the programme. 
In addition, providers could also be mindful of the challenges in integrating multiple systems to store, access, or share content between provider and participants or participants and participants or existing technology infrastructure. Thus one strategy to overcome this could be to allocate devices to participants and train them to register and load the device from their own computer. The material might be loaded to the school server or downloaded from a website.

PLD providers may have participants with impairments or disabilities that limit their use of the mobile device. Functions such as 'live' text-to-speech, speech recognition, an external screen magnifier and keyboard commands with navigational prompts could be explored to cater for participants' needs. Another option could be to provide the users who have accessibility issues with a bigger device.

The language videos loaded on to the mobile devices were deemed effective for building language proficiency and have the potential to impact positively on participants' learning by providing opportunities to enrich their language. However, they were also seen as one-way learning with no opportunities for discussion about content, potentially causing roadblocks for learners who needed extra support. The videos could be the spark for the discussion and interaction during whole group sessions with participants. Programme facilitators may need to think creatively and carefully about how best to ignite discussion from the video into the face-to-face sessions. A participant in the current study also regarded the generic nature of the videos as a stumbling block; therefore the partnering of iwi-specific resources alongside current material may enhance a language-learning programme more.

\section{Recommendations for Future Research}

Reflection on the brief history of the Māori language and mobile learning, an examination of the current use of mobile devices as a tool for supporting language development and analyses of participants' experiences with these devices has provided some insight into the challenges and opportunities of mobile technologies to support the revitalisation of the Māori language. There are still critical questions that remain including the implications of promoting 'one Māori language' for a largescale programme and the risk in doing that for the preservation of tribal dialect and community identity. Could the use of technology result in a less desirable flattening of Māori language and culture into one, modern but somewhat artificial form? Te Paepae Motuhake (2011) has recommended that technology be embraced to support the revitalisation of the Māori language. Teacher acceptance of mobile 
devices for learning, in particular language learning or learning the Māori language, could be explored in order to fully understand the aspects that influence their acceptance or rejection.

\section{Chapter Summary}

Language, culture and heritage all play an important role in shaping one's identity and giving meaning to life. Māori language once spoken by nearly everyone in New Zealand declined to a moribund state due to impacts such as colonisation and urbanisation. The serious plight of the language caused the rise of Māori-led initiatives aimed to regenerate the Māori language and reassert Māori identity to ensure it would not become like the moa - extinct. There are many policies, agencies, initiatives and institutions that have contributed, and continue to contribute, to the advancement of the Māori language. However, despite all of the initiatives, our language continues to be endangered and thus requires serious attention. There remains a lot of work to ensure that the Māori language thrives, including exploring new initiatives and pathways.

One of these pathways is technology, particularly mobile devices, and the potential of these tools to assist teachers in Māori medium educational settings to attain Māori language proficiency. Recommended by Te Paepae Motuhake (2011) and others (Ministry of Economic Development, 2008; Ministry of Education, 2007), teachers need support to increase the quality of language they use and technology should be embraced to provide that support to every learner. Although technology "is only as valuable as the person who picks it up" (ITPNZ, n.d., p. 15), it can serve a useful purpose for supporting learners as they build towards language proficiency. Technology should not be seen as a panacea, a cure all for the revitalisation of the Māori language, but it could be a powerful tool in providing access to language, culture, and identity to the multitudes. Tools that may be familiar to our 'Digital Natives', our leaders of the future, should be used to ensure our language survives and thrives. 


\section{References}

Abdous, M., Camarena, M. M., \& Facer, B. R. (2009). MALL technology: Use of academic podcasting in the foreign language classroom. Cambridge Journals, 21, 76-95. http://dx.doi.org/10.1017/S0958344009000020

Adiguzel, T., Capraro, R. M., \& Wilson, V. L. (2011). An examination of teacher acceptance of handheld computers. International Journal of Special Education, 26(3), 12-27. http://www.eric.ed.gov/PDFS/EJ958994.pdf

Aubusson, P., Schuck, S., \& Burden, K. (2009). Mobile learning for teacher professional learning: Benefits, obstacles and issues. ALT-J Research in Learning Technology, 17(3), 233-247. http://www.researchin learningtechnology.net/index.php/rlt/article/view/10879

Ball, D. L., \& Cohen, D. K. (1999). Developing practices, developing practitioners: Toward a practice-based theory of professional development. In G. Skyes \& L. Darling-Hammond (Eds.), Teaching as the learning profession: Handbook of policy and practice (pp. 3-32). San Francisco: Jossey Bass.

Belanger, Y. (2005). Duke University iPod first year experience final evaluation report. Retrieved from http://cit.duke.edu/pdf/reports/ipod_initiative_04_05.pdf

Benton, R. (1981). The flight of the Amokura: Oceanic languages and formal education in the South Pacific. Wellington: New Zealand Council for Educational Research.

Bishop, R. (1997). Interviewing as collaborative storying. Educational Research and Perspectives, 24(1), 28-47.

Bishop, R. (2005). Freeing ourselves from neocolonial domination in research. In N. K. Denzin \& Y. S Linclon (Eds.), The Sage handbook of qualitative research ( $3^{\text {rd }}$ ed., pp. 109-139). Thousand Oaks: Sage.

Blake, R. J. (2009). The use of technology for second language distance learning. The Modern Language Journal, 93(s1), 822-835. http://dx.doi.org/10.1111\%2Fj.1540-4781.2009.00975.x

Borko, H. (2004). Professional development and teacher learning: Mapping the terrain. Educational Researcher, 33(8), 3-15. http://dx.doi.org/10.3102\%2F0013189X033008003

Castagno, A., \& Brayboy, B. (2008). Culturally responsive schooling for indigenous youth: A review of the literature. Review of Educational Research, 78(4), 941993. doi: $10.3102 / 0034654308323036$ 
Centre for Knowledge Societies. (2005, April). Learning lab: Inclusive education using mobile devices. Paper presented at the International Conference on Inclusive Design, Royal College of Art, London, UK.

Chen, H-J. H. (2011). Developing and evaluating SynctoLearn, a fully automatic video and transcript synchronization tool for EFL learners. Computer Assisted Language Learning, 24(2), 117-130. http://dx.doi.org/10.1080/09588221.2010. 526947

Creswell, J. W. (2009). Research design: Qualitative, quantitative, and mixed methods approaches. Los Angeles: Sage.

Cunningham, C. (1999). Responsive research in Māori education. (A paper prepared for the Research Division, Ministry of Education). Wellington: Ministry of Education.

Cunningham, C. (2000). A framework for addressing Māori knowledge in research, science and technology. Pacific Health Dialog, 7(1) 62-69.

Daly, C., Pachler, N., \& Pelletier, C. (2009a). Continuing professional development in ICT for teachers. (Prepared for and on behalf of the British Educational Communications and Technology Agency (Becta)). Retrieved from http://www.becta.org.uk

Daly, C., Pachler, N., \& Pelletier, C. (2009b). Continuing professional development in ICT for teachers: A literature review. (Prepared for and on behalf of the British Educational Communications and Technology Agency (Becta)). Retrieved from http://www.becta.org.uk

Davis, F. D. (1989). Perceived usefulness, perceived ease of use and user acceptance of information technology. MIS Quarterly, 13(3), 319-339. http://dx.doi.org/10.2307\%2F249008

Dede, C. (2006) (Ed.). The evolution of online teacher professional development. Online professional development for teachers: Emerging models and methods. Cambridge, MA: Harvard Education Press.

Dede, C. (2008). Theoretical perspectives influencing the use of information technology in teaching and learning. In J. Voogt \& G. Knezek (Eds.), International handbook of information technology in primary and secondary education (pp. 43-62). http://dx.doi.org/10.1007\%2F978-0-387-73315-9_3

Durie, M. (1997). Identity, access and Māori advancement. Edited proceedings of the NZEAS Research Conference, Auckland.

Durie, M. (1999). Whaiora Māori health development $\left(2^{\text {nd }}\right.$ ed.). Auckland: Oxford University Press.

Education Review Office. (2009). Managing professional learning and development in primary schools. Wellington: Ministry of Education. 
Garet, M., Porter, A., Desimone, L., Birman, B., \& Yoon, K. (2001). What makes professional development effective? Results from a national sample of teachers. American Educational Research Journal, 38(4), 915-945. http://dx.doi.org/10.3102\%2F00028312038004915

Garrett, N. (2009). Technology in the service of language learning: Trends and issues. The Modern Language Journal, 93(s1), 697-718. http://dx.doi.org/10.1111\%2Fj.1540-4781.2009.00968.x

Gee, J. P., \& Hayes, E. R. (2011). Language and learning in the digital age. Oxon: Routledge.

Graham, J. P. H. (2009). Whakatangata kia kaha: Toitū te whakapapa, toitū te tuakiri, toitū te mana: An examination of the contribution of Te Aute College to Māori advancement (PhD thesis). Massey University, Palmerston North, New Zealand.

Graham, J., \& Meyer, L. H., McKenzie, L., McClure, J., \& Weir, K. F. (2010). Māori and Pacific secondary student and parent perspectives on achievement, motivation and NCEA. Assessment Matters, 2, 132-157.

Gray, C., Pilkington, R., Hagger-Vaughan, L., \& Tomkins, S. (2007). Integrating ICT into classroom practice in modern foreign language teaching in England: Making room for teacher's voices. European Journal of Teacher Education, 30(4), 407429. http://dx.doi.org/10.1080/02619760701664193

Guskey, T. R. (2000). Evaluating professional development. Thousand Oaks, CA: Corwin Press.

Haig, I. T. (1997). Titiro Moko! Whakarongo, Moko! Speaking with Aunty Ada. In P. Te Whaiti, M. McCarthy, \& A. Durie (Eds.), Mai i Rangiātea Māori wellbeing and development. Auckland: Auckland University Press.

Hülsmann, T. (2009). Podcasting for learning in universities. Distance Education, 30(3), 451-458. http://dx.doi.org/10.1080/01587910903236585

Hutt Valley Tribal Committee. (1960). The story of "Arohanui ki te tangata": The meeting house of "Goodwill to all men" Waiwhetu, Lower Hutt City, Wellington, New Zealand. Lower Hutt: A. K. Wilson Limited.

Ifenthaler, D., \& Schweinbenz, V. (2013). The acceptance of Tablet-PCs in classroom instruction: The teachers' perspectives. Computers in Human Behavior, 29(3), 525-534. http://dx.doi.org/10.1016\%2Fj.chb.2012.11.004

Institutes of Technology and Polytechnics of New Zealand. (n.d.) Critical success factors for effective use of e-learning with Māori learners. Retrieved from www.itpnz.ac.nz

Irwin, K., \& Ramsden, I. (1995). Toi Wāhine The Worlds of Māori Women. Auckland: Penguin Books. 
Jones, A. (2004). A review of the research literature on barriers to the uptake of ICT by teachers. (Prepared for and on behalf of the British Educational Communications and Technology Agency (Becta)). Retrieved from http://www.becta.org.uk

Karabulut, A., LeVelle, K., Li, J., \& Suvorov, R. (2012). Technology for French learning: A mismatch between expectations and reality. CALICO Journal, 29(2), 341-366. https://calico.org/memberBrowse. $p h p$ ?action=article\&id=916.

Karetu, T. (1975). Language and Protocol of the Marae. Te Ao Hurihuri. Auckland: Longman Paul.

Karetu, T., \& Waite, J. (1988). Te Reo Māori. New Zealand Official Yearbook 19881989 (pp. 217-227). Wellington: Department of Statistics. Retrieved from http://www3.stats.govt.nz/New_Zealand_Official_Yearbooks/198889/NZOYB_1988-89.html\#idsect2_1_40841

Keiha, P., Moorfield, J., Ka'ai, T., \& Spooner, H. (2008). Advancing a digital strategy for learning and teaching te reo Māori. Retrieved from http://www.akoaotearoa.ac.nz/gppg-ebook

Kukulska-Hulme, A. (2005). Conclusions. In A. Kukulska-Hulme \& J. Traxler (Eds.), Mobile learning: A handbook for educators and trainers (pp. 189-196). Oxon: Routledge.

Kukulska-Hulme, A. (2012). Language learning defined by time and place: A framework for next generation designs. In J. E. Diaz-Vera (Ed.), Left to my own devices: Learner autonomy and mobile assisted language learning innovation and leadership in English language teaching (pp. 1-13). Bingley, UK: Emerald.

Kukulska-Hulme, A., \& Pettit, J. (2009). Practitioners as innovators: Emergent practice in personal mobile learning, work and leisure. In A. Mohammed (Ed.), Mobile learning: Transforming the delivery of education and training: Issues in distance education (pp. 135-155). Athabasca: Athabasca University Press.

Kukulska-Hulme, A., \& Shield, L. (2008). An overview of mobile assisted language learning: From content delivery to supported collaboration and interaction. ReCALL, 20(3), 271-289. http://dx.doi.org/10.1017/S0958344008000335

Kukulska-Hulme, A., \& Traxler, J. (Eds.). (2005). Mobile learning: A handbook for educators and trainers. Oxon: Routledge.

Laurillard, D. (2007). Pedagogical forms of mobile learning: Framing research questions. In N. Pachler (Ed.), Mobile learning: Towards a research agenda (pp. 153-176). London: WLE Centre, Institute of Education. Retrieved from http://www.wlecentre.ac.uk/cms/files/occasionalpapers/mobilelearning_pachler 2007.pdf 
Lave, J., \& Wenger, E. (1991). Situated learning: Legitimate peripheral participation. Cambridge, England: Cambridge University Press.

Mataira, K. (1980). The effectiveness of the silent way method in the teaching of Māori as a second language (Unpublished MEd thesis). University of Waikato, Hamilton.

McCarty, S. (2005). Spoken internet to go: Popularization through podcasting. JALT CALL Journal, 1(2), 67-74. http://www.waoe.org/president/podcasting article.html

McKenzie, T., \& Toia, R. (2013). Integrating diversity in teacher professional learning and development. In S. May, (Ed.), LED2011: Refereed conference proceedings of the 3nd International Conference on Language, Education and Diversity. Auckland, New Zealand: University of Auckland.

McKenzie, T., Toia, R., \& McRae, H. (2010). Anywhere, anytime: Creating a mobile indigenous language platform. Ubiquitous Learning, 2(3), 167-178.

McQuillan, J. (2006). iPod in education: The potential for language acquisition. (One in a series of iPod in Education white papers). Retrieved from http://edcommunity.apple.com/ali/galleryfiles/12071/iPod_Edu_Whitepaper_Lang uage_Acquisition.pdf

Mead, H. M., \& Grove, N. (2003). Ngā Pēpeha a ngā Tịpuna The Sayings of the Ancestors. Wellington: Printlink.

Merriam, S. B. (1998). Qualitative research and case study applications in education. San Francisco: Jossey-Bass.

Miller, J. (1958). Early Victorian New Zealand: A study of racial tension and social attitudes 1839-1852. Wellington: Oxford University Press.

Ministry of Economic Development. (2008). The digital strategy 2.0. Wellington: Ministry of Economic Development. Retrieved from http://www.digitalstrategy.govt.nz

Ministry of Education. (2006a). Te Reo Māori: Hei Ārai Kawenga Te Reo Māori: A pathway for learning (Draft). Wellington: Learning Media.

Ministry of Education. (2006b). Instructed second language acquisition: Case studies (pp. 44-52). Wellington: Learning Media.

Ministry of Education. (2007). The New Zealand curriculum. Wellington: Learning Media.

Ministry of Education. (2009a). Ka Hikitia - Managing for Success: The Māori Education Strategy 2008-2012 (Updated ed.). Wellington: Ministry of Education. 
Ministry of Education. (2009b). Te Aho Arataki Marau mō te Ako i Te Reo Māori: Kura Auraki curriculum guidelines for teaching te reo Māori in English-medium schools: Years 1-13. Wellington: Learning Media.

Ministry of Māori Development. (2003). Te Rautaki Reo Māori: The Māori Language Strategy. Wellington: Ministry of Māori Development.

Nation, I. S. P., \& Macalister, J. (2010). Language curriculum design. New York: Routledge.

New Zealand Council for Educational Research. (2004). Critical success factors and effective pedagogy for e-learning in tertiary education. (Background paper prepared for Institutes of Technology and Polytechnics of New Zealand). Wellington: New Zealand Council for Educational Research. Retrieved from http://www.minedu.govt.nz/ /media/MinEdu/Files/EducationSectors/TertiaryEd ucation/NZCERFinalReport.pdf

O'Regan, H. (2006). State of the reo nation: Māori language learning. In M. Mulholland and Contributors (Eds). State of the Māori Nation Twenty-first century issues in Aotearoa. Auckland: Reed.

Pachler, N., Bachmair, B., \& Cook, J. (2010). Mobile learning: Structures, agency, practices. New York: Springer.

Pasnik, S. (2007). iPod in education: The potential for teaching \& learning (One in a series of iPod in Education white papers). Retrieved from http://images.apple.com/education/ipodpaper/iPod_in_Education_whitepaper.pdf

Pehimana, T. (1995). Tīpuna Wāhine Toa. In K. Irwin, \& I. Ramsden (Eds.), Toi Wāhine: The worlds of Māori women (p. 21). Auckland: Penguin Books.

Penetito, W. (2010). What's Māori about Māori education. Wellington: Victoria University Press.

Perry, D. (2003). Handheld computers (PDAs) in schools. Coventry: Becta. Retrieved from http://dera.ioe.ac.uk/1644/1/becta_2003_handhelds report.pdf

Pihama, L., Smith, K., Taki, M., \& Lee, J. (2004). A literature review on kaupapa Māori and Māori education pedagogy (Prepared for ITP New Zealand). Retrieved from http://akoaotearoa.ac.nz/download/ng/file/group-996/n3979--literature-review-onkaupapa-mori-and-mori-education-pedagogy.pdf

Prensky, M. (2001). Digital natives, digital immigrants Part 1. On the Horizon, 9(5), 1-6. http://www.emeraldinsight.com/journals.htm?articleid=1532742

Rainger, P. (2005). Accessibility and mobile learning. In A. Kukulska-Hulme \& J. Traxler, (Eds.), Mobile learning: $A$ handbook for educators and trainers (pp. 57-69). Oxon: Routledge. 
Ratima, M., \& May, S. (2011). A review of indigenous second language acquisition: Factors leading to proficiency in te reo Māori (the Māori language). MAI Review, 1. Retrieved from http://www.review.mai.ac.nz/index.php/MR/article/view/412/594

Reedy, T. (2000). Te Reo Māori: The past 20 years and looking forward. Oceanic Linguistics, 30(1), 157-169. Retrieved from http://www.jstor.org/stable/3623221

Reinfeld, M., \& Pihama, L. (2007). Matarākau: Ngā Kōrero mō ngā Rongoā o Taranaki. Taranaki: Karangaora.

Rosell-Aguilar, A. (2007). Top of the pods: In search of a podcasting "pedagogy" for language learning. Computer Assisted Language Learning, 20(5), 471-492.

Schlager, M. S., \& Fusco, J. (2003). Teacher professional development, technology, and communities of practice: Are we putting the cart before the horse? The Information Society, 19(3), 203-220. http://dx.doi.org/10.1080/01972240309464

Scrimshaw, P. (2004). Enabling teachers to make successful use of ICT. (Prepared for and on behalf of British Educational Communications and Technology (Becta)). Retrieved from http://www.becta.org.uk

Sharples, M. (2006). Big issues in mobile learning: Report of a workshop by the Kaleidoscope Network of Excellence Mobile Learning Initiative. Nottingham: University of Nottingham. Retrieved from http://matchsz.inf.elte.hu/tt/docs/Sharples-20062.pdf

Sharples, M., Arnedillo-S`anchez, I., Milrad, M., \& Vavoula, G. (2008). Mobile learning: Small devices, big issues. In: N. Balacheff, S. Ludvigsen, T. de Jong, \& S. Barnes (Eds). Technology enhanced learning: Principles and products (pp. 233-249). Heidelberg, Germany: Springer. http://oro.open.ac.uk/ id/eprint/31416

Sharples, M., Taylor, J., \& Vavoula, G. (2005, October). Towards a theory of mobile learning. In H. van der Merwe \& T. Brown (Eds.), Mobile technology: The future of learning in your hands, mLearn 2005 book of abstracts, $4^{\text {th }}$ World Conference on mLearning, Cape Town.

Sharples, M., Taylor, J., \& Vavoula, G. (2007). A theory of learning for the mobile age. In R. Andrews \& C. Haythornthwaite (Eds.), The Sage handbook of elearning research (pp. 221-247). London: Sage. http://dx.doi.org/10.1007\% 2F978-3-531-92133-4_6

Shohel, M. M. C., \& Banks, F. (2012). School-based teachers' professional development through technology-enhanced learning in Bangladesh. Teacher development: An international journal of teachers' professional development, 16(1), 25-42. http://dx.doi.org/10.1080/13664530.2012.668103 
Shuler, C. (2009). Pockets of potential: Using mobile technologies to promote children's learning. New York: The Loan Ganz Cooney Centre at Sesame Workshop. Retrieved from http://www.joanganzcooneycenter.org/wpcontent/uploads/2010/03/pockets_of_potential_1_.pdf

Simon, J., Smith, L. T., Cram, F., Hōhepa, M., McNaughton, S., \& Stephenson, M. (2001). A civilising mission? Perceptions and representations of the New Zealand native schools system. Auckland: Auckland University Press.

Smith, G. H. (1990). Research issues related to Maori education. Paper presented to NZARE Special Interests Conference, Massey University reprinted in 1992, The Issue of Research and Maori. Auckland: Research Unit for Maori Education, University of Auckland.

Smith, L. T. (1996). Kaupapa Māori health research. In Hui Whakapiripiri: A hui to discuss strategic directions for health research. Wellington: Wellington School of Medicine: Te Rōpū Rangahau Hauora a Eru Pōmare.

Smith, L. T. (1999). Decolonizing methodologies: Research and indigenous peoples. London: Zed Books.

Smith, L. T. (2005). On tricky ground: Researching the native in the age of uncertainty. In N. K. Denzin \& Y. S Linclon (Eds.), The Sage handbook of qualitative research (pp. 85-107). Thousand Oaks: Sage.

Snyder, I., Jones, A., \& Lo Bianco, J. (2005). Using information and communication technologies in adult literacy education: New practice, new challenges. Adelaide: NCVER. Retrieved from www.ncver.edu.au

Spolsky, B. (2003). Reassessing Māori regeneration. Language in Society, 32, 553578.

Stanley, G. (2006). Podcasting: Audio on the internet comes of age. TESL-EJ, 9(4), 1-7. Retrieved from http://www.tesl-ej.org/ej36/int.pdf

Taiwhati, M., Toia, R., Te Maro, P., McRae, H., \& McKenzie, T. (2010). Takina te Kawa: Laying the foundation, a research engagement methodology in Aotearoa (New Zealand). The Australian Journal of Indigenous Education, 39, 110-117.

Tamati, D. A. (2008). Engaging the Māori e-learner: Instructional technology, design and delivery (Unpublished Med thesis). Unitec, Auckland, New Zealand.

Te Kanawa, H., \& Whaanga, H. (2005). The Māori language revitalisation agenda and Te Whakapiki Reo and Te Whakapiki i te Reo: Meeting the needs of teachers. Journal of Maori and Pacific Development, 6(2). Retrieved from http://search.informit.com.au/fullText;dn=058264708337557;res=IELIND 
Te Maro, P., Averill, R., \& Higgins, J. (2008). Evaluation of support for pāngarau teachers working in wharekura. In Te Poutama Tau evaluation report 2007: Research findings in pāngarau (pp. 27-46). Wellington: Ministry of Education.

Te Paepae Motuhake (2011). Te Reo Mauriora: Te Arotakenga o te Rāngai Reo Māori me te Rautaki Reo Māori. Review of the Māori Language Sector and the Māori Language Strategy. Retrieved from http://www.tpk.govt.nz/_documents/te-reo-mauriora.pdf

Te Puni Kōkiri. (1999). Te Tūāoma the Māori language: The steps that have been taken. Wellington: Te Puni Kōkiri.

Te Puni Kōkiri. (2010). 2009 Rangahau i Ngā Waiaro, Ngā Uara me Ngā Whakapono Mō te Reo Māori 2009 Survey of Attitudes, Values and Beliefs Towards Māori Language. Wellington: Te Puni Kōkiri. Retrieved from http://www.tpk.govt.nz/en/in-print/our-publications/publications/2009-survey-ofattitudes-values-and-beliefs-towards-the-maorilanguage/download/2010\%2009\%2001\%20RP\%202009\%20Survey\%20of\%2 0Attitudes, $\% 20$ Values $\% 20$ and $\% 20$ Beliefs $\% 20$ Towards $\% 20$ the $\% 20$ Maori\%20L anguage.pdf

Te Taura Whiri i te Reo Māori. (2012). Māori Language Level Finder Examination (LFE): Candidate handbook. Retrieved from http://www.tetaurawhiri.govt.nz/english/services_e/LFE\%20Candidate $\% 20 \mathrm{Han}$ dbook\%202012.pdf

Timperley, H., Wilson, A., Barrar, H., \& Fung, I. (2007). Teacher professional learning and development: Best evidence synthesis iteration. Wellington, New Zealand: Ministry of Education.

Traxler, J. (2008). Podcasting in context. In G. Salmon \& P. Edirisingha (Eds.), Podcasting for learning in universities (pp. 12-19). Berkshire, England: Open University Press.

Trifonova, A., Knapp, J., Ronchetti, M., \& Gamper, J. (2004). Mobile ELDIT: Challenges in the transition from an e-learning to an m-learning system. Trento, Italy: University of Trento. Retrieved from http://eprints.biblio.unitn.it/532/1/paper4911.pdf

Tuuta, M., Bradnam, L., Hynds, A., Higgins, J., with Broughton, R. (2004). Evaluation of Te Kauhua Mãori Mainstream Pilot Programme. (Report to the Ministry of Education). Wellington: Ministry of Education.

United Nations Educational, Scientific and Cultural Organization (UNESCO). (2003, March). Language vitality and endangerment. UNESCO Ad Hoc Expert Group on Endangered Languages, Paris. Retrieved from http://unesdoc.unesco.org/images/0018/001836/183699E.pdf 
Venkatesh, V., Morris, M. G., Davis, G. B., \& Davis, F. D. (2003). User acceptance of information technology: Toward a unified view. MIS Quarterly, 27(3), 425-478. Retrieved from http://faizwanuar.com/web/Readings files/Venkatesh+User +Acceptance+of+Information+Technology+2003.pdf

Vrasidas, C., \& Glass, G. V. (2007). Teacher professional development and ICT: Strategies and models. In L. Smolin, K. Lawless, \& N. C. Burbules (Eds.), Yearbook of the National Society for the Study of Education, 106(2), 87-102. http://dx.doi.org/10.1111\%2Fj.1744-7984.2007.00116.x

Waitangi Tribunal. (1989). Report of the Waitangi Tribunal on the Te Reo Maori Claim (WAI 11) $\left(2^{\text {nd }}\right.$ ed.). Wellington: Waitangi Tribunal. Retrieved from http://www.waitangi-tribunal.govt.nz/scripts/reports/reports/11/2580F91B5D6F-46F4-ADE0-BC27CA535C01.pdf

Waiti, P. (2005). Evaluation of Kaupapa Ara Whakawhiti Mātauranga (KAWM). Wellington: Ministry of Education. Retrieved from http://www.educationcounts.govt.nz/publications/ict/5087

Warschauer, M. (2004). Technology and social inclusion. Rethinking the digital divide. Cambridge, MA: MIT Press.

Webb, S. (2006). Can ICT reduce social exclusion? The case of an adults' English language learning programme. British Educational Research Journal, 32(3), 481-507. http://dx.doi.org/10.1080/01411920600635478

Winitana, C. (2011). My language, my inspiration - The struggle continues. Wellington: Huia.

Wishart, J. (2009). Use of mobile technology for teacher training. In M. Ally (Ed.), Mobile learning transforming the delivery of education and training. Edmonton: AU Press, Athabasca University. Retrieved from http://www.aupress.ca/books/120155/ebook/13_Mohamed_Ally_2009Article13.pdf

Yoon, K. S., Duncan, T., Lee, S. W-Y., Scarloss, B., \& Shapley, K. (2007). Reviewing the evidence on how teacher professional development affects students' achievement (Issues \& Answers Report, REL 2007-No.033). Washington, DC: U.S. Department of Education, Institute of Education Sciences, National Center for Education Evaluation and Regional Assistance, Regional Educational Laboratory Southwest. Retrieved from http://ies.ed.gov/ncee/edlabs/

Yuen, A. H. K., \& Ma, M. W. K. (2008). Exploring teacher acceptance of e-learning technology. Asia-Pacific Journal of Teacher Education, 36(3), 229-243. http://dx.doi.org/10.1080\%2F13598660802232779 
Yunus, M. (2007). Malaysian ESL teachers' use of ICT in their classrooms: Expectations and realities (pp. 79-95). New York: Cambridge University Press. http://dx.doi.org/10.1017/S0958344007000614. 
Appendices 


\section{Appendix 1: Interview Questions - Participant (Main Group)}

Group: Main

\section{Introduction}

Introduce the person, the date, the time and the venue before the interview starts.

\section{Te Tūāpapa}

1. What are your iwi affiliations?

2. What is your role in your school?

3. If you are a teacher how many years have you been teaching?

4. What is your role in Whakapiki i te Reo?

5. What was your primary reason for undertaking Whakapiki i te Reo?

6. Before Whakapiki i te Reo, where did you learn te reo Māori? (e.g. university, home)

7. Tell me about the different ways you have learned te reo. (e.g. speaking to grandparents, books, reading Māori books)

8. What was the most effective method or which method did you like best? (Which method did you like best?)

\section{Te Taha Hinengaro}

1. What kinds of technology do you currently use in your everyday life?

2. How do you feel about using technology?

3. How did you initially feel about using the iPod to develop your proficiency in te reo Māori?

4. How often do you use the iPod for personal use? What aspects of the iPod do you use? On a daily, weekly, or fortnightly basis?

5. How often do you use the iPod for the purposes of Whakapiki i te Reo? (If less than once a week what were the reasons?) On a daily, weekly, or fortnightly basis?

\section{Te Taha Tinana}

6. Can you explain to me how you use the iPod for your te reo Māori development?

7. Do you use the iPod in the classroom with your students? If yes, can you explain how? If no, what are the reasons why you don't use it? 
8. How has the use of iPods supported the students' proficiency in te reo Māori? How do you know this? Have you recorded the shifts?

9. Has your improved practices and/or knowledge helped to improve student language learning? How do you know this? Have you recorded the shifts?

10. Has the use of the iPod changed your teaching practice in the classroom? If yes how?

11. What have been the disadvantages or the challenges of using the iPod for te reo Māori development for you personally and as a teacher in your class? How about for other teachers across the syndicate and school wide?

12. What have been the advantages or the opportunities of using the iPod for te reo Māori development for you personally and as a teacher in your class? How about for other teachers across the syndicate and school wide?

\section{Te Taha Wairua}

13. In regards to kanohi-ki te-kanohi, what do you think are the advantages and disadvantages between learning te reo Māori when the teacher is physically in the room and when the teacher is on the iPod screen?

\section{Te Taha Whānau}

14. The Whakapiki i te Reo programme is based on a whole school approach where all or the majority of teachers undertake the programme. Can you tell me how this has impacted on your development of your te reo Māori as well as your teaching practice.

15. The Whakapiki i te Reo programme is also based on an in-school approach using a regional co-ordinator and in-school facilitator to support participants. Can you tell me how these two roles have impacted on your te reo Māori development.

\section{Te Taha Mana Whenua}

16. In what ways do you think that the iPod could be used to contribute to and incorporate iwi-specific language and knowledge?

17. Is there anything else that you would like to tell me about in regards to using iPods? 


\section{Appendix 2: Interview Questions - In-school Facilitator}

Group: Main

\section{Introduction}

Introduce the person, the date, the time and the venue before the interview starts.

\section{Te Tūāpapa}

1. What are your iwi affiliations?

2. What is your role in your school?

3. If you are a teacher how many years have you been teaching?

4. What is your role in Whakapiki i te Reo? What does this role entail?

5. What was your primary reason for undertaking Whakapiki i te Reo?

6. Before Whakapiki i te Reo, where did you learn te reo Māori? (e.g. university, home)

7. Tell me about the different ways you have learned te reo. (e.g. speaking to grandparents, books, reading Māori books)

8. What was the most effective method or which method did you like best? (Which method did you like best?)

\section{Te Taha Hinengaro}

1. What kinds of technology do you currently use in your everyday life?

2. How do you feel about using technology?

3. How did you initially feel about using the iPod to develop your proficiency in te reo Māori?

4. How often do you use the iPod for personal use? What aspects of the iPod do you use? On a daily, weekly, or fortnightly basis?

5. How often do you use the iPod for the purposes of Whakapiki i te Reo? (If less than once a week what were the reasons?) On a daily, weekly, or fortnightly basis?

\section{Te Taha Tinana}

6. Can you explain to me how you use the iPod for your te reo Māori development?

7. Do you use the iPod in the classroom with your students? If yes, can you explain how? If no, what are the reasons why you don't use it? 
8. How has the use of iPods supported the students' proficiency in te reo Māori? How do you know this? Have you recorded the shifts?

9. Has your improved practices and/or knowledge helped to improve student language learning? How do you know this? Have you recorded the shifts?

10. Has the use of the iPod changed your teaching practice in the classroom? If yes how?

11. What have been the disadvantages or the challenges of using the iPod for te reo Māori development for you personally and as a teacher in your class? How about for other teachers across the syndicate and school wide?

12. What have been the advantages or the opportunities of using the iPod for te reo Māori development for you personally and as a teacher in your class? How about for other teachers across the syndicate and school wide?

\section{Te Taha Wairua}

13. In regards to kanohi-ki te-kanohi, what do you think are the advantages and disadvantages between learning te reo Māori when the teacher is physically in the room and when the teacher is on the iPod screen?

\section{Te Taha Whānau}

14. The Whakapiki i te Reo programme is based on a whole school approach where all or the majority of teachers undertake the programme. Can you tell me how this has impacted on your development of your te reo Māori as well as your teaching practice.

15. The Whakapiki i te Reo programme is also based on an in-school approach using a regional co-ordinator and in-school facilitator to support participants. Can you tell me how these two roles have impacted on the development of your development of te reo Māori.

\section{Te Taha Mana Whenua}

16. In what ways do you think that the iPod could be used to contribute to and incorporate iwi-specific language and knowledge?

17. Is there anything else that you would like to tell me about in regards to using iPods? 


\section{Appendix 3: Interview Questions - Regional Co-ordinator}

Group: Main

\section{Introduction}

Introduce the person, the date, the time and the venue before the interview starts.

\section{Te Tūāpapa}

1. What are your iwi affiliations?

2. What is your role in Whakapiki i te Reo? What does this role entail?

3. What was your primary reason for being a part of Whakapiki i te Reo?

4. Were you a teacher prior to Whakapiki $i$ te Reo? If yes, for how many years?

5. Before Whakapiki i te Reo, where did you learn te reo Māori? (e.g. university, home)

6. Tell me about the different ways you have learned te reo. (e.g. speaking to grandparents, books, reading Māori books)

7. What was the most effective method or which method did you like best? (Which method did you like best?)

\section{Te Taha Hinengaro}

1. What kinds of technology do you currently use in your everyday life?

2. How do you feel about using technology?

3. How did you initially feel about using the mobile devices to develop your own or the participants' proficiency in te reo Māori?

4. Which mobile devices do you use? The iPod, iPad or both? How often do you use the iPod or the iPad for personal use? What aspects of these do you use? On a daily, weekly, or fortnightly basis?

5. How often do you use the iPod, iPad or both for the purposes of Whakapiki $i$ te Reo? (If less than once a week what were the reasons?) On a daily, weekly, or fortnightly basis?

\section{Te Taha Tinana}

6. Do you use the iPod or the iPad for your own te reo Mãori development? Can you explain to me how you do this?

7. Do you use the iPod or the iPad in your sessions with the participants of Whakapiki i te Reo? If yes, can you explain how? If no, what are the reasons why you don't use it? 
8. How has the use of iPods supported the participants' proficiency in te reo Māori? How do you know this? Have you recorded the shifts?

9. Has your improved practices and/or knowledge helped to improve the participants' language learning? How do you know this? Have you recorded the shifts?

10. Has the use of the iPod or iPad changed your teaching practice and delivery? If yes how?

11. What have been the disadvantages or the challenges of using the iPod for te reo Māori development for you personally and as a regional co-ordinator? How about for participants of Whakapiki i te Reo?

12. What have been the advantages or the opportunities of using the iPod for te reo Māori development for you personally and as a regional co-ordinator? How about for participants of Whakapiki i te Reo?

\section{Te Taha Wairua}

13. In regards to kanohi-ki te-kanohi, what do you think are the advantages and disadvantages between learning te reo Māori when the teacher is physically in the room and when the teacher is on the iPod screen?

\section{Te Taha Whānau}

14. The Whakapiki i te Reo programme is based on a whole school approach where all or the majority of teachers undertake the programme. Can you tell me how this has impacted on your development of your te reo Māori as well as your teaching practice.

15. The Whakapiki i te Reo programme is also based on an in-school approach using a regional co-ordinator and in-school facilitator to support participants. Can you tell me how these two roles have impacted on the development of your development of te reo Māori.

\section{Te Taha Mana Whenua}

16. In what ways do you think that the iPod or the iPad could be used to contribute to and incorporate iwi-specific language and knowledge?

17. Is there anything else that you would like to tell me about in regards to using iPods or iPads? 


\section{Appendix 4: Interview Questions - Participant (Comparison Group)}

Do learners make expected gains in language proficiency through the use of mobile devices in comparison to standard face-to-face methods of language instruction and, if there are differences, which of these can be associated with mobile device use?

Group: Comparison

\section{Te Tūāpapa}

1. What are your iwi affiliations?

2. What is your role in your school?

3. How many years have you been teaching?

4. What is your role in Whakapiki i te Reo?

5. What was your primary reason for undertaking Whakapiki i te Reo?

6. Before Whakapiki i te Reo, where did you learn te reo Māori? (e.g. university, home)

7. Tell me about the different ways you have learned te reo (e.g. speaking to grandparents, books, reading Māori books)

8. What was the most effective method or which method did you like best?

\section{Te Taha Hinengaro}

1. What kinds of professional development programmes have you been involved in, in the past?

2. How did you initially feel about undertaking professional development for te reo Māori?

3. Do you use any technology in this professional development programme? If so, which ones?

4. How often do you use these technologies for personal use? On a daily, weekly, or fortnightly basis?

5. How often do you use these technologies for the purposes of Whakapiki i te Reo? (If less than once a week what were the reasons?) On a daily, weekly, or fortnightly basis? 


\section{Te Taha Tinana}

6. Can you explain to me how the Whakapiki i te Reo programme is facilitated for your te reo Māori development?

7. How has the learning gained from the Whakapiki $i$ te Reo programme supported the students' proficiency in te reo Māori? How do you know this? Have you recorded the shifts?

8. Has the use the learning gained from the Whakapiki $i$ te Reo programme changed your teaching practice in the classroom? If yes how?

9. What have been the disadvantages or the challenges of face-to-face facilitation for te reo Māori development for you personally and as a teacher in your class? How about for other teachers across the syndicate and school wide?

10. What have been the advantages or the opportunities of face-to-face facilitation for te reo Māori development for you personally and as a teacher in your class? How about for other teachers across the syndicate and school wide?

\section{Te Taha Wairua}

11. In regards to kanohi-ki te-kanohi, what do you think are the advantages and disadvantages of learning te reo Māori with face-to-face facilitation only?

\section{Te Taha Whānau}

12. Can you tell me how the whole school/small group/individual learning approach has impacted on your development of your te reo Māori as well as your teaching practice.

13. Can you tell me how the in-school approach to te reo Māori development has impacted on your te reo Māori development.

\section{Te Taha Mana Whenua}

14. In what ways do you think the programme has contributed/could contribute to and incorporate iwi-specific language and knowledge?

15. Is there anything else that you would like to tell me? 


\section{Appendix 5: Observation Criteria}

Name

Date

School Venue

Observation Observer

The purpose of the observation is for the person being observed to demonstrate their expertise in utilising the iPod Touch $\AA$ or $\mathrm{iPad} \AA$.

\section{Observation process}

The person being observed will be asked to demonstrate how they utilise the iPod Touch ${ }^{\circledR}$ as part of the Whakapiki $i$ te Reo programme. As the person being observed demonstrates items in the list below the achieved column will be ticked. When the person being observed finishes their demonstration, the observer will ask them if they are able to demonstrate items on the list that have not yet been met. At the end of the observation the marks will be totalled and categorised into a low, medium or high user of the $\mathrm{iPod}$ Touch $\AA / \mathrm{iPad} \circledast$ (see back for details).

\begin{tabular}{|l|l|l|}
\hline Criteria & Achieved & $\begin{array}{l}\text { Not } \\
\text { achieved }\end{array}$ \\
\hline Turn on the iPod Touch®/iPad® & & \\
\hline Charge the iPod Touch®/iPad® & & \\
\hline Attach the iPod Touch®/iPad® to the computer & & \\
\hline Locate the Music folder & & \\
\hline Listen to music files & & \\
\hline Turn the volume up and down & & \\
\hline Scroll up and down the files to select a song & & \\
\hline Locate the Movies folder & & \\
\hline View the Wete reo or Hopu reo videos & & \\
\hline Fast forward or rewind the videos & & \\
\hline Locate the Voice Memos function & & \\
\hline Record audio using the Voice Memos function & & \\
\hline Custom label audio recordings & & \\
\hline Retreive past audio recordings in Voice Memos & & \\
\hline Copy audio recordings to a computer & & \\
\hline Turn on Wi-Fi to connect to the Internet & & \\
\hline $\begin{array}{l}\text { Synchronise content from the computer to the iPod } \\
\text { Touch®/iPad® }\end{array}$ & & \\
\hline Use 'Settings' function i.e. sounds, time and date... & & \\
\hline Access the Internet via Safari & & \\
\hline $\begin{array}{l}\text { Access email using iPod Touch } \text { email details) } \\
\text { encludes able to set up }\end{array}$ & & \\
\hline
\end{tabular}


A list of other aspects the participant is able to do with the iPod Touch $\circledast / i P a d \circledast$. Results of the Observation

A low user will be able to demonstrate $0-5$ aspects of the criteria, a medium user 6 -15 aspects and a high user $16-20$ aspects of the criteria (plus any other aspects that are not written in the criteria).

The results from the observation show that is a (circle or highlight the appropriate result below):

Low user of the iPod Touch $® / \mathrm{iPad} \AA$ and is able to to demonstrate $0-5$ aspects outlined in the observation criteria.

Medium user of the iPod Touch $® / \mathrm{iPad} 囚$ and is able to to demonstrate $6-15$ aspects outlined in the observation criteria.

High user of the iPod Touch $₫ / \mathrm{iPad} \circledast$ and is able to to demonstrate $16-20$ aspects outlined in the observation criteria.

Any other comments

Name and signature of the observee

Name and signature of the observer 
Appendix 6: Waikato Proficiency Tests
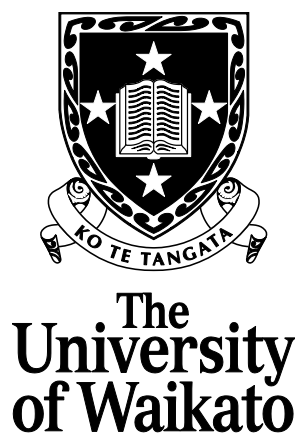

Te Whare Wānanga o Waikato

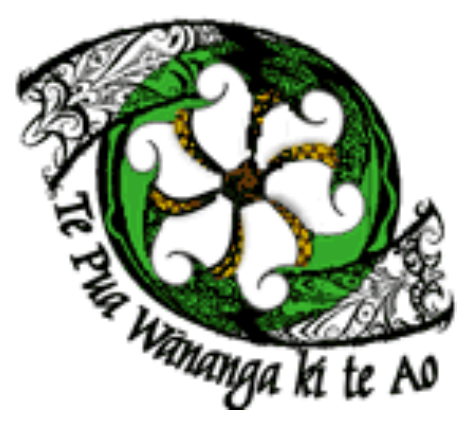

Te Whakapiki Reo Te Pua Wānanga ki te Ao

\section{Te whakamātautau reo}

WHAKARONGO - PĀNUI - TUHITUHI - KŌRERO

\section{GiNA WEBER}

INGOA:

RĀ:

\begin{tabular}{|l|l|}
\hline WHAKARONGO & \\
\hline PĀNUI & \\
\hline TUHITUHI & \\
\hline KŌRERO & \\
\hline PIRO/ KAUTE & \\
\hline
\end{tabular}




\section{RĀRANGI ŪPOKO}

WĀHANGA TUATAHI

WĀHANGA A - WHAKARONGO............................. 3

WĀHANGA E - PĀNUI. 5

WĀHANGA I - TUHITUHI.................................... 9

Pukapuka whakatara...........................12

Nā Te Rōpū Kaiwhakahaere Kirimana..........13

WĀHANGA TUARUA

WHAKAWHITIWHITI KŌRERO 


\section{WĀHANGA A - WHAKARONGO}

\section{Whakarongo tuatahi}

Whakarongo ki te kauhau, ka whakautu ai i ngā pātai.

\section{Hei mahi i}

Porowhitahia te whakautu tika.

Ko te kaupapa o tēnei kōrero ko...

(a) tētahi wahine toa, ki te tākaro kurupōro.

(e) te tīma kurupōro o Aotearoa.

(h) ngā wāhine kawe i te taumata tākaro kurupōro.

\section{Hei mahi ii}

Porowhitahia ngā āhuatanga e pā ana ki a Gina Weber me āna mahi. Kua oti te mea tuatahi māhau. (Kia rima atu)
(a) He wahine toa a Gina Weber ki te kurupōro.
(e) He kuia a Gina.
(h) Nō Rāhui Pokeka a Gina.
(i) Ko Tainui tōna iwi.
(k) He tino pakari ngā tima o Tāmaki-Makau-Rau.
(m) Ko te tino mahi hākinakina o te whānau Weber ko te tēnehi.
(n) Me kaha ki te whakapakari tinana.
(ng) Kahore tōna whānau i tautoko i ana mahi.
(p) He wahine whakahīhī a Gina.
(r) Ka uru ki te tīma o Aotearoa ka kitea e te ao whānui. 


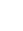

11

9

13 Whakarongo tuarua

${ }^{7} 15$

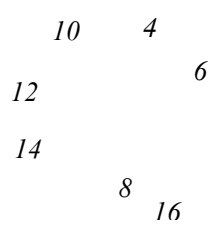

Whakarongo anō ki te kāuhau, ka whakautu ai i ngā p̧ātai e whai mai ana.

19

20

\section{Hei mahi i}

Pānuitia ēnei rerenga kōrero, ka whakarite ai mehemea kei te tika, kei te hē rānei. Tuhia he $\boldsymbol{T}$ (Tika) / he $\boldsymbol{H}(H \bar{e})$ rānei, ki roto i ngā taiapa () kei muri i ia rerenga kupu.

1. He kōrero tēnei mō Gina Weber. He wahine toa mō te pā whutupōro.

2. I uru a Gina ki roto ki te tīma tuarua o Aotearoa i te wā e tekau mā ono ( ） ana ōna tau.

3. He uri a ia nō Te Taitokerau.

4. He pai ki a ia te noho ki roto i ngā taone pakupaku.

5. He pakari ake ngā tīma ki roto i ngā rohe pēnei i a Tāmaki-Makau-Rau, ( ） Te Awakairanga me Ōtautahi.

\section{Hei mahi ii}

Whakaotihia te whakarāpopoto mā te tuhi i tētahi kupu ki ia ango.

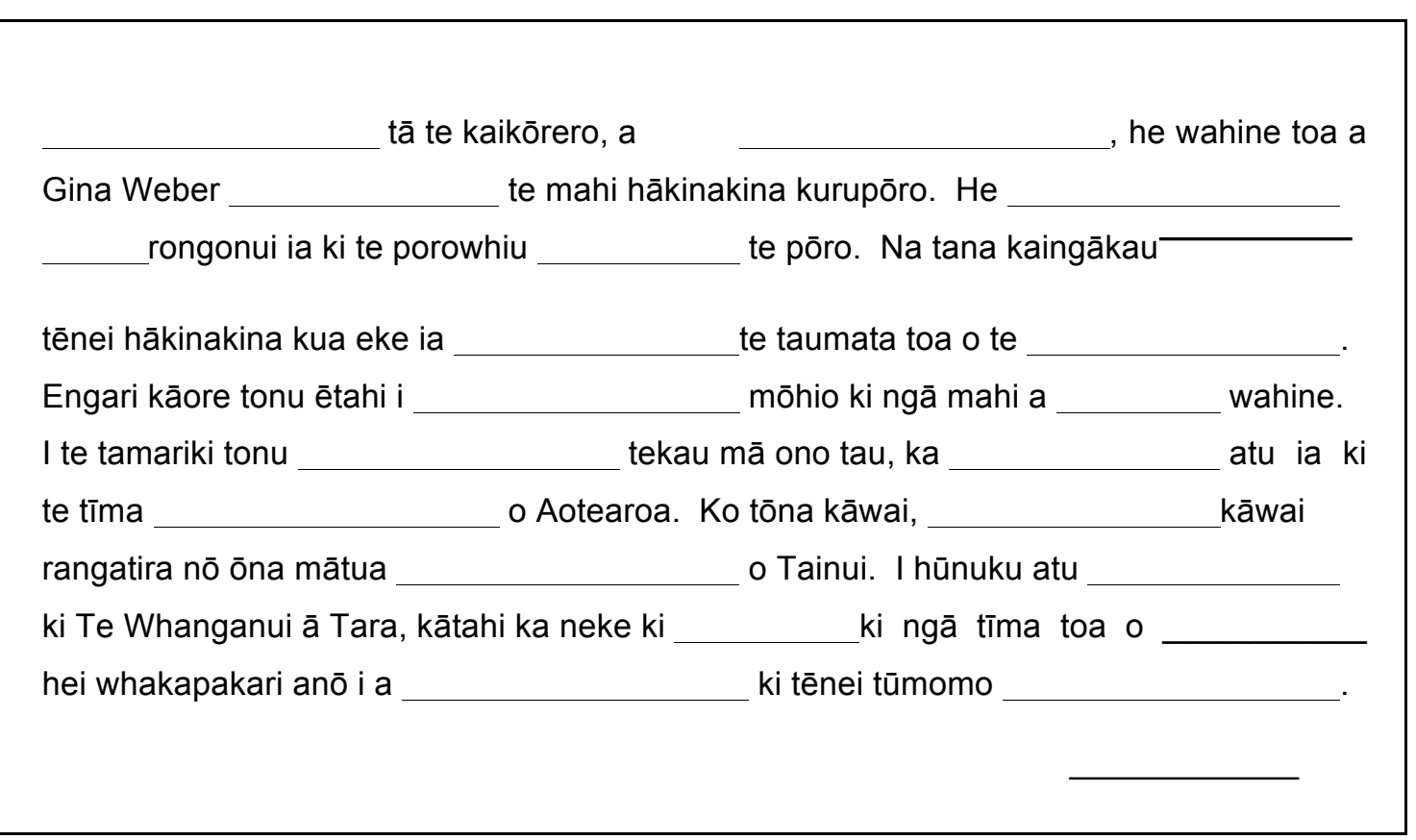




\section{WĀHANGA E - TE PĀNUI}

Pānuitia te 'Tuhinga Pānui - (Pānuitanga)'. Whakautua ngā pātai.

\section{Hei mahi $i$}

Tuhia te nama o te kowae kōrero ki ngā ango tika mō ngā kīanga e whai ake nei.

\begin{tabular}{|l|}
\hline Te whakapakari tinana. \\
\hline Tōna waimarie. \\
\hline Te āhua o Gina. \\
\hline
\end{tabular}

\section{Hei mahi ii}

Ko ènei rerenga kupu, he whakarāpopototanga o ngā whakaaro matua o te tuhituhi. Whakahoangia ki te kōwae tika o te tuhituhi (Pānui). Kua oti te mea tuatahi māhau.

Ngā hākinakina pai ki a ia.

He tinana nui.

He ngākau hūmārie.

Ngā haerenga ki ngā motu.

Mā te kaha, mā te tautoko ka taea.

He pai kia tokoroa te tangata mō te kurupōro.

He rawe ki a ia ētahi atu mahi hākinakina. 
Pānuitia anō te tuhituhi, ka whakautu ai i ngā pātai kei te whai mai.

\section{Hei mahi iii}

Porowhitahia te whakautu tika.

1. E ai ki a Gina...
(a) me tokorua ngā tangata.
(e) me purei te wahine i te poirawhi, i te tēnehi rānei.
(h) he pai tōna tokoroa.
(i) he pai tona tāraroa mō te purei tēnehi.

2. Hei whakapakari i tōna tinana...
(a) haere ai a Gina ki te whare rēhia.
(e) tākaro ai a Gina i ētahi hākinakina me te harihari reta.
(h) omaoma ai a Gina ia ata.
(i) kauhoe ai a Gina ia rā.

3. Kua tae a Gina ki te taumata o te kurupōro...
(a) i tana māngere.
(e) i te tautoko a tauiwi.
(h) i te ohorere.
(i) i tōna ake kaha me te tautoko o tōna whānau.

4. Kua tae a Gina ki...
(a) Ahitereiria.
(e) Hāmoa.
(h) Itari.
(i) Āwherika-ki-te-tonga. 
5. He wahine...

(a) whakahīhī a Gina.

(i) ngoikore a Gina.

(h) kaha a Gina ki te waiata.

(i) whakamā a Gina ki te kōrero mō tōna toa.

\section{Hei mahi iv}

He aha te tikanga o ēnei kupu? Porowhitahia te whakautu tika.

1. tokoroa
(a) he tawhiti
(e) he tāroaroa
(h) he taone

2. wetiweti
(a) 'ka mau te wehi'
(e) tino anuanu
(h) tino hūmārie

3. whakakoi
(a) he māripi
(e) whakapai tinana
(h) piata ana

4. poirawhi
(a) he hīkoi
(e) he rukuruku
(h) he tākaro pāoro

5. harihari
(a) mau haere
(e) kanikani haere
(h) katakata haere 


\section{Hei mahi v}

Anei ètahi taitara hei tāpiri atu ki tēnei tuhituhi. Porowhitahia ngā taitara e toru ka tino āhei ki te pānuitanga.

1. He Wahine Toa.

2. Wahine Tiaki Mokai.

3. Wahine Tū, Wahine Toa.

4. He Toa Netipōro.

5. Whāia Ngā Taumata Tiketike. 


\section{WĀHANGA I-TUHITUHI}

Tuhia mai he kōrero poto i te reo Māori (kupu - 400), mō ngā mahi hākinakina. Ka taea e koe te whakamahi i o whakautu mō ngā mahi whakarongo me ngā mahi pānui hei āwhina i a koe ki te tuhi. Whakaurua mai ōhou ake whakaaro.

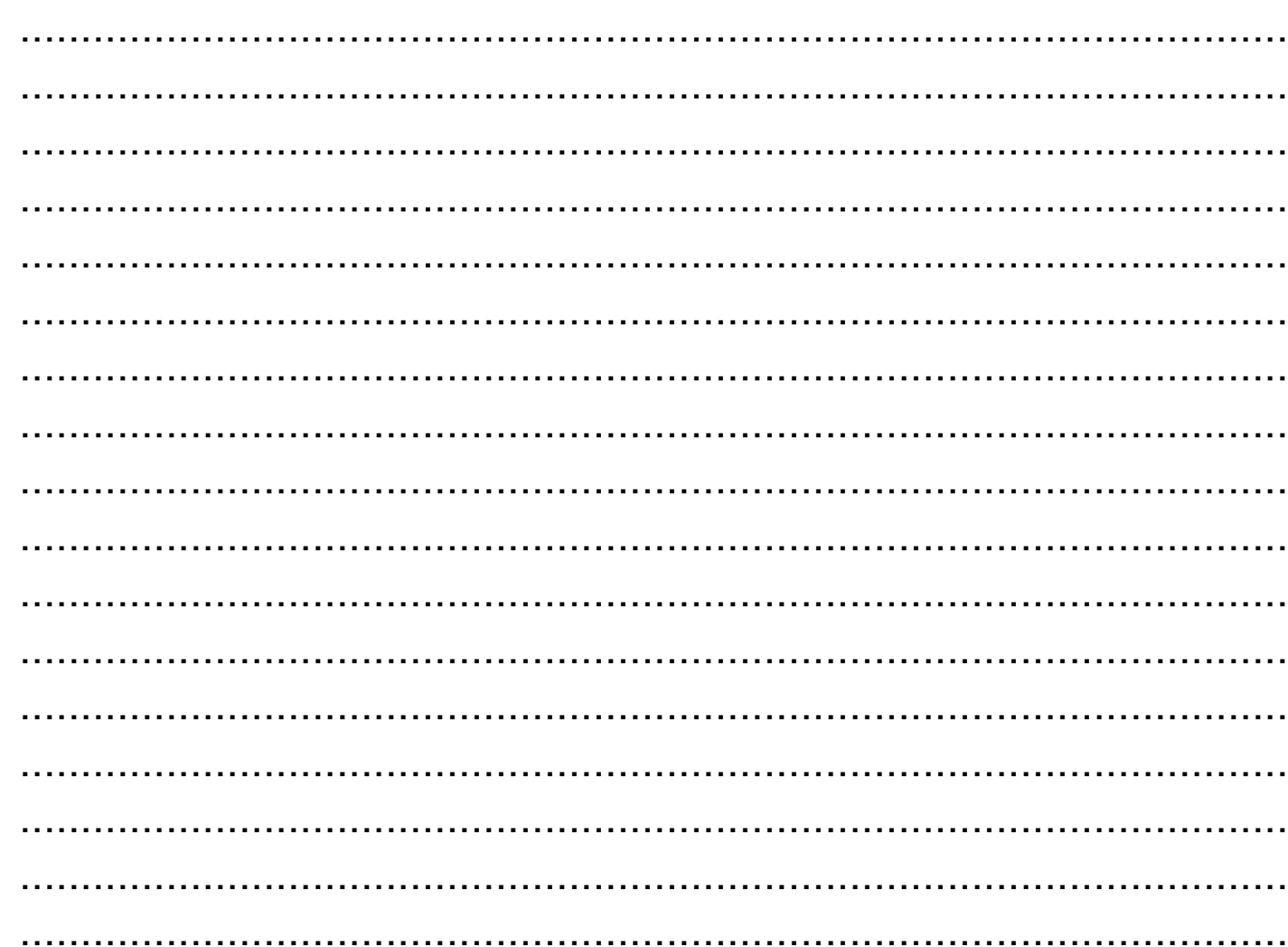




\section{Pukapuka whakatara}

Paltridge B. 1992 EAP Placement Testing : An Integrated Approach. English for Specific Purposes. 11, $243-268$.

Te Tautoko 15: Learning Media 1992 Hillary Commission: Ngā Hākinakina 


\section{WHAKARATARATA}

- Ko wai tō/ ō iwi?

- Kei hea tō kāinga?

- Kei tēhea rohe?

- He pēhea te āhua o tō kāinga?

- He tamariki āhau?

\section{TE TAUMATA}

(Kia mōhiotia ai ngā āhuatanga whakaako, te reo, me ngā āhuatanga hei āwhina i te tauira.)

(a) Kei roto koe i tētahi rōpū tākaro hākinakina? E tākaro ana koe i tētahi momo hākinakina? He aha ngā hākinakina tākaro tahi ai koe ki ō tamariki?

(e) He pēhea ki a koe ēnei mahi hākinakina? He aha ai?

(i) Mēna i a koe te tikanga whakahaere rōpū hākinakina, ka aha koe? Ka whakawhiti koe ki tāwāhi? He aha ai?

(o) He aha ngā painga o ngā mahi hākinakina?

He aha ngā mea kāore e pai o ngā mahi hākinakina?

(u) He aha te mea tino uaua o te ako/ whakaako i te reo Māori? He aha te mea e tino hiahia ana koe kia pakari ake ai tōu reo? (porowhitahia)

$\begin{array}{llll}\text { kōrero } & \text { whakarongo } & \text { pānui } & \text { kupu } \\ \text { tuhituhi } & \text { whakahua } & \text { whakatakoto } & \end{array}$

\section{TE RAPARAPA}

(k) He aha o hiahia mai i tēnei mahi?

Me pēhea ēnei e tutuki ai?

He aha e kore tutuki ai?

(m) He pātai anō āhau mō ngā mahi reo Māori ka whakahaerehia e mātou ki konei?

\section{WHAKAMUTU}

(n) He kōrero kē atu āu? 


\section{Tuhinga Pānui}

1. Tōna tikanga kē, ko ngā wāhine tokoroa e ono putu, e rua inihi, pai kē a ia mo ngā takaro poirawhi, netipōro rānei. E whakaae ana a Gina na tōna tokoroa a ia i waimarie, i āwhina. "Ina eke ahau ki runga i te puke porowhiu kātahi ka tino nui rawa atu, tino wetiweti nei hoki taku āhua."

2.

He mahi hākinakina te kurupōro na te whānau o ngā Weber mai rā anō i a ia e pakupaku ana. Kei te kaingākau anō ia ki ētahi atu mahi hākinakina pēnei i te kurupōro whakapā, te poiwhana me te poirawhi. Ko ēnei tākaro me tana mahi harihari reta ngā hākinakina hei whakapai, hei whakakorikori i tōna tinana.

3. E kī ana a Gina mīharo katoa a ia i te mea kua tū a ia hei toa mo Aotearoa. Rite tonu ōna whakaaro ki ngā tāngata mahi hākinakina kua eke ki tēnei taumata. Engari, ma te kaha anake ka taea tēnei āhuatanga. Kia kaha tonu koe ki te whakakoi, ki te whakapakari i to tinana kia eke ai koe ki te taumata o ngā mahi hākinakina. A, ma te whānau anō hoki o mahi e tautoko."

4. Na te hākinakina kurupōro a Gina i kawe ki ngā momo whenua o te ao pērā i a Kanata, Amerika, Haina, a Itari me ētahi atu.

5. He wahine whakamā a Gina ki te kōrero mo ngā taumata kua ekea e ia, a, kino katoa a ia kia kiia ko ia te toa tuatahi. Ko āna kōrero whakamutunga, mehemea ka waimarie koe ki te uru ki roto ki te tīma o Aotearoa, ka kite koe i te ao whānui. 


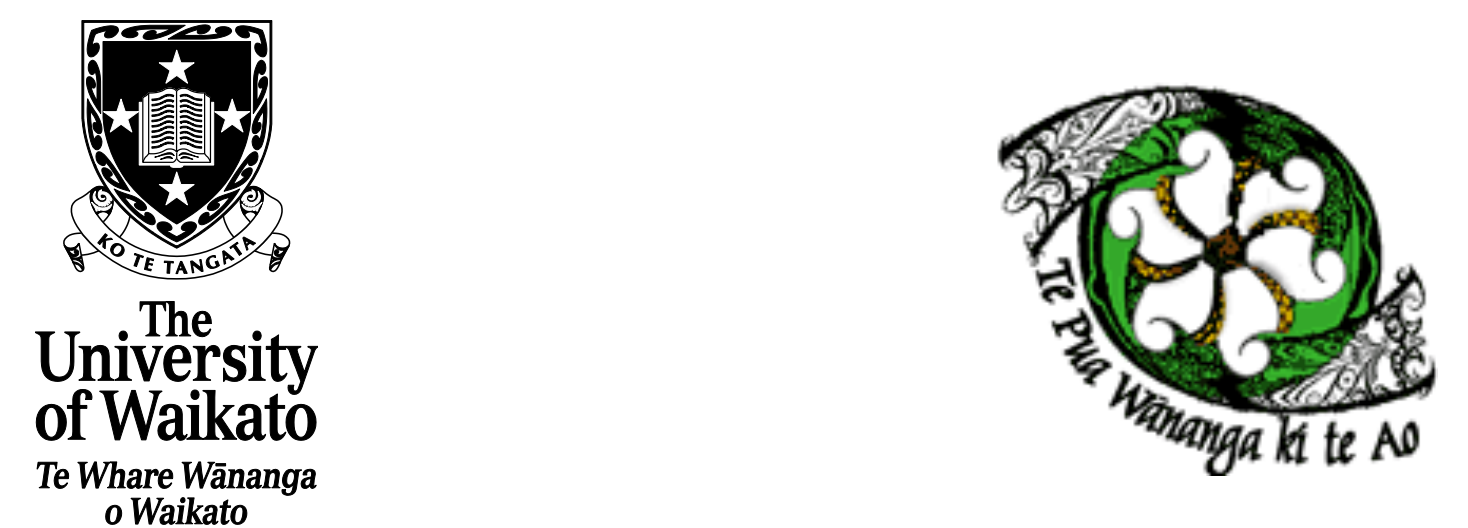

\section{TE WHAKAMĀTAUTAU REO}

Whakarongo - PĀnUI - TUHITUHI - KŌrero

\section{NGĀ MAHI Ā TE RĒHIA}

INGOA:

RĀ:

\begin{tabular}{|l|l|}
\hline WHAKARONGO & \\
\hline PĀNUI & \\
\hline TUHITUHI & \\
\hline KŌRERO & \\
\hline PIROI KAUTE & \\
\hline
\end{tabular}

TĀ TE TAUIRA

WHAKAPUTA (EXIT TEST) 
RĀRANGI ŪPOKO

WĀHANGA TUATAHI

WĀHANGA A - WHAKARONGO.................... 3

WĀHANGA E - PĀNUI

5

WĀHANGA I - TUHITUHI........................... 9

PUKAPUKA WHAKATARA......................... 12

WĀHANGA TUARUA

WHAKAWHITIWHITI KŌRERO 


\section{WĀHANGA A - WHAKARONGO}

\section{Whakarongo Tuatahi}

Whakarongo ki te kauhau ka whakautu ai i ngā pātai.

\section{Hei Mahi i}

Porowhitahia te whakautu tika.

Ko te kaupapa o tēnei kōrero ko...
(a) Te whakataetae haka.
(e) Te waiata-ā-ringa.
(h) Ngā kapa haka i toa.

\section{Hei Mahi ii}

Porowhitahia kia ono ngā āhuatanga e pā ana ki ngā whakataetae kapa haka $i$ kōrerohia. Kua oti te mea tuatahi māhau. (Kia kaua e piki ake i te ono)
(a) I tū ngā whakataetae ki Tāmaki makau rau.
(e) He kuia a Rēhia.
(h) He whiriwhiri i ngā kapa hei māngai mō te rohe.
(i) Tokowhitu ngā kapa i tū.
(k) Tekau mā whā ngā kapa i whakataetae.
(m) Ko ētahi o ngā kapa i tū noa ki te whakangahau.
(n) He nui ngā tamariki pākeha o te kapa whakangahau tuatahi.
(ng) Kei te hē te whakahua i te reo Māori a ētahi kapa tamariki.
(p) Ka tino pakari te reo ki te hē te whakahua.
(r) I whakaurua e te kapa tuatahi he waiata pākehā. 
Whakarongo anō ki te kauhāu, ka whakautu ai i ngā pātai e whai mai ana.

\section{$\stackrel{9}{\text { Hei Mahi i }}$}

Pānuitia ēnei rerenga kupu, ka whakarite ai mehemea kei te tika, kei te hē rānei (e ai ki te kōrero). Tuhia he $\boldsymbol{T}$ (Tika) / he $\boldsymbol{H}$ (Hē) rānei, ki ngā taiapa ().

1. Ko tēnei whakataetae haka i tū i te tau 1973.

2. He taonga tuku iho ngā mahi a Rēhia.

3. I tū te kapa o te kāreti o Tīpene.

4. Ko te waiata tino ataahua o te kapa tuatahi ko tā rātou waiata-ā-ringa.

5. I Waikato te kaituhi e noho ana.

\section{Hei Mahi ii}

Whakakiia ngā ango. Kia kōtahi noa iho te kupu ki ia ango.

whakamahia e te ngā kupu o tētahi

hei whakakaupapa i ana mō te whakataetae haka tū ki Âkarana. Ko whakataetae a-rohe i tū te tau 1973 hei

i ngā kapa haka māngai mō te rohe Tāmaki makau rau. I tērā wā ai ngā whakataetae a-rohe tau, ia

tau. Mai ēnei e kitea ai wai ka tū i

whakataetae nui o te motu. ètahi i tū noa te whakangahau i te ko ētahi i tū te whakataetae. He maha ngā tamariki pākehā. 


\section{WĀHANGA E - TE PĀNUI}

Pānuitia te "Tuhinga pānui ", ka whakautu ai i ngā pātai.

Hei Mahi i

Tuhia te nama o te kōwae e hāngai ana ki ēnei kōrero.

Na ngā toa i kitea ai, i rongohia ai te tino wana o ngā mahi a Te Rēhia.

Mahia, manaakitia, pupuritia ngā taonga a rātau mā kia kaua e tukuna kia ngaro hāere

Ma wai rā e whakawana ake te tū a te kapa haka.

\section{Hei Mahi ii}

He rerenga kōrero ēnei kua whakarāpopototia. Tuhia te nama o te kōwae e hāngai tika ana. Kua oti te mea tuatahi māu.

\begin{tabular}{|l|}
\hline $\begin{array}{l}\text { Ko te wana o ā rātau mahi i mau tonu, } \\
\mathbf{a}, \text { mutu noa. }\end{array}$ \\
\hline $\begin{array}{l}\text { Ahakoa e noho pani ana te rōpu nei, e mau kaha } \\
\text { ana rātau ki ngā mahi a kui mā, a koro mā. }\end{array}$ \\
\hline Ma te tāne e whakawana ake ngā mahi waiata. \\
\hline $\begin{array}{l}\text { Mai tēra wā ki tēnei wā, e kore tonu ana ētahi o } \\
\text { tātau e whakaae ki ēnei mahi whakataetae. }\end{array}$ \\
\hline I rongohia ai "ēra" o ā tatau waiata. \\
\hline $\begin{array}{l}\text { I runga i te āhua o ngā tinana, ka hoki whakamua } \\
\text { ngā whakaaro. }\end{array}$ \\
\hline Hei tōna wā, kua tū mai hei rōpu toa. \\
\hline
\end{tabular}

Ahakoa e noho pani ana te rōpu nei, e mau kaha

Ta te tane e whakawana ake ngã mahi walata.

Mai tēra wā ki tēnei wā, e kore tonu ana ētahi o tātau e whakaae ki ēnei mahi whakataetae.

I rongohia ai "ēra" o ā tatau waiata.

I runga i te āhua o ngā tinana, ka hoki whakamua

Hei tōna wā, kua tū mai hei rōpu toa. 
Pānuitia anōtia te tuhinga pānui, ka whakautu ai i ngā pātai.

\section{Hei Mahi iii}

Porowhitahia te whakautu tika.

1. E aroha ana te kaiwhakawā...
(a) ki te tino tauhou o te kapa o Hīrere.
(e) ki te kapa i toa i ngā whakataetae.
(h) ki ngā puhi o Wikitōria.
(i) ki te rōpu whakamā ki te mātakitaki atu.

2. Ki te tauriterite te hari o te waiata...
(a) pai ana ki te whakarongo atu.
(e) ka rongohia te tino wana.
(h) rongo kau ana te tangata i te waiata kotahi, kua rongo ia i te katoa.

3. He nanakia tonu te kapa o Hīrere ahakoa tō rātau...
(a) korenga e whiwhi kōtiro mā rātau.
(e) tauhou ki te whakataetae.
(h) kaha ki te kōrero Māori.

4. E tika ana kia tuarua te kapa nei i taua pō...
(a) Te Rōpu Mihinare o Ākarana.
(e) Te Rōpu Manutaki.
(h) Rangimārie.

5. Na ngā mahi a Te Rēhia...
(a) i ngaro hāere ai tō tātau reo.
(e) i rite tonu ai te titoa o te waiata hou.
(h) i pau ai te hau o tētahi o ngā kaitātaki. 


\section{Hei Mahi iv}

He aha te tikanga o ēnei kupu? Porowhitahia te whakautu tika.

1. whakawana
(a) ka mau te wehi
(e) pekepeke hāere
(h) maroke

2. tauriterite
(a) whakakotahi
(e) ōrite ana
(h) rerekē

3. nanakia
(a) taurekareka
(e) anahera
(h) pai tonu

4. whakamā
(a) i tū māia
(e) tauhou ki tēnei mahi
(h) kua waia kē ki te whakataetae

5. whakatikitikitanga
(a) i herua ngā makawe ki runga ūpoko
(e) piataata mai ana
(h) te hinuhinu o ngā makawe 


\section{Hei Mahi v}

Anei ètahi ūpoko kōrero hei tāpiri atu ki tēnei tuhinga pānui. Porowhitahia ngā ūpoko kōrero e toru e tino hāngai ana ki te Tuhinga Pānui.

1. Ngā Whakataetae Nui o te Motu.

2. Pupuritia! He Tāonga Tuku Iho.

3. Mā te Whakamā e Ngaro ai ngā Mahi.

4. He Whakataetae, He Waiata Hou.

5. Ngā Kapa o Tāmaki makau rau. 


\section{WĀHANGA I - TUHITUHI}

Tuhia mai he körero poto i te reo Mäori mö ngä whakataetae kapa haka o te motu. Ka taea e koe te whakamahi i o whakautu mö ngä mahi whakarongo me ngä mahi pänui hei äwhina i a koe ki te tuhi. Whakaurua mai öhou ake whakaaro. 


\section{Pukapuka Whakatara:}

Paltridge B. 1992 EAP Placement Testing : An Integrated Approach. English for Specific Purposes. 11, 243 - 268.

Kāretu, T. He Pitopito Kōrero; Ngā Mahi ā te Rēhia. 


\section{Tuhinga Pānui}

1. Āroha ana ngā puhi o Wikitoria i te korenga e whiwhi tāne mā ratou hei paku whakawana ake i ā rātou waiata. Ka maroke kē te kapa tū mai he kōtiro anake, he tāne anake ranei; mā tētahi anō tētahi e āwhina, e tautoko, ka wana ai te haka. Reka ana ngā reo o Wikitoria ki te waiata ēngari, ki a au nei, he tauriterite rawa tā rātou hari o ā rātou waiata, ā, rongo kau ana te tangata i te waiata kotahi noa iho nei ā rātou kua rongo ia i te katoa. Hāunga rā ēnei kōrero, e kare mā, kia kaha tonu ki a koutou.

2. Ko te kapa o Hīrere i tū mai he nanakia tonu ahakoa tō rātou tino tauhou ki ēnei mahi. Ko ētahi o ā rātou waiata nō ngā moutere o Te Moana-nui-ā-Kiwa, ā, pai ana hoki te whakarongo atu ki ērā waiata ā tātou e mahia mai ana. Kei a koutou tētahi tangata pai ki te haka, e hoa mā, ā, māna koutou e whakaako kia tū rawa ake anō ai koutou kua tino pai kē koutou. Kia ora Wiremu.

3. Ko te kapa i toa i ngā whakataetae ko tērā e kiia rā ko Te Rōpu Manutaki. Nā tēnei kapa ka kitea te tino wana o te kapa ki te mahi i ngā mahi tuku iho ā ō tātou koroua. Whakaeke mai ana te kapa nei rongo tonu te tangata i te wana, $\bar{a}$, i mau tonu i $\bar{a}$ rātou tō rātou wana ā mutu noa ā rātou mahi. Ki a au nei, ko tā rātou poi tā rātou mea i tino pīrangi rawa atu au nā te mea i kaha rawa atu te wana - otirā i pērā katoa ā rātou mahi. Ko tā rātou waiata i wana anō hoki, ā, ko tā rātou anake te mea i tino wana o ngā waiata katoa i waiatahia i taua pō rā. Kia ora, e Pita, koutou ko tō rōpu, e tika ana kia toa koutou i taua pō.

4. Ko te rōpu o Rangimārie he rōpu whakamā nei ki te mātakitaki atu ēngari i pai tonu rātou. Ko ō ratou reo he ātaahua ki te whakarongo atu ahakoa ko ētahi o ā rātou mahi kāore i tino rite te wana ki ètahi atu o ngā rōpu i tū mai. Aua atu, hei tōna wā kua tū mai koutou hei toa mō ēnei mahi, e kare mā nō reira kia kaha ki a koutou, e kī ana hoki te kōrero, 'Whāia e koe te iti kahurangi; ki te tūohu koe me maunga teitei'.

5. Ko te Rōpu Mihinare o Ākarana he rōpu kaha ki te pupuri i ēnei mahi, ā, kitea atu ana tō rātou waia ki te tū whakataetae mai. Otirā, i tuarua rātou i tēnei wā, ā, ki a au nei ātaahua kē ana tā rātou haka. Mutu rawa ake tā rātou haka mai kua pau kē te hau o te kaitātaki i tōna kaha whakahau i tana kapa - puta ana te ihi i tēnei tū haka. Tēnā koutou kua noho pani nei i te āhuatanga o tō koutou whāea, tuahine kua moe nei i tōna moenga roa. 
6. Ko te Puru o Tamaki he rōpu hou ki ēnei whakataetae ēngari ēhara i te kapa hou ki ēnei mahi. Ko tō rātou kaitātaki ka ātaahua kē ki te mātakitaki atu e tātaki mai ana i tana kapa. Hoki ana ngā whakaaro ki ngā wā o mua i te piataata mai o ngā tinana tāne i te panitanga ki te hinu, i te whakatikitikitanga o ngā makewe o ngā tane, ā, i te tū tonu mai o te tangata. Tēnā koutou, e hoa mā.

7. Koinei rā ètahi whakaaro o tētahi i noho hei kaiwhakawā i ngā whakataetae nei. Ahakoa te kore e whakaae o ètahi o tātou ki ēnei mahi kāore e taea te whakahē te kōrero nā ēnei mahi i mau tonu ai ngā haka me ngā waiata ā rātou mā, ā, nā ēnei mahi hoki i rite tonu ai te titoa o te waiata hou. Heoi anō tāku, kia kaha mai tātou ki te manaaki i ēnei tāonga kei te toe mai ki a tātou - kaua hoki ēnei e tukuna kia ngaro haere pēnei me tō tātou reo e ngaro haere nei i te rangatahi, ā, i ètahi anō o ngā pakeke. Mā ēnei mahi pea e mau tonu ai te reo - koina rā tōku nā wawata.

Kia ora koutou katoa. 
INGOA:

WHAKARATARATA

- Ko wai tō/ ō iwi?

- Kei hea tō kāinga?

- Kei tēhea rohe?

- He pēhea te āhua o tō kāinga?

- He tamariki āhau?

\section{Te TAumata}

(Kia mōhiotia ai ngā āhuatanga whakaako, te reo, me ngā āhuatanga hei āwhina i te tauira.)

(a) Kei te ako koe i ngā mahi kapa haka i to kura/ i to kāinga rānei? Ngā reo e rua? Kei hea tō kura?

(e) He pēhea ki a koe ēnei mahi?

(i) He aha ngā painga o ngā mahi kapa haka? He ngā mea kāore e pai o ngā mahi kapa haka?

(o) He aha te mea tino uaua o te ako/whakaako i te reo Māori? $\mathrm{He}$ aha te mea e tino hiahia ana koe kia pakari ake ai tōu reo? (porowhitahia)

$\begin{array}{llll}\text { kōrero } & \text { whakarongo } & \text { pānui } & \text { kupu } \\ \text { tuhituhi } & \text { whakahua } & \text { whakatakoto } & \end{array}$

\section{TE RAPARAPA}

(k) He aha o hiahia mai i tēnei mahi?

Me pēhea ēnei e tutuki ai?

He aha e kore tutuki ai?

(m) He pātai anō āhau mō ngā mahi reo Māori ka whakahaerehia e mātou ki konei?

\section{WHAKAMUTU}

(n) He kōrero kē atu āu? 


\title{
Appendix 7: Ethics Forms
}

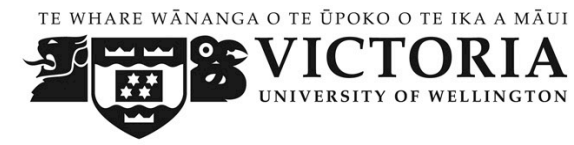

\section{FACULTY OF EDUCATION}

\section{INFORMATION LETTER FOR PRINCIPAL (MAIN STUDY)}

\author{
Research Title: The Challenges and Opportunities of Using Mobile Devices to \\ Attain Māori Language Proficiency.
}

Tēnā koe e te rangatira,

nei rā ngā mihi maioha ki a koe e pīkau nei i ngā taumahatanga o ngā whakaakoranga mō a tātou taonga, ā tātou mokopuna, rātou e tū nei hei rangatira mō āpōpō.

Ko Tabitha McKenzie tēnei e tū ngākau iti nei ki mua i te aroaro o te iwi, o te hapū, o te whānau, me ngā herenga waka, ngā herenga tangata e hono ai tātou ki a tātou. E mihi ana ki a koutou, nō reira, tēnā koutou, tēnā koutou, tēnā rā tātou katoa.

My name is Tabitha McKenzie and I am a PhD student at Victoria University of Wellington (VUW), Faculty of Education. I would like to conduct research with participants involved in Whakapiki i te Reo (WPR). The purpose of this study is to explore the challenges and opportunities of using mobile devices to attain proficiency in te reo Māori. Another main question for my research is to explore if learners make expected gains in language proficiency through the use of mobile devices in comparison to standard face-to-face methods of language instruction and, if there are differences, which of these can be associated with mobile device use?

I am informing you of the research project and the process I am taking to approach your teaching staff involved in the VUW WPR programme and inviting them to take part in the research.

\section{What will the study involve?}

There are two options that participants can take part in the research.

Option 1: Questionnaire and proficiency test

If the participant agrees to take part in this research they will be one of up to 40 participants taking part in one individual questionnaire each. The questionnaire will be administered electronically and will take approximately 20 minutes to complete. This research will also involve using the participants' pre and post-test results from the Waikato Proficiency Test. The pre and post-test results will be analysed in terms of the changes that have or have not occurred.

Option 2: Interview, observation and proficiency test

If the participant agrees to take part in this research they will be one of up to 20 participants taking part in two individual interviews each. Each interview will take approximately 1 hour at a negotiated time and location. The participant will also be observed using the mobile device for the purposes of the VUW WPR 
programme. There will also be two observations over two separate time periods at a negotiated time and location, taking approximately 20 minutes each with 510 minutes discussion time at the end. I will request to audio record the participant's responses. This research will also involve using the participants' Waikato proficiency pre and post-test results and analysing changes that have or have not occurred.

\section{Confidentiality}

Any information that is obtained in connection with this study and that can be identified with any of the participants will remain confidential and will be disclosed only with the participant's permission or with your permission, except where disclosure is required by law. The transcripts from the interviews will be transcribed by an external person and any te reo Māori that is used will be quality assured by a Māori language expert to ensure my interpretation/translation of the text is that of which the interviewee intended. I will also formulate a reference group to to provide assistance with my data. Any transcriber, Māori language expert or reference group participant who provide assistance with this research will be asked to sign a confidentiality agreement. The results of this research will be presented in a thesis as well as written and verbal reports, but your name, the participants' names or the names of the school will not be identifiable in any of these documents or reports.

\section{Ethics}

My practice as an emerging researcher based in Te Kura Māori, Ako Pai, is informed by the ethical guidelines developed in Hei Korowai. A summary of these guidelines is attached, and the full document is available for you to read at any stage of the project. The VUW Faculty of Education Human Ethics Committee has approved the ethical application (Reference No.RM 18040). If at any time you have any questions or concerns about your treatment as a research participant in this study, contact Dr. Allison Kirkman, Chair of the Victoria University of Wellington Human Ethics Committee (Telephone: 04463 5676; Email: allison.kirkman@vuw.ac.nz).

\section{Data Storage and Deletion}

All paper-based and audio data will be stored in a locked filing cabinet in a locked office at VUW. The electronic data will be kept in a password-protected file. As required by copyright, the data will be stored for 5 years after publication and then deleted/wiped/shredded after the 5-year storage period.

\section{Reporting/Dissemination}

The results of this research will be submitted for a doctoral degree, for publication in research and or professional journals and may be presented at a conference. A copy of any such reports can be obtained from me. Thank you for considering involvement in this research. If you have any questions about the study now or at any time in the future, please feel free to contact my supervisors or myself using the contact information below.

Ka mutu i konei i runga anō i te hiahia ka whai kiko te mahi nei mō ngā kura, arā, ko ngā tamariki mokopuna, ngā mātua, ngā kaiako, me te whānau whānui. Tēnā anō tātou katoa.

Nāku noa

Nā Tabitha McKenzie 
Researcher

Tabitha McKenzie

PhD student, Te Kura Māori

Faculty of Education

Victoria University of Wellington

PO Box 17-310, Karori

Wellington, NZ

044639684

tabitha.mckenzie@vuw.ac.nz
Supervisors

Professor Wally Penetito

044635169

wally.penetito@vuw.ac.nz

Professor Luanna Meyer

044639598

luanna.meyer@vuw.ac.nz 
CONSENT FORM FOR PRINCIPAL (MAIN STUDY)

Research Title: The Challenges and Opportunities of Using Mobile Devices to Attain Māori Language Proficiency.

This research has been assessed and approved by Victoria University of Wellington Faculty of Education Ethics Committee (Reference No.RM 18040).

Please tick the appropriate box to indicate your agreement/disagreement with the statements and to provide informed consent to approach participants for participation in this research.

Yes No

I have been given and have understood an explanation of this research project. I have had an opportunity to ask questions and

have answered to my satisfaction.

them

Name of Principal:

Email:

Date: Signed:

$\square$ I would like to be sent a copy of any reports arising from this research.

Please return this form to Tabitha McKenzie. Thank you. 
INFORMATION LETTER FOR PRINCIPAL (COMPARISON STUDY)

\section{Research Title: The Challenges and Opportunities of Using Mobile Devices to Attain Māori Language Proficiency.}

Tēnā koe e te rangatira,

nei rā ngā mihi maioha ki a koe e pīkau nei i ngā taumahatanga o ngā whakaakoranga mō a tātou taonga, ā tātou mokopuna, rātou e tū nei hei rangatira mō āpōpō.

Ko Tabitha McKenzie tēnei e tū ngākau iti nei ki mua i te aroaro o te iwi, o te hapū, o te whānau, me ngā herenga waka, ngā herenga tangata e hono ai tātou ki a tātou. E mihi ana ki a koutou, nō reira, tēnā koutou, tēnā koutou, tēnā rā tātou katoa.

My name is Tabitha McKenzie and I am a PhD student at Victoria University of Wellington, Faculty of Education. I would like to conduct research with participants involved in Whakapiki i te Reo (WPR). The purpose of this study is to explore if learners make expected gains in language proficiency through the use of mobile devices in comparison to standard face-to-face methods of language instruction and, if there are differences, which of these can be associated with mobile device use?

I am informing you of the purpose of my research and the process of approaching your teaching staff involved in WPR and inviting them to take part in the research.

\section{What will the study involve?}

If the participant agrees to take part in this research they will be one of up to 10 participants taking part in one individual interview each. The interview will take approximately 1 hour at a negotiated time and location. I will also request the interview be audio recorded.

This research will also involve using the participants' pre and post-test results from the Waikato Proficiency Test. The pre and post-test results will be analysed in terms of the changes that have or have not occurred.

\section{Confidentiality}

Any information that is obtained in connection with this study and that can be identified with any of the participants will remain confidential and will be disclosed only with the participant's permission or with your permission, except where disclosure is required by law. The transcripts from the interviews will be transcribed by an external person and any te reo Māori that is used will be quality assured by a Māori language expert to ensure my interpretation/translation of the text is that of which the interviewee intended. I will also formulate a reference group to to provide assistance with my data. Any transcriber, Māori language expert or reference group participant who provide assistance with this research will be asked to sign a confidentiality agreement. The results of this research will be presented in a thesis as well as written and verbal reports, but your name, the participants' names or the names of the school will not be identifiable in any of these documents or reports. 


\section{Ethics}

My practice as an emerging researcher based in Te Kura Māori, Ako Pai, is informed by the ethical guidelines developed in Hei Korowai. A summary of these guidelines is available for you to read at any stage of the project. The VUW Faculty of Education Human Ethics Committee has approved the ethical application (Reference No.RM 18040). If at any time you have any questions or concerns about your treatment as a research participant in this study, contact Dr. Allison Kirkman, Chair of the Victoria University of Wellington Human Ethics Committee (Telephone: 04463 5676; Email: allison.kirkman@vuw.ac.nz).

\section{Data Storage and Deletion}

All paper-based and audio data will be stored in a locked filing cabinet in a locked office at VUW. The electronic data will be kept in a password-protected file. As required by copyright, the data will be stored for 5 years after publication and then deleted/wiped/shredded after the 5-year storage period.

\section{Reporting/Dissemination}

The results of this research will be submitted for a doctoral degree, for publication in research and or professional journals and may be presented at a conference. A copy of any such reports can be obtained from me.

Thank you for considering involvement in this research. If you have any questions about the study now or at any time in the future, please feel free to contact my supervisors or myself using the contact information below.

Ka mutu i konei i runga anō i te hiahia ka whai kiko te mahi nei mō ngā kura, arā, ko ngā tamariki mokopuna, ngā mātua, ngā kaiako, me te whānau whānui. Tēnā anō tātou katoa.

Nāku noa

Nā Tabitha McKenzie

\section{Researcher}

Tabitha McKenzie

PhD student, Te Kura Māori

Faculty of Education

Victoria University of Wellington

PO Box 17-310, Karori

Wellington, NZ

044639684

tabitha.mckenzie@vuw.ac.nz

\author{
Supervisors \\ Professor Wally Penetito \\ 044635169 \\ wally.penetito@vuw.ac.nz \\ Professor Luanna Meyer \\ 044639598 \\ luanna.meyer@vuw.ac.nz
}




\section{CONSENT FORM FOR PRINCIPAL (COMPARISON STUDY)}

Research Title: The Challenges and Opportunities of Using Mobile Devices to Attain Māori Language Proficiency.

This research has been assessed and approved by Victoria University of Wellington Faculty of Education Ethics Committee (Reference No.RM 18040).

Please tick the appropriate box to indicate your agreement/disagreement with the statements and to provide informed consent to approach participants for participation in this research.

Yes No

I have been given and have understood an explanation of this research project. I have had an opportunity to ask questions and

have answered to my satisfaction.

them

Name of Principal:

Email:

Date: Signed:

$\square$ I would like to be sent a copy of any reports arising from this research.

Please return this Consent Form to Tabitha McKenzie. Thank you. 


\section{INFORMATION LETTER FOR INTERVIEW - FACILITATOR (COMPARISON STUDY)}

\section{Research Title: The Challenges and Opportunities of Using Mobile Devices to Attain Māori Language Proficiency.}

Tēnā koe e te rangatira,

nei rā ngā mihi maioha ki a koe e pīkau nei i ngā taumahatanga o ngā whakaakoranga mō a tātou taonga, ā tātou mokopuna, rātou e tū nei hei rangatira mō āpōpō.

Ko Tabitha McKenzie tēnei e tū ngākau iti nei ki mua i te aroaro o te iwi, o te hapū, o te whānau, me ngā herenga waka, ngā herenga tangata e hono ai tātou ki a tātou. E mihi ana ki a koutou, nō reira, tēnā koutou, tēnā koutou, tēnā rā tātou katoa.

My name is Tabitha McKenzie and I am a PhD student at Victoria University of Wellington (VUW), Faculty of Education. I would like to invite you to consider participating in a research study. The purpose of this study is to explore if learners make expected gains in language proficiency through the use of mobile devices in comparison to standard face-to-face methods of language instruction and, if there are differences, which of these can be associated with mobile device use?

\section{What will the study involve?}

If you agree to take part in this research you will be one of up to 10 participants involved in a Whakapiki $i$ te Reo (WPR) programme taking part in one individual interview each. I would like to undertake the interview by sitting with you and recording your responses to questions about my topic. (Possible interview questions are attached). The interview will take approximately 1 hour at a negotiated time and location. I would also like to audio record your responses.

\section{Confidentiality}

Any information that is obtained in connection with this study and that can be identified with you will remain confidential and will be disclosed only with your permission, except where disclosure is required by law. The transcripts from the interviews will be transcribed by an external person and any te reo Māori that is used will be quality assured by a Māori language expert to ensure my interpretation/translation of the text is that of which the interviewee intented. I will also formulate a reference group to to provide assistance with my data. Any transcriber, Māori language expert or reference group participant who provide assistance with this research will be asked to sign a confidentiality agreement. The results of this research will be presented in a thesis as well as written and verbal reports, but you will not be identifiable in any of these documents or reports.

Please note that you are under no obligation to give consent to participate in this study. Your decision about whether or not you want to participate will not affect your present or future relationship with VUW or the WPR contract. If you decide to participate, you have the right to withdraw your consent before data collection is complete and discontinue your participation (the researcher will notify you of this date). 


\section{Ethics}

My practice as an emerging researcher based in Te Kura Māori, Ako Pai, is informed by the ethical guidelines developed in Hei Korowai. A summary of these guidelines is available for you to read at any stage of the project. The VUW Faculty of Education Human Ethics Committee has approved the ethical application (Reference No.RM 18040). If at any time you have any questions or concerns about your treatment as a research participant in this study, contact Dr. Allison Kirkman, Chair of the Victoria University of Wellington Human Ethics Committee (Telephone: 04463 5676; Email: allison.kirkman@vuw.ac.nz).

\section{Data Storage and Deletion}

All paper-based and audio data will be stored in a locked filing cabinet in a locked office at VUW. The electronic data will be kept in a password-protected file. As required by copyright, the data will be stored for 5 years after publication and then deleted/wiped/shredded after the 5-year storage period.

\section{Reporting/Dissemination}

The results of this research will be submitted for a doctoral degree, for publication in research and or professional journals and may be presented at a conference. A copy of any such reports can be obtained from me.

Thank you for considering involvement in this research. If you have any questions about the study now or at any time in the future, please feel free to contact my supervisors or myself using the contact information below.

Ka mutu i konei i runga anō i te hiahia ka whai kiko te mahi nei mō ngā kura, arā, ko ngā tamariki mokopuna, ngā mātua, ngā kaiako, me te whānau whānui. Tēnā anō tātou katoa.

Nāku noa

Nā Tabitha McKenzie

\section{Researcher}

Tabitha McKenzie

PhD student, Te Kura Māori

Faculty of Education

Victoria University of Wellington

PO Box 17-310, Karori

Wellington, NZ

044639684

tabitha.mckenzie@vuw.ac.nz

\author{
Supervisors \\ Professor Wally Penetito \\ 044635169 \\ wally.penetito@vuw.ac.nz \\ Professor Luanna Meyer \\ 044639598 \\ luanna.meyer@vuw.ac.nz
}




\section{CONSENT FORM FOR INTERVIEW - FACILITATOR (COMPARISON STUDY)}

Research Title: The Challenges and Opportunities of Using Mobile Devices to Attain Māori Language Proficiency.

This research has been assessed and approved by Victoria University of Wellington Faculty of Education Ethics Committee (Reference No.RM 18040).

Please tick the appropriate box to indicate your agreement/disagreement with the statements and to provide informed consent for participation in this research.

Yes No

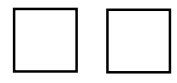

I have been given and have understood an explanation of this research project. I have had an opportunity to ask questions and have them answered to my satisfaction.

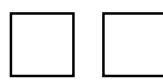

I understand that I may withdraw from this research (before data collection is complete) without having to give reasons or without penalty of any sort.

I understand that the data collected will be kept confidential to the researcher and her supervisors. Any transcriber, Māori language expert or reference group participant who provide assistance with the transcribing of audio recordings, quality assurance for te reo Māori and give feedback for this research will be asked to sign a confidentiality

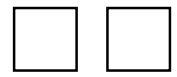
agreement.

I understand that the published results will not use my name or include descriptions that in any way identify me.

I understand that the audio recordings and the interview data will be electronically wiped within five years of the publication of the research.

I agree to be interviewed once at a location and time negotiated by the researcher and myself.

Name

of

Participant:

Email:

Date: Signed:

$\square$ I would like to be sent a copy of any reports arising from this research.

Please return this Consent Form to Tabitha McKenzie. Thank you. 


\section{INFORMATION LETTER FOR INTERVIEWS AND OBSERVATIONS - PARTICIPANT (MAIN STUDY)}

\section{Research Title: The Challenges and Opportunities of Using Mobile Devices to Attain Māori Language Proficiency.}

Tēnā koe e te rangatira,

nei rā ngā mihi maioha ki a koe e pīkau nei i ngā taumahatanga o ngā whakaakoranga mō a tātou taonga, ā tātou mokopuna, rātou e tū nei hei rangatira mō āpōpō.

Ko Tabitha McKenzie tēnei e tū ngākau iti nei ki mua i te aroaro o te iwi, o te hapū, o te whānau, me ngā herenga waka, ngā herenga tāngata e hono ai tātou ki a tātou. E mihi ana ki a koutou, nō reira, tēnā koutou, tēnā koutou, tēnā rā tātou katoa.

My name is Tabitha McKenzie and I am a PhD student at Victoria University of Wellington (VUW), Faculty of Education. I would like to invite you to consider participating in a research study. The purpose of this study is to explore the challenges and opportunities of using mobile devices to attain proficiency in te reo Māori. Another main question for my research is to explore if learners make expected gains in language proficiency through the use of mobile devices in comparison to standard face-to-face methods of language instruction and, if there are differences, which of these can be associated with mobile device use?

\section{What will the study involve?}

This study comprises interviews, observations of mobile device use and the Waikato proficiency test.

If you agree to be interviewed you will be one of up to 20 participants involved in the VUW Whakapiki i te Reo (WPR) programme taking part in two individual interviews each. I would like to undertake the interview by sitting with you and recording your responses to questions about my topic, which is to explore the opportunities and challenges of using mobile devices to attain proficiency in te reo Māori. Each interview will take approximately 1 hour and I would like to interview you twice, over two separate time periods at a negotiated time and location. The purpose of this is to gather your initial thoughts and then revisit the questions to see if there is any change after a period of time using the mobile device. I would also like to audio record your responses. Possible interview questions are attached.

I would also like to observe you using the mobile device for the purposes of the programme. There will also be two observations over two separate time periods at a negotiated time and location, approximately 20 minutes each with 5-10 minutes discussion time after the observation. The purpose of this is to observe your initial skills and thoughts and then revisit these to see if there is any change after a period of time using the mobile device. I would also like to audio record your responses.

This research will also involve using the participants' pre and post-test results from the Waikato Proficiency Test. The pre and post-test results will be analysed in terms of the changes that have or have not occurred. 


\title{
Confidentiality
}

Any information that is obtained in connection with this research and that can be identified with you will remain confidential and will be disclosed only with your permission, except where disclosure is required by law. The transcripts from the interviews and observations will be transcribed by an external person and any te reo Māori that is used will be quality assured by a Māori language expert to ensure my interpretation/translation of the text is that of which the interviewee intented. I will also formulate a reference group to to provide assistance with my data. Any transcriber, Māori language expert or reference group participant who provide assistance with this research will be asked to sign a confidentiality agreement. The results of this research will be presented in a thesis as well as written and verbal reports, but you will not be identifiable in any of these documents or reports.

Please note that you are under no obligation to give consent to participate in this study. Your decision about whether or not you want to participate will not affect your present or future relationship with VUW or the WPR contract. If you decide to participate, you have the right to withdraw your consent before data collection is complete and discontinue your participation (the researcher will notify you of this date).

\section{Ethics}

My practice as an emerging researcher based in Te Kura Māori, Ako Pai, is informed by the ethical guidelines developed in Hei Korowai. A summary of these guidelines is attached, and the full document is available for you to read at any stage of the project. The VUW Faculty of Education Human Ethics Committee has approved the ethical application (Reference No. RM 18040). If at any time you have any questions or concerns about your treatment as a research participant in this study, contact Dr. Allison Kirkman, Chair of the Victoria University of Wellington Human Ethics Committee (Telephone: 04463 5676; Email: allison.kirkman@vuw.ac.nz).

\section{Data Storage and Deletion}

All paper-based and audio data will be stored in a locked filing cabinet in a locked office at VUW. The electronic data will be kept in a password-protected file. As required by copyright, the data will be stored for 5 years after publication and then deleted/ wiped/ shredded after the 5-year storage period.

\section{Reporting/Dissemination}

The results of this research will be submitted for a doctoral degree, for publication in research and or professional journals and may be presented at a conference. A copy of any such reports can be obtained from me.

Thank you for considering involvement in this research. If you have any questions about the study now or at any time in the future, please feel free to contact my supervisors or myself using the contact information below.

Ka mutu i konei i runga anō i te hiahia ka whai kiko te mahi nei mō ngā kura, arā, ko ngā tamariki mokopuna, ngā mātua, ngā kaiako, me te whānau whānui. Tēnā anō tātou katoa.

Nāku noa

Nā Tabitha McKenzie

Researcher

\author{
Supervisors \\ Professor Wally Penetito \\ 044635169 \\ wally.penetito@vuw.ac.nz \\ Professor Luanna Meyer \\ 044639598 \\ luanna.meyer@vuw.ac.nz
}

Te Kura Māori, Faculty of Education

Victoria University of Wellington

PO Box 17-310, Karori

Wellington, NZ

044639684

tabitha.mckenzie@vuw.ac.nz 


\section{CONSENT FORM FOR INTERVIEWS AND OBSERVATIONS - PARTICIPANT (MAIN STUDY)}

\section{Research Title: The Challenges and Opportunities of Using Mobile Devices to Attain Māori Language Proficiency.}

This research has been assessed and approved by Victoria University of Wellington Faculty of Education Ethics Committee (Reference No.RM 18040).

Please tick the appropriate box to indicate your agreement/disagreement with the statements and to provide informed consent for participation in this research.

Yes No

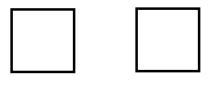

I have been given and have understood an explanation of this research project. I have had an opportunity to ask questions and have them answered to my satisfaction.

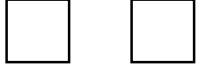

I understand that I may withdraw from this research (before data collection is complete) without having to give reasons or without penalty of any sort.

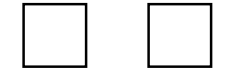

I understand that the data collected will be kept confidential to the researcher and her supervisors. Any transcriber, Māori language expert or reference group participant who provide assistance with the transcribing of audio recordings, quality assurance for te reo Māori and give feedback for this research will be asked to sign a confidentiality
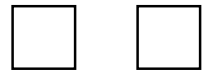
agreement.

I understand that the published results will not use my name or include<smiles>C1CCC1</smiles>

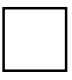
descriptions that in any way identify me.

I understand that the audio recordings and the interview data will be electronically wiped within five years of the publication of the research.

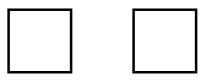

I agree to be interviewed twice at a location and time negotiated by the researcher and myself.

$\square$

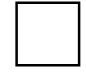

I agree to be observed twice at a location and time negotiated by the researcher and myself.

I agree for the researcher to use my Waikato Proficiency test pre and post test results.

Name of Participant:

Email:

Date: Signed:

$\square$ I would like to be sent a copy of any reports arising from this research.

Please return this Consent Form to Tabitha McKenzie. Thank you. 


\section{INFORMATION LETTER FOR QUESTIONNAIRE - PARTICIPANT (MAIN STUDY)}

Research Title: The Challenges and Opportunities of Using Mobile Devices to Attain Language Proficiency.

Tēnā koe e te rangatira,

nei rā ngā mihi maioha ki a koe e pīkau nei i ngā taumahatanga o ngā whakaakoranga mō a tātou taonga, ā tātou mokopuna, rātou e tū nei hei rangatira mō āpōpō.

Ko Tabitha McKenzie tēnei e tū ngākau iti nei ki mua i te aroaro o te iwi, o te hapū, o te whānau, me ngā herenga waka, ngā herenga tangata e hono ai tātou ki a tātou. E mihi ana ki a koutou, nō reira, tēnā koutou, tēnā koutou, tēnā rā tātou katoa.

My name is Tabitha McKenzie and I am a PhD student at Victoria University of Wellington (VUW), Faculty of Education. I would like to invite you to consider participating in a research study. The purpose of this study is to explore the challenges and opportunities of using mobile devices to attain proficiency in te reo Māori. Another main question for my research is to explore if learners make expected gains in language proficiency through the use of mobile devices in comparison to standard face-to-face methods of language instruction and, if there are differences, which of these can be associated with mobile device use?

\section{What will the study involve?}

If you agree to take part in this research you will be one of up to 40 participants involved in the VUW Whakapiki i te Reo (WPR) programme taking part in one individual questionnaire each. The questionnaire will be administered electronically and will take approximately 20 minutes to complete. Possible questionnaire questions are attached. This research will also involve using the your pre and post-test results from the Waikato Proficiency Test. The pre and post-test results will be analysed in terms of the changes that have or have not occurred.

\section{Confidentiality}

Any information that is obtained in connection with this study and that can be identified with you will remain confidential and will be disclosed only with your permission, except where disclosure is required by law. Any te reo Māori that is used to answer the questionnaire will be quality assured by a Māori language expert to ensure my interpretation/translation of the text is that of which the participant intented. I will also formulate a reference group to provide assistance with my data. Any Māori language expert or reference group participant who provides assistance with this research will be asked to sign a confidentiality agreement. The results of this research will be presented in a thesis as well as written and verbal reports, but you will not be identifiable in any of these documents or reports.

Please note that you are under no obligation to give consent to participate in this study. Your decision about whether or not you want to participate will not affect 
your present or future relationship with VUW or the WPR contract. If you decide to participate, you have the right to withdraw your consent before data collection is complete and discontinue your participation (the researcher will notify you of this date). Your decision to discontinue participation will not affect your present or future relationship with VUW or the WPR contract.

\section{Ethics}

My practice as an emerging researcher based in Te Kura Māori, Ako Pai, is informed by the ethical guidelines developed in Hei Korowai. A summary of these guidelines is attached, and the full document is available for you to read at any stage of the project. The VUW Faculty of Education Human Ethics Committee has approved the ethical application (Reference No.RM 18040). If at any time you have any questions or concerns about your treatment as a research participant in this study, contact Dr. Allison Kirkman, Chair of the Victoria University of Wellington Human Ethics Committee (Telephone: 04463 5676; Email: allison.kirkman@vuw.ac.nz).

\section{Data Storage and Deletion}

All paper-based and electronic data will be stored in a locked filing cabinet in a locked office at VUW. The electronic data will be kept in a password-protected file. As required by copyright, the data will be stored for 5 years after publication and then deleted/wiped/shredded after the 5-year storage period.

\section{Reporting/Dissemination}

The results of this research will be submitted for a doctoral degree, for publication in research and or professional journals and may be presented at a conference. A copy of any such reports can be obtained from me.

Thank you for considering involvement in this research. If you have any questions about the study now or at any time in the future, please feel free to contact my supervisors or myself using the contact information below.

Ka mutu i konei i runga anō i te hiahia ka whai kiko te mahi nei mō ngā kura, arā, ko ngā tamariki mokopuna, ngā mātua, ngā kaiako, me te whānau whānui. Tēnā anō tātou katoa.

Nāku noa

Nā Tabitha McKenzie

\section{Researcher}

Tabitha McKenzie

PhD student, Te Kura Māori

Faculty of Education

Victoria University of Wellington

PO Box 17-310, Karori

Wellington, NZ

044639684

tabitha.mckenzie@vuw.ac.nz

\author{
Supervisors \\ Professor Wally Penetito \\ 044635169 \\ wally.penetito@vuw.ac.nz \\ Professor Luanna Meyer \\ 044639598 \\ luanna.meyer@vuw.ac.nz
}




\section{CONSENT FORM FOR QUESTIONNAIRE - PARTICIPANT (MAIN STUDY)}

Research Title: The Challenges and Opportunities of Using Mobile Devices to Attain Māori Language Proficiency.

This research has been assessed and approved by Victoria University of Wellington Faculty of Education Ethics Committee (Reference No.RM 18040).

Please tick the appropriate box to indicate your agreement/disagreement with the statements and to provide informed consent for participation in this research.

Yes No

I have been given and have understood an explanation of this research project. I have had an opportunity to ask questions and have them answered to my satisfaction.<smiles>C1CCC1</smiles>

I understand that I may withdraw from this research (before data collection is complete) without having to give reasons or without penalty of any sort.

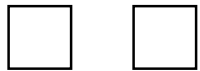

I understand that the published results will not use my name or include descriptions that in any way identify me.

I understand that the audio recordings and the interview data will be electronically wiped within five years of the publication of the research.

I agree to be complete a questionnaire related to this research.

I understand that the data collected will be kept confidential to the

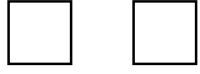

researcher and her supervisors. Any transcriber, Māori language expert or reference group participant who provide assistance with the transcribing of audio recordings, quality assurance for te reo Māori and give feedback for this research will be asked to sign a confidentiality agreement.

I agree for the researcher to use my pre and post-test results for the Waikato Proficiency test.

Name of Participant:

Email:

Date: Signed:

I would like to be sent a copy of any reports arising from this research.

Please return this Consent Form to Tabitha McKenzie. Thank you. 


\title{
INFORMATION LETTER FOR INTERVIEW - PARTICIPANT (COMPARISON STUDY)
}

\author{
Research Title: The Challenges and Opportunities of Using Mobile Devices \\ to Attain Māori Language Proficiency.
}

Tēnā koe e te rangatira,

nei rā ngā mihi maioha ki a koe e pīkau nei i ngā taumahatanga o ngā whakaakoranga mō a tātou taonga, ā tātou mokopuna, rātou e tū nei hei rangatira mō āpōpō.

Ko Tabitha McKenzie tēnei e tū ngākau iti nei ki mua i te aroaro o te iwi, o te hapū, o te whānau, me ngā herenga waka, ngā herenga tangata e hono ai tātou ki a tātou. E mihi ana ki a koutou, nō reira, tēnā koutou, tēnā koutou, tēnā rā tātou katoa.

My name is Tabitha McKenzie and I am a PhD student at Victoria University of Wellington (VUW), Faculty of Education. I would like to invite you to consider participating in a research study. The purpose of this study is to explore the challenges and opportunities of using mobile devices to attain proficiency in te reo Māori. Another main question for my research is to explore if learners make expected gains in language proficiency through the use of mobile devices in comparison to standard face-to-face methods of language instruction and, if there are differences, which of these can be associated with mobile device use?

\section{What will the study involve?}

If you agree to take part in this research you will be one of up to 10 participants involved in a Whakapiki i te Reo (WPR) programme taking part in one individual interview each. I would like to undertake the interview by sitting with you and recording your responses to questions about my topic. (Possible interview questions are attached). The interview will take approximately 1 hour at a negotiated time and location. I would also like to audio record your responses. This research will also involve using your pre and post-test results from the Waikato Proficiency Test. The pre and post-test results will be analysed in terms of the changes that have or have not occurred.

\section{Confidentiality}

Any information that is obtained in connection with this study and that can be identified with you will remain confidential and will be disclosed only with your permission, except where disclosure is required by law. The transcripts from the interviews will be transcribed by an external person and any te reo Māori that is used will be quality assured by a Māori language expert to ensure my interpretation/translation of the text is that of which the interviewee intented. I will also formulate a reference group to to provide assistance with my data. Any transcriber, Māori language expert or reference group participant who provide assistance with this research will be asked to sign a confidentiality agreement. The results of this research will be presented in a thesis as well as written and verbal reports, but you will not be identifiable in any of these documents or reports. 
Please note that you are under no obligation to give consent to participate in this study. Your decision about whether or not you want to participate will not affect your present or future relationship with VUW or the WPR contract. If you decide to participate, you have the right to withdraw your consent before data collection is complete and discontinue your participation (the researcher will notify you of this date).

\section{Ethics}

My practice as an emerging researcher based in Te Kura Māori, Ako Pai, is informed by the ethical guidelines developed in Hei Korowai. A summary of these guidelines is available for you to read at any stage of the project. The VUW Faculty of Education Human Ethics Committee has approved the ethical application (Reference No.RM 18040). If at any time you have any questions or concerns about your treatment as a research participant in this study, contact Dr. Allison Kirkman, Chair of the Victoria University of Wellington Human Ethics Committee (Telephone: 04463 5676; Email: allison.kirkman@vuw.ac.nz).

\section{Data Storage and Deletion}

All paper-based and audio data will be stored in a locked filing cabinet in a locked office at VUW. The electronic data will be kept in a password-protected file. As required by copyright, the data will be stored for 5 years after publication and then deleted/wiped/shredded after the 5-year storage period.

\section{Reporting/Dissemination}

The results of this research will be submitted for a doctoral degree, for publication in research and or professional journals and may be presented at a conference. A copy of any such reports can be obtained from me.

Thank you for considering involvement in this research. If you have any questions about the study now or at any time in the future, please feel free to contact my supervisors or myself using the contact information below.

Ka mutu i konei i runga anō i te hiahia ka whai kiko te mahi nei mō ngā kura, arā, ko ngā tamariki mokopuna, ngā mātua, ngā kaiako, me te whānau whānui. Tēnā anō tātou katoa.

Nāku noa

Nā Tabitha McKenzie

\section{Researcher}

Tabitha McKenzie

PhD student, Te Kura Māori

Faculty of Education

Victoria University of Wellington

PO Box 17-310, Karori

Wellington, NZ

044639684

tabitha.mckenzie@vuw.ac.nz

\author{
Supervisors \\ Professor Wally Penetito \\ 044635169 \\ wally.penetito@vuw.ac.nz \\ Professor Luanna Meyer \\ 044639598 \\ luanna.meyer@vuw.ac.nz
}




\section{CONSENT FORM FOR INTERVIEW - PARTICIPANT (COMPARISON STUDY)}

Research Title: The Challenges and Opportunities of Using Mobile Devices to Attain Māori Language Proficiency.

This research has been assessed and approved by Victoria University of Wellington Faculty of Education Ethics Committee (Reference No.RM 18040).

Please tick the appropriate box to indicate your agreement/disagreement with the statements and to provide informed consent for participation in this research.

Yes No

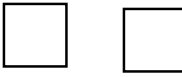

I have been given and have understood an explanation of this research project. I have had an opportunity to ask questions and have them answered to my satisfaction.

I understand that I may withdraw from this research (before data collection is complete) without having to give reasons or without penalty of any sort.

I understand that the data collected will be kept confidential to the researcher and her supervisors. Any transcriber, Māori language expert or reference group participant who provide assistance with the transcribing of audio recordings, quality assurance for te reo Māori and give feedback for this research will be asked to sign a confidentiality agreement.

I understand that the published results will not use my name or include descriptions that in any way identify me.

I understand that the audio recordings and the interview data will be electronically wiped within five years of the publication of the research.

I agree to be interviewed once at a location and time negotiated by the researcher and myself.

I agree for the researcher to use my pre- and post-test results from the Waikato Proficiency test.

Name of Participant:

Email:

Date: Signed:

$\square$ I would like to be sent a copy of any reports arising from this research.

Please return this Consent Form to Tabitha McKenzie. Thank you. 


\section{CONFIDENTIALITY AGREEMENT - MĀORI LANGUAGE EXPERT}

Research Title: The Challenges and Opportunities of Using Mobile Devices to Attain Māori Language Proficiency.

This research has been assessed and approved by Victoria University of Wellington Faculty of Education Ethics Committee (Reference No.RM 18040).

I, will be quality assuring the Māori language used in scripts by participants and interpreted by the researcher for the research project "The Challenges and Opportunities of Using Mobile Devices to Attain Māori Language Proficiency".

All information that is provided to me to quality assure will be deemed confidential and I will ensure that it is not released to any third party.

Name:

Date: Signed: 


\section{CONFIDENTIALITY AGREEMENT - TRANSCRIBER}

Research Title: The Challenges and Opportunities of Using Mobile Devices to Attain Māori Language Proficiency.

This research has been assessed and approved by Victoria University of Wellington Faculty of Education Ethics Committee (Reference No.RM 18040).

I, will be transcribing scripts for the research project "The Challenges and Opportunities of Using Mobile Devices to Attain Māori Language Proficiency".

All information that is provided to me to transcribe will be deemed confidential and I will ensure that it is not released to any third party.

Name:

Date: Signed: 